\title{
Biomarkers in real-life COPD management
}

Citation for published version (APA):

Oshagbemi, O. A. (2019). Biomarkers in real-life COPD management. [Doctoral Thesis, Maastricht University]. Maastricht University. https://doi.org/10.26481/dis.2019120200

Document status and date:

Published: 01/01/2019

DOI:

10.26481/dis.2019120200

Document Version:

Publisher's PDF, also known as Version of record

\section{Please check the document version of this publication:}

- A submitted manuscript is the version of the article upon submission and before peer-review. There can be important differences between the submitted version and the official published version of record.

People interested in the research are advised to contact the author for the final version of the publication, or visit the DOI to the publisher's website.

- The final author version and the galley proof are versions of the publication after peer review.

- The final published version features the final layout of the paper including the volume, issue and page numbers.

Link to publication

\footnotetext{
General rights rights.

- You may freely distribute the URL identifying the publication in the public portal. please follow below link for the End User Agreement:

www.umlib.nl/taverne-license

Take down policy

If you believe that this document breaches copyright please contact us at:

repository@maastrichtuniversity.nl

providing details and we will investigate your claim.
}

Copyright and moral rights for the publications made accessible in the public portal are retained by the authors and/or other copyright owners and it is a condition of accessing publications that users recognise and abide by the legal requirements associated with these

- Users may download and print one copy of any publication from the public portal for the purpose of private study or research.

- You may not further distribute the material or use it for any profit-making activity or commercial gain

If the publication is distributed under the terms of Article $25 \mathrm{fa}$ of the Dutch Copyright Act, indicated by the "Taverne" license above, 


\section{BIOMARKERS IN REAL-LIFE COPD MANAGEMENT}

Olorunfemi Ayodele Oshagbemi 

Dedicated to my mum who I lost in the process of completing this work. I miss you so much. Rest in peace, STAR MUM. 
Copyright (C) Olorunfemi Ayodele Oshagbemi, 2019

All rights reserved. No part of this book may be reproduced or transmitted in any form or by any means, without prior permission in writing from the author, or when appropriate, the publisher of the manuscript.

ISBN: 978-94-6380-575-9

Cover design and Layout: Foster Carter

Printing: Proefschriftmaken 


\title{
BIOMARKERS IN REAL-LIFE COPD MANAGEMENT
}

\author{
Dissertation \\ To obtain the degree of Doctor at the Maastricht University \\ on the authority of the Rector Magnificus, \\ Prof. dr. Rianne M. Letschert \\ in accordance with the Board of Deans \\ to be defended in public on Monday $2^{\text {nd }}$ December 2019 \\ at 16:00 hours
}

by

Olorunfemi Ayodele Oshagbemi 


\section{Promotors:}

Prof. dr. E.F. Wouters

Prof. dr. F. de Vries

\section{Co-promotor:}

Dr. F.M.E. Franssen, CIRO Horn

Assessment committee:

Prof. dr. Kees Neef, Chairman

Prof. dr. Daiana Stolz, University of Basel, $\mathrm{CH}$

Prof. dr. Jean Muris

Prof. dr. Maurice Zeegers

Dr. Mona Bafadhel, University of Oxford, UK 


\section{Table of Contents}

$\begin{array}{lll}\text { Chapter } 1 \quad \text { Introduction and scope } & 9\end{array}$

Chapter $2 \quad$ Trends in moderate and severe exacerbations among COPD 21 patients in the UK 2005-2013

Chapter $3 \quad$ Stability of blood eosinophils in patients with chronic obstructive 41 pulmonary disease and in control subjects, and the impact of sex, age, smoking, and baseline counts

Chapter $4 \quad$ C-reactive protein as a biomarker of response to inhaled 59 corticosteroids

Chapter $5 \quad$ Blood eosinophilia, use of inhaled corticosteroids and risk of 77 COPD exacerbations, and mortality

Chapter 6 Blood eosinophil counts, withdrawal of inhaled corticosteroids and 95 risk of COPD exacerbations and mortality in the clinical practice research datalink (CPRD)

Chapter $7 \quad$ Use of high-dose Intermittent systemic glucocorticoids and risk of fractures in patients with chronic obstructive pulmonary disease

$\begin{array}{llr}\text { Chapter } 8 & \text { General discussion } & 129 \\ \text { Appendices } & \text { Summary } & 144 \\ & \text { Samenvatting } & 148 \\ & \text { Valorisation addendum } & 152 \\ & \text { Acknowledgement } & 157 \\ & \text { List of publications } & 158 \\ & \text { About the author } & 160\end{array}$



Introduction and scope 1

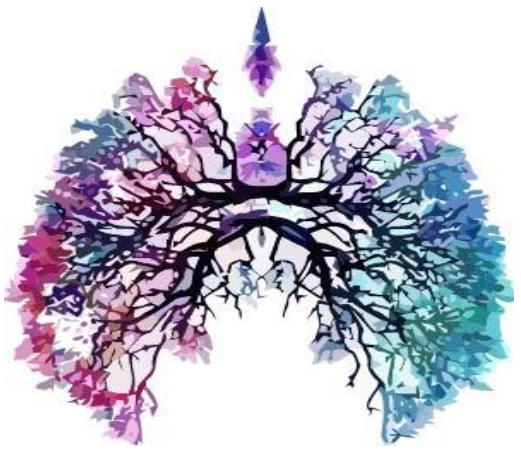




\section{CHRONIC OBSTRUCTIVE PULMONARY DISEASE}

Chronic obstructive pulmonary disease (COPD) is a common, preventable and treatable disease characterised by relentless respiratory symptoms and airflow limitation that is due to airway and/or alveolar aberrations usually triggered by significant exposure to noxious gases. ${ }^{1}$ Diagnosis of COPD should be considered in subjects with respiratory symptoms such as difficulty in breathing (dyspnoea), chronic cough, excessive sputum production and history of tobacco use, ${ }^{2}$ although occupational and indoor air pollution also contributes to the disease onset. ${ }^{3}$ There is accumulating evidence that early-life exposures and impaired lung development play a central role in the pathophysiology of the disease in a significant proportion of patients. ${ }^{4}$ COPD is a leading cause of morbidity and mortality worldwide. It was the third leading cause of disability-adjusted life years among non-communicable diseases, according to the Global Burden of Disease Study $2017 .{ }^{5}$ COPD is projected to hold an equal position among the leading causes of death worldwide in $2030 .^{6,7}$ It also places a very high burden on the health system. ${ }^{11}$ Additionally, the disease is associated with tremendous social and economic impact. ${ }^{8}$ In the European Union, COPD accounts for 38.9 billion euros and 52.4 billion dollars in direct and indirect costs annually in the United States (U.S). ${ }^{9,10}$

\section{DIAGNOSIS AND CLASSIFICATION OF COPD}

Spirometry is the current tool for COPD diagnosis. Post-bronchodilator forced expiratory volume-one second/forced vital capacity $\left(F E V_{1} / F V C\right)<0.70$ confirms the presence of airflow limitation and the diagnosis of COPD in symptomatic individuals. ${ }^{1}$ The severity of airflow limitation is classified according to the $\mathrm{FEV}_{1}$ as percentage of predicted. The Global Initiative for Obstructive Lung Disease (GOLD) categorises 4 spirometric stages:

- $\quad$ GOLD 1 - mild: FEV1 $\geq 80 \%$ predicted

- GOLD 2 - moderate: $50 \% \leq \mathrm{FEV} 1<80 \%$ predicted

- GOLD 3 - severe: $30 \% \leq$ FEV1 < 50\% predicted

- $\quad$ GOLD 4 - very severe: FEV1 < 30\% predicted. ${ }^{1}$

It is well recognised that the degree of airflow limitation is a poor predictor of patient-related outcomes in COPD. There is a substantial overlap in dyspnoea, health status and exercise capacity between patients in different spirometric GOLD stages. ${ }^{12}$ Thus, the burden of disease cannot be predicted from the severity of lung impairment alone. ${ }^{1}$ To provide a more integrated diagnosis of the disease, the GOLD strategy adopted a composite COPD assessment approach to group patients based on symptoms and previous history of exacerbations or hospitalisations. Symptoms are assessed using the Modified British Medical Research Council (mMRC) or COPD assessment test (CAT) scale. ${ }^{1}$ The mMRC is a simple measure of breathlessness resulting in a score from $0-4$, while CAT is an eight-item measure of health status impairment in COPD patients and ranges from 0 to 40 . $^{1}$ According to symptoms and risk of exacerbations, patients are classified as: 
- Group A: low risk (0-1 exacerbation per year, not requiring hospitalisation) and fewer symptoms (mMRC 0-1 or CAT <10)

- Group B: low risk (0-1 exacerbation per year, not requiring hospitalisation) and more symptoms (mMRC $\geq 2$ or CAT $\geq 10$ )

- Group C: high risk ( $\geq 2$ exacerbations per year, or one or more requiring hospitalisation) and fewer symptoms (mMRC 0-1 or CAT $<10$ )

- Group D: high risk ( $\geq 2$ exacerbations per year, or one or more requiring hospitalisation) and more symptoms (mMRC $\geq 2$ or CAT $\geq 10){ }^{1}$

\section{EXACERBATIONS}

The natural course of COPD is characterised by acute events, referred to as exacerbations, which are defined as the acute worsening of a patient's symptoms beyond normal day-to-day variations that require additional pharmacotherapy. ${ }^{1}$ Exacerbations of respiratory symptoms are frequently triggered by bacterial or viral infections, ${ }^{13}$ although in recent years different biological exacerbation clusters have been identified. ${ }^{14}$ During exacerbations, there is an increased hyperinflation and gas trapping with reduced expiratory flow, thus resulting in increased dyspnoea. ${ }^{15}$ Exacerbations of COPD have a considerable impact on health status, ${ }^{16}$ lung function, ${ }^{17}$ and exercise capacity. ${ }^{18}$ Also, they are associated with substantial mortality and economic impact. Mortality rates of 22 to $43 \%$ after 1 year and 36 to $49 \%$ after 2 years following hospitalisation for COPD have been reported. ${ }^{19}$ Exacerbations are responsible for approximately 1.5 million emergency department visits and 700,000 medical admissions annually in the U.S. ${ }^{20}$ Given the central role of exacerbations in the pathophysiology of the disease, prevention of exacerbations is one of the fundamental treatment goals in COPD management. To prevent these events, it is important to understand the demographic, biochemical, clinical and other factors that predict exacerbations in individual patients. Smoking, air pollution, severe airflow limitation, a history of prior exacerbations and comorbidities are well-recognised risk factors and triggers for exacerbations ${ }^{21}$ but are insufficient to predict which individuals with COPD will have exacerbations and when.

\section{PHARMACOLOGIC MANAGEMENT OF STABLE COPD}

The goal of management of patients with COPD is to reduce symptoms, improve exercise tolerance, health status and decrease the frequency and severity of exacerbations. ${ }^{1}$ There is currently no evidence from clinical trials has shown any existing drug treatment capable of modifying lung function decline in the long-term or reducing mortality risk. ${ }^{22-24}$ Various classes of drugs are used in the treatment of COPD, including bronchodilators, inhaled corticosteroids (ICS), oral glucocorticoids, phosphodiesterase-4 (PDE-4) inhibitors, methylxanthines, and antibiotics. ${ }^{1}$ Most drugs used in the treatment of COPD are administered as inhalers. GOLD 2017 proposed a model for the initiation and subsequent escalation and de-escalation of pharmacologic management based on the assessment of patient symptoms and exacerbations risk. ${ }^{25}$ However, with the introduction of GOLD 2019, this treatment scheme has now changed. ${ }^{1}$

Bronchodilators include short-acting beta2-receptor agonists (SABAs) and (ultra) long-acting beta2-receptor agonists, (LABAs or ultra-LABAs) act by binding to 
the beta2-receptors in the airways subsequently increasing cyclic-AMP resulting in bronchorelaxation. ${ }^{1}$ They are recommended for the treatment of COPD patients with mild or moderate disease. Antimuscarinic agents act by blocking the brochoconstrictor effect of acetylcholine on the M3 muscarinic receptors resulting in relaxation of the airway smooth muscles. ${ }^{26}$ There are also short (e.g. ipratropium) and long acting (e.g. tiotropium and aclidinium) antimuscarinic agents (SAMAs and LAMAs). Short acting bronchodilators usually have a duration of action of 4 to 8 hours, ${ }^{27}$ and are used as needed to improve patients symptoms and lung function. ${ }^{28}$ Long-acting bronchodilators are the mainstay of pharmacological treatment of patients with COPD, ${ }^{25}$ either as monotherapy or in combination of LABAs and LAMAs. These medications bring about bronchodilation by different mechanisms and provide synergistic benefits. ${ }^{2}$ The efficacy of these drugs in improving lung function, quality of life, and exercise tolerance as well as in reducing COPD exacerbations is well established. ${ }^{1}$

Traditionally, ICS and systemically administered glucocorticoids (GCs) have played a central role in COPD management. Although the exact mechanism of action of ICS is still debated, ${ }^{29}$ it is well established that they possess an anti-inflammatory effect. $^{30}$ It is recommended that ICS therapy be combined with LABAs or LAMAs, in response to uncontrolled exacerbations. ${ }^{21}$ The use of ICS alone was found to have no effect on long-term $\mathrm{FEV}_{1}$ decline or mortality in COPD patients. ${ }^{31}$ However, in patients with moderate to severe exacerbations ICS combined with LABAs were found to be more effective than either of the agents alone in reducing exacerbations and lung function decline. ${ }^{32}$ In addition to clinical benefits, ICS has been associated with significant adverse effects, including the risk of fractures, ${ }^{33}$ skin bruising and oral candidiasis. $^{34}$ The Pharmacovigilance Risk Assessment of the European Medicines Agency (EMA) acknowledged that ICS treatment further increased the risk of pneumonia among COPD patients. ${ }^{35}$ Targeting patients who will benefit from corticosteroid therapy is important, as it may help in reducing ICS-related side effects and treatment costs. ${ }^{36}$ The main factors known to increase the risk of pneumonia among patients treated with ICS include older age ( $>55$ years), a body mass index (BMI) $\left(<25 \mathrm{~kg} / \mathrm{m}^{2}\right)$, greater severity in airflow limitation, prior history of exacerbation and low blood eosinophil counts. ${ }^{37}$ Despite recommendations in clinical guidelines, ICS are still overprescribed among COPD patients. ${ }^{37}$

During exacerbations of the disease, systemic GCs are prescribed in order to shorten recovery time and improve lung function. They also improve oxygenation and reduce the risk of early relapse, treatment failure and the length of hospitalisation. ${ }^{1}$ Systemic GCs are not recommended in the treatment of stable COPD, and exposure is known to be associated with high risks of systemic adverse effects, ${ }^{1}$ including the risk of skin bruising and oral candidiasis. ${ }^{33}$ Other studies have reported an increased risk of fractures with corticosteroid use. ${ }^{38,39}$ Van Staa et al conducted a retrospective cohort study, which included over 200,000 patients exposed to oral corticosteroids and an equal number of controls with a mean age of 57 , years and discovered that patients exposed to higher daily and cumulative doses of oral corticosteroid had an increased risk of vertebral, forearm hip and non-vertebral fractures. ${ }^{40}$ Three dose categories were assessed: low dose (less than $2.5 \mathrm{mg} / \mathrm{day}$ ), medium (2.5-7.5 $\mathrm{mg} /$ day), and high dose (7.5 mg/day or more). However, these dose stratification does not provide a clear insight into the effect of GCs among patients with COPD considering that a dose of $40 \mathrm{mg}$ daily for 5 days is recommended in the treatment of severe exacerbations. ${ }^{41}$ While the effects of oral GCs on fracture risks in COPD are 
well documented, ${ }^{42}$ only one study has explored high-dose intermittent use of GCs and risk of fractures among COPD patients ${ }^{43}$ prior to this Ph.D. thesis. Consequently, more studies are required among COPD patients to further understand the impact of intermittent use of corticosteroids using appropriate comparator groups.

In recent years, other pharmacological treatments aimed at reducing exacerbations have been introduced in COPD management, including roflumilast (a PDE-4 inhibitor) for patients with severe disease and a bronchitic phenotype, ${ }^{44}$ and macrolide antibiotics for non-smoking patients with refractory exacerbations despite inhaler therapies. ${ }^{45-47}$

\section{BIOMARKERS}

A biomarker is defined as a measure of any molecule or material, which could be either cells or tissues that reflects a disease process. ${ }^{48}$ The essential roles of biomarkers in health include; enhancing disease diagnosis, monitoring of disease prognosis, and guiding therapy, with the aim of improving patient outcomes and reducing potential side effects of treatments. ${ }^{49,50}$ For biomarkers to play a vital role in improving the management of patients, they must possess several properties: 1) a biological role in the pathogenesis of the disease, 2) easy to accurately measure, 3 ) sensitive to changes in order to enable repeatability, 4) modifiable by therapeutic interventions, 5) retain a long half-life, 6) and associated with outcome. ${ }^{51}$ Additionally, they have to be relevant, sensitive and specific to the disease or condition, reliable to be used in different settings, clinically interpretable, simple and cost-effective to deploy. ${ }^{52,53}$

Over the last decades, there has been increasing interest in the potential role of biomarkers in COPD. For example, the Evaluation of COPD Longitudinally to Identify Predictive Surrogate End-points (ECLIPSE) study, which was a 3-year multicentre study, aimed to measure biomarkers in blood, urine, sputum and breath condensate in order to identify clinically relevant COPD subtypes and relate these biomarkers to markers of disease progression. ${ }^{54}$ Among the biomarkers assessed, Creactive protein (CRP), fibrinogen, and serum interleukin-6, met the validation criteria. ${ }^{55} \mathrm{~A}$ review of the current state of biomarkers in COPD reported that changes in biomarker levels indeed predicted important outcomes such as exacerbations and mortality. ${ }^{56}$ Fibrinogen was one of the most promising biomarkers reported to be associated with the risk of COPD, disease progression and death. ${ }^{57}$ However, early investigations observed no significant relationship between plasma fibrinogen and decline in lung function. ${ }^{58}$ Furthermore, researchers found a weak association between fibrinogen and mortality, on the other parameters fibrinogen was outperformed by other biomarkers. ${ }^{58}$ Findings on fibrinogen as a diagnostic biomarker for exacerbations have been mixed and variable. In addition, the high variation around the mean values have suggested that fibrinogen is probably not a suitable biomarker for COPD management. ${ }^{60}$

More recently, a number of studies have investigated blood eosinophil counts as a potential biomarker of interest in COPD management. ${ }^{61-65}$ Eosinophils are derived from progenitor stem cells in the bone marrow and released into the blood upon maturity. They play a central role in homeostasis and disease pathogenesis in various tissues, including the lungs. ${ }^{61}$ Blood eosinophil concentration is reported as an absolute count (cells $/ \mu \mathrm{L}$ ) or as a percentage of total leukocytes. ${ }^{61}$ The interest in its potential use was heightened by a large cohort study, which showed that elevated 
blood eosinophil count was associated with an increased risk of exacerbations. ${ }^{62}$ Also post-hoc analyses from the TRial of Inhaled STeroids ANd long-acting beta2-agonists (TRISTAN) and Investigating New Standards for Prophylaxis in Reducing Exacerbations (INSPIRE) trials $(n=2,672)$ showed that COPD patients with blood eosinophil counts $\geq 2 \%$ had a reduced exacerbation risk compared to patients with blood eosinophil counts $<2 \%$ when treated with ICS containing treatments compared to patient without ICS therapy. ${ }^{63}$ However, in the SCO30002 study no significant difference was found between patients with blood eosinophil counts $\geq 2 \%$ versus $<2 \%$. ${ }^{63}$ Post-hoc analyses of the WISDOM trial showed that withdrawal of ICS resulted in increased risk of exacerbations at blood eosinophil counts of $\geq 4 \%$ or $\geq 300$ cells/ $\mu \mathrm{L} .{ }^{64}$ Other researchers have also reported that COPD patients with elevated blood eosinophil counts had lower risk of exacerbations when treated with ICS compared to patients without elevated eosinophil counts. ${ }^{65}$ However, a randomized, double-blind trial which included over 2000 COPD patients with mean age of 64 years, followed for 52 weeks, found that ICS/LABA combination was inferior to LABA/LAMA combination in exacerbation reduction, even among patients with elevated blood eosinophil counts. ${ }^{66}$ With these conflicting findings, it is important to further explore the role of blood eosinophil counts as a biomarker in a general practice setting. This will ensure directing ICS therapy to patients who will potentially benefit from its use, reducing the possibility of adverse side effects, especially within general practice. Researchers have questioned what exact blood eosinophil cut-off value should be used to predict patients who will potentially benefit from ICS therapy. ${ }^{64}$ Further, for blood eosinophils to be recognised as a reliable biomarker for ICS therapy among COPD patients, it is critical that the stability of this biomarker is established.

While the role of blood eosinophil counts for biomarker-guided use of ICS among COPD patients is mounting, C-reactive protein (CRP) is another biomarker of significant interest in COPD management. It is produced in the liver and is known to bind to the receptors of the phagocytes and plays a role in apoptosis and necrosis. ${ }^{67}$ CRP is generally indicated as a biomarker for systemic inflammation, which is considered a risk factor for morbidity and mortality. In stable COPD, increased CRP is found to be independent of other risk factors for COPD such as smoking. ${ }^{68}$ Elevated CRP level has been associated with an increased risk of exacerbations requiring hospitalisation and with an increased risk of COPD mortality. ${ }^{51}$ The use of CRP as a biomarker of response to treatment and the impact of pharmacotherapies on CRP levels is controversial. A randomised placebo-controlled trial conducted among COPD patients previously exposed to ICS found that withdrawal from ICS resulted in increased CRP levels by $71 \%$, whereas after 2 weeks of ICS therapy, CRP levels reduced by $50 \%$, but no change was observed in the placebo arm. ${ }^{69} \mathrm{~A}$ double-blind placebo-controlled study showed that exposure to inhaled fluticasone suppressed the levels of CRP and withdrawal of therapy increased CRP levels. ${ }^{70}$ Additionally, Pinto et al, ${ }^{68}$ employing cross-sectional analysis of a cohort study showed that CRP levels were lower in COPD patients treated with ICS. The role of biomarkers including blood eosinophils and CRP in the management of COPD needs to be systematically evaluated before they can be implemented in personalised disease management. The use of a single biomarker to help in guiding therapy is deemed a "one-eyed" approach, as such evaluating several biomarkers has the potential of increased precision-guided treatment decisions among patients with COPD. ${ }^{71}$ 


\section{AIM OF THIS THESIS}

From this introduction, it is clear that COPD is a multicomponent and unpredictable disease. Disease classification is no longer based on the severity of airflow limitation only, but also on symptoms and risk of exacerbations. However, current disease management is limited by the inability to predict the course of the disease, and response to pharmacological treatments. Biomarkers can contribute to personalised disease management by stratifying patients according to risk profiles, and predicting response to therapy. Indeed, several biomarkers have been proposed in COPD management, but have not been extensively investigated in a real-life setting. Since exacerbations play a pivotal role in the burden of COPD, and for the wider society, thus they are considered crucial outcomes of disease management. Therefore, the aim of the current thesis was to evaluate the potential role of blood eosinophils and CRP as biomarkers for predicting exacerbations response to ICS among patients with COPD in the general population.

\section{OUTLINE OF THIS THESIS}

Chapter 2 explores trends in moderate and severe exacerbations among COPD patients in the UK from 2005 to 2013.

Chapter 3 provides insight on the stability of blood eosinophil counts among COPD patients and the impact of age, sex, smoking status and baseline blood eosinophil counts within the UK general practice.

Chapter 4 evaluates the risk of moderate-to-severe exacerbations, severe exacerbations and all-cause mortality among COPD patients exposed to ICS, stratified by CRP tertiles.

Chapter $\mathbf{5}$ explores the risk of acute exacerbations, hospitalisations/accident and emergency visits, and all-cause mortality among COPD patients with specific absolute or relative blood eosinophil counts cut-offs.

Chapter 6 investigates the impact of blood eosinophil counts on the withdrawal of ICS and the risk of moderate-to-severe exacerbations, severe exacerbations, and allcause mortality among COPD patients and the impact of blood eosinophil counts.

Chapter 7 evaluates the impact of intermittent high-dose glucocorticoid use on fracture risk among patients with COPD, the impact of proxy indicators of disease severity and the effect of dose in the Danish population.

Chapter 8 discusses previous chapters, methodological considerations, the future direction for research and clinical practice. 


\section{References}

1. GOLD. Global strategy for the prevention, diagnosis and treatment of chronic obstructive pulmonary disease (2019 Report). 2018. https://goldcopd.org/wpcontent/uploads/2018/11/GOLD-2019v1.7-FINAL-14Nov2018-WMS.pdf. Accessed November 15, 2018.

2. Buist AS, McBurnie MA, Vollmer WM, et al. International variation in the prevalence of COPD (The BOLD Study): a population-based prevalence study. Lancet. 2007;370(9589):741750.

3. Eisner MD, Anthonisen N, Coultas D, et al. An official American Thoracic Society public policy statement: Novel risk factors and the global burden of chronic obstructive pulmonary disease. Am J Respir Crit Care Med. 2010;182(5):693-718.

4. Bui DS, Lodge CJ, Burgess JA, et al. Childhood predictors of lung function trajectories and future COPD risk: a prospective cohort study from the first to the sixth decade of life. Lancet Respir Med. 2018;6(7):535-544.

5. Roth GA, Abate $\mathrm{D}$, Abate $\mathrm{KH}$, et al. Global, regional, and national age-sexspecific mortality for 282 causes of death in 195 countries and territories, 1980-2017: a systematic analysis for the Global Burden of Disease Study 2017. Lancet. 2018;392(10159):17361788.

6. GBD 2010 Mortality and Causes of Death Collaborators. Global and regional mortality from 235 causes of death for 20 age groups in 1990 and 2010: A systematic analysis for the Global Burden of Disease Study 2010. Lancet. 2012;380(9859):2095-2128.

7. Vos T, Flaxman AD, Naghavi M, et al. Years lived with disability (YLDs) for 1160 sequelae of 289 diseases and injuries 1990-2010: A systematic analysis for the Global Burden of Disease Study 2010. Lancet. 2012;380(9859):2163-2196.

8. Jinjuvadia $\mathrm{C}$, Jinjuvadia $\mathrm{R}$, Mandapakala $\mathrm{C}$, et al. Trends in Outcomes, Financial Burden, and Mortality for Acute Exacerbation of Chronic Obstructive Pulmonary Disease (COPD) in the United States from 2002 to 2010. COPD. 2016; 14(1):72-79.

9. Lõpez-Campos JL, Tan W, Soriano JB. Global burden of COPD. Respirology.
2016;21(1):14-23

10. Guarascio AJ, Ray S, Finch CK, Self T. The clinical and economic burden of Chronic Obstructive Pulmonary Disease in the USA. Clin Outcomes Res. 2013;5:235-245.

11. Smid DE, Spruit MA, Houben-Wilke S, et al. Burden of COPD in patients treated in different care settings in the Netherlands. Respir Med. 2016.

12. Han MLK, Quibrera PM, Carretta EE, et al. Frequency of exacerbations in patients with chronic obstructive pulmonary disease: an analysis of the SPIROMICS cohort. Lancet Respir Med. 2017.

13. Wedzicha JA, Seemungal TA. COPD exacerbations: defining their cause and prevention.

Lancet. 2007;370(9589):786-796.

14. Bafadhel M, McKenna S, Terry S, et al. Blood eosinophils to direct corticosteroid treatment of exacerbations of chronic obstructive pulmonary disease: A randomized placebo-controlled trial. Am J Respir Crit Care Med. 2012;186(1):48-55.

15. Parker CM, Voduc N, Aaron SD, et al. Physiological changes during symptom recovery from moderate exacerbations of COPD. Eur Respir J. 2005;26(3):420-428.

16. Spencer S, Jones PW. Time course of recovery of health status following an infective exacerbation of chronic bronchitis. Thorax. 2003;58(7):589593.

17. Celli BR, Thomas NE, Anderson J a, et al. Effect of pharmacotherapy on rate of decline of lung function in chronic obstructive pulmonary disease: results from the TORCH study. Am J Respir Crit Care Med. 2008;178(4):332-338.

18. Cote CG, Dordelly LJ, Celli BR. Impact of COPD exacerbations on patientcentered outcomes. Chest. 2007;131(3):696-704.

19. Obstructive C, Disease P, SolerCataluña JJ, et al. Severe acute exacerbations and mortality in patients with chronic obstructive pulmonary disease. Thorax. 2005;60(11):925-931.

20. Hasegawa K, Tsugawa Y, Tsai C-L, et al. Frequent utilization of the emergency department for acute exacerbation of chronic obstructive pulmonary disease. Respir Res. 2014;15(1):40.

21. Viniol C, Vogelmeier CF. 
Exacerbations of COPD. Eur Respir Rev. 2018;27(147):170103.

22. Burge PS, Calverley PM, Jones PW, et al. Randomised, double blind, placebo controlled study of fluticasone propionate in patients with moderate to severe chronic obstructive pulmonary disease: the ISOLDE trial. BMJ. 2000;320(7245):1297-1303.

23. Anthonisen NR, Connett JE, Kiley JP, et al. Effects of Smoking Intervention and the Use of an Inhaled Anticholinergic Bronchodilator on the Rate of Decline of FEV1: The Lung Health Study. JAMA J Am Med Assoc. 1994;272(19):1497-1505.

24. Pauwels RA, Löfdahl C-G, Laitinen LA, et al. Long-Term Treatment with Inhaled Budesonide in Persons with Mild Chronic Obstructive Pulmonary Disease Who Continue Smoking. N Engl J Med. 1999;340(25):1948-1953.

25. Vogelmeier CF, Criner GJ, Martinez FJ, et al. Global Strategy for the Diagnosis, Management, and Prevention of Chronic Obstructive Lung Disease 2017 Report. GOLD Executive Summary. Am J Respir Crit Care Med. 2017;195(5):557-582.

26. Laine DI. Long-acting muscarinic antagonists for the treatment of chronic obstructive pulmonary disease. Expert Rev Clin Pharmacol. 2010;3(1):43-53.

27. Higgins BG, Powell RM, Cooper S, et al. Effect of salbutamol and ipratropium bromide on airway calibre and bronchial reactivity in asthma and chronic bronchitis. Eur Respir J. 1991;4(4):415 LP-420.

28. Sestini P, Renzoni E, Robinson S, et al. Short-acting beta 2 agonists for stable chronic obstructive pulmonary disease. Cochrane database Syst Rev. 2002;(4):CD001495.

29. Suissa S, Patenaude V, Lapi F, Ernst $P$. Inhaled corticosteroids in COPD and the risk of serious pneumonia. Thorax. 2013;68(11):1029-1036.

30. Suissa S, McGhan R, Niewoehner D, Make B. Inhaled Corticosteroids in Chronic Obstructive Pulmonary Disease. Proc Am Thorac Soc. 2007;4(7):535-542.

31. Yang I a, Fong KM, Sim EH a, et al. Inhaled corticosteroids for stable chronic obstructive pulmonary disease. Cochrane Database Syst Rev. 2007;(2):CD002991.

32. Brusselle G, Price D, Gruffydd-Jones $\mathrm{K}$, et al. The inevitable drift to triple therapy in COPD: An analysis of prescribing pathways in the UK. Int $J$
COPD. 2015;10(1):2207-2217.

33. van Staa TP, Leufkens HG, Cooper C. Use of inhaled corticosteroids and risk of fractures. J Bone Miner Res. 2001;16(3):581-588.

34. Korsgaard J, Ledet M. Potential side effects in patients treated with inhaled corticosteroids and long-acting $\beta 2$ agonists. Respir Med. 2009;103(4):566-573.

35. EMA. Inhaled Corticosteroids Containing Medicinal Products Indicated in the Treatment of Chronic Obstructive Pulmonary Disease.; 2016. https://www.ema.europa.eu/en/docume nts/referral/inhaled-corticosteroidsarticle-31-referral-ema-completesreview-inhaled-corticosteroidschronic_en.pdf.

36. Oshagbemi OA, Burden AM, Braeken DCW, et al. Stability of blood eosinophils in patients with chronic obstructive pulmonary disease and in control subjects, and the impact of sex, age, smoking, and baseline counts. $A m$ J Respir Crit Care Med. 2017;195(10).

37. Agusti A, Fabbri LM, Singh D, et al. Inhaled corticosteroids in COPD: Friend or foe? Eur Respir J. January 2018;52(6).

38. Price $D$, West $D$, Brusselle $G$, et al. Management of COPD in the UK primary-care setting: An analysis of real life prescribing patterns. Int $J$ COPD. 2014;9:889-905

39. Kanis JA, Johansson $\mathrm{H}$, Oden $\mathrm{A}$, et al. A meta-analysis of prior corticosteroid use and fracture risk. $J$ Bone Miner Res. 2004;19(6):893-899.

40. van Staa TP, Leufkens HG, Abenhaim L, Zhang B, Cooper C. Oral corticosteroids and fracture risk: relationship to daily and cumulative doses. Rheumatology. 2000;39(12):1383-1389.

41. Leuppi JD, Schuetz P, Bingisser R et al. Short-term vs conventional glucocorticoid therapy in acute exacerbations of chronic obstructive Pulmonary disease. J Am Med Assoc. 2013;309(21):2223-2231.

42. Rice JB, White AG, Scarpati LM, et al. Long-term Systemic Corticosteroid Exposure: A Systematic Literature Review. Clin Ther. 2017; 39(11):22162229.

43. De Vries F, Bracke M, Leufkens HGM, et al. Fracture risk with intermittent high-dose oral glucocorticoid therapy. Arthritis Rheum. 2007;56(1):208-214.

44. Calverley PM, Rabe KF, Goehring U$\mathrm{M}$, et al. Roflumilast in symptomatic 
chronic obstructive pulmonary disease: two randomised clinical trials. Lancet. 2009;374(9691).

45. Seemungal T, Wilkinson T, Hurst J, et al. Long-term erythromycin therapy is associated with decreased chronic obstructive pulmonary disease exacerbations. Am J Respir Crit Care Med. 2008;178(11):1139-1147.

46. Uzun S, Djamin RS, Kluytmans J, et al. Azithromycin maintenance treatment in patients with frequent exacerbations of chronic obstructive pulmonary disease (COLUMBUS): a randomised, doubleblind, placebo-controlled trial. lancet Respir Med. 2014;2(5):361-368.

47. Albert RK, Connett J, Bailey WC, et al. Azithromycin for Prevention of Exacerbations of COPD. N Engl J Med. 2011;365(8):689-698.

48. Cazzola M, MacNee W, Martinez FJ, et al. Outcomes for COPD pharmacological trials: from lung function to biomarkers. Eur Respir J. 2008;31(2):416 LP-469.

49. Mannino DM. Biomarkers in COPD: The search continues! Eur Respir J. 2015;45(4):872-874.

50. Morrow DA, de Lemos JA. Benchmarks for the assessment of novel cardiovascular biomarkers. Circulation. 2007;115(8):949-952.

51. Leuzzi G, Galeone C, Taverna F, et al. C-reactive protein level predicts mortality in COPD: a systematic review and meta-analysis. Eur Respir Rev. 2017;26(143).

52. Stockley RA. Biomarkers in COPD: time for a deep breath. Thorax. 2007;62(8):657 LP-660.

53. Jones PW, Agusti AG. Outcomes and markers in the assessment of chronic obstructive pulmonary disease. Eur Respir J. 2006; 27(4):822-32.

54. Vestbo J, Anderson W, Coxson HO, et al. Evaluation of COPD Longitudinally to Identify Predictive Surrogate Endpoints (ECLIPSE). Eur Respir J. 2008;31(4):869-873.

55. Balkissoon R. COPD association and repeatability of blood biomarkers in the ECLIPSE cohort. COPD J Chronic Obstr Pulm Dis. 2012;9(1):84.

56. Sin DD, Vestbo J. Biomarkers in chronic obstructive pulmonary disease. Proc Am Thorac Soc. 2009;6(6):543545.

57. Duvoix A, Dickens J, Haq I, et al. Blood fibrinogen as a biomarker of chronic obstructive pulmonary disease. Thorax. 2013;68(7):670-676.

58. Dahl M, Tybjaerg-Hansen A, Vestbo J,
Lange $P$, Nordestgaard BG. Elevated plasma fibrinogen associated with reduced pulmonary function and increased risk of chronic obstructive pulmonary disease. Am $J$ Respir Crit Care Med. 2001;164(6):1008-1011.

59. Celli BR, Locantore N, Yates J, et al. Inflammatory biomarkers improve clinical prediction of mortality in chronic obstructive pulmonary disease. $A m \mathrm{~J}$ Respir Crit Care Med. 2012;185(10):1065-1072.

60. Agusti A, Sin DD. Biomarkers in COPD. Clin Chest Med. 2014;35(1):131-141.

61. George L, Brightling CE. Eosinophilic airway inflammation: Role in asthma and chronic obstructive pulmonary disease. Ther Adv Chronic Dis. 2016; (1):34-51.

62. Vedel-Krogh S, Nielsen SF, Lange P, V et al. Blood Eosinophils and Exacerbations in COPD: the Copenhagen General Population Study. Am J Respir Crit Care Med. 2015:rccm.201509-18690C.

63. Pavord ID, Lettis S, Locantore N, et al. Blood eosinophils and inhaled corticosteroid/long-acting $\beta-2$ agonist efficacy in COPD. Thorax. 2016;71(2):118-125.

64. Watz $\mathrm{H}$, Tetzlaff $\mathrm{K}$, Wouters EFM, et al. Blood eosinophil count and exacerbations in severe chronic obstructive pulmonary disease after withdrawal of inhaled corticosteroids: A post-hoc analysis of the WISDOM trial. Lancet Respir Med. 2016;4(5):390-398.

65. Cheng S-L. Blood eosinophils and inhaled corticosteroids in patients with COPD: systematic review and metaanalysis. Int J Chron Obstruct Pulmon Dis. 2018;13:2775-2784.

66. Roche N, Chapman KR, Vogelmeier $\mathrm{CF}$, et al. Blood Eosinophils and Response to Maintenance COPD Treatment: Data from the FLAME Trial. Am J Respir Crit Care Med. March 2017;195(9):1189-1197.

67. Comes A, lanosi ES, Gabriela Jimborean. Inflammatory Biomarkers in Chronic Obstructive Pulmonary Disease. J Interdiscip Med. 2016;1:12.

68. Pinto-Plata VM, Müllerova H, Toso JF, et al. C-reactive protein in patients with COPD, control smokers and nonsmokers. Thorax. 2006;61(1):23-28.

69. Sin DD, Lacy P, York E, et al. Effects of Fluticasone on Systemic Markers of Inflammation in Chronic Obstructive Pulmonary Disease. Am J Respir Crit Care Med. 2004;170(7):760-765. 
70. Man SFP, Sin DD. Effects of corticosteroids on systemic inflammation in chronic obstructive pulmonary disease. Proc Am Thorac Soc. $2005 ; 2(1): 78-82$.
71. Müller B, Tamm M. Biomarkers in acute exacerbation of chronic obstructive pulmonary disease: Among the blind, the one-eyed is king. Am J Respir Crit Care Med. 2006;174(8):848-849. 

Trends in moderate and severe exacerbations among COPD patients in the UK from 2005 to 2013

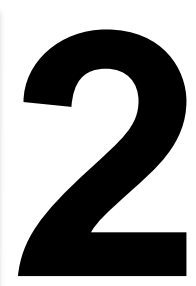

Respiratory Medicine (2018) 144:1-6

Olorunfemi A. Oshagbemi

Spencer J. Keene Johanna. H.M. Driessen

Rachel Jordan Emiel F.M. Wouters Anthonius de Boer

Frank de Vries

Frits M.E. Franssen

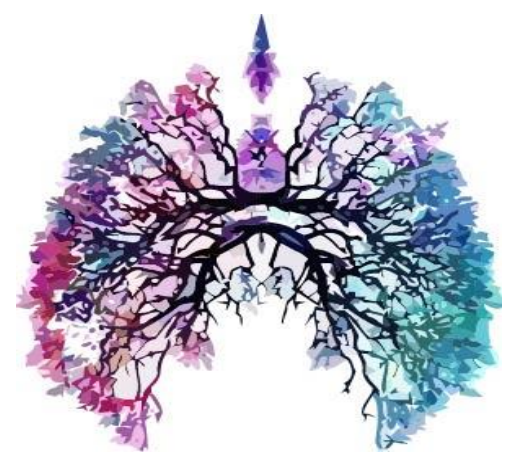




\section{ABSTRACT}

Introduction: Exacerbations of chronic obstructive pulmonary disease (COPD) is characterised by increased symptoms such as dyspnoea, cough and sputum production and/or purulence, leading to greater risk of hospitalisation and mortality. Very few studies have measured long term trends in the incidence of exacerbations of COPD. We therefore investigated the incidence of moderate and severe exacerbations in the United Kingdom (UK) general population.

Methods: A population based-study including Clinical Practice Research Datalink (CPRD) patients $\geq 40$ years with a current diagnosis of COPD within the UK from 2004 to 2013 was conducted. Individuals with a history of asthma were excluded from main analyses. We calculated the incidence rates for any, moderate, and severe exacerbations. The incidence rates for any, moderate and severe exacerbations for COPD in each calendar year were calculated as follows: the sum of any or moderate or severe exacerbations for COPD in that year divided by the total duration of followup in the same calendar year from 2005 through to 2013. We then analysed these rates by gender and age categories ( $40-59$ years, $60-79$ years and $\geq 80$ years).

Results: Among 213,561 patients with an incident COPD diagnosis, 86,300 patients were included in the study. From 2005 to 2013, the incidence rate of any exacerbations increased from 89 to 98 per 1000 person-years (PYs) $(p=0.005)$. Women had significantly higher incidence rates of any exacerbation for each calendar year when compared to men $(p<0.0001)$. The incidence rate of any and moderate exacerbations increased with age from 2005 to 2007. For severe exacerbations incidence decreased from 2005 to 2007 before increasing from 2008 until the end of follow-up (43 per 1000 PYs (95\% confidence interval, 42-45/1000PYs) in 2013). Incidence rates of severe exacerbations were similar by gender and patients aged $80+$ years had higher incidence rates of severe exacerbations from 2005 to 2008 after which their incidence rates dropped in subsequent years.

Conclusion: This is the first study that reports the long-term changes in the incidence rates of moderate and severe exacerbations within the UK general practice. Women showed a substantially higher risk of any COPD exacerbations, and their risk is increasing. The incidence rates of any exacerbations increased during the study period, while severe exacerbations were variable. Furthermore, incidence rates varied substantially by age group. 


\section{INTRODUCTION}

Exacerbations of chronic obstructive pulmonary disease (COPD) are defined as acute episodes of increased respiratory symptoms necessitating additional therapy. ${ }^{1}$ Main symptoms are increased dyspnoea, cough and sputum production and/or purulence. Exacerbations of COPD negatively impact on lung function ${ }^{2}$ health status ${ }^{3}$ and muscle function. ${ }^{4}$ Also, they are important drivers of hospitalisations ${ }^{5}$ and are associated with high mortality risk. ${ }^{6}$ Hence, prevention of exacerbations of COPD is one of the main goals of pharmacologic treatment of the disease and multiple options for drug therapy are available. ${ }^{7}$ In the United Kingdom (UK), £253 million British Pounds (GBP) is spent yearly on COPD management, with more than $50 \%$ of the costs attributed to exacerbations. ${ }^{8}$ Also, COPD-related mortality has increased from $2004-2012(-29,000$ died in 2012) while incidence of COPD decreased and then remained stable over the same period $(-115,000$ new diagnosed COPD in 2012). There are over a million bed days and 140,000 hospital admissions each year in the UK due to COPD $(1.7 \%$ of all hospital admissions and bed days). ${ }^{9}$

The role of demographic characteristics in shaping the trends in exacerbations and related hospitalisations over time has not been adequately described in a UK population. Understanding trends in acute exacerbations and related hospitalisations can help redirect healthcare policies and interventions to subgroups most affected by exacerbations, allow comparison between countries to aid healthcare planning, predict future healthcare challenges, and provide a basis for improving future management. Thus, there is a need to understand the constantly changing trends and to subsequently target health planning and policies towards groups who are at high risk of exacerbations of COPD. ${ }^{10}$ Management of patients with COPD in the UK is performed mainly within the primary care setting. ${ }^{11}$ Therefore, this study aims to describe the incidence rates of moderate and severe exacerbations for COPD by age and gender within the UK primary care setting from 2005-2013.

\section{METHODS}

\section{Data source}

This study was conducted with data from the Clinical Practice Research Datalink (CPRD), formerly known as the General Practice Research Database (GPRD). CPRD contains computerized medical records of 674 primary care practices in the UK. Data collection started in January 1987 and over 11 million persons are currently included, corresponding with $7 \%$ of the UK population. ${ }^{12,13}$ The introduction of the Quality and Outcomes Framework (QOF) in April 2004, was aimed at facilitating quality reporting of various diseases by GPs, including COPD and its related outcomes. ${ }^{14}$ The quality management system uses indicators recorded by GPs to monitor effectiveness in COPD reporting and to reduce the rate of misdiagnosis. Indeed, a high positive predictive value in identifying patients with COPD based on these read codes has been reported, ${ }^{12}$ and the CPRD has been used in various studies on COPD. ${ }^{15-17}$ 
Using CPRD ensured that our results are generalizable within the UK population. The independent scientific advisory committee of the Medicines and Healthcare product Regulatory Agency (MHRA) database research approved this study. (ISAC protocol No: 18_046R).

\section{Study population}

We selected all patients aged $\geq 40$ years with a diagnosis of COPD as recorded by read codes within the CPRD. The study period was from 1 January 2004 until 31 December 2013 corresponding to the period since the introduction of the Quality and Outcomes Framework (QOF). However, we calculated the incidence rates from 2005 through to 2013. For the main analyses, we excluded all patients with a history of asthma from the study and COPD diagnosis prior to 2004. Follow-up ended at the earliest of the study end date (31 December 2013), or the patient's death or transfer out of the practice. The primary endpoint was the first acute exacerbation of COPD in a given calendar year, identified using validated read codes for exacerbations of $\mathrm{COPD}^{18}$ from the referral and/or clinical files. We defined this as any exacerbations of COPD. The secondary outcomes were defined as follows: (i) exacerbations of COPD without hospitalisations/accident and emergency (AE) visits evaluated using validated read codes for exacerbations of COPD from the clinical file only. This was defined as moderate exacerbations of COPD. (ii) COPD-related hospitalisations/AE visit evaluated using read codes for hospitalisations/AE visits for COPD from both clinical and/or referral file in addition with validated read codes for exacerbations of COPD from the referral file. This was defined as severe exacerbations of COPD. Referral files contains referral details recorded by GPs while the clinical file contains all the medical history data entered by the GP. ${ }^{19}$

\section{Statistical analysis}

For our main analyses, we only counted the first outcome of interest within a given calendar year (i.e. patients with an outcome only contributed time at risk from January 1 up to the date of the first outcome within each year). The incidence rates for moderate/severe, moderate and severe exacerbations for COPD in each calendar year was calculated as follows: the sum of any or moderate or severe exacerbations for COPD in that year divided by the total duration of follow-up in the same calendar year. We only calculated incidence rates from 2005 through to 2013 . The incidence rates were expressed as the number of exacerbations per 1000 person-years (PY). We then analysed these rates by gender and age categories (40-59 years, 60-79 years and $\geq 80$ years). The incidence rates are accompanied by $95 \%$ confidence intervals $(\mathrm{Cl})$. Using chi-square test, we compared the changes in trends with statistically significant difference determined at $p<0.05$ between calendar year, gender and age categories. All analyses were carried out using SAS 9.4 (SAS Institute, Cary, $\mathrm{NC})$. 


\section{Sensitivity analysis}

We performed two sensitivity analyses. As far as we know, there are no established methods to estimate incidence rates of moderate and severe exacerbations among COPD patients. In the first sensitivity analysis we no longer counted the first event within a given calendar year, but we added up all exacerbations that occurred in a calendar year. To overcome the problem of potentially counting the same event more than once, we stipulated a gap of at least 30 days between consecutive events of any exacerbations of COPD. This sensitivity analysis was carried out to depict the overall trend of any exacerbations of COPD using validated read codes form referral or/and clinical files. In the second sensitivity analysis, we included patients with a history of asthma and estimated the incidence rates of any exacerbations taking only the first exacerbation into consideration.

\section{RESULTS}

We identified 213,561 patients with COPD diagnosis within the CPRD of whom 86,300 met the inclusion criteria. The mean age of patients in our study was 68 years and $45.5 \%(n=39,241)$ were women (see supplementary Table S.2.1).

\section{Trends of any exacerbations for COPD}

We observed 30,996 any exacerbation for COPD during the study period. Table 2.1 shows the overall incidence rates of any exacerbations for COPD. From 2005 to 2007, the incidence rates of the primary outcome any exacerbations remained stable at around 88 per 1000PYs. A rise in incidence rates of any exacerbations was noted from 2008 to 2012 (112 per 1000PYs (95\%Cl, 109-114/1000PYs)). However, we observed a decrease in the incidence rates of any exacerbations to 98 per 1000 PYs in 2013. Overall, there was a $10 \%$ increase in the incidence rates of any exacerbations from 2005 to 2013 , which was statistically significant $(p=0.005)$.

\begin{tabular}{|c|c|c|c|}
\hline Year & $\begin{array}{l}\text { No. of any exacerbations } \\
n=30,996\end{array}$ & PY at risk & IR /1000 PY (95\% Cl) \\
\hline 2005 & 1,110 & 12514.4 & 89 (84-95) \\
\hline 2006 & 1,678 & 18981.8 & $88(84-93)$ \\
\hline 2007 & 2,194 & 24905.1 & $88(85-92)$ \\
\hline 2008 & 2,838 & 30441.4 & $93(90-97)$ \\
\hline 2009 & 3,356 & 35161.5 & $95(92-99)$ \\
\hline 2010 & 4,315 & 40319.5 & $107(104-110)$ \\
\hline 2011 & 4,839 & 44777.5 & $108(105-111)$ \\
\hline 2012 & 5,500 & 49260.1 & $112(109-114)$ \\
\hline 2013 & 5,166 & 52893.7 & $98(95-100)$ \\
\hline
\end{tabular}

Gender specific incidence rates are shown in Figure 2.1a. In both men and women, any exacerbations incidence rates followed a somewhat similar pattern of year-to-year 
change. The incidence rates for both men and women increased from 84 and 95 in 2005 to 90 and 107 per 1000 PYs in 2013 respectively. Women had greater incidence rates of any exacerbations in each calendar year compared to men $(p<0.0001)$.

Figure 2.2a shows the incidence rates of any exacerbations by age. There was an increase in incidence rates of any exacerbations with increasing age group from 2005 to 2007, which disappeared from 2009 to 2013. In 2008 the incidence rates of any exacerbations were the same among patients 40-59 and 60-79 years old. We observed a decrease in year-to-year incidence rates of any exacerbations for $80+$ year-old patients. In contrast, any exacerbation rates increased across the study period for patients in the 40-59 and the 60-79 year old age groups.

\section{Trends of moderate exacerbations for COPD}

From 2005 until 2013, a total of 30,973 moderate exacerbations were observed in our study population. Table 2.2 shows the annual incidence rates of moderate exacerbations for COPD. The general trend of moderate exacerbation was similar to that of any exacerbations for COPD by age and gender. From 2005 to 2007, the incidence rate of the moderate exacerbations remained stable at around 88 per 1000PYs before increasing to 112 per 1000 PYs $(95 \% \mathrm{Cl}, 109-114 / 1000 \mathrm{PYs})$ in 2012. We found a significant increase in moderate exacerbations for COPD by $10 \%$ from 2005 to 2013 ( $p=0.005)$.

\section{Trends of severe exacerbations for COPD}

Between 2005 and 2013 we found 8,032 severe COPD exacerbations. From 2005 to 2007 we found a decline in the incidence rates of severe exacerbations for COPD from 18 to 11 per 1000 PYs. However, there was a steady increase from 2008 until the end of the study period. In 2013, the incidence rate was 43 per 1000 PYs. Figure $2.1 \mathrm{~b}$ shows the incidence rates of severe exacerbations by gender (Table 2.3). Similar to the overall trend, both men and women showed a flattened ' $U$ ' shaped decrease in incidence rates of severe exacerbations before an increase from 2008 to their peak rates in 2013. Women and men had similar incidence rates in each calendar year of the study $(p=0.747)$.

Figure 2.2b shows the incidence rates of severe exacerbations for COPD by age. We noticed an increasing incidence rate of severe exacerbations for COPD by age from 2005 to 2008. In 2012 and 2013 patients age 60-79 years had a significantly higher incidence rate compared to other age groups $(p<0.0001)$. For each age group, the incidence rates for severe exacerbations decreased from 2005 to 2007 before increasing from 2008 to 2013 (Figure 2.2b). For all age groups, the rates in 2009 were similar. 
Table 2.2. Incidence rates ${ }^{\mathrm{a}}$ of moderate exacerbations for COPD from 2005-2013 ${ }^{\mathrm{b}}$.

\begin{tabular}{cccc}
\hline Year & $\begin{array}{c}\text { No. of moderate } \\
\text { exacerbations } \\
\mathrm{n}=30,973^{\mathrm{a}}\end{array}$ & PY at risk & IR $/ 1000 \mathrm{PY}(95 \% \mathrm{Cl})$ \\
\hline 2005 & 1,110 & 12514.8 & $89(84-94)$ \\
2006 & 1,676 & 18983.3 & $88(84-92)$ \\
2007 & 2,193 & 24905.2 & $88(85-92)$ \\
2008 & 2,835 & 30443.4 & $93(90-96)$ \\
2009 & 3,352 & 35164.4 & $95(92-98)$ \\
2010 & 4,313 & 40320.7 & $107(104-110)$ \\
2011 & 4,835 & 44779.7 & $108(105-111)$ \\
2012 & 5,496 & 49261.5 & $112(109-114)$ \\
2013 & 5,163 & 52895.7 & $98(95-100)$ \\
\hline
\end{tabular}

Abbreviations: AECOPD, acute exacerbation chronic obstructive pulmonary disease; IR, incidence rate; HR, hazard ratio; $\mathrm{AE}$, accident and emergency; $\mathrm{PY}$, person-years; $\mathrm{Cl}$, confidence interval.

${ }^{a}$ Only one event per calendar year was counted.

busing validated read codes for AECOPD from clinical file only.

Table 2.3. Incidence rates of severe exacerbations for COPD from 2005-2013 ${ }^{\mathrm{b}}$

\begin{tabular}{cccc}
\hline Year & $\begin{array}{c}\text { No. of severe exacerbations }^{\text {a }} \\
\mathrm{n}=8,032\end{array}$ & PY at risk & IR /1000 PY (95\% Cl) \\
\hline 2005 & 229 & 12896 & $18(16-20)$ \\
2006 & 248 & 19646.9 & $13(11-14)$ \\
2007 & 277 & 25792.1 & $11(10-12)$ \\
2008 & 455 & 31421.6 & $14(13-16)$ \\
2009 & 556 & 36382.1 & $15(14-17)$ \\
2010 & 821 & 41713.3 & $20(18-21)$ \\
2011 & 1,224 & 46192.4 & $26(25-28)$ \\
2012 & 1,902 & 50388.8 & $38(36-39)$ \\
2013 & 2,320 & 53691 & $43(42-45)$ \\
\hline
\end{tabular}

Abbreviations: AECOPD, acute exacerbation chronic obstructive pulmonary disease; IR, incidence rate; HR, hazard ratio; $A E$, accident and emergency; PY, person-years; $\mathrm{Cl}$, confidence interval.

${ }^{a}$ Only one event per calendar year was counted.

'using read codes for hospitalisation/AE visits for COPD from clinical and/or referral files in addition with validated read codes for AECOPD from referral file.

\section{Sensitivity analysis of trends of any exacerbations of COPD.}

For the first sensitivity analysis, we considered multiple events in a given calendar year. A total of 37,160 any exacerbations of COPD were observed during the study period. The trends were similar to that observed for moderate/severe exacerbations of COPD when we evaluated only one event in a calendar year. However, we found a non-significant increase of $3 \%$ in the incidence rates of any COPD exacerbations from 2005 to 2013. (see supplementary Table S.2.2). In the second sensitivity analysis we included patients with a history of asthma. The incidence rates declined gradually until 2007 and remained the same from 2008 to 2009. The incidence rates dropped from 119 to 103 per 1000 PYs from 2011 to 2013. Overall, there was a $2 \%$ decrease in the incidence rates of any COPD exacerbations, which was not statistically significant $(p=0.577)$. (see supplementary Table S.2.3) 

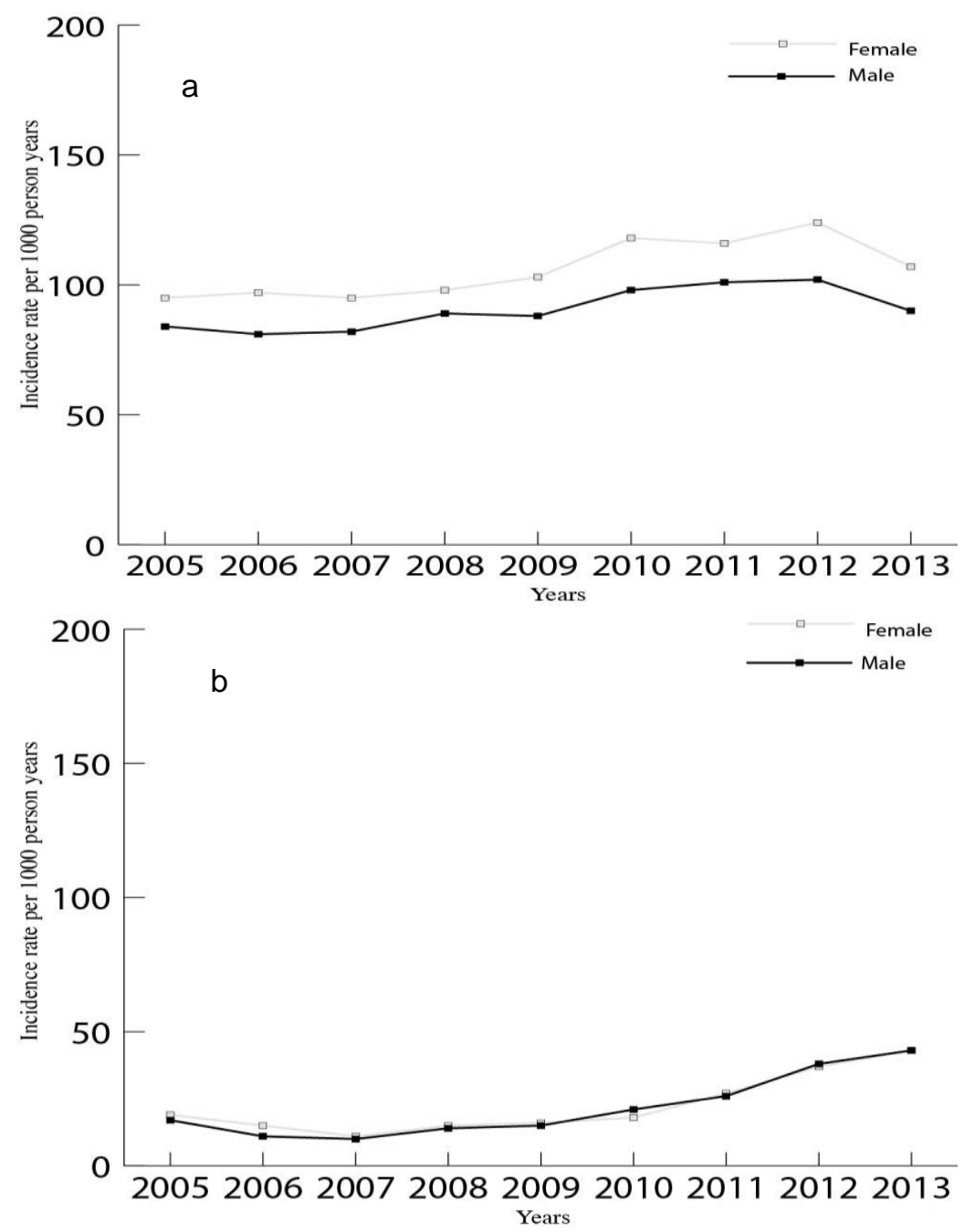

Figure 2.1. Incidence rates of (a) any exacerbations ${ }^{a}$ or (b) severe exacerbations ${ }^{b}$ for COPD by gender.

Abbreviations: AECOPD, acute exacerbation chronic obstructive pulmonary disease; AE, accident and emergency; PY, person-years.

ausing validated read codes for AECOPD from clinical and/or referral files.

${ }^{b}$ using read codes for hospitalisation/AE visits for COPD from clinical and/or referral files in addition with validated read codes for AECOPD from referral file. 

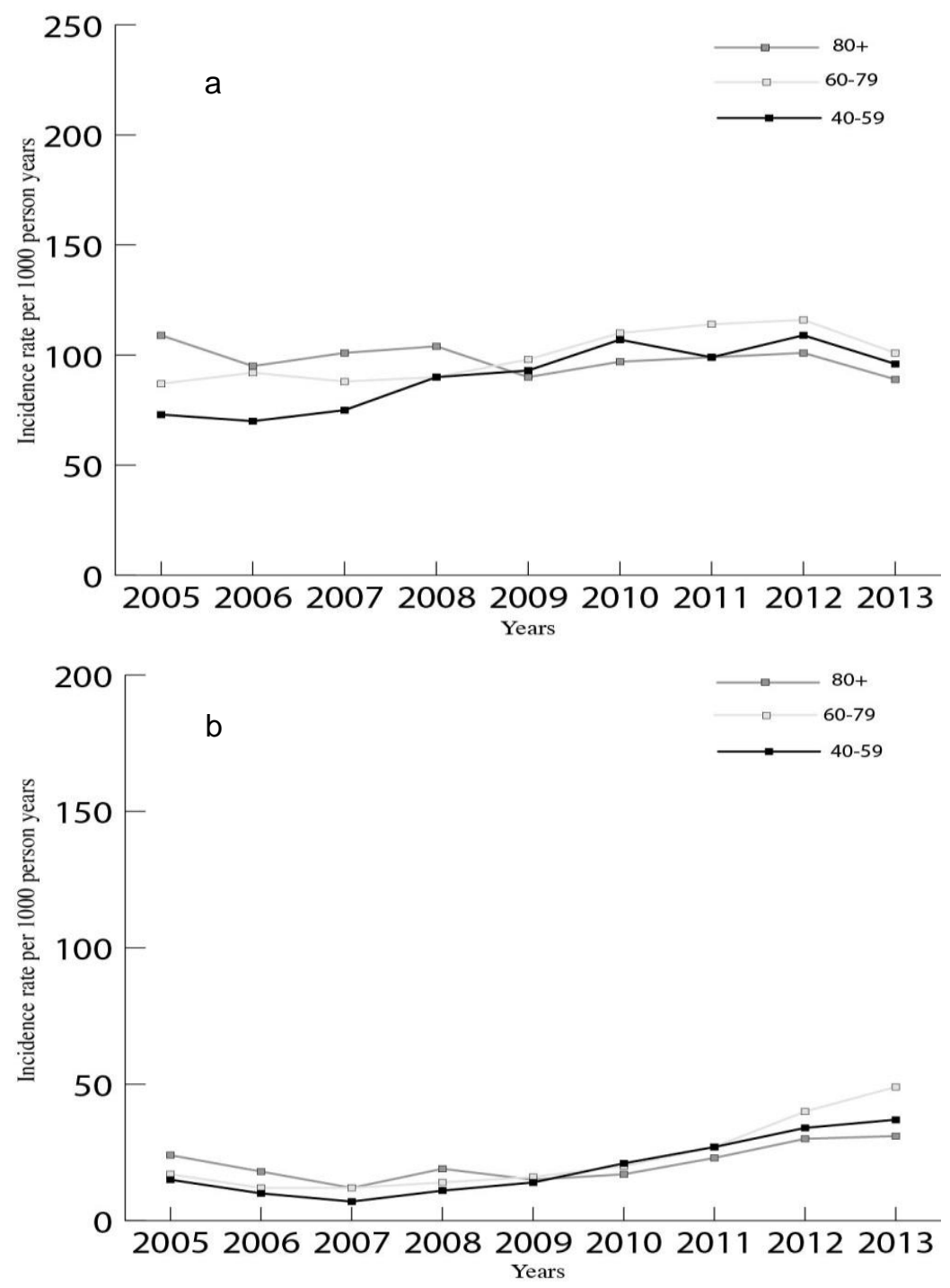

Figure 2.2. Incidence rates of (a) any exacerbations $s^{a}$ or (b) severe exacerbations ${ }^{b}$ for COPD by age.

Abbreviations: AECOPD, acute exacerbation chronic obstructive pulmonary disease; AE, accident and emergency; PY, person-years.

${ }^{a}$ using validated read codes for AECOPD from clinical and/or referral files.

busing read codes for hospitalisation/AE visits for COPD from clinical and/or referral files in addition with validated read codes for AECOPD from referral file. 


\section{DISCUSSION}

\section{Summary of main findings}

Using the world's largest primary care database, this study showed a significant increase in the incidence rates from 2005 to 2013 for the primary endpoint, any exacerbations of COPD. For severe exacerbations, incidence rates increased from 2008 to 2013. Women had higher incidence rates of any exacerbations compared to men throughout the study period but they had similar incidence rates of severe exacerbations for COPD from 2005 to 2013. The incidence rate of any exacerbations for COPD was higher in patients 80+ years from 2005 to 2008, after which this trend was not observed.

\section{Comparison with existing literature}

To the best of our knowledge there has been no previous large-scale population based studies on the trends of moderate to severe exacerbations of COPD in the UK. Previous studies have focused mainly on prevalence rates of COPD, ${ }^{20-22}$ with no emphasis on the trends of acute exacerbations of COPD. Using the Health Improvement Network database, Snell et al, ${ }^{9}$ reported a $27 \%$ increase in the prevalence of COPD in the UK from 2004 to 2012. This increase in prevalence of COPD is correlated with the increase in incidence of moderate and severe exacerbations of COPD in our study.

A study conducted among 423 COPD patients within the Dutch general practice from 1980 to 2006 reported a reduction in overall annual exacerbation rates which is contrary to our findings. ${ }^{10}$ The study also observed that the decreasing trends was independent of age and sex. ${ }^{10}$ It is difficult to draw a definite conclusion for the declining trends of acute exacerbations of COPD in their study, but it might be related to changes in treatment guidelines for COPD and increased emphasis on vaccination during the study period. ${ }^{10}$ In our study, we also found that the incidence rates of acute exacerbations increased with increasing age in certain years. This might be due to disease progression and severity of the disease state. Investigators have reported a relationship between old age and underreporting of acute exacerbations, ${ }^{23}$ which means that the incidence rates might be underestimated among older patients.

Although, few studies have focused on incidence rates of moderate exacerbations of COPD more have focused on COPD exacerbation requiring hospitalisations (severe exacerbations). Fuhrman et al, ${ }^{24}$ examined the temporal trends in acute exacerbations related hospitalisations from 1998 to 2007 in France, and found that admission rates increased significantly, especially among females. Although, our study also reported an increase in severe exacerbations there were only slight differences by gender for all years. Another study conducted in Brazil found no changes in hospitalisation rates from 1998 to 2009. ${ }^{25}$ The Hospital Episode Statistics published by the UK department of health from 1998 to 2003 showed an increase in the number of admissions for COPD, ${ }^{26}$ with 140,000 hospital admissions 
each year. ${ }^{9}$ It has been reported that $30 \%$ of patients hospitalised for exacerbations will be seen again and possibly admitted with another exacerbation within 8 weeks. ${ }^{26}$ Contrary to our findings, a study investigating the incidence of COPD which defined COPD diagnosis based on $A E$ visit and hospitalisation in Canada reported a reduction in the incidence of COPD from 1996 to $2007 .{ }^{20}$ Similarly, Kinnula et al, ${ }^{27}$ reported a decrease in the rates of hospitalisations associated with COPD in Finland from 1998 to 2007. The exact reason for the low incidence rates of severe exacerbations in our study is not completely understood. However, this might be related to the fact that most COPD patients die from various fatal comorbidities associated with COPD severity before they could be hospitalised for an acute exacerbations of COPD. ${ }^{28}$ Another explanation is that many patients have problems in identifying symptom aggravation and fail to report exacerbations to health experts, ${ }^{29,30}$ resulting in spontaneous hospitalisations and AE visits. Additionally, GPs often record COPD hospitalisation using less specific read codes. ${ }^{31}$ Merinopoulou et al, ${ }^{32}$ reported that the rates of COPD-related hospitalisations from 2011 to 2013 were higher in patients with more severe disease state, with most severe patients (GOLD D) having 3 times the number of exacerbations compare to least severe groups (GOLD A). The lack of information on disease stage in our study made it impossible to corroborate their finding.

Whilst emphasis has been on adherence to treatment guidelines among COPD patients in different Global Initiative for Obstructive Lung Disease (GOLD) recommendations as a means of reducing the prevalence of COPD-related exacerbations, a significant dissociation has been reported between adherence to guidelines and actual management of COPD patients. ${ }^{33}$ A study conducted among 24,957 COPD patients in the UK showed that the patients were not managed in accordance to GOLD and National Institute for Health and Care Excellence recommendations, with substantial amount of patients not receiving appropriate medications. ${ }^{34}$ Despite current developments with LAMA/LABA and ICS in treatment of COPD patients we found no objective reduction in exacerbations in our study. Although, low adherence to therapy, ${ }^{35}$ and improper inhaler technique among COPD patients ${ }^{7}$ may have contributed to the observed trends. Furthermore, variation in the incidence of exacerbations seems to follow the incidence of influenza A during the study period, suggesting that this might have had an impact our study. ${ }^{36}$ It is also important to note that the use of long-acting agents was low in our study cohort.

\section{Strengths and limitations}

A major strength of this study was the inclusion of patients from one of the world's largest primary care databases, thus providing a very large sample size. Second, we were able to assess the incidence rates of moderate and severe exacerbations over a long period. Third, we considered periods since the introduction of the QOF ensuring greater quality and validity of data recording. Fourth, we used validated read codes for acute exacerbations of COPD. Lastly, a validity study of COPD patients in the CPRD 
concluded that patients with COPD can be identified easily using specific read codes. $^{37}$

Despite the numerous strengths, this study had some limitations. The use of the read codes for acute exacerbation may have underestimated the true incidence rates of COPD exacerbations. However, the read codes used have been reported to have a high positive predictive value (PPV) of $96 \%$ in identifying patients with COPD exacerbation in the CPRD, ${ }^{18}$ and we explored both clinical and referral files to ensure all exacerbations were identified. Nevertheless, we may have missed a considerable amount of exacerbations that may be miscoded e.g. as respiratory tract infections or pneumonia. Although we excluded asthma patients from the main analyses, it was impossible to rule out the inclusion of patients with reversible airflow limitation in this study. ${ }^{38}$ Furthermore, the PPV of approximately $50.2 \%$ and a sensitivity of $5.4 \%$ in identifying hospitalisations for COPD within the CPRD is arguably low, which may have resulted from GPs recording hospitalisation for COPD by generic hospitalisation codes and/or acute exacerbation read codes. ${ }^{31}$ As such the incidence rate for severe exacerbations is likely to an underestimate of the true incidence in the UK. While the method of diagnosis of COPD has not changed since 2005, GPs ability to identify exacerbations of COPD might have changed over time, ${ }^{32}$ which may have had an effect on our findings.

\section{Implication for future research and clinical practice}

The introduction of QOF in 2004 was aimed at ensuring quality recording of diagnosis and treatment of COPD and other chronic diseases. ${ }^{39}$ Although, approximately equal numbers of patients were diagnosed with COPD annually during the study period. The higher incidence rates of any exacerbations among women and among older patients suggests emphasis be placed on adherence to treatment guidelines and other interventions among these patient groups. The increased incidence of any exacerbations in our study since the introduction of QOF, is concerning. This coincides with sceptics questioning the relevance of QOF in aiding holistic clinical care ${ }^{39}$ although it cannot be denied that its introduction has resulted in a modest reduction in overall emergency admission rates for long-term conditions. ${ }^{39}$ ECLIPSE investigators, suggest that patients with two or more exacerbations in a year represent a distinct "frequent exacerbators" phenotype, and have increased risk of future exacerbation events. ${ }^{40}$ Though these group of patients could not be identified in our study. Fundamentally, it is important for GPs to identify these patients by carefully exploring patient's history and targeting interventions based on recommendations from clinical guidelines. Also, greater emphasis should be made on treatment adherence by COPD patients, as "frequent exacerbators" and patients with history of hospitalisation have been reported to be less likely to adhere to therapy. ${ }^{35}$ 


\section{Conclusion}

This is the first study that reports the long-term changes in the incidence rates of moderate and severe exacerbations as recorded by UK general practitioners. Women showed a substantially higher risk of any COPD exacerbations, and their risk is increasing. The incidence rates of any exacerbations increased during the study period, while severe exacerbations were variable. Furthermore, incidence rates varied substantially by age group. In addition, these findings have the potential to help redirect health policies, planning and interventions to target subgroups more effectively, and may provide a basis for improving overall COPD management in the future.

\section{Conflict of interest}

The authors declare no conflict of interest. 


\section{References}

1. Wedzicha JA, Seemungal TA. COPD exacerbations: defining their cause and prevention.

Lancet. 2007;370(9589):786-796.

2. Dransfield MT, Kunisaki KM, Strand $M J$, et al. Acute exacerbations and lung function loss in smokers with and without chronic obstructive pulmonary disease. Am J Respir Crit Care Med. 2017;195(3):324-330.

3. Seemungal T, Donaldson GC, Paul E $a$, et al. Effect of exacerbation on quality of life in patients with chronic obstructive pulmonary disease. $A m \mathrm{~J}$ Respir Crit Care Med. 1998;157(5 Pt 1):1418-1422.

4. Spruit MA, Gosselink R, Troosters T, et al. Muscle force during an acute exacerbation in hospitalised patients with COPD and its relationship with CXCL8 and IGF-I. Thorax. 2003;58(9):752-756.

5. Foo J, Landis $\mathrm{SH}$, Maskell J, et al. Continuing to confront COPD international patient survey: Economic impact of COPD in 12 countries. PLoS One. 2016;11(4).

6. Obstructive C, Disease P, SolerCataluña JJ, et al. Severe acute exacerbations and mortality in patients with chronic obstructive pulmonary disease. Thorax. 2005;60(11):925-931.

7. Vogelmeier CF, Criner GJ, Martinez FJ, et al. Global Strategy for the Diagnosis, Management, and Prevention of Chronic Obstructive Lung Disease 2017 Report. GOLD Executive Summary. Am J Respir Crit Care Med. 2017;195(5):557-582.

8. Qureshi $H$, Sharafkhaneh A, Hanania NA. Chronic obstructive pulmonary disease exacerbations: latest evidence and clinical implications. Ther $A d v$ Chronic Dis. 2014;5(5):212-227.

9. Snell N, Strachan D, Hubbard R, et al. S32 Epidemiology of chronic obstructive pulmonary disease (COPD) in the uk: findings from the british lung foundation's 'respiratory health of the nation' project. Thorax. 2016;71(Suppl 3):A20.1-A20.

10. Bischoff EWMA, Schermer TRJ, Bor $\mathrm{H}$, Brown $P$, et al. Trends in COPD prevalence and exacerbation rates in Dutch primary care. $\mathrm{Br} J$ Gen Pract. 2009;59(569):927-933.

11. James GD, Donaldson GC, Wedzicha JA, et al.. Trends in management and outcomes of COPD patients in primary care, 2000-2009: a retrospective cohort study. NPJ Prim care Respir Med. 2014; 24:14015

12. Quint JK, Müllerova H, DiSantostefano $\mathrm{RL}$, et al. Validation of chronic obstructive pulmonary disease recording in the Clinical Practice Research Datalink (CPRD-GOLD). BMJ Open . 2014;4(7).

13. Herrett E, Gallagher AM, Bhaskaran K, et al. Data Resource Profile: Clinical Practice Research Datalink (CPRD). Int J Epidemiol. 2015;44(3):827-836.

14. Taggar JS, Coleman T, Lewis S, et al. The impact of the Quality and Outcomes Framework (QOF) on the recording of smoking targets in primary care medical records: cross-sectional analyses from The Health Improvement Network (THIN) database. BMC Public Health. 2012;12(1):1-11.

15. Barakat MF, McDonald HI, Collier TJ, et al. Acute kidney injury in stable COPD and at exacerbation. Int J Chron Obstruct Pulmon Dis. 2015;10(1):20672077.

16. Mullerova $\mathrm{H}$, Shukla A, Hawkins A, et al. Risk factors for acute exacerbations of COPD in a primary care population: a retrospective observational cohort study. BMJ Open. 2014;4(12):e006171.

17. Wurst KE, Shukla A, Muellerova $\mathrm{H}$, et al. Respiratory pharmacotherapy use in patients newly diagnosed with chronic obstructive pulmonary disease in a primary care setting in the UK: a retrospective cohort study. COPD. 2014;11(5):521-530.

18. Rothnie KJ, Müllerová $H$, Hurst JR, et al. Validation of the recording of acute exacerbations of COPD in UK primary care electronic healthcare records. PLoS One. 2016;11(3).

19. Padmanabhan S. CPRD GOLD Data Specification.

https://www.ed.ac.uk/files/atoms/files/c prd_gold_full_data_specification.pdf. Published 2015. Accessed May 15, 2018.

20. Gershon AS, Wang C, Wilton AS, et al. Trends in chronic obstructive pulmonary disease prevalence, incidence, and mortality in ontario, Canada, 1996 to 2007: a populationbased study. Arch Intern Med. 2010;170(6):560-565.

21. Terzikhan N, Verhamme KMC, Hofman 
A, et al. Prevalence and incidence of COPD in smokers and non-smokers: the Rotterdam Study. Eur J Epidemiol. 2016;31(8):785-792.

22. De Marco R, Accordini S, Cerveri I, et al. Incidence of chronic obstructive pulmonary disease in a cohort of young adults according to the presence of chronic cough and phlegm. $A m \mathrm{~J}$ Respir Crit Care Med. 2007;175(1):3239.

23. Langsetmo L, Platt RW, Ernst P, et al. Underreporting exacerbation of chronic obstructive pulmonary disease in a longitudinal cohort. Am J Respir Crit Care Med. 2008;177(4):396-401.

24. Fuhrman $\mathrm{C}$, Roche $\mathrm{N}$, Vergnenègre $\mathrm{A}$, et al. Hospital admissions related to acute exacerbations of chronic obstructive pulmonary disease in France, 1998-2007. Respir Med. 2011;105(4):595-601.

25. Antunes FP, Costa M da CN, Paim JS, et al. Trends in hospitalizations for respiratory diseases in Salvador, Bahia State, Brazil, 1998-2009. Cad Saude Publica. 2012;28(5):869-877.

26. Donaldson GC, Wedzicha JA. COPD exacerbations .1: Epidemiology. Thorax. 2006;61(2):164-168.

27. Kinnula VL, Vasankari T, Kontula E, et al. The 10-year COPD programme in Finland: Effects on quality of diagnosis, smoking, prevalence, hospital admissions and mortality. Prim Care Respir J. 2011;20(2):178-183.

28. Lykkegaard J, De Pon R, Davidsen JR, et al. Trends in the lifetime risk of COPD exacerbation requiring hospitalisation. Eur Respir J. 2013.

29. Kessler R, Ståhl E, Vogelmeier C, et al. Patient Understanding, Detection, and Experience of COPD Exacerbations: An Observational, Interview-Based Study. Chest. 2006;130(1):133-142.

30. Wilkinson TMA, Donaldson GC, Hurst JR, et al. Early Therapy Improves Outcomes of Exacerbations of Chronic Obstructive Pulmonary Disease. Am J Respir Crit Care Med. 2004;169(12):1298-1303.

31. Rothnie KJ, Müllerová H, Thomas SL, et al. Recording of hospitalizations for acute exacerbations of COPD in UK electronic health care records. Clin Epidemiol. 2016;8:771-782.

32. Merinopoulou E, Raluy-Callado M Ramagopalan S, et al. COPD exacerbations by disease severity in England. Int J COPD. 2016;11(1):697709.

33. Chalmers JD, Tebboth A, Gayle A, et al. Determinants of initial inhaled corticosteroid use in patients with GOLD A/B COPD: a retrospective study of UK general practice. NPJ Prim Care Respir Med. 2017;27:43.

34. Price D, West D, Brusselle $G$, et al. Management of COPD in the UK primary-care setting: An analysis of real life prescribing patterns. Int $J$ COPD. 2014;9:889-905.

35. Wisniewski D, Porzezinska $M$, Gruchala-Niedoszytko M, Niedoszytko M, Slominski JM, Jassem E. Factors influencing adherence to treatment in COPD patients and its relationship with disease exacerbations. Pneumonol Alergol Pol. 2014;82(2):96104.

36. Hardelid P, Rait G, Gilbert R, et al. Recording of influenza-like illness in UK primary care 1995-2013: Cohort study. PLoS One. 2015;10(9).

37. Quint JK, Müllerova H, DiSantostefano $R L$, et al. Validation of chronic obstructive pulmonary disease recording in the Clinical Practice Research Datalink (CPRD-GOLD). BMJ Open. 2014;4(7).

38. Gorska K, Krenke R, Korczynski P, et al. Eosinophilic airway inflammation in chronic obstructive pulmonary disease and asthma. J Physiol Pharmacol. 2008;59 Suppl 6:261-270.

39. Forbes LJ, Marchand C, Doran T, et al. The role of the Quality and Outcomes Framework in the care of long-term conditions: a systematic review. $\mathrm{Br} J$ Gen Pract. 2017;67(664):e775-e784.

40. Han MK, Quibrera PM, Carretta EE, et al. Frequency of exacerbations in patients with chronic obstructive pulmonary disease: an analysis of the SPIROMICS cohort. Lancet Respir Med. 2017;5(8):619-626. 


\section{Supplementary Material}

S.2.1. Baseline characteristics of COPD patients.

\begin{tabular}{|c|c|c|}
\hline & $\mathrm{n}=86,300$ & $\%$ \\
\hline Females & 39,241 & 45.5 \\
\hline Mean age (years, SD) & 68.1 & 11.3 \\
\hline \multicolumn{3}{|l|}{ Age category (years) } \\
\hline $40-59$ & 19,475 & 22.6 \\
\hline $60-79$ & 51,982 & 60.2 \\
\hline \multirow{2}{*}{\multicolumn{3}{|c|}{$\mathrm{BMI}\left(\mathrm{kg} / \mathrm{m}^{2}\right)$ in the past 6 months }} \\
\hline & & \\
\hline Underweight $\left(\mathrm{BMl}<18.5 \mathrm{~kg} / \mathrm{m}^{2}\right)$ & 4,784 & 5.5 \\
\hline Normal weight (BMI $18.5-24.9 \mathrm{~kg} / \mathrm{m}^{2}$ ) & 29,808 & 34.5 \\
\hline Overweight (BMI $25.0-30.0 \mathrm{~kg} / \mathrm{m}^{2}$ ) & 26,529 & 30.7 \\
\hline Obese $\left(\mathrm{BMI}>30,0 \mathrm{~kg} / \mathrm{m}^{2}\right)$ & 20,938 & 24.4 \\
\hline Missing & 4,241 & 4.9 \\
\hline \multicolumn{3}{|l|}{ Smoking status at index date } \\
\hline Never & 9,005 & 10.4 \\
\hline Current & 38,207 & 44.3 \\
\hline Former & 38,662 & 44.8 \\
\hline Missing & 426 & 0.5 \\
\hline \multicolumn{3}{|l|}{ Drug use (in the past 6 months) } \\
\hline SABAs & 48,624 & 56.3 \\
\hline LABAs & 7,542 & 8.7 \\
\hline SAMAS & 7,576 & 8.8 \\
\hline LAMAs & 15,102 & 17.5 \\
\hline Xanthine derivatives & 770 & 0.3 \\
\hline Antidepressants & 17,063 & 19.8 \\
\hline \multicolumn{3}{|l|}{ History of co-morbidities } \\
\hline Diabetes Mellitus & 9,619 & 11.1 \\
\hline Anxiety & 12,267 & 14.2 \\
\hline Osteoporosis & 15,063 & 5.9 \\
\hline Malignancies excluding non-melanoma skin cancer & 12,357 & 14.3 \\
\hline Chronic liver disease & 292 & 0.3 \\
\hline Ischaemic heart disease & 12,493 & 14.5 \\
\hline
\end{tabular}

Abbreviations: SD, standard deviation; COPD, chronic obstructive pulmonary disease; BMI, body mass index; SABAs, short-acting beta2 agonists; LABAs, long-acting beta-2 agonists; SAMAs, short-acting muscarinic antagonists; LAMAs, long-acting muscarinic antagonists; ICS, inhaled corticosteroids.

S.2.2. Incidence rates ${ }^{a}$ of any exacerbations for COPD from $2005-2013^{b}$.

\begin{tabular}{lccc}
\hline Year & $\begin{array}{c}\text { No. of any exacerbations } \\
\mathrm{n}=30996\end{array}$ & $\mathrm{PY}$ at risk & $\mathrm{IR} / 1000 \mathrm{PY}(95 \% \mathrm{Cl})$ \\
\hline 2005 & 1,471 & 13350.9 & $110(105-116)$ \\
2006 & 2,260 & 20607.8 & $109(105-114)$ \\
2007 & 3,034 & 27540.5 & $110(107-114)$ \\
2008 & 3,934 & 34209.7 & $114(112-118)$ \\
2009 & 4,760 & 40181.9 & $118(115-122)$ \\
2010 & 6,247 & 46885.5 & $133(130-136)$ \\
2011 & 7,137 & 52995.1 & $134(132-138)$ \\
2012 & 8,090 & 59217.2 & $137(134-139)$ \\
2013 & 7,250 & 64304.4 & $113(110-115)$
\end{tabular}

Abbreviations: AECOPD, acute exacerbation chronic obstructive pulmonary disease; IR, incidence rate; HR, hazard ratio; AE, acciden and emergency; PY, person-years; $\mathrm{Cl}$, confidence interval.

${ }^{a}$ We counted all events occurring 30 days between consecutive events within a calendar year.

busing validated read codes for AECOPD from clinical and/or referral files. 
S.2.3. Incidence rates ${ }^{\mathrm{a}}$ of any exacerbations for COPD from 2005-2013 among COPD patients with history of asthma ${ }^{\mathrm{b}}$.

\begin{tabular}{lccc}
\hline Year & $\begin{array}{c}\text { No. of any exacerbations } \\
\mathrm{n}=53,514\end{array}$ & $\mathrm{PY}$ at risk & $\mathrm{IR} / 1000 \mathrm{PY}(95 \% \mathrm{Cl})$ \\
\hline 2005 & 2,098 & 19984.5 & $105(101-109)$ \\
2006 & 3,100 & 30311.7 & $102(99-106)$ \\
2007 & 4,082 & 39632.7 & $103(100-106)$ \\
2008 & 5,106 & 48203.1 & $106(103-109)$ \\
2009 & 5,858 & 55284.1 & $106(103-109)$ \\
2010 & 7,390 & 63121.3 & $117(115-120)$ \\
2011 & 8,273 & 69617.8 & $119(116-121)$ \\
2012 & 9,204 & 76043.7 & $121(119-123)$ \\
2013 & 8,403 & 81196.9 & $103(101-106)$ \\
\hline
\end{tabular}

Abbreviations: AECOPD, acute exacerbation chronic obstructive pulmonary disease; IR, incidence rate; $\mathrm{HR}$, hazard ratio; $\mathrm{AE}$, accident and emergency; PY, person-years; $\mathrm{Cl}$, confidence interval.

${ }^{a}$ Only one event per calendar year was counted.

busing validated read codes for AECOPD from clinical and/or referral files.

S.2.4. Incidence rates of any exacerbations of COPD from $2005-2013$ by gender ${ }^{a}$.

\begin{tabular}{|c|c|c|c|c|c|c|}
\hline \multirow[b]{2}{*}{ Year } & \multicolumn{3}{|l|}{ A 50} & \multicolumn{3}{|c|}{ Women } \\
\hline & $\begin{array}{l}\text { No of any exacerbations } \\
\qquad n=15,609\end{array}$ & PY at risk & IR /1000 PY & $\begin{array}{l}\text { No of any exacerbations } \\
\qquad n=15,387\end{array}$ & PY at risk & IR /1000 PY \\
\hline 2005 & 579 & 6902.9 & 84 (78-91) & 531 & 5611.5 & 95 (87-103) \\
\hline 2006 & 856 & 10465.5 & $82(77-87)$ & 822 & 8516.2 & $97(90-103)$ \\
\hline 2007 & 1,132 & 13676.2 & $83(78-88)$ & 1,062 & 11228.9 & 95 (89-100) \\
\hline 2008 & 1,487 & 16628.7 & 89 (85-93) & 1,351 & 13812.7 & $98(93-103)$ \\
\hline 2009 & 1,698 & 19195.5 & $88(85-93)$ & 1,658 & 15966.0 & $104(99-109)$ \\
\hline 2010 & 2,154 & 21933.4 & 98 (94-102) & 2,161 & 18386.1 & $118(113-122)$ \\
\hline 2011 & 2,451 & 24244.7 & $101(97-105)$ & 2,388 & 20532.8 & $116(112-121)$ \\
\hline 2012 & 2,700 & 26598.9 & $102(98-105)$ & 2,800 & 22661.1 & $124(119-128)$ \\
\hline 2013 & 2,552 & 28494.1 & $90(86-93)$ & 2,614 & 24399.5 & $107(103-111)$ \\
\hline
\end{tabular}

Abbreviations: AECOPD, acute exacerbation chronic obstructive pulmonary disease; IR, incidence rate; PY, person-years.

ausing validated read codes for AECOPD from clinical and/or referral files

S.2.5. Incidence rates of moderate exacerbations of COPD from 2005-2013 by gender ${ }^{\mathrm{a}}$

\begin{tabular}{|c|c|c|c|c|c|c|}
\hline \multirow[b]{2}{*}{ Year } & \multicolumn{3}{|c|}{ Men } & \multicolumn{3}{|c|}{ Women } \\
\hline & $\begin{array}{c}\text { No of moderate } \\
\text { exacerbations } \\
n=15,599\end{array}$ & PY at risk & IR /1000 PY & $\begin{array}{c}\text { No of moderate } \\
\text { exacerbations } \\
n=15,374\end{array}$ & PY at risk & IR /1000 PY \\
\hline 2005 & 579 & 6903.4 & $84(78-91)$ & 531 & 5611.5 & 95 (87-103) \\
\hline 2006 & 856 & 10465.6 & $82(77-87)$ & 820 & 8517.7 & $96(90-103)$ \\
\hline 2007 & 1,132 & 13676.2 & $83(78-88)$ & 1,061 & 11229.1 & $94(89-100)$ \\
\hline 2008 & 1,485 & 16630.6 & $89(85-94)$ & 1,350 & 13812.8 & $98(93-103)$ \\
\hline 2009 & 1,697 & 19195.8 & $88(84-93)$ & 1,655 & 15968.5 & $104(99-108)$ \\
\hline 2010 & 2,152 & 21934.6 & 98 (94-102) & 2,161 & 18386.1 & $118(113-122)$ \\
\hline 2011 & 2,450 & 24245.1 & $101(97-105)$ & 2,385 & 20534.6 & $116(112-121)$ \\
\hline 2012 & 2,698 & 26599.4 & $101(98-105)$ & 2,798 & 22662.1 & $124(119-128)$ \\
\hline 2013 & 2,550 & 28495.4 & $90(86-93)$ & 2,613 & 24400.3 & $107(103-111)$ \\
\hline
\end{tabular}

Abbreviations: AECOPD, acute exacerbation chronic obstructive pulmonary disease; IR, incidence rate; PY, person-years.

a using validated read codes for AECOPD from clinical file only 


\section{Chapter 2}

S.2.6. Incidence rates of severe exacerbations of COPD from 2005-2013 by gender $^{\mathrm{a}}$

\begin{tabular}{|c|c|c|c|c|c|c|}
\hline \multirow[b]{2}{*}{ Year } & \multicolumn{3}{|c|}{ Men } & \multicolumn{3}{|c|}{ Women } \\
\hline & $\begin{array}{c}\text { No of severe } \\
\text { exacerbations } \\
n=4,318\end{array}$ & PY at risk & IR /1000 PY & $\begin{array}{c}\text { No of severe } \\
\text { exacerbations } \\
n=3,714\end{array}$ & PY at risk & IR /1000 PY \\
\hline 2005 & 119 & 7108.1 & $17(14-20)$ & 110 & 5787.9 & $19(16-23)$ \\
\hline 2006 & 115 & 10811.4 & $11(9-13)$ & 133 & 8835.5 & $15(13-18)$ \\
\hline 2007 & 149 & 14116.3 & $11(9-12)$ & 128 & 11675.8 & $11(9-13)$ \\
\hline 2008 & 238 & 17150.8 & $14(12-16)$ & 216 & 14270.9 & $15(13-17)$ \\
\hline 2009 & 299 & 19806.7 & $15(13-17)$ & 258 & 16575.4 & $16(14-18)$ \\
\hline 2010 & 467 & 22577.2 & $21(19-23)$ & 354 & 19136.1 & $18(17-21)$ \\
\hline 2011 & 656 & 24941.7 & $26(24-28)$ & 568 & 21250.8 & 27 (25-29) \\
\hline 2012 & 1,029 & 27054.8 & $38(36-40)$ & 873 & 23334.1 & 37 (35-40) \\
\hline 2013 & 1,246 & 28788.9 & $43(41-46)$ & 1,074 & 24902.7 & $43(41-46)$ \\
\hline
\end{tabular}

Abbreviations: AECOPD, acute exacerbation chronic obstructive pulmonary disease; IR, incidence rate; PY, person-years.

a using read codes for hospitalisation/AE visits for COPD from clinical and/or referral files in addition with validated read codes for AECOPD from referral file. 


Stability of blood eosinophils in patients with chronic obstructive pulmonary disease and in control subjects, and the impact of age sex, smoking status and baseline counts

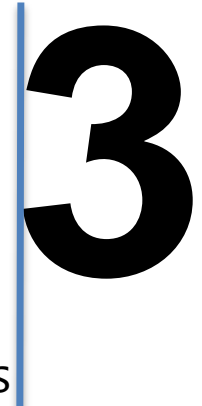

Am J Respir Crit Care Med.2017;195(10):1402-1404 (published as a letter)

Olorunfemi A. Oshagbemi Andrea M. Burden Dionne C.W. Braeken Henskens Yvonne Emiel F.M. Wouters Johanna H.M. Driessen Frank de Vries Frits M.E. Franssen

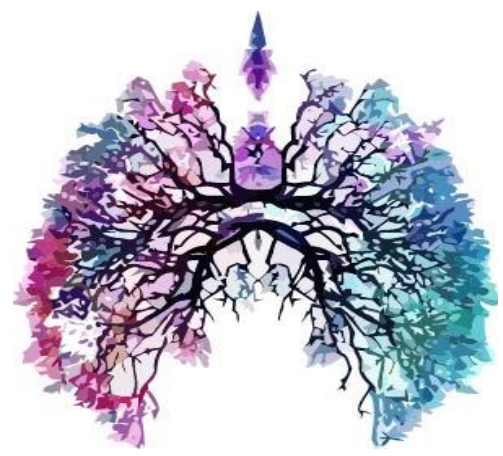




\section{ABSTRACT}

Background: Increasing data supports the role of blood eosinophils as a biomarker for identifying steroid-responsive patients with chronic obstructive pulmonary disease (COPD). The objective of this study was to investigate the stability of blood eosinophil counts over time in patients with COPD and non-COPD controls, and the impact of gender, age, smoking and baseline counts.

Methods: The study was conducted with data obtained from the Clinical Practice Research Datalink (CPRD) in the United Kingdom (UK). Patients aged 40 years and older diagnosed with COPD were matched with up to two non-COPD controls by gender, year of birth and medical practice. The primary outcome of interest was persistence of blood eosinophils counts $<2 \%$ or $\geq 2 \%$ throughout follow-up before and after stratification for possible confounders.

Results: The stability of blood eosinophil counts was significantly lower in COPD patients versus non-COPD (chi-square test $\left(x^{2}\right)=66.48 ; p<0.001$ ). In patients with COPD, stability decreased from $90 \%$ at 6 months to $79 \%$ at 1 -year and subsequently dropped to $51 \%$ in 4 years. When stratified by baseline eosinophil count, patients with counts greater than $6 \%$ showed the greatest stability while patients with eosinophil levels lower than $2 \%$ showed the least stability. Stability of blood eosinophil counts decreased with increasing age, was significantly higher in males as compared to females $\left(x^{2}=40.57 ; p<0.001\right)$, and was higher in smokers compared to non-smokers $\left(x^{2}=6 \cdot 35 ; p<0 \cdot 001\right)$.

Conclusions: While the clinical impact of gender and smoking is probably low, age and baseline eosinophil levels had more impact on long-term stability of blood eosinophil counts. 


\section{INTRODUCTION}

Chronic obstructive pulmonary disease (COPD) is a major cause of worldwide morbidity and mortality. ${ }^{1,2}$ It is currently responsible for 2.75 million deaths annually, and it is projected to be the third leading cause of death globally by the year $2030 .^{3}$ Although COPD is defined by the presence of persistent airflow limitation, it is well known that exacerbations play a central role in the progression, and the clinical and societal burden of the diseases. ${ }^{3}$

One of the major goals of pharmacological management is the prevention of exacerbations. ${ }^{4}$ Various respiratory drug classes are known to reduce the number of exacerbations, including long-acting beta-agonists (LABAs), ${ }^{5}$ long-acting anticholinergics (LAMAs), ${ }^{3}$ and inhaled corticosteroids (ICS). ${ }^{6}$ While it is traditionally recommended that patients with severe COPD and repeated exacerbations are treated with ICS containing regimens, alternative approaches were introduced in recent years. ${ }^{6}$ This is based on the growing recognition of the heterogeneity of exacerbations, ${ }^{7}$ the lack of efficacy of ICS in a large proportion of patients, and the concerns of side effects of ICS. ${ }^{8,9}$ However, it is also recognized that a proportion of patients respond very well to ICS, ${ }^{6}$ and there is increasing data supporting the role of serum eosinophils to identify these steroid-responsive patients. ${ }^{10}$ Patients with high blood eosinophil counts seem to benefit more from ICS in terms of exacerbation rate reduction, ${ }^{11}$ while ICS could be withdrawn without increases in exacerbation rates in patients with low blood eosinophil counts. ${ }^{12}$ However, the optimal cut-off in blood eosinophils remains to be established. Moreover, little is known about the long-term stability of blood eosinophils as a biomarker in both patients with COPD as well as non-COPD subjects in the general population, and the impact of patient characteristics and environmental factors such as age, gender, smoking and baseline eosinophil counts remain unclear. ${ }^{12}$

Therefore, the aim of this study was to determine the stability of blood eosinophil counts over time in patients with COPD and non-COPD controls derived from the general population. We also examined the influence of gender, age, smoking status and eosinophil counts at baseline on eosinophil stability.

\section{METHODS}

\section{Data source}

This study was conducted with data obtained from the Clinical Practice Research Datalink (CPRD), formerly known as the General Practice Research Database (GPRD). CPRD contains computerized medical records of 674 primary care practices in the United Kingdom (UK). Data collection started in January 1987 and over 11 million persons are currently included, corresponding with $7 \%$ of the UK population. ${ }^{13}$ For this study the period of valid data collection has been limited to 1 January 2005 and later, corresponding to the introduction of the Quality and Outcomes Framework 
(QOF) in April 2004, which facilitates quality reporting of various diseases, including COPD. ${ }^{14}$ The quality management system, uses indicators recorded by general practitioners (GPs) to monitor effectiveness in COPD reporting and to reduce the rate of misdiagnosis. Indeed, a high positive predictive value in identifying patients with COPD based on these read codes has been reported ${ }^{15}$ and CPRD has been used in various studies on COPD. ${ }^{16-18}$ (ISAC protocol No:16_131R).

\section{Study population}

The study population consisted of all individuals aged 40 years and older with a diagnosis of COPD recorded by a read code during the period of valid data collection (1 January 2005 to 31 January 2015). Each patient with COPD was matched with up to two non-COPD controls by gender, year of birth and medical practice. Patients were followed from the date of the first blood eosinophil count up to the last valid eosinophil count during the period of valid data collection or end of study (31 January 2015). Only patients with at least two blood eosinophil counts on different dates were included. Patients with a history of asthma or COPD exacerbations within 30 days before the start of follow-up were excluded from both groups. All patients using maintenance systemic corticosteroid therapy 30 days before start of follow-up, irrespective of the medical indication, were excluded in further analysis.

\section{Outcomes}

The primary outcome of interest was stability of blood eosinophils, defined as blood eosinophil count, which persistently remained $<2 \%$ or $\geq 2 \%$ throughout follow-up. Blood eosinophil counts which did not persistently remain $<2 \%$ or $\geq 2 \%$ during the period of patient follow-up were considered unstable. As a secondary outcome, we redefined instability as an absolute change of $\geq 2 \%$ in blood eosinophil counts between two consecutive readings taken on different days, regardless of the index value. The percentage eosinophil count was obtained by dividing the absolute eosinophil counts by total white blood cell counts both in $10^{\circ} \mathrm{cells} / \mathrm{L}$ multiplied by one hundred. If a patient had multiple measurements on the same day, the first measurement was used.

\section{Statistical analysis}

Kaplan-Meier survival curves were plotted to describe the stability of blood eosinophil counts for COPD patients and matched controls (using the LIFETEST procedure SAS 9.4 [SAS Institute, Cary, NC]). All patients were categorised according to eosinophil count at baseline ( $<2.0 \%, 2.0-3.9 \%, 4.0-5.9 \%, \geq 6.0 \%)$, age (40-59 years, $60-79$ years and $80+$ years), gender and smoking status (current smoking 'yes' or 'no'). The comparison of eosinophil stability between the various strata was deduced using survival plots and chi-square $\left(x^{2}\right)$ test with statistically significant differences determined between groups at $p<0.05$. 


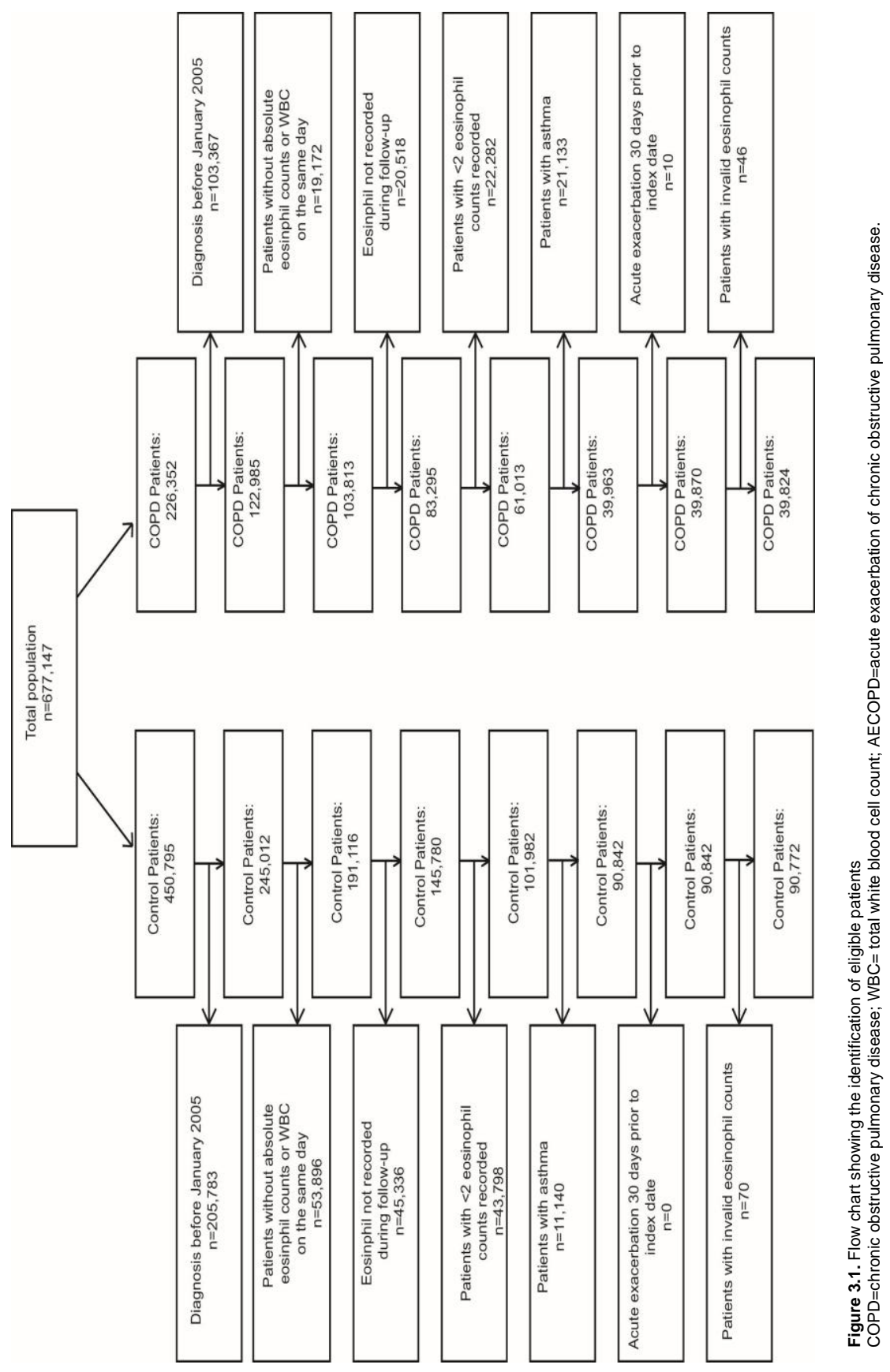


Proportions of patients with stable blood eosinophil counts were determined at various periods in time.

Sensitivity analyses.

In the sensitivity analysis, we defined stability as blood eosinophil counts persistently $<0.34 \times 10^{9}$ cells/L or $\geq 0.34 \times 10^{9}$ cells/L throughout follow up. Blood eosinophil counts that did not persistently $<0.34 \times 10^{9}$ cells $/ \mathrm{L}$ or $\geq 0.34 \times 10^{9}$ cells $/ \mathrm{L}$ during followup were considered unstable (see supplementary Table S.3.1).

\section{RESULTS}

From the inception cohort of 677,147 patients, 226,352 had a diagnosis of COPD and were matched with up to two non-COPD controls $(450,795)$ starting January 2005 . A total of 39,824 patients with COPD and 90,772 without COPD (non-COPD) met the various inclusion criteria for this study population (Figure 3.1). Table 3.1 displays the baseline characteristics of all subjects in the analyses. The mean age $( \pm$ SD) at index date in COPD patients was $69.4 \pm 10.6$ years and $69.9 \pm 10.6$ years for matched nonCOPD controls. The mean duration of follow-up was $3.0 \pm 2.3$ years for COPD patients and $2.9 \pm 2.1$ years for non-COPD controls. The mean number of blood eosinophil reading from each patient with COPD was $6.2 \pm 1.2$ and $5.1 \pm 1.3$ for nonCOPD controls. The mean eosinophil count was $3.0 \pm 3.2 \%$ versus $2.9 \pm 3.0 \%$ for patients with COPD and matched controls, respectively. The percentage of COPD patients with an eosinophil count $<2 \%$ was $36.4 \%$ at baseline compared with $36.9 \%$ of non-COPD controls. With regard to prior medication use, COPD patients had higher utilisation of all measured medications in the 6-months prior to index date, with higher use of SABAs compared to controls (55.8\% vs. $2 \cdot 6 \%$ ). The prevalence of cardiovascular diseases, osteoporosis and anxiety disorder was higher in patients with COPD, compared to non-COPD controls. The mean absolute eosinophil counts were $(0.23 \pm 0.26) \times 10^{9} \mathrm{cells} / \mathrm{L}$ for COPD patients and $(0.21 \pm 0.35) \times 10^{9} \mathrm{cells} / \mathrm{L}$ for non-COPD controls $(p<0.001)$.

Figure 3.2 shows that the 10 -year stability of blood eosinophil count was significantly different in COPD patients versus non-COPD $\left(x^{2}=66 \cdot 48 ; p<0.001\right)$. The stability of blood eosinophil counts increased with baseline counts in both COPD as well as non-COPD controls, with eosinophil counts greater than $6 \%$ showing the greatest stability while patients with eosinophil levels lower than $2 \%$ having the least stability (COPD: $x^{2}=2246 \cdot 82$; $p<0.001$; non-COPD: $x^{2}=5749 \cdot 03 ; p<0 \cdot 001$, Figure 3.3). In addition, the stability of blood eosinophil counts in patients with COPD was highest in individuals aged 40-59 years and decreased with increasing age category $\left(x^{2}=203.39 ; p<0.001\right.$, Figure $\left.3.4 a\right)$. Figure $3.4 b$ depicts the stability in non-COPD patients by age $\left(x^{2}=621 \cdot 17 ; p<0.001\right)$. 
Table 3.1. Baseline characteristics of patients with COPD and controls without COPD.

\begin{tabular}{|c|c|c|c|c|}
\hline & \multicolumn{2}{|c|}{ COPD Patients } & \multicolumn{2}{|c|}{ Non-COPD Controls } \\
\hline & $\mathrm{n}=39,824$ & $\%$ & $n=90,772$ & $\%$ \\
\hline Follow-up time, years, mean (SD) & 3.0 & 2.3 & 2.9 & 2.1 \\
\hline Number of females & 18,284 & 45.9 & 44,468 & 48.9 \\
\hline Age, years, mean (SD) & 69.4 & 10.6 & 69.9 & 10.6 \\
\hline \multicolumn{5}{|l|}{ Age category } \\
\hline 40-59 years & 7,159 & 18.0 & 15,001 & 16.5 \\
\hline $60-79$ years & 25,358 & 63.7 & 57,899 & 63.8 \\
\hline$>80$ years & 7,307 & 18.3 & 17,872 & 19.7 \\
\hline \multicolumn{5}{|l|}{ Index blood eosinophil count } \\
\hline Absolute, $3 \times 10^{9}$ cells $/ \mathrm{L}$, mean (SD) & 0.23 & 0.26 & 0.21 & 0.35 \\
\hline Percentage, mean (SD) & 3.0 & 3.2 & 2.9 & 3.0 \\
\hline \multicolumn{5}{|l|}{ Index blood eosinophil count category } \\
\hline Low $(<2.0 \%)$ & 14,492 & 36.4 & 33,486 & 36.9 \\
\hline Moderate $(2.0-3.9 \%)$ & 15,231 & 38.3 & 35,755 & 39.4 \\
\hline High $(4.0-5.9 \%)$ & 6,496 & 16.3 & 14,644 & 16.1 \\
\hline Very high $(>6.0 \%)$ & 3,605 & 9.0 & 6,887 & 7.6 \\
\hline \multicolumn{5}{|l|}{ Smoking status, n (\%) } \\
\hline Never & 4,412 & 11.1 & 46,581 & 51.3 \\
\hline Current & 16,107 & 40.5 & 13,298 & 14.7 \\
\hline Former & 19,286 & 48.3 & 30,849 & 33.9 \\
\hline Missing & 19 & 0.1 & 44 & 0.1 \\
\hline \multicolumn{5}{|l|}{ Drug use 6 months before } \\
\hline SABAs & 22,202 & 55.8 & 2,317 & 2.6 \\
\hline LABAs & 3,728 & 9.4 & 181 & 0.2 \\
\hline SAMAS & 3,473 & 8.7 & 275 & 0.2 \\
\hline LAMAs & 6,879 & 17.3 & 193 & 0.2 \\
\hline ICSs & 11,667 & 28.2 & 1,270 & 1.4 \\
\hline Xanthine derivatives & 314 & 0.8 & 27 & 0.0 \\
\hline \multicolumn{5}{|l|}{ History of comorbidities } \\
\hline Cardiovascular diseases & 9,397 & 23.6 & 18,334 & 28.5 \\
\hline Stroke & 2,993 & 7.5 & 5,720 & 6.3 \\
\hline Rheumatoid arthritis & 1,402 & 3.5 & 2,434 & 2.7 \\
\hline Anxiety & 6,005 & 15.1 & 11,065 & 12.2 \\
\hline Osteoporosis & 2,609 & 6.6 & 4,730 & 5.2 \\
\hline Any cancer (excluding non-melanoma skin cancer) & 6,227 & 15.6 & 14,426 & 15.9 \\
\hline Chronic liver disease & 122 & 0.3 & 174 & 0.2 \\
\hline Pulmonary fibrosis & 332 & 0.8 & 160 & 0.2 \\
\hline
\end{tabular}

Stability was also significantly different between genders; with males having significantly higher stability in blood eosinophil counts $\left(x^{2}=40.57 ; p<0.001\right.$, Figure 3.5a). Figure $3.5 \mathrm{~b}$ displays eosinophil stability among matched controls, by gender, with significant difference between males and females $\left(x^{2}=155.02 ; p<0.001\right)$. When patients with COPD were stratified by smoking status (Figure 3.6) smokers had a higher stability in blood eosinophil counts compared to non-smokers $\left(x^{2}=6.35\right.$; $\mathrm{p}<0.001)$. In an additional analysis, we reanalysed the data using our secondary outcome of blood eosinophil counts stability. The results obtained were similar to those from our primary analysis except for the stability by blood eosinophil counts at baseline. 
Table 3.2 shows the proportion of COPD patients with stable blood eosinophil counts after stratification by baseline blood eosinophil count, age, gender and smoking status over periods of follow-up based on our primary outcome definition. In patients with COPD the stability decreased from $90 \%$ at 6 months to $79 \%$ at 1 -year, and subsequently dropped to $51 \%$ in 4 years. By blood eosinophil counts at baseline we observed an increase in stability with increasing counts at each time point. Stability in blood eosinophils decreased with increasing age. As shown in Table 3.2, the clinical impact of gender and smoking status on blood eosinophils was limited. In Table 3.3 we show the proportion of non-COPD patients with stable eosinophil counts and the various stratifications. The correlation for blood eosinophil count, age, gender, and smoking status at baseline is shown in Table 3.4. The results did not change significantly following the exclusion of patients with prior systemic corticosteroids use.

Table 3.2. Proportion of COPD patients with stable eosinophil counts among stratified by gender age, eosinophil counts and smoking status at different time points.

\begin{tabular}{|c|c|c|c|c|c|c|c|}
\hline & 6 months & 9 months & 1 year & 2 years & 4 years & 6 years & 8 years \\
\hline COPD Patients & $90 \%$ & $82 \%$ & $79 \%$ & $65 \%$ & $51 \%$ & $40 \%$ & $40 \%$ \\
\hline \multicolumn{8}{|l|}{ Eosinophil count } \\
\hline$<2.0 \%$ & $83 \%$ & $75 \%$ & $65 \%$ & $52 \%$ & $40 \%$ & $32 \%$ & $29 \%$ \\
\hline $2.0 \%-3.9 \%$ & $88 \%$ & $81 \%$ & $71 \%$ & $60 \%$ & $49 \%$ & $39 \%$ & $31 \%$ \\
\hline $4.0-5.9 \%$ & $95 \%$ & $91 \%$ & $85 \%$ & $79 \%$ & $62 \%$ & $59 \%$ & $55 \%$ \\
\hline$\geq 6.0 \%$ & $97 \%$ & $94 \%$ & $90 \%$ & $83 \%$ & $72 \%$ & $68 \%$ & $65 \%$ \\
\hline \multicolumn{8}{|l|}{ Age } \\
\hline $40-59$ years & $90 \%$ & $85 \%$ & $80 \%$ & $68 \%$ & $51 \%$ & $50 \%$ & $44 \%$ \\
\hline $60-79$ years & $89 \%$ & $84 \%$ & $77 \%$ & $65 \%$ & $49 \%$ & $43 \%$ & $39 \%$ \\
\hline $80+$ years & $85 \%$ & $79 \%$ & $73 \%$ & $59 \%$ & $42 \%$ & $38 \%$ & $31 \%$ \\
\hline \multicolumn{8}{|l|}{ Gender } \\
\hline Females & $87 \%$ & $83 \%$ & $77 \%$ & $60 \%$ & $45 \%$ & $40 \%$ & $39 \%$ \\
\hline Males & $87 \%$ & $84 \%$ & $78 \%$ & $61 \%$ & $47 \%$ & $43 \%$ & $40 \%$ \\
\hline \multicolumn{8}{|l|}{ Smoking status } \\
\hline Yes & $90 \%$ & $83 \%$ & $75 \%$ & $63 \%$ & $51 \%$ & $41 \%$ & $40 \%$ \\
\hline No & $90 \%$ & $83 \%$ & $75 \%$ & $61 \%$ & $49 \%$ & $40 \%$ & $37 \%$ \\
\hline
\end{tabular}

Abbreviation: $\mathrm{COPD}=$ chronic obstructive pulmonary disease

Table 3.3. Proportion of non-COPD patients with stable eosinophil counts among stratified by gender age, eosinophil counts and smoking status at different time points.

\begin{tabular}{|c|c|c|c|c|c|c|c|}
\hline & 6 months & 9 months & 1 year & 2 years & 4 years & 6 years & 8 years \\
\hline \multicolumn{8}{|l|}{ Eosinophil count } \\
\hline$<2.0 \%$ & $84 \%$ & $78 \%$ & $72 \%$ & $58 \%$ & $41 \%$ & $35 \%$ & $29 \%$ \\
\hline $2.0 \%-3.9 \%$ & $89 \%$ & $78 \%$ & $77 \%$ & $64 \%$ & $48 \%$ & $39 \%$ & $33 \%$ \\
\hline $4.0-5.9 \%$ & $95 \%$ & $93 \%$ & $91 \%$ & $84 \%$ & $73 \%$ & $64 \%$ & $57 \%$ \\
\hline$\geq 6.0 \%$ & $97 \%$ & $96 \%$ & $95 \%$ & $90 \%$ & $83 \%$ & $74 \%$ & $66 \%$ \\
\hline \multicolumn{8}{|l|}{ Age } \\
\hline $40-59$ years & $92 \%$ & $89 \%$ & $84 \%$ & $72 \%$ & $58 \%$ & $49 \%$ & $45 \%$ \\
\hline $60-79$ years & $90 \%$ & $86 \%$ & $81 \%$ & $68 \%$ & $51 \%$ & $45 \%$ & $37 \%$ \\
\hline $80+$ years & $88 \%$ & $83 \%$ & $76 \%$ & $61 \%$ & $43 \%$ & $36 \%$ & $31 \%$ \\
\hline \multicolumn{8}{|l|}{ Gender } \\
\hline Females & $89 \%$ & $84 \%$ & $80 \%$ & $65 \%$ & $50 \%$ & $42 \%$ & $36 \%$ \\
\hline Males & $90 \%$ & $85 \%$ & $82 \%$ & $68 \%$ & $55 \%$ & $45 \%$ & $40 \%$ \\
\hline \multicolumn{8}{|l|}{ Smoking status } \\
\hline Yes & $91 \%$ & $85 \%$ & $83 \%$ & $69 \%$ & $53 \%$ & $45 \%$ & $40 \%$ \\
\hline No & $91 \%$ & $85 \%$ & $83 \%$ & $68 \%$ & $51 \%$ & $43 \%$ & $38 \%$ \\
\hline
\end{tabular}


Table 3.4. Pearson correlation coeffient for the association between blood eosinophil count, age, gender, and smoking status at baseline for COPD and non-COPD patients.

\begin{tabular}{|c|c|c|c|c|c|}
\hline \multirow[t]{3}{*}{ COPD } & Eosinophil Count & & Age & Gender & Smoking status \\
\hline & & correlation & 0.02 & -0.08 & -0.04 \\
\hline & & $P$ value & $<0.001$ & $<0.001$ & $<0.001$ \\
\hline Non-COPD & Eosinophil Count & $\begin{array}{l}\text { correlation } \\
\mathrm{P} \text { value }\end{array}$ & $\begin{array}{l}-0.008 \\
<0.001\end{array}$ & $\begin{array}{c}-0.08 \\
<0.001\end{array}$ & $\begin{array}{l}-0.009 \\
<0.001\end{array}$ \\
\hline
\end{tabular}

Abbreviation: $\mathrm{COPD}=$ chronic obstructive pulmonary disease

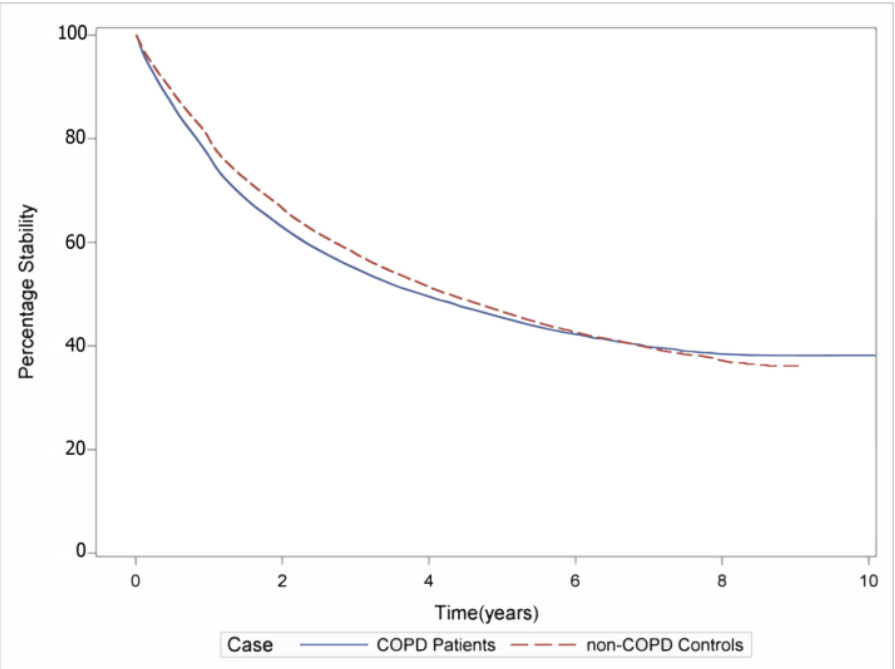

Figure 3.2 Kaplan Meier curve depicting the stability of blood eosinophil counts in all COPD patients and matched controls. 

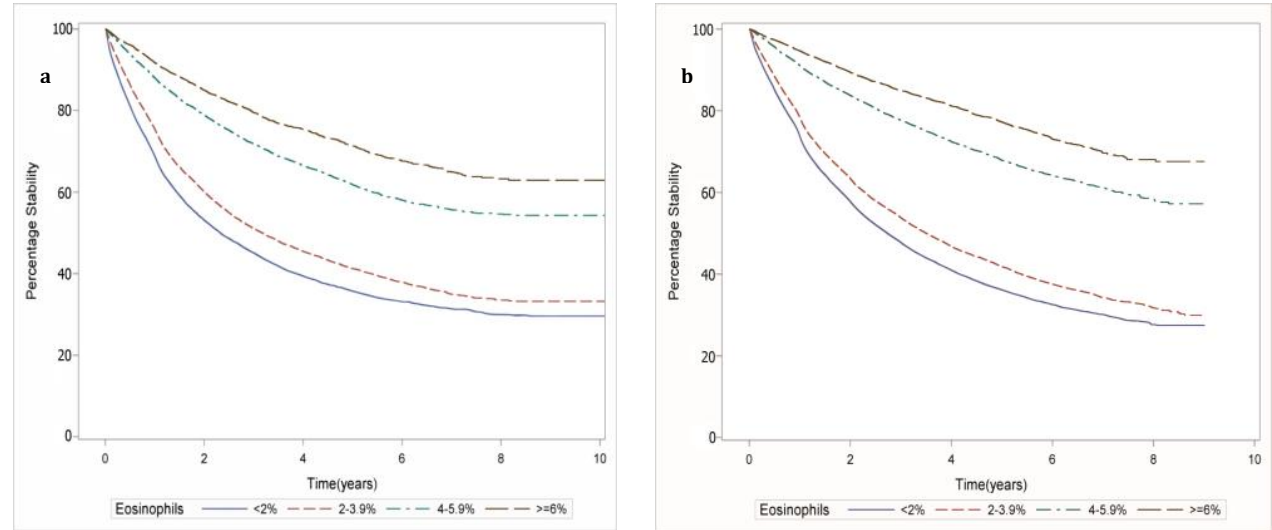

Figure 3.3 Kaplan Meier curves comparing stability of blood eosinophil count in (a) COPD patients and (b) controls by baseline eosinophil counts.

\section{Sensitivity analysis}

The long-term stability of blood eosinophil counts was lower in COPD patients versus non-COPD $(P<0.001)$ (see supplementary Table S.3.1). The stability of blood eosinophil was higher in COPD patients with baseline counts less than $0.34 \times 10^{9}$ cells/L compared to patients with baseline counts of at least $0.34 \times 10^{9}$ cells $/ \mathrm{L}$. Also the stability of blood eosinophils in COPD was highest in individuals aged 40-59 years and decreased with increasing age in both study groups. Both in COPD as well as non-COPD, females had significantly higher stability in blood eosinophil counts compared to males $(P<0.001)$. There was no difference in stability between current smokers and non-smokers among COPD patients. However, among non-COPD controls, stability was higher in non-smokers compared to smokers.

\section{DISCUSSION}

This is the first population-based study, which shows that the stability of blood eosinophil counts was statistically significantly lower in patients with COPD compared to non-COPD controls. It was approximately $80 \%$ at one year, $60-65 \%$ at two years of follow-up, and declined progressively thereafter in both groups. Second, it showed that stability of blood eosinophil counts is higher with increased baseline levels, while advancing age has an opposite effect. Third, it indicated that gender and smoking status might have little impact on the stability of blood eosinophils. These data extend our understanding of blood eosinophil counts as a potential biomarker in COPD management, and has important implications for the follow-up of COPD patients in clinical practice and research studies. The results differed slightly in our sensitivity analysis; using absolute blood eosinophil thresholds. 
While traditionally considered a characteristic of asthma, several studies have shown eosinophilic inflammation in patients with COPD. ${ }^{8,19}$ Interestingly, there is accumulated evidence that blood eosinophilia is a biomarker for response to corticosteroid treatment in COPD. ${ }^{11}$ However, while several studies reported crosssectional data on eosinophilia in COPD, only a few studies have investigated the natural trajectory of blood eosinophil counts in COPD. Pascoe et al, reported a $66 \%$ prevalence of blood eosinophilia $\geq 2 \%$ in former or current smokers with moderate-tosevere COPD and a history of exacerbations, among patients participating in a pharmacological study. ${ }^{11}$ Using an identical definition, Watz et al, ${ }^{12}$ recently reported a prevalence of $54 \%$ in former or current smoking patients with severe airflow limitation and at least one exacerbation in the previous 12 months. The highest percentage was observed in the NHANES cohort, ${ }^{20}$ where $71 \%$ of subjects with spirometry-defined COPD had blood eosinophilia $>2 \%$, compared with $66 \%$ of subjects with normal lung function. Finally, using a cut-off of $\geq 3 \cdot 3 \%$, Vedel-Krogh et $\mathrm{al}^{21}{ }^{21}$ observed that $28 \%$ of subjects with spirometry defined COPD from a large population sample had elevated blood eosinophil counts. However, longitudinal data on blood eosinophils was not available in all of these studies. Using data from the ECLIPSE study, Singh et al. ${ }^{19}$ investigated the longitudinal changes in blood eosinophil counts in patients with moderate-to-severe COPD (mean $\mathrm{FEV}_{1}$ approximately 50\%) and non-smoking controls with normal lung function, not matched by age. While the baseline prevalence of blood eosinophilia $\geq 2 \%$ was not reported, $37 \%$ of COPD patients and $36 \%$ of controls had eosinophil counts persistently $\geq 2 \%$ at all visits, while approximately $14 \%$ of COPD patients had eosinophil counts persistently $<2 \%$ and the rest of patients had variable counts.

In the present study, approximately $64 \%$ of patients with COPD as well as gender, age, and medical practice-matched controls had blood eosinophilia $\geq 2 \%$, suggesting that eosinophilia is not a COPD-specific trait. Moreover, our results indicate that stability of eosinophilia is lower in COPD compared to non-COPD. The pathophysiology underlying this observation and its clinical relevance remains to be established. Also, this is the first study to show the impact of potential confounders on the stability of blood eosinophils.

Our analysis showed that patients with blood eosinophil counts $\geq 6 \%$ had a higher stability compared with counts $<2 \%$ during follow up. We did not identify any study that aimed to determine the stability of eosinophil count in healthy populations. However, a cohort study which enrolled 410 COPD patients, found that baseline eosinophil count was strongly correlated with eosinophil counts after 5 years of followup..$^{22}$ Recently, Disantostefano et al, ${ }^{20}$ showed that old age was associated with blood eosinophilia in COPD and non-COPD. However, there are currently no longitudinal studies evaluating the impact of age on blood eosinophil counts among patients with COPD. Comparing younger and older subjects with asthma, Mathur et al, ${ }^{23}$ showed an age-related decline in eosinophil functional activity, but differences in absolute or relative eosinophil counts were not reported. The current data indicate that stability of 
blood eosinophilia decreases with age in both COPD patients as well as matched controls. Studies on age-related changes in blood eosinophil counts in healthy populations are needed, but currently unavailable. The exact mechanism for the differences observed in eosinophil stability by age category in COPD is unknown. However, a possible mechanism for decreased stability with age is the decreased superoxide anion production and delayed degranulation of eosinophil-derived neurotoxin in older patients. ${ }^{24}$ Animal studies in rats suggest a defect in the eosinophil accumulation sites and chemotactic activity in older animals. ${ }^{25}$
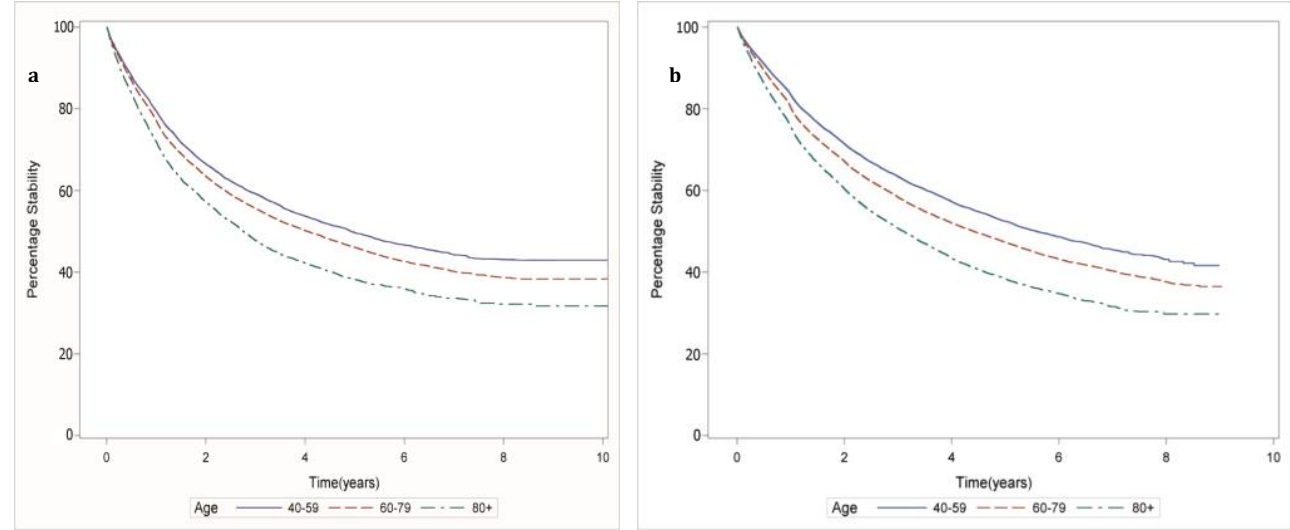

Figure 3.4. Kaplan Meier curves comparing stability of blood eosinophil count in (a) COPD patients and (b) controls by age.
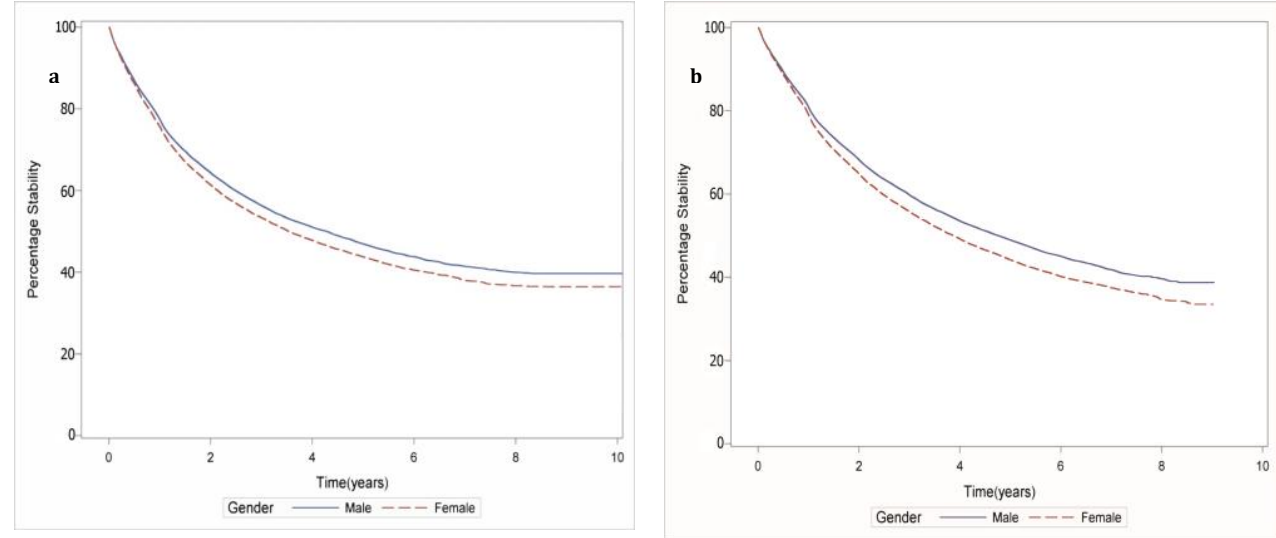

Figure 3.5. Kaplan Meier curves comparing stability of blood eosinophil count in (a) COPD patients and (b) controls by sex.

The current study showed that a statistically significant difference exists in the stability blood eosinophil counts between males and females, and by smoking status. Although the stability of blood eosinophil counts did not differ by smoking 
status for absolute blood eosinophil counts. The clinical relevance of these findings is yet to be explored.

The use of data from a large number of COPD patients in primary care, the inclusion of matched controls and the long follow-up period are major strengths of the current study. This is the first study that showed the stability of blood eosinophil counts over a 10-year period, making our findings robust. Moreover, this is the first study that employed a unique approach (time-to-event) in the determination of blood eosinophil stability. However, this study also has notable limitations. Although the positive predictive value of identifying patients with COPD in the CPRD is $90 \%$, lung function data were unavailable. Thus, it was not possible to investigate the stability of blood eosinophilia in the various GOLD stages of COPD. Secondly, we used $2 \%$ and $0.34 \times 10^{9}$ cells/L cut-off to define stability of blood eosinophil counts in our study, while some studies have considered different cut-offs. Also, it is impossible to rule out the inclusion of patients with reversible airflow limitation in the study. Finally, we did not include patients that were younger than 40 years in our study.

Blood eosinophil counts are increasingly recognised as an important biomarker for predicting response to ICS therapy in COPD patients, with better response observed among patients with elevated counts. The current study confirms that blood eosinophilia is common in COPD and matched controls and suggests that this is not a COPD-specific trait as the proportion of subjects with blood eosinophilia was comparable in both COPD and non-COPD controls. Also, when determining blood eosinophil counts and the frequency of follow-up in clinical practice or pharmacological studies, it is important to take into account the impact of age and baseline levels on the long-term stability of blood eosinophil counts, with the impact of gender and smoking found to be less pronounced. While this is the largest study to date investigating how blood eosinophil counts changes with time, the relationship with (different types of) exacerbations and their recovery remains to be established.

\section{Conflict of interest}

The authors declare no conflict of interest. 
Chapter 3
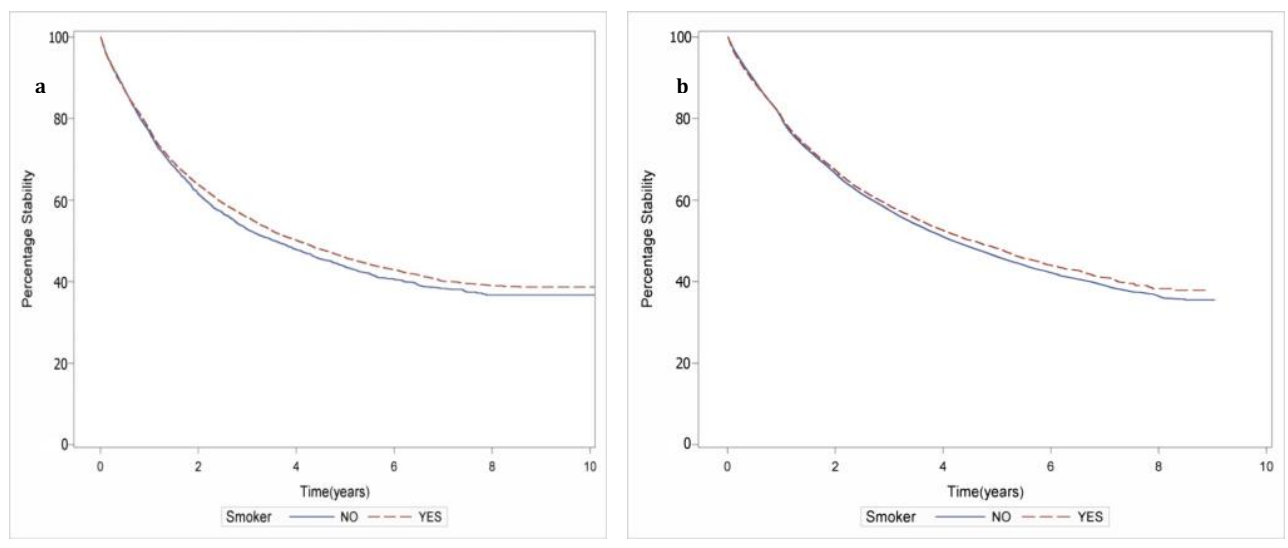

Figure 3.6. Kaplan Meier curves comparing stability of blood eosinophil count in (a) COPD patients and (b) controls by smoking status at baseline.

$\overline{54}$ 


\section{References}

1. Bafadhel M, McKenna S, Terry S, et al. Blood eosinophils to direct corticosteroid treatment of exacerbations of chronic obstructive pulmonary disease: A randomized placebo-controlled trial. Am J Respir Crit Care Med. 2012;186(1):48-55.

2. Vestbo J, Anderson W, Coxson $\mathrm{HO}$, et al. Evaluation of COPD Longitudinally to Identify Predictive Surrogate Endpoints (ECLIPSE). Eur Respir J. 2008;31(4):869-873.

3. Tashkin DP, Celli B, Senn S, et al. A 4year trial of tiotropium in chronic obstructive pulmonary disease. $N$ Engl J Med. 2008;359(15):1543-1554.

4. Vestbo J, Hurd SS, Agusti AG, et al. Global strategy for the diagnosis, management, and prevention of chronic obstructive pulmonary disease: GOLD executive summary. $A m \mathrm{~J}$ Respir Crit Care Med. 2013;187(4):347-365.

5. Wedzicha JA, Buhl R, Lawrence D, et al. Monotherapy with indacaterol once daily reduces the rate of exacerbations in patients with moderate-to-severe COPD: Post-hoc pooled analysis of 6 months data from three large phase III trials. Respir Med. 2015;109(1):105111.

6. Jones PW, Willits LR, Burge PS, et al. Disease severity and the effect of fluticasone propionate on chronic obstructive pulmonary disease exacerbations. Eur Respir J. 2003;21(1):68-73.

7. Wedzicha JA, Banerji D, Chapman KR, et al. Indacaterol-Glycopyrronium versus Salmeterol-Fluticasone for COPD. $N$ Engl $J$ Med. 2016;374(23):2222-2234.

8. Bafadhel M, McKenna S, Terry S, et al. Acute exacerbations of chronic obstructive pulmonary disease: Identification of biologic clusters and their biomarkers. Am J Respir Crit Care Med. 2011;184(6):662-671.

9. Price D, West D, Brusselle $G$, et al. Management of COPD in the UK primary-care setting: An analysis of real life prescribing patterns. Int $J$ COPD. 2014;9:889-905.

10. lyer AS, Dransfield MT. Serum eosinophils as a COPD biomarker: ready for prime time? Lancet Respir Med. 2016;4(5):341-343.

11. Pascoe S, Locantore N, Dransfield MT, et al. Blood eosinophil counts as markers of response to inhaled corticosteroids in COPD? -Authors' reply. Lancet Respir Med. 2015;3(8):e27.

12. Watz $\mathrm{H}$, Tetzlaff $\mathrm{K}$, Wouters EFM, et al. Blood eosinophil count and exacerbations in severe chronic obstructive pulmonary disease after withdrawal of inhaled corticosteroids: A post-hoc analysis of the WISDOM trial. Lancet Respir Med. 2016;4(5):390-398.

13. Herrett E, Gallagher AM, Bhaskaran K, et al. Data Resource Profile: Clinical Practice Research Datalink (CPRD). Int J Epidemiol. 2015;44(3):827-836.

14. Taggar JS, Coleman T, Lewis S, et al. The impact of the Quality and Outcomes Framework (QOF) on the recording of smoking targets in primary care medical records: cross-sectional analyses from The Health Improvement Network (THIN) database. BMC Public Health. 2012;12(1):1-11.

15. Rothnie KJ, Müllerová $\mathrm{H}$, Hurst JR, et al. Validation of the recording of acute exacerbations of COPD in UK primary care electronic healthcare records. PLoS One. 2016;11(3).

16. Barakat MF, McDonald HI, Collier TJ, et al. Acute kidney injury in stable COPD and at exacerbation. Int $J$ Chron Obstruct Pulmon Dis. 2015;10(1):20672077.

17. Müllerová $H$, Shukla $A$, Hawkins $A$, et al. Risk factors for acute exacerbations of COPD in a primary care population: a retrospective observational cohort study. BMJ Open. 2014;4(12):e006171.

18. Wurst KE, Shukla A, Muellerova $\mathrm{H}$, et al. Respiratory pharmacotherapy use in patients newly diagnosed with chronic obstructive pulmonary disease in a primary care setting in the UK: a retrospective cohort study. COPD. 2014;11(5):521-530.

19. Singh D, Kolsum U, Brightling CE, et al. Eosinophilic inflammation in COPD: prevalence and clinical characteristics. Eur Respir J. 2014; 44(6):1697-700.

20. Disantostefano RL, Hinds D, Van Le H, et al. Relationship between blood eosinophils and clinical characteristics in a cross-sectional study of a US population-based COPD cohort. Respir Med. 2016;112:88-96.

21. Vedel-Krogh S, Nielsen SF, Lange P, 
Vestbo J, Nordestgaard BG. Blood Eosinophils and Exacerbations in COPD: the Copenhagen General Population Study. Am J Respir Crit Care Med. 2015:rccm.201509$18690 \mathrm{C}$.

22. Hardin M, Putcha N, Hansel NN, et al. The Significance of Peripheral Blood Eosinophils and $\lg \mathrm{E}$ Levels in COPDGene Subjects. In: B38. TALKING ABOUT COPD BIOMARKERS. American Thoracic Society International Conference American Thoracic Society; 2015:A2921-A2921.

23. Mathur SK, Schwantes EA, Jarjour NN, et al. Age-related changes in eosinophil function in human subjects. Chest. 2008;133(2):412-419.

24. Yagi T, Sato A, Hayakawa $H$, et al. Failure of aged rats to accumulate eosinophils in allergic inflammatory of the airway. $J$ Allergy Clin Immunol. 1997;99(1 I):38-47.

25. Gorska K, Krenke R, Korczynski P, et al. Eosinophilic airway inflammation in chronic obstructive pulmonary disease and asthma. J Physiol Pharmacol. 2008;59 Suppl 6:261-270. 


\section{Supplementary Material}

Table S.3.1. Proportion of COPD patient with stable eosinophil counts among stratified by gender age, eosinophil counts and smoking status at different time points.

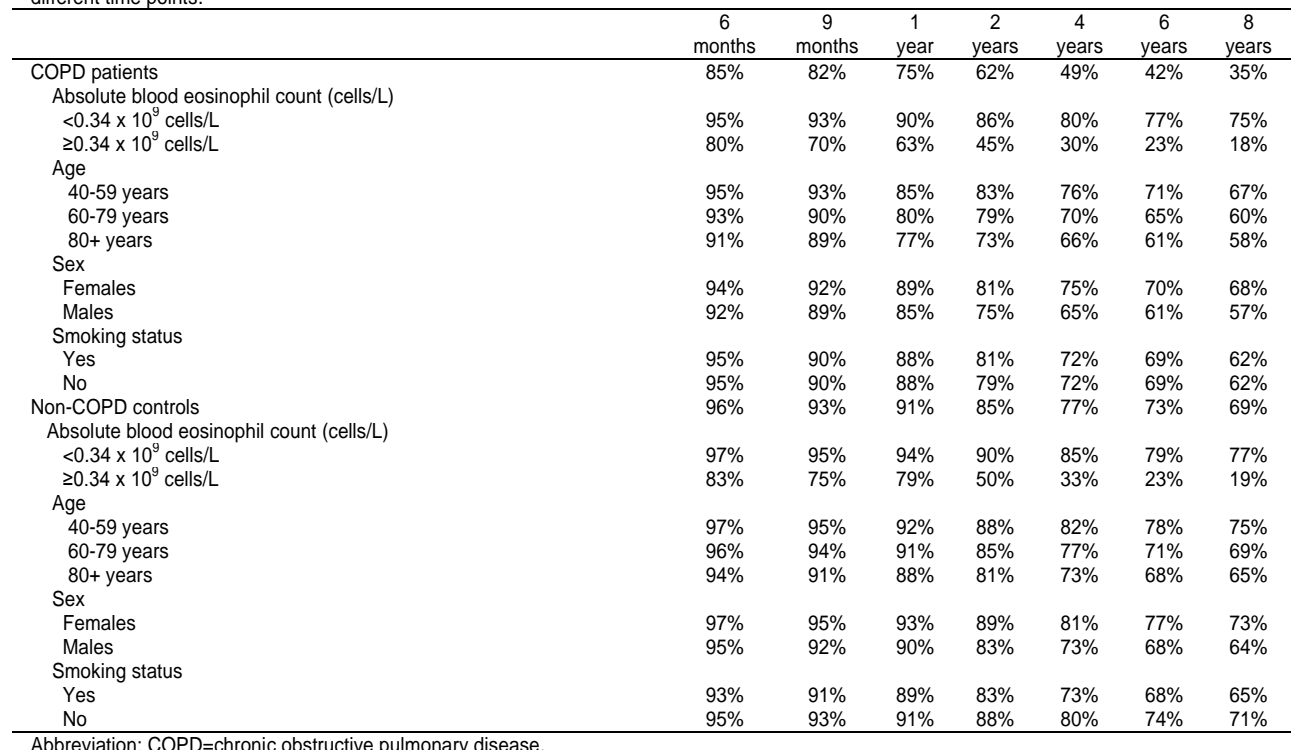





\section{C-reactive protein as a biomarker of response to inhaled corticosteroids among patients with COPD}

Olorunfemi A. Oshagbemi Frits M.E. Franssen

Emiel F.M. Wouters Anke-Hilse Maitland-van der Zee Johanna H.M. Driessen

Anthonius de Boer Frank de Vries

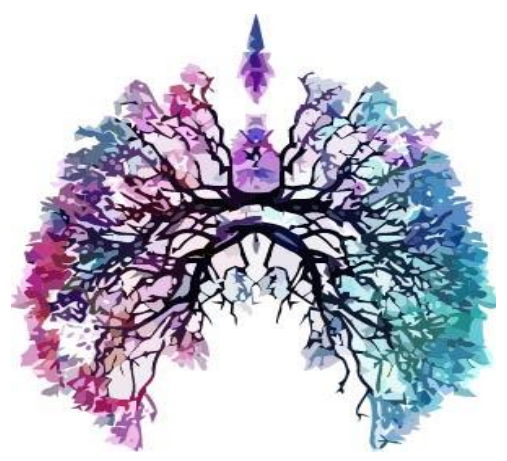




\section{ABSTRACT}

Background: The Evaluation of Chronic obstructive pulmonary disease (COPD) Longitudinally to Identify Surrogate End-points (ECLIPSE) study identified C-reactive protein (CRP) as a key biomarker in systemic inflammation among patients with COPD; reports have suggested that inhaled corticosteroids (ICS) attenuate CRP levels. Therefore, the aim of this study was to evaluate the risk of moderate-to-severe exacerbations, severe exacerbations and all-cause mortality among patients with COPD currently exposed to ICS stratified by CRP levels compared to never ICS users with low CRP levels in a large general practice setting.

Methods: In this population-based cohort study from 1 January 2005 to 31 January 2014, we used data from the Clinical Practice Research Datalink (CPRD) in the United Kingdom. We included subjects age 40 or more who had a diagnosis of COPD. ICS exposure was determined based on the time since the most recent prescription, and classified as current (1-30 days), recent (31-60 days), past (>60 days) or never users. We evaluated the risk of moderate-to-severe exacerbations, severe exacerbations and all-cause mortality among ICS users stratified by CRP levels, using Cox regression analysis adjusting for confounders (SAS 9.4). Current and never users of ICS were further stratified by CRP measurements into categories (category 1 (0-3 mg/L), category 2 (4-7 mg/L) and category 3 ( $\geq 8 \mathrm{mg} / \mathrm{L})$. The reference category included never ICS users with low CRP levels (0-3 mg/L). We conducted a sensitivity analysis, using a CRP threshold of $\geq 20 \mathrm{mg} / \mathrm{L}$ instead of $(\geq 8$ $\mathrm{mg} / \mathrm{L}$.

Results: We included 17,722 subjects diagnosed with COPD who met the inclusion criteria. Among current or never ICS with elevated CRP levels we found no significantly reduced risk of moderate-to-severe or severe exacerbations compared to never ICS users with CRP levels of $0-3 \mathrm{mg} / \mathrm{L}$. For patients currently exposed to ICS with CRP levels $\geq 8 \mathrm{mg} / \mathrm{L}$ there was no reduced risk of moderate-to-severe (adjusted hazard ratio [adj. HR] 0.99; 95\% confidence interval [Cl] 0.76-1.31) or severe exacerbations (adj.HR 1.52; 95\% Cl: 0.71-3.27). Similarly, there was no decreased risk of moderate-to-severe or severe exacerbations among never ICS users with CRP levels $\geq 8 \mathrm{mg} / \mathrm{L}$. However, we found an increased risk of all-cause mortality among COPD patients with CRP levels $\geq 8 \mathrm{mg} / \mathrm{L}$ currently exposed to ICS with (adj.HR 2.38; $95 \% \mathrm{Cl}: 1.81-3.13$ ) and never ICS users (adj.HR 2.81; 95\% Cl: 2.20-3.58) compared to never ICS users with CRP levels of $0-3 \mathrm{mg} / \mathrm{L}$.

Conclusions: We did not find a reduced risk of moderate and/or severe COPD exacerbations among COPD patients with varying CRP levels currently exposed to ICS. However, we found an increased risk of all-cause mortality among patients with elevated ( $\geq 8 \mathrm{mg} / \mathrm{L}$ ) CRP levels irrespective of ICS use. 


\section{INTRODUCTION}

Chronic obstructive pulmonary disease (COPD) is a major cause of morbidity and mortality worldwide ${ }^{1}$ and is projected to be the third leading cause of death by the year $2030 .^{2}$ Due to the heterogeneity of COPD, there is a growing interest in biomarkers and their potential to guide therapy among sub-groups of patients with COPD. ${ }^{3}$ Inhaled corticosteroids (ICS) are additionally used to suppress inflammation and reduce exacerbation risk in patients unresponsive to bronchodilators. Hurst and colleagues assessed 36 biomarkers with the potential for diagnosis and management of COPD, one of which was C-reactive protein (CRP). ${ }^{4} \mathrm{CRP}$ is an acute-phase protein synthesised predominantly by the hepatocytes and acts by binding to receptors of the phagocytes and impacting on apoptosis and necrosis. ${ }^{5}$ The ECLIPSE study illustrated that after 3 years of follow-up, all-cause mortality and exacerbation frequency was higher in persistently inflamed COPD patients (as measured by an increase in various biomarkers including CRP) compared to non-inflamed patients. ${ }^{6}$ COPD is not an isolated condition with pathological mechanisms specifically localised in the lungs, but a heterogeneous disease with chronic inflammatory processes in various tissues accompanied by changes in various biomarkers. ${ }^{3}$

Reports from clinical studies have suggested that ICS attenuate CRP levels among patients with moderate to severe $\mathrm{COPD}^{7-9}$ and elevated CRP levels have been linked with increased risk of severe exacerbations and mortality. ${ }^{10,11}$ The Copenhagen City Heart Study followed COPD patients, a small proportion of whom were exposed to ICS over a period of 8 years, and reported that patients with elevated CRP levels in combination with other biomarkers were at increased risk of severe exacerbations. ${ }^{12} \mathrm{~A}$ randomised controlled trial (RCT) that enrolled more than 6,000 COPD patients over a 3-year period found that ICS exposure reduced COPD exacerbations but not all-cause mortality. ${ }^{13}$

Furthermore, meta-analysis of 15 studies showed that high baseline CRP was associated with a higher risk of mortality among COPD patients. ${ }^{11}$ The use of ICS has been reported to significantly reduce CRP levels, ${ }^{7-9}$ hence we speculate that this attenuation of CRP will result in decreased risk of exacerbations and mortality. Biomarker guided therapy has the potential to help reduce the risk of fractures and pneumonia associated with ICS exposure by identifying patients groups more likely to benefit from ICS treatment. ${ }^{3}$ No longitudinal study has yet evaluated the role of CRP in guiding ICS therapy among patients with COPD in a large general practice setting. Therefore, the aim of this study was to evaluate the risk of moderate-to-severe exacerbations, severe exacerbations and all-cause mortality among patients with COPD currently exposed to ICS and never ICS users stratified by CRP categories compared to never ICS users with the lowest CRP categories. 


\section{METHODS}

\section{Data source}

Data for this study were obtained from the Clinical Practice Research Datalink (CPRD). CPRD holds computerised medical records of 674 primary care practices in the United Kingdom. The database provides detailed information on drug prescriptions, clinical events, demographics, specialist referrals, and hospital admissions. ${ }^{14}$ In addition, laboratory test results are available, including biomarker information. Data collection began in January 1987 and over 11 million persons are currently included. ${ }^{15}$ This database has been used in various studies on COPD. ${ }^{16-18}$ Approval for this study was obtained from the Independent Scientific Adversary Committee (ISAC) of the Medicines and Healthcare product Regulatory Authority (protocol no: 18_323R).

\section{Study population}

For this study we selected all newly diagnosed COPD subjects aged 40 years and older as recorded by a first read code during our study period 1 January 2005 (after the introduction of Quality Outcome Framework (QOF)) to the 31 January 2014. Subjects were followed from the date of their COPD diagnosis (index date) until the end of data collection, date of death, and end of study or when the outcome of interest occurred, whichever came first. Subjects needed to have at least one CRP measurement before the index date to be included in the study. Subjects with a history of asthma at baseline were excluded. Subjects with acute exacerbations of COPD or oral glucocorticoid use within 30 days prior to index date were excluded.

\section{Exposure}

Each patient's follow-up time was divided into fixed periods of 90 days. Exposure to ICS was determined time-dependently during follow-up. Prior to the start of each interval, ICS exposure was determined based on the time since the most recent prescription, and classified as current (1-30 days), recent (31-60 days), past (>60 days) or never use. Never users of ICS comprised of patients without ICS exposure during follow-up. Subjects could move between exposure groups over time. Our exposure groups of interest included current (subjects exposed to ICS within the first 30 days to the start of an interval) and never users (subjects with no ICS use within an interval). Current and never users of ICS were further stratified by the most recent CRP measurements, with the CRP levels classified into categories (category $1(0-3$ $\mathrm{mg} / \mathrm{L})$, category $2(4-7 \mathrm{mg} / \mathrm{L})$ and category $3(\geq 8 \mathrm{mg} / \mathrm{L})$. We derived CRP categories by splitting the CRP distribution at the $33.3^{\text {th }}$ and $66.7^{\text {th }}$ centiles using the PROC univariate procedure (SAS 9.4) (SAS Institute, Cary, NC).

We employed a 12 months look-back period to determine CRP levels during follow-up; this choice was based on the mechanistic plausibility for ICS to attenuate CRP over this time period, hence we also provided a missing CRP category. ${ }^{9}$ Patients 
with missing CRP measurements were classified into a separate category. When two or more CRP measurements were recorded on the same date, the mean CRP value was calculated. We used the term "elevated CRP" levels to refer to CRP levels $>3$ $\mathrm{mg} / \mathrm{L}$ in this work.

\section{Outcome}

The primary outcome of interest was a moderate-to-severe exacerbation, which was defined using validated definitions (H312200, H3y1.00) for acute exacerbations of COPD from the clinical and referral files. ${ }^{19,20}$ The secondary outcome was a severe exacerbation, defined as a COPD-related hospitalisation/accident and emergency visit using read codes (8H2R.00,66Yi.00) from either the clinical or referral files or the read codes (H312200, H3y1.00) for acute exacerbations from the referral file. The primary and secondary outcomes were not fully mutually exclusive. We also evaluated the risk of all-cause mortality. Referral files contain referral details recorded by general practitioners (GPs) while the clinical file contains all medical data entered by the GP. ${ }^{21}$

\section{Covariates}

Potential confounders were assessed time-dependently with the exception of gender, smoking status, alcohol use, and body mass index, which were determined at baseline. The following covariates were considered as potential confounders, and identified at the start of each interval: a history of congestive heart failure, ischemic heart disease, anxiety, chronic liver disease, cancer excluding non-melanoma skin cancer, stroke, rheumatoid arthritis, diabetes mellitus, hypertension, inflammatory bowel disease, solid organ transplant, atopic dermatitis, renal dialysis, human immunodeficiency virus or osteoporosis. In addition, the use of the following drugs within 6 months prior to the start of an interval were considered as potential confounders: antihistamines, proton pump inhibitors, antipsychotics, or antidepressants. ${ }^{22-25}$ We statistically adjusted our analyses for proxy indicators of the severity of obstructive airway disease, as previously defined as the use of short- and long-acting beta-agonists, short- and long-acting anti-muscarinic agents, xanthine derivatives or oral corticosteroids. ${ }^{26,27}$ In addition, the use of antibiotics for COPD exacerbations in the month prior to an interval was considered as a potential confounder. $^{28}$

\section{Statistical analysis}

We evaluated the risk of moderate-to-severe exacerbations, severe exacerbations and all-cause mortality stratified by ICS use and CRP levels using Cox regression analysis (SAS 9.4) (SAS Institute, Cary, NC). Current and never ICS users were stratified by CRP levels. Categories were made to reduce the impact of outlying values and to account for the positively skewed distribution of CRP. The reference category for this study included patients who were never exposed to ICS with the 
lowest CRP levels (0-3 mg/L). Furthermore, we compared the risk of study outcomes between never users in category $2(4-7 \mathrm{mg} / \mathrm{L}$ ) and current ICS users in category 2 (4$7 \mathrm{mg} / \mathrm{L})$, never ICS users in category 3 ( $\geq 8 \mathrm{mg} / \mathrm{L}$ ) and current ICS users category 3 ( $\geq 8 \mathrm{mg} / \mathrm{L}$ ) using Wald test and we only reported any significant differences the groups in our fully-adjusted analyses $p$-values less than 0.05 . Potential confounders were included in the final model if they changed the beta-coefficient for the association between current ICS and never use and the outcome of interest by at least $5 \%$ or when consensus about inclusion existed within the team of researchers, supported by clinical evidence from literature.

\section{Sensitivity analysis}

Further analysis repeated the abovementioned analyses but broke down the highest CRP level category into patients with a serum CRP level 8-19 mg/L and those with values $\geq 20 \mathrm{mg} / \mathrm{L}$. We chose this threshold because we felt that it may better reflect the acute phase inflammatory process. ${ }^{29}$

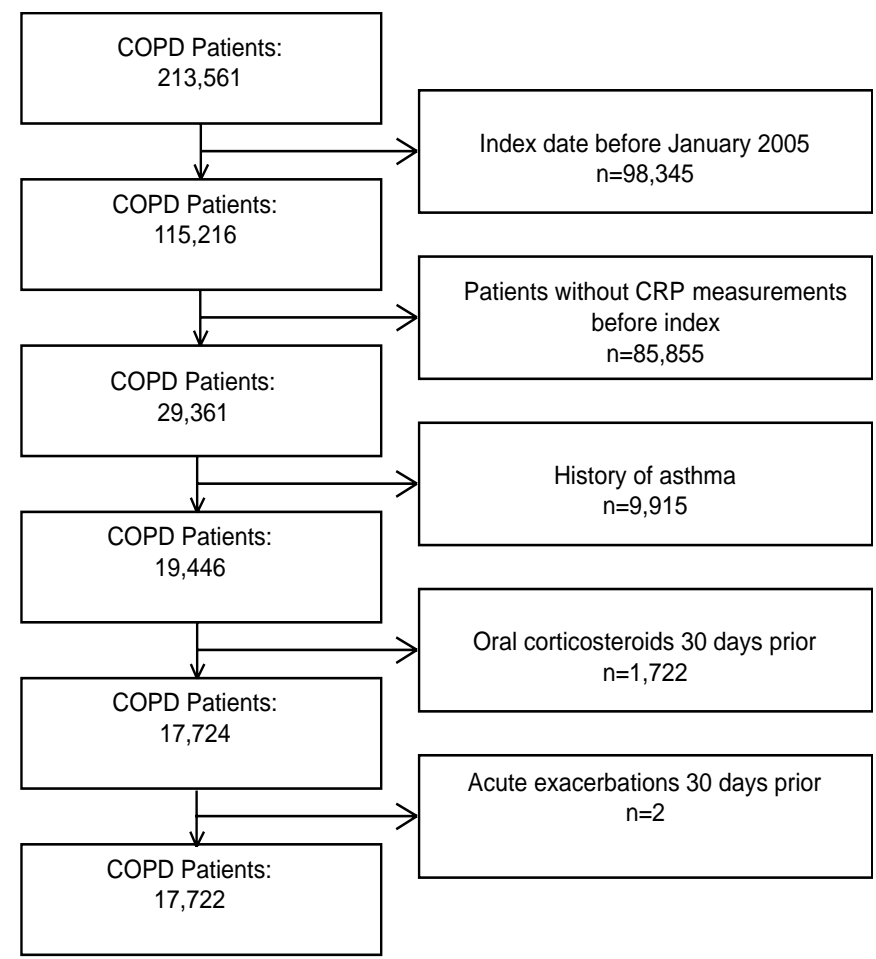

Figure 4.1. Flow chart showing the selection of eligible patients. 


\section{RESULTS}

We identified 213,561 patients with COPD and 17,722 met the inclusion criteria (Figure 4.1). Table 4.1 shows the baseline characteristics of all COPD patients. At baseline 5,162 COPD patients were exposed to ICS and 12,560 were not. Over half of the ICS users were females, with a mean age of 69.1 years. At baseline, the mean CRP levels were $12.9( \pm 29.0) \mathrm{mg} / \mathrm{L}$ for ICS users with COPD and $12.4( \pm 30.0) \mathrm{mg} / \mathrm{L}$ COPD patients who had not used ICS. About $29.3 \%$ of ICS users were obese versus $24.1 \%$ of ICS naïve subjects, $35.6 \%$ of ICS users were current smokers compared to $45.0 \%$ among subjects not exposed to ICS.

\section{Moderate-to-severe and severe exacerbations}

Table 4.2 shows that risk of moderate-to-severe exacerbations was not different between COPD patients who were current ICS users with CRP levels of $0-3 \mathrm{mg} / \mathrm{L}$ compared to never ICS users with low CRP serum (0-3 mg/L, adjusted hazard [adj.] ratio [HR] 0.95; 95\% confidence interval [Cl] 0.70-1.27 (4-7 mg/L or $\geq 8 \mathrm{mg} / \mathrm{L})$. Wald tests showed that the risk of moderate-to-severe COPD exacerbations was not different between ICS users and never users with COPD. Regardless of ICS exposure status, risk of moderate-to-severe COPD exacerbations was not statistically different between different CRP categories (0-3 mg/L vs. $4-7 \mathrm{mg} / \mathrm{L}$ vs. or $\geq 8 \mathrm{mg} / \mathrm{L}$ ). Table 4.3 shows that these findings were largely similar for the risk of severe COPD exacerbations.

\section{All-Cause Mortality}

All-cause mortality among COPD patients with low CRP levels $(0-3 \mathrm{mg} / \mathrm{L})$ was not different between current ICS users and never ICS users, adj. HR please add (Table 4.4). This finding was consistent when ICS use was compared with never use in other CRP categories (4-7 mg/L or $\geq 8 \mathrm{mg} / \mathrm{L}$ ). However, we found an approximately threefold of all-cause mortality among patients with CRP levels $\geq 8 \mathrm{mg} / \mathrm{L}$ compared to COPD patients with low CRP serum levels (0-3 mg/L), adj.HR 2.81; $95 \% \mathrm{Cl}: 2.20$ 3.58 for ICS naïve COPD patients.

\section{Sensitivity analysis}

In the sensitivity analysis, never or current use of ICS among COPD patients with CRP levels of $\geq 20 \mathrm{mg} / \mathrm{L}$ was not associated with a significant reduction in the risk of moderate-to-severe or severe COPD exacerbations compared to never ICS users with low CRP serum levels (0-3 mg/L, Tables S.4.1 and S.4.2). But we found that risk of all-cause mortality among COPD patients with CRP levels $\geq 20 \mathrm{mg} / \mathrm{L}$ was $3.5-4$-fold increased among ICS and ICS naïve patients, e.g. adj.HR 4.03; 95\% Cl: 3.11-5.22 among never users of ICS) compared never users with no elevated CRP (Table S.4.3). 


\begin{tabular}{|c|c|c|c|c|}
\hline & \multicolumn{2}{|c|}{ ICS users $^{a}$} & \multicolumn{2}{|c|}{ ICS naïve ${ }^{a}$} \\
\hline & $\mathrm{n}=5,162$ & $\%$ & $n=12,560$ & $\%$ \\
\hline Females & 2,688 & 52.1 & 5,981 & 47.6 \\
\hline Mean age (years, SD) & 69.1 & 11.7 & 68.2 & 11.0 \\
\hline Mean follow-up (years, SD) & 3.0 & 2.2 & 3.0 & 2.2 \\
\hline \multicolumn{5}{|l|}{ Age category (years) } \\
\hline $40-59$ & 1,069 & 20.7 & 2,766 & 22.0 \\
\hline $60-79$ & 3,030 & 58.7 & 7,659 & 61.0 \\
\hline $80+$ & 1,063 & 20.6 & 2,135 & 17.0 \\
\hline \multicolumn{5}{|l|}{$\mathrm{BMI}\left(\mathrm{kg} / \mathrm{m}^{2}\right)$ in the past 6 months } \\
\hline Underweight $\left(\mathrm{BMI}<18.5 \mathrm{~kg} / \mathrm{m}^{2}\right)$ & 264 & 5.1 & 797 & 6.3 \\
\hline Normal weight (BMI 18.5-24.9 kg/ m²) & 1,640 & 31.8 & 4,498 & 35.8 \\
\hline Overweight (BMI $25.0-30.0 \mathrm{~kg} / \mathrm{m}^{2}$ ) & 1,596 & 30.9 & 3,905 & 31.1 \\
\hline Obese $\left(\mathrm{BMI}>30.0 \mathrm{~kg} / \mathrm{m}^{2}\right)$ & 1,512 & 29.3 & 3,029 & 24.1 \\
\hline Missing & 150 & 2.9 & 331 & 2.6 \\
\hline Mean CRP level (mg/L, SD) & 12.9 & 29.0 & 12.4 & 30.0 \\
\hline \multicolumn{5}{|l|}{ Smoking status at index date } \\
\hline Never & 737 & 14.3 & 1,211 & 9.6 \\
\hline Current & 1,839 & 35.6 & 5,656 & 45.0 \\
\hline Former & 2,581 & 50.0 & 5,688 & 45.3 \\
\hline Missing & 5 & 0.1 & 5 & 0.1 \\
\hline \multicolumn{5}{|l|}{ Drug use (in the past 6 months) } \\
\hline SABAs & 3,375 & 65.4 & 4,168 & 32.2 \\
\hline LABAs & 2,304 & 44.6 & 388 & 3.1 \\
\hline SAMAs & 500 & 9.7 & 619 & 4.9 \\
\hline LAMAs & 1,010 & 19.6 & 673 & 5.4 \\
\hline Xanthine derivatives & 43 & 0.8 & 12 & 0.1 \\
\hline Antipsychotics & 63 & 1.2 & 133 & 1.1 \\
\hline \multicolumn{5}{|l|}{ History of co-morbidities } \\
\hline Cardiovascular disease & 1,232 & 23.9 & 2,610 & 20.8 \\
\hline Diabetes Mellitus & 726 & 14.1 & 1439 & 11.5 \\
\hline Anxiety & 953 & 18.5 & 2,187 & 17.4 \\
\hline Osteoporosis & 443 & 8.6 & 943 & 7.5 \\
\hline Any cancer (except non-melanoma skin cancer) & 922 & 17.9 & 2,186 & 17.4 \\
\hline Chronic liver disease & 16 & 0.3 & 62 & 0.5 \\
\hline
\end{tabular}

\section{DISCUSSION}

In this study, the risk of moderate and/or severe COPD exacerbations or all-cause mortality was comparable between ICS users and non-users, irrespective of CRP levels. Regardless of ICS exposure status, risk of moderate- and/or severe COPD exacerbations was not different between different CRP categories (0-3 mg/L vs. 4-7 $\mathrm{mg} / \mathrm{L}$ vs. or $\geq 8 \mathrm{mg} / \mathrm{L}$ ), whereas all-cause mortality was approximately three-fold increased among patients with CRP levels $\geq 8 \mathrm{mg} / \mathrm{L}$ as compared to COPD patients with low (0-3 mg/L) CRP serum levels.

Exacerbations of COPD are important drivers of COPD-related hospitalisations and mortality. ${ }^{30}$ Very few researchers have evaluated the role of CRP in guiding ICS use in the improvement of moderate-to-severe or severe exacerbations. In a large population-based prospective study that included over 6,000 COPD patients, Thomsen et $\mathrm{al}^{31}{ }^{31}$ reported that patients with elevated CRP levels, fibrinogen, and leucocyte counts had increased risk of exacerbations. However, when the investigators evaluated each elevated biomarker separately (including CRP), they 
found no significantly increased risk of frequent exacerbations, in line with our findings.

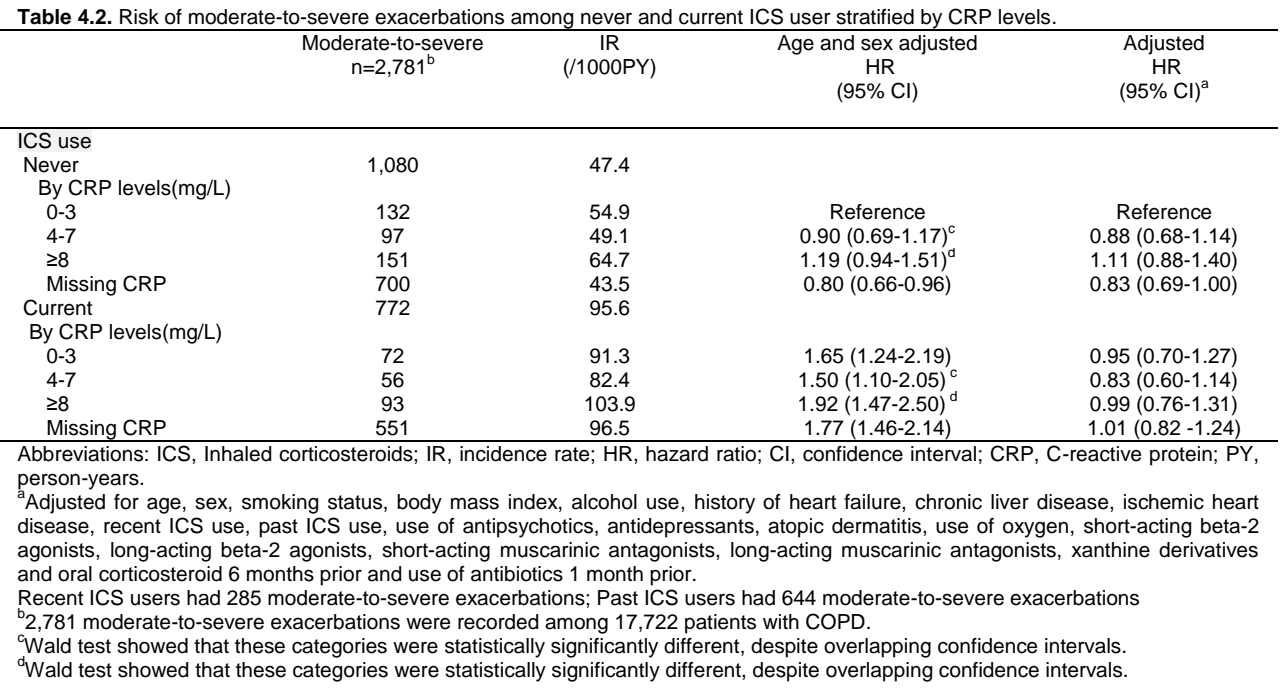

It is important to note that the authors stated that the use of ICS was "relatively rare" among the patients enrolled and might have affected their findings (with only $3 \%$ of the study population was exposed to ICS at baseline)..$^{31}$ In our study, we noted an increased risk of moderate and/or severe exacerbations when we adjusted only for age and sex, following adjustments for all possible confounders the risk disappeared. This is the first study to specifically evaluate the risk of moderate-to-severe, severe exacerbations and all-cause mortality among COPD patients currently exposed to ICS stratified by CRP levels. A randomised controlled trial conducted across 11 centers among 289 COPD patients treated with ICS with or without LABA, found no reduction in CRP levels although serum protein D levels decreased, suggesting that ICS treatment affects lung-specific biomarkers rather than systemic inflammatory markers. ${ }^{8}$ Furthermore, ECLIPSE investigators found that elevated levels of CRP, fibrinogen and leukocyte counts were associated with the occurrence of exacerbations in the first year in univariate analyses. ${ }^{32}$ However, the effect disappeared following multivariate adjustments except for leucocyte counts. Approximately $30 \%$ of patients with COPD exacerbations have been reported to have normal CRP levels, ${ }^{33}$ which questions the validity of CRP as a robust biomarker. Furthermore, De Torres et $\mathrm{al}^{34}{ }^{34}$ reported that current exposure to glucocorticoids did not influence CRP levels, contrary to previous reports. ${ }^{7}$ Consistent with our study, there was a huge variation in CRP levels across the mean, suggesting that CRP cannot be used as a clinical diagnostic tool. ${ }^{35}$ The exact mechanism by which ICS interact with CRP in COPD remains unclear. However, interleukin 6, a potent regulator of CRP generation known to be present in high concentrations in the serum 
and expiratory condensates of patients with COPD, can be down-regulated by corticosteroids. $^{36}$

Table 4.3. Risk of severe exacerbations among never and current ICS user stratified by CRP levels.

\begin{tabular}{|c|c|c|c|c|}
\hline & $\begin{array}{l}\text { Severe exacerbations } \\
\qquad \mathrm{n}=367^{\mathrm{b}}\end{array}$ & $\begin{array}{c}\mathrm{IR} \\
(/ 1000 \mathrm{PY})\end{array}$ & $\begin{array}{c}\text { Age and sex adjusted } \\
\mathrm{HR} \\
(95 \% \mathrm{Cl})\end{array}$ & $\begin{array}{c}\text { Adjusted } \\
\text { HR } \\
(95 \% \mathrm{Cl})^{\mathrm{a}}\end{array}$ \\
\hline \multicolumn{5}{|l|}{ ICS use } \\
\hline \multicolumn{4}{|l|}{ By CRP levels(mg/L) } & \\
\hline $0-3$ & 13 & 5.2 & Reference & Reference \\
\hline $4-7$ & 12 & 5.8 & $1.11(0.51-2.43)^{\mathrm{C}}$ & $1.08(0.49-2.37)$ \\
\hline$\geq 8$ & 17 & 6.9 & $1.34(0.65-2.76)^{a}$ & $1.24(0.60-2.56)$ \\
\hline Missing CRP & 81 & 4.8 & $0.91(0.51-1.63)$ & $0.95(0.53-1.70)$ \\
\hline Current & 110 & 11.0 & & \\
\hline \multicolumn{5}{|l|}{ By CRP levels(mg/L) } \\
\hline $0-3$ & 7 & 7.3 & $1.35(0.54-3.38)$ & $0.83(0.32-2.13)$ \\
\hline $4-7$ & 12 & 14.4 & $2.64\left(1.21-5.79^{c}\right.$ & $1.60(0.71-3.60)$ \\
\hline$\geq 8$ & 16 & 14.3 & $2.64(1.27-5.50)^{d}$ & $1.52(0.71-3.27)$ \\
\hline Missing CRP & 75 & 10.6 & $1.96(1.09-3.54)$ & $1.22(0.65-2.28)$ \\
\hline \multicolumn{5}{|c|}{$\begin{array}{l}\text { Abbreviations: ICS, Inhaled corticosteroids; IR, incidence rate; HR, hazard ratio; CI, confidence interval; CRP, C-reactive protein; PY, } \\
\text { person-years. } \\
\text { aAdjusted for age, sex, smoking status, body mass index, alcohol use, history of heart failure, chronic liver disease, diabetes mellitus, } \\
\text { ischemic heart disease, osteoporosis, recent ICS use, past ICS use, use of proton-pump inhibitors, antidepressants, oxygen, } \\
\text { antipsychotics, statins, short-acting beta-2 agonists, long-acting beta-2 agonists, short-acting muscarinic antagonists, long-acting } \\
\text { muscarinic antagonists, xanthine derivatives and oral corticosteroids in the } 6 \text { months prior and use of antibiotics specific for COPD } 1 \\
\text { month prior. }\end{array}$} \\
\hline
\end{tabular}

All-cause mortality is an important end-point, which is seldom assessed among COPD patients mostly due to the short duration of patient follow-up in most studies. In our study, we found an increased risk of all-cause mortality among COPD patients with elevated CRP levels $(8 \mathrm{mg} / \mathrm{L})$ compared to patients with low CRP levels. Consistent with our finding, the Lung Heart Study which enrolled over 4,800 patients with mild to moderate COPD stratified into CRP quartiles reported that patients with elevated CRP levels were at increased risk of all-cause mortality. ${ }^{37}$ Similarly, a cohort study of 1,302 patients with airflow limitation with a median follow-up of 8-years in Denmark, reported a greater risk of COPD deaths among patients with elevated CRP levels compared to patients with lower CRP levels. ${ }^{12}$ However, a randomised doubleblind multi-centre study which enrolled 218 patients with stable COPD, found that elevated CRP levels did not increase the risk of all-cause mortality. ${ }^{34}$ This might be due to the low statistical power of their study. More recently, a meta-analysis and systematic review of 15 studies, which included 11,180 COPD patients, found that higher baseline CRP was associated with a higher risk of mortality. ${ }^{11}$ Cardiovascular events and cancers accounted for most deaths. ${ }^{11,38}$ With no clear CRP cut-off, researchers have called for the adoption of a clearly defined threshold for clinical and observational studies, in order to truly reveal the potential role of CRP in COPD management. ${ }^{39}$

The heterogeneity of systemic inflammation has been recognised in patients with COPD. These include high heterogeneity in serum CRP, fibrinogen, and TNF, which are largely attributed to host or disease-related factors. ${ }^{40}$ Increased CRP levels 
have been reported in obese patients and epidemiological data shows an age-related increase in inflammatory biomarkers. ${ }^{40}$ In a general population, a dose-related effect has been reported between cigarette smoking and increased levels of CRP and fibrinogen ${ }^{41,42}$ and CRP levels remained elevated for close to two decades after smoking cessation. ${ }^{43}$

\begin{tabular}{|c|c|c|c|c|}
\hline & $\begin{array}{l}\text { All-cause mortality } \\
n=2,839^{b}\end{array}$ & $\begin{array}{c}\mathrm{IR} \\
(/ 1000 \mathrm{PY})\end{array}$ & $\begin{array}{c}\text { Age and sex adjusted } \\
\mathrm{HR} \\
(95 \% \mathrm{Cl})\end{array}$ & $\begin{array}{c}\text { Adjusted } \\
\mathrm{HR} \\
(95 \% \mathrm{Cl})^{\mathrm{a}}\end{array}$ \\
\hline \multicolumn{5}{|l|}{ ICS use } \\
\hline $\begin{array}{l}\text { Never } \\
\text { By CRP levels }(\mathrm{mg} / \mathrm{L})\end{array}$ & \multicolumn{4}{|c|}{ By CRP levels(mg/L) } \\
\hline $0-3$ & 84 & 33.6 & Reference & Reference \\
\hline $4-7$ & 84 & 40.5 & $1.17(0.86-1.58)$ & $1.21(0.89-1.63)$ \\
\hline$\geq 8$ & 291 & 117.3 & $3.11(2.44-3.96)$ & $2.81(2.20-3.58)$ \\
\hline Missing CRP & 679 & 39.6 & $1.10(0.88-1.38)$ & $1.16(0.93-1.46)$ \\
\hline \multicolumn{4}{|l|}{ By CRP levels(mg/L) } & \\
\hline $0-3$ & 37 & 37.9 & $1.08(0.74-1.59)$ & $0.81(0.55-1.20)$ \\
\hline $4-7$ & 35 & 41.2 & $1.18(0.80-1.76)$ & $0.90(0.60-1.34)$ \\
\hline$\geq 8$ & 163 & 142.5 & $3.59(2.75-4.67)$ & $2.38(1.81-3.13)$ \\
\hline Missing CRP & 404 & 55.6 & $1.55(1.22-1.96)$ & $1.15(0.90-1.47)$ \\
\hline \multicolumn{5}{|c|}{$\begin{array}{l}\text { Abbreviations: ICS, Inhaled corticosteroids; IR, incidence rate; HR, hazard ratio; CI, confidence interval; CRP, C-reactive protein; PY, } \\
\text { person-years. } \\
\text { aAdjusted for age, sex, smoking status, body mass index, alcohol use, history of heart failure, chronic liver disease, ischemic heart } \\
\text { disease, atopic dermatitis, diabetes mellitus, cancer, recent ICS use, past ICS use, use of oxygen, statins, short-acting beta- } 2 \\
\text { agonists, long-acting beta- } 2 \text { agonists, short-acting muscarinic antagonists, long-acting muscarinic antagonists, xanthine derivatives } \\
\text { and oral corticosteroid use in the } 6 \text { months prior and use of antibiotics specific for COPD } 1 \text { month prior. } \\
\text { Recent ICS users had } 264 \text { deaths; Past ICS users had } 798 \text { deaths } \\
\text { b2,839 deaths were recorded among } 17,722 \text { patients with COPD. }\end{array}$} \\
\hline
\end{tabular}

Although better understanding of the effects of confounders on CRP levels exist, its stability and variability remain critical to its relevance as a guide for therapeutic interventions in COPD. The ECLIPSE study reported CRP as the least stable biomarker assessed, with only $21 \%$ of patients having a 3 -months measurement within $25 \%$ of baseline values. ${ }^{44}$ Furthermore, CRP is known to have a half-life of CRP in plasma of 19 hours and the National Health and Nutrition Examination Survey (NHANES) observed significant short-term variability (approximately 2.5 weeks) in CRP levels, particularly at high values. ${ }^{45}$ This makes CRP a poor biomarker for personalised management of COPD.

A major strength of this study was the inclusion of patients from one of the world's largest primary care databases, thereby providing a large population-based cohort of COPD patients with CRP measurements followed over time with fair recording of all-cause mortality. ${ }^{46,47}$ Second, in our study we used validated definitions for moderate and/or severe exacerbations of COPD, using read codes reported to have a $96 \%$ positive predictive value of identifying acute exacerbations within the CPRD. ${ }^{20}$ Nevertheless, we may have missed considerable numbers of exacerbations, which may be miscoded e.g. as respiratory tract infections such as pneumonia. Third, time-varying classification of exposure to ICS, CRP and covariates allowed us to conduct an "on-treatment analysis", which results in less non-differential misclassification of exposure than in an 'intention to treat analysis' which ignores ICS exposure during follow-up. Lastly, data on confounding factors such as smoking 
status, BMI, comorbidities, and drugs prescribed were available and as such these covariates were adjusted for in our models.

This study also had limitations. There is a potential for confounding by disease severity as we lacked information on patients COPD disease stage. Confounding by disease severity is a multifactorial phenomenon that may act in different directions. Although we lacked information on the degree of airflow limitations we adjusted for proxies of COPD disease severity. While we excluded asthma patients, it was impossible to rule out the inclusion of patients with reversible airflow limitation. CRP measurements are not routinely collected as part of the diagnosis of COPD; they are most likely requested by the GP in suspicion of bacterial infections and might have introduced misclassification bias in our study. We expect this bias to be non-differential among COPD patients exposed to ICS and ICS never users leading to biased estimate towards the null. While this might have masked the true risk of moderate and/or severe exacerbations among patients with elevated CRP levels, we found significant associations among patients with elevated CRP levels for all-cause mortality, suggesting that our results could not have been affected by this bias. Furthermore, because ICS use increases the risk of pneumonia, these patients might have a higher CRP levels among the ICS users potentially resulting in differential misclassification. This will lead to bias estimates towards or away from the null. However, considering the similarities in mean CRP levels between "ever before" ICS users and ICS non-using patients, it is less likely that this bias had a huge impact on or estimates. We had a significant amount of patients with missing CRP serum levels during follow-up; this was due to the choice of a 1-year look-back period for CRP assessment. While the choice of this look-back window resulted in missing CRP values, this choice was rightly made considering the mechanistic plausibility of ICS to attenuate CRP and exacerbations over this time period. ${ }^{9}$ The choice of a longer period would have resulted in less missing CRP counts during follow-up but will not be plausible in clinical settings.

In conclusion, we did not find a reduced risk of moderate and/or severe COPD exacerbations among COPD patients with varying CRP levels currently exposed to ICS. However, we found an increased risk of all-cause mortality among patients with elevated ( $\geq 8 \mathrm{mg} / \mathrm{L}$ ) CRP levels irrespective of ICS use. There is tremendous enthusiasm and effort to improve precision medicine using biomarkers in COPD. While CRP might be a useful biomarker for COPD prognosis, it does not seem to have the potential to guide ICS therapy in COPD management.

\section{Conflict of interest}

The authors declare no conflict of interest. 


\section{References}

1. GOLD. Global strategy for the prevention, diagnosis and treatment of chronic obstructive pulmonary disease (2019 Report). 2018. https://goldcopd.org/wpcontent/uploads/2018/11/GOLD-2019v1.7-FINAL-14Nov2018-WMS.pdf. Accessed November 15, 2018.

2. GBD 2010 Mortality and Causes of Death Collaborators. Global and regional mortality from 235 causes of death for 20 age groups in 1990 and 2010: A systematic analysis for the Global Burden of Disease Study 2010. Lancet. 2012;380(9859):2095-2128.

3. Oshagbemi OA, Burden AM, Braeken DCW, et al. Stability of blood eosinophils in patients with chronic obstructive pulmonary disease and in control subjects, and the impact of sex, age, smoking, and baseline counts. $A m$ J Respir Crit Care Med. 2017;195(10).

4. Hurst JR, Donaldson GC, Perera WR, et al. Use of plasma biomarkers at exacerbation of chronic obstructive pulmonary disease. Am J Respir Crit Care Med. 2006.

5. Barnes PJ, Chowdhury B, Kharitonov $\mathrm{SA}$, et al. Pulmonary Biomarkers in Chronic Obstructive Pulmonary Disease. Am J Respir Crit Care Med. 2006;174(1):6-14.

6. Agustí A, Edwards LD, Rennard SI, et al. Persistent systemic inflammation is associated with poor clinical outcomes in copd: A novel phenotype. PLOS One. 2012;7(5).

7. Sin DD, Lacy P, York E, Man SFP. Effects of Fluticasone on Systemic Markers of Inflammation in Chronic Obstructive Pulmonary Disease. Am J Respir Crit Care Med. 2004;170(7):760-765.

8. Sin DD, Man SFP, Marciniuk DD, et al. The effects of fluticasone with or without salmeterol on systemic biomarkers of inflammation in chronic obstructive pulmonary disease. $A m \mathrm{~J}$ Respir Crit Care Med. 2008;177(11):1207-1214.

9. Lin Y-H, Liao X-N, Fan L-L, et al. Longterm treatment with budesonide/formoterol attenuates circulating CRP levels in chronic obstructive pulmonary disease patients of group D. PLoS One. 2017;12(8):e0183300.

10. Comes A, lanosi ES, Gabriela J. Inflammatory Biomarkers in Chronic
Obstructive Pulmonary Disease. $J$ Interdiscip Med. 2016;1:12.

11. Leuzzi G, Galeone C, Taverna F, et al. C-reactive protein level predicts mortality in COPD: a systematic review and meta-analysis. Eur Respir Rev. 2017;26(143).

12. Dahl M, Vestbo J, Lange $\mathrm{P}$, et al. Creactive protein as a predictor of prognosis in chronic obstructive pulmonary disease. Am J Respir Crit Care Med. 2007;175(3):250-255.

13. Calverley PMA, Anderson JA, Celli B, et al. Salmeterol and fluticasone propionate and survival in chronic obstructive pulmonary disease. $N$ Engl J Med. 2007;356(8):775-789.

14. Quint JK, Müllerova H, DiSantostefano $\mathrm{RL}$, et al. Validation of chronic obstructive pulmonary disease recording in the Clinical Practice Research Datalink (CPRD-GOLD). BMJ Open . 2014;4(7).

15. Herrett E, Gallagher AM, Bhaskaran K, et al. Data Resource Profile: Clinical Practice Research Datalink (CPRD). Int J Epidemiol. 2015;44(3):827-836.

16. Barakat MF, McDonald HI, Collier TJ, et al. Acute kidney injury in stable COPD and at exacerbation. Int $J$ Chron Obstruct Pulmon Dis. 2015;10(1):20672077.

17. Mullerova $\mathrm{H}$, Shukla A, Hawkins A, Quint J. Risk factors for acute exacerbations of COPD in a primary care population: a retrospective observational cohort study. BMJ Open. 2014;4(12):e006171.

18. Wurst KE, Shukla A, Muellerova $\mathrm{H}$, et al. Respiratory pharmacotherapy use in patients newly diagnosed with chronic obstructive pulmonary disease in a primary care setting in the UK: a retrospective cohort study. COPD. 2014;11(5):521-530.

19. Rothnie K, Mullerova H, Hurst J, et al. Validation of the recording of acute exacerbations of COPD in the clinical practice research datalink: Phase 1 results. Eur Respir J. 2015;46(suppl 59).

20. Rothnie KJ, Müllerová H, Hurst JR, et al. Validation of the recording of acute exacerbations of COPD in UK primary care electronic healthcare records. PLoS One. 2016;11(3).

21. Padmanabhan S. CPRD GOLD Data Specification.

https://www.ed.ac.uk/files/atoms/files/c 
prd_gold full_data specification.pdf. Published 2015. Accessed May 15, 2018.

22. Chatila WM, Thomashow BM, Minai $\mathrm{OA}$, et al. Comorbidities in chronic obstructive pulmonary disease. Proc Am Thorac Soc. 2008;5(4):549-555.

23. Dal Negro RW, Bonadiman L, Turco P. Prevalence of different comorbidities in COPD patients by gender and GOLD stage. Multidiscip Respir Med. 2015;10(1):24.

24. Franssen FME, Rochester CL. Comorbidities in patients with COPD and pulmonary rehabilitation: Do they matter? Eur Respir Rev. 2014;23(131):131-141.

25. Divo M, Cote C, De Torres JP, et al. Comorbidities and risk of mortality in patients with chronic obstructive pulmonary disease. Am J Respir Crit Care Med. 2012;186(2):155-161.

26. de Melo MN, Ernst P, Suissa $\mathrm{S}$. Inhaled corticosteroids and the risk of a first exacerbation in COPD patients. Eur Respir J. 2004;23(5):692-697.

27. Ernst P, Gonzalez A V, Brassard P, et al. Inhaled corticosteroid use in chronic obstructive pulmonary disease and the risk of hospitalization for pneumonia. Am J Respir Crit Care Med. 2007;176(2):162-166.

28. NICE. Chronic obstructive pulmonary disease (acute exacerbation): antimicrobial prescribing. 2018. https://www.nice.org.uk/guidance/ng11 4.

29. Melbye H, Hvidsten D, Holm A, et al. The course of C-reactive protein response in untreated upper respiratory tract infection. $\mathrm{Br} J$ Gen Pract. 2004;54(506):653-658. https://www.ncbi.nlm.nih.gov/pubmed/1 5353049.

30. Wedzicha JA, Seemungal TA. COPD exacerbations: defining their cause and prevention. Lancet. 2007;370(9589):786-796.

31. Thomsen M, Ingebrigtsen TS, Marott $\mathrm{JL}$, et al. Inflammatory biomarkers and exacerbations in chronic obstructive pulmonary disease. JAMA - J Am Med Assoc. 2013;309(22):2353-2361.

32. Hurst JR, Vestbo J, Anzueto A, et al. Susceptibility to exacerbation in chronic obstructive pulmonary disease. $N$ Engl J Med. 2010;363(12):11281138.

33. Weis N, Almdal T. C-reactive protein-can it be used as a marker of infection in patients with exacerbation of chronic obstructive pulmonary disease? Eur $J$
Intern Med. 2006;17(2):88-91.

34. de Torres JP, Pinto-Plata V, Casanova $C$, et al. C-reactive protein levels and survival in patients with moderate to very severe COPD. Chest. 2008;133(6):1336-1343.

35. Agusti A, Sin DD. Biomarkers in COPD. Clin Chest Med. 2014;35(1):131-141.

36. Man SFP, Sin DD. Effects of corticosteroids on systemic inflammation in chronic obstructive pulmonary disease. Proc Am Thorac Soc. 2005;2(1):78-82.

37. Man SFP, Connett JE, Anthonisen NR, et al. C-reactive protein and mortality in mild to moderate chronic obstructive pulmonary disease. Thorax. 2006;61(10):849-853.

38. Pinto-Plata VM, Müllerova H, Toso JF, et al. C-reactive protein in patients with COPD, control smokers and nonsmokers. Thorax. 2006;61(1):23-28.

39. Müller B, Tamm M. Biomarkers in acute exacerbation of chronic obstructive pulmonary disease: Among the blind, the one-eyed is king. Am J Respir Crit Care Med. 2006;174(8):848-849.

40. Breyer M, P A Rutten E, Spruit M, et al. Systemic Inflammation in Patients with Chronic Obstructive Pulmonary Disease: Results from the Cosmic Study. Open J Respir Dis. 2012;2(3):66-72.

41. Kannel WB, D'Agostino RB, Belanger AJ. Fibrinogen, cigarette smoking, and risk of cardiovascular disease: insights from the Framingham Study. Am Heart J. 1987;113(4):1006-1010.

42. Bazzano LA, He J, Muntner P, Vupputuri S, et al. Relationship between cigarette smoking and novel risk factors for cardiovascular disease in the United States. Ann Intern Med. 2003;138(11):891-897

43. Wannamethee SG, Lowe GDO, Shaper AG, et al. Associations between cigarette smoking, pipe/cigar smoking, and smoking cessation, and haemostatic and inflammatory markers for cardiovascular disease. Eur Heart J. 2005;26(17):1765-1773.

44. Dickens JA, Miller BE, Edwards LD, et al. COPD association and repeatability of blood biomarkers in the ECLIPSE cohort. Respir Res. 2011;12(1):146.

45. Bower JK, Lazo M, Juraschek SP, et al. Within-person variability in highsensitivity C-reactive protein. Arch Intern Med. 2012;172(19):1519-1521.

46. Haynes K. Mortality: The final outcome. 
Pharmacoepidemiol Drug Saf.

2019;28(5):570-571. Dedman D,
Gallagher AM, Den

47. Gallagher AM, Dedman D,

of date of death recording in the Clinical Practice Research Datalink GOLD database in England compared with the Office for National Statistics death registrations.

Pharmacoepidemiol

Drug Saf. 2019;28(5):563-569. 


\section{Supplementary Material}

Table S.4.1. Risk of moderate-to-severe exacerbations among never and current ICS users stratified by CRP levels.

\begin{tabular}{|c|c|c|c|c|}
\hline & $\begin{array}{c}\text { Moderate-to-severe } \\
n=2,781^{b}\end{array}$ & $\begin{array}{c}\mathrm{IR} \\
(/ 1000 \mathrm{PY})\end{array}$ & $\begin{array}{c}\text { Age and sex adjusted } \\
\mathrm{HR} \\
(95 \% \mathrm{Cl})\end{array}$ & $\begin{array}{l}\text { Adjusted } \\
\text { HR } \\
(95 \% \mathrm{Cl})^{\mathrm{a}}\end{array}$ \\
\hline \multicolumn{5}{|l|}{ ICS use } \\
\hline Never & 1,080 & 47.4 & & \\
\hline \multicolumn{5}{|c|}{ By CRP levels (mg/L) } \\
\hline $4-7$ & $\begin{array}{l}132 \\
97\end{array}$ & $\begin{array}{l}54.9 \\
49.1\end{array}$ & $\begin{array}{l}\text { Rererence } \\
0.90(0.69-1.17)^{c}\end{array}$ & $\begin{array}{c}\text { Rererence } \\
0.88(0.68-1.14)\end{array}$ \\
\hline $8-19$ & 98 & 67.7 & $1.24(0.96-1.61)^{d}$ & $1.17(0.90-1.52)$ \\
\hline$\geq 20$ & 53 & 59.7 & $1.11(0.81-1.53)^{\mathrm{e}}$ & $1.01(0.73-1.39)$ \\
\hline Missing & 700 & 43.5 & $0.80(0.66-0.96)$ & $0.83(0.69-1.00)$ \\
\hline Past & 644 & 50.4 & $0.93(0.77-1.12)$ & $0.80(0.66-0.97)$ \\
\hline Recent & 285 & 79.7 & $1.47(1.20-1.81)$ & $0.90(0.72-1.12)$ \\
\hline Current & 772 & 95.6 & & \\
\hline \multicolumn{5}{|c|}{ By CRP levels (mg/L) } \\
\hline $0-3$ & 72 & 91.3 & $1.65(1.24-2.19)$ & $0.95(0.70-1.27)$ \\
\hline $4-7$ & 56 & 82.4 & $1.50(1.10-2.05)^{\mathrm{c}}$ & $0.83(0.60-1.14)$ \\
\hline $8-19$ & 53 & 97.0 & $1.76(1.28-2.43)^{\mathrm{d}}$ & $0.95(0.68-1.31)$ \\
\hline$\geq 20$ & 40 & 114.8 & $2.17(1.53-3.10)^{\mathrm{e}}$ & $1.07(0.74-1.54)$ \\
\hline Missing & 551 & 96.5 & $1.77(1.46-2.14)$ & $1.01(0.83-1.24)$ \\
\hline
\end{tabular}

Abbreviations: ICS, Inhaled corticosteroids; IR, incidence rate; HR, hazard ratio; Cl, confidence interval; CRP, C-reactive protein; PY, person-years.

${ }^{a}$ Adjusted for age, sex, smoking status, body mass index, alcohol use, history of heart failure, chronic liver disease, ischemic heart disease, use of antipsychotic, antidepressants, recent ICS use, past ICS use, atopic dermatitis, use of oxygen, short-acting beta-2 agonists, long-acting beta-2 agonists, short-acting muscarinic antagonists, long-acting muscarinic antagonists, xanthine derivatives and oral corticosteroid 6 months prior and use of antibiotics 1 month prior.

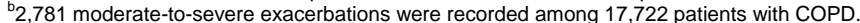

'Wald test showed that these categories were statistically significantly different, despite overlapping confidence intervals.

dWald test showed that these categories were statistically significantly different, despite overlapping confidence intervals.

${ }^{e}$ Wald test showed that these categories were statistically significantly different, despite overlapping confidence intervals.

Table S.4.2. Risk of severe exacerbations among never and current ICS users stratified by CRP levels.

\begin{tabular}{|c|c|c|c|c|}
\hline 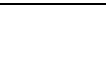 & $\begin{array}{c}\text { Severe exacerbations } \\
n=367^{b}\end{array}$ & $\begin{array}{c}\text { IR } \\
(/ 1000 P Y)\end{array}$ & $\begin{array}{c}\text { Age and sex adjusted } \\
\text { HR } \\
(95 \% \mathrm{Cl})\end{array}$ & $\begin{array}{c}\text { Adjusted } \\
\text { HR } \\
(95 \% \mathrm{Cl})^{\mathrm{a}}\end{array}$ \\
\hline \multicolumn{5}{|l|}{ ICS use } \\
\hline Never & 123 & 5.1 & & \\
\hline \multicolumn{5}{|c|}{ By CRP levels (mg/L) } \\
\hline $0-3$ & 13 & 5.2 & Reference & Reference \\
\hline $4-7$ & 12 & 5.8 & $1.11(0.51-2.43)^{\mathrm{c}}$ & $1.08(0.49-2.37)$ \\
\hline 8-19 & 10 & 6.5 & $1.27(0.56-2.90)^{\mathrm{d}}$ & $1.22(0.53-2.78)$ \\
\hline$\geq 20$ & 7 & 7.4 & $1.45(0.58-3.63)^{\mathrm{e}}$ & $1.28(0.51-3.22)$ \\
\hline Missing & 81 & 4.8 & $0.91(0.51-1.63)$ & $0.95(0.53-1.70)$ \\
\hline Past & 95 & 6.5 & $1.24(0.70-2.22)$ & $1.12(0.62-2.01)$ \\
\hline Recent & 39 & 9.0 & $1.70(0.91-3.18)$ & $1.13(0.59-2.18)$ \\
\hline \multirow{2}{*}{\multicolumn{5}{|c|}{ By CRP levels $(\mathrm{mg} / \mathrm{L})$}} \\
\hline & & & & \\
\hline $0-3$ & 7 & 7.3 & $1.35(0.54-3.38)$ & $0.83(0.32-2.13)$ \\
\hline $4-7$ & 12 & 14.4 & $2.64(1.21-5.79)^{\mathrm{C}}$ & $1.60(0.71-3.60)$ \\
\hline $8-19$ & 10 & 14.8 & $2.72(1.19-6.20)^{\mathrm{a}}$ & $1.61(0.69-3.78)$ \\
\hline$\geq 20$ & 6 & 13.6 & $2.53(0.96-6.65)^{\mathrm{e}}$ & $1.39(0.52-3.77)$ \\
\hline Missing & 75 & 10.6 & $1.96(1.09-3.54)$ & $1.22(0.65-2.28)$ \\
\hline
\end{tabular}

Abbreviations: ICS, Inhaled corticosteroids; IR, incidence rate; HR, hazard ratio; Cl, confidence interval; CRP, C-reactive protein; PY, person-years.

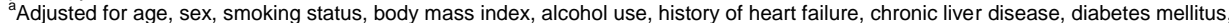
ischemic heart disease, osteoporosis, use of proton-pump inhibitors, antidepressants, recent ICS use, past ICS use, oxygen, antipsychotics, statins, short-acting beta-2 agonists, long-acting beta-2 agonists, short-acting muscarinic antagonists, long-acting muscarinic antagonists, xanthine derivatives and oral corticosteroids in the 6 months prior and use of antibiotics specific for COPD 1 month prior.

${ }^{\mathrm{b}} 367$ severe exacerbations were recorded among 17,722 patients with COPD.

'Wald test showed that these categories were statistically significantly different, despite overlapping confidence intervals.

${ }^{d}$ Wald test showed that these categories were statistically significantly different, despite overlapping confidence intervals.

${ }^{e}$ Wald test showed that these categories were statistically significantly different, despite overlapping confidence intervals. 
Table S.4.3. Risk of all-cause mortality among never and current ICS users stratified by CRP levels

\begin{tabular}{|c|c|c|c|c|}
\hline & $\begin{array}{c}\text { All-cause mortality } \\
n=2,839^{\mathrm{b}}\end{array}$ & $\begin{array}{c}\mathrm{IR} \\
(/ 1000 \mathrm{PY})\end{array}$ & $\begin{array}{c}\text { Age and sex adjusted } \\
\mathrm{HR} \\
(95 \% \mathrm{Cl})\end{array}$ & $\begin{array}{c}\text { Adjusted } \\
\text { HR } \\
(95 \% \mathrm{Cl})^{\mathrm{a}}\end{array}$ \\
\hline \multicolumn{5}{|l|}{ ICS use } \\
\hline \multicolumn{5}{|c|}{$\begin{array}{l}\text { Never } \\
\text { By CRP levels(mg/L) }\end{array}$} \\
\hline $0-3$ & 84 & 33.6 & Reference & Reference \\
\hline $4-7$ & 84 & 40.5 & $1.17(0.86-1.58)$ & $1.21(0.89-1.64)$ \\
\hline $8-19$ & 106 & 69.0 & $1.89(1.42-2.52)$ & $1.84(1.38-2.45)$ \\
\hline$\geq 20$ & 185 & 196.0 & $4.93(3.81-6.38)$ & $4.03(3.11-5.22)$ \\
\hline Missing & 679 & 39.6 & $1.10(0.88-1.38)$ & $1.17(0.93-1.47)$ \\
\hline Past & 798 & 53.9 & $1.46(1.16-1.82)$ & $1.43(1.14-1.79)$ \\
\hline Recent & 264 & 60.0 & $1.68(1.32-2.15)$ & $1.44(1.12-1.84)$ \\
\hline Current & 639 & 62.4 & & \\
\hline \multicolumn{5}{|c|}{ By CRP levels (mg/L) } \\
\hline $0-3$ & 37 & 37.9 & $1.08(0.74-1.59)$ & $0.88(0.59-1.29)$ \\
\hline $4-7$ & 35 & 41.2 & $1.18(0.80-1.76)$ & $0.97(0.65-1.44)$ \\
\hline $8-19$ & 66 & 95.3 & $2.54(1.84-3.50)$ & $2.02(1.46-2.80)$ \\
\hline$\geq 20$ & 97 & 214.6 & $5.00(3.73-6.70)$ & $3.17(2.36-4.27)$ \\
\hline Missing & 404 & 55.6 & $1.55(1.22-1.96)$ & $1.24(0.98-1.57)$ \\
\hline
\end{tabular}

Abbreviations: ICS, Inhaled corticosteroids; IR, incidence rate; HR, hazard ratio; Cl, confidence interval; CRP, C-reactive protein; PY, person-years.

${ }^{a}$ Adjusted for age, sex, smoking status, body mass index, alcohol use, history of heart failure, chronic liver disease, ischemic heart disease, atopic dermatitis, diabetes mellitus, cancer, use of oxygen, statins, recent ICS use, past ICS use, short-acting beta-2 agonists, long-acting beta-2 agonists, short-acting muscarinic antagonists, long-acting muscarinic antagonists, xanthine derivatives and oral corticosteroid use in the 6 months prior and use of antibiotics specific for COPD 1 month prior.

${ }^{b} 2,839$ deaths were recorded among 17,722 patients with COPD. 



\section{Blood eosinophilia, use of inhaled corticosteroids and risk of COPD exacerbations and mortality}

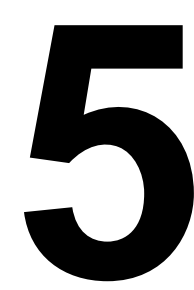

Pharmacoepidemiol Drug Saf.2018;27(11):1191-1199

Olorunfemi A. Oshagbemi

Frits M.E. Franssen

Dionne C.W. Braeken Henskens Yvonne

Emiel F.M. Wouters Anke-Hilse Maitland-van der Zee Andrea M. Burden Frank de Vries

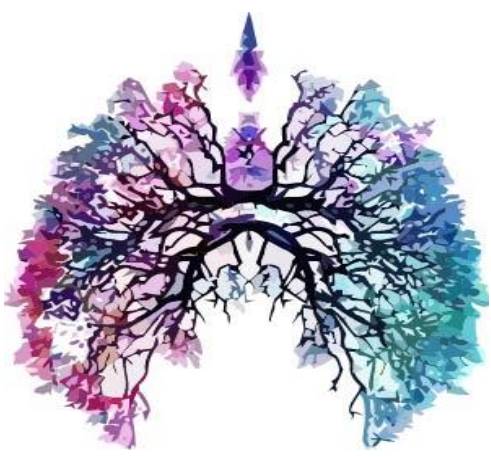




\section{ABSTRACT}

Background: It remains unclear whether eosinophilia is useful in guiding inhaled corticosteroid (ICS) therapy in chronic obstructive pulmonary disease (COPD) patients. The goal of this study was to evaluate the risk of acute exacerbations, COPD-related hospitalisations/accident and emergency (AE) visits and all-cause mortality with various levels of eosinophil counts among COPD patients using ICS.

Methods: A cohort study was conducted using the United Kingdom (UK) Clinical Practice Research Datalink. Patients were aged $\geq 40$ years and had COPD $(n=32,693)$. Current users of ICS were stratified by relative and absolute eosinophil counts to determine the risk of outcomes with blood eosinophilia using Cox regression analysis.

Results: Among COPD patients, current use of ICS was not associated with a reduced risk of acute COPD exacerbations, COPD-related hospitalisations/AE visits and all-cause mortality. Stratification of ICS use by absolute or relative eosinophil counts did not result in significant differences in risk of COPD exacerbations or hospitalisations/AE visits. However, all-cause mortality was reduced by $12-24 \%$ among patients with eosinophilia.

Conclusions: COPD-related acute exacerbations or hospitalisations/AE visits were not reduced with eosinophilia among users of ICS with COPD. However, all-cause mortality was reduced by $12 \%-24 \%$. These findings are potentially important and require further evaluation in prospective studies. 


\section{INTRODUCTION}

Chronic obstructive pulmonary disease (COPD) is a major cause of morbidity and mortality worldwide and is defined by the presence of chronic respiratory symptoms and persistent airflow limitation. ${ }^{1}$ While bronchodilators are the cornerstone of pharmacological management of COPD, patients with frequent exacerbations are often additionally treated with inhaled corticosteroids (ICS). ${ }^{2}$ Exacerbations play a central role in the pathophysiology of COPD as they are related to lung function decline, poor health status and increased mortality. ${ }^{3}$ While non-response to ICS therapy is common, ${ }^{4}$ potential side effects of ICS include fractures and pneumonia.

Clinical data have suggested that blood eosinophil count, which is present in up to $40 \%$ of COPD patients, ${ }^{5}$ is a promising biomarker of response to ICS in patients with COPD. ${ }^{6-9}$ Eosinophilic airway inflammation has been associated with an increased risk of exacerbations, and patients with eosinophilic inflammation responded better to ICS therapy than non-eosinophilic patients. ${ }^{6,10}$ Pascoe and colleagues, ${ }^{6}$ performed a post-hoc analysis of data from two replicate, randomised, double blind trials with duration of 12 months. In the analysis, vilanterol $25 \mu \mathrm{g}$ was compared with $25 \mu \mathrm{g}$ vilanterol plus $50 \mu \mathrm{g}, 100 \mu \mathrm{g}$, or $200 \mu \mathrm{g}$ fluticasone furoate in patients with moderate-to-severe COPD. They observed that $68 \%$ of COPD patients had peripheral blood eosinophilia. Importantly, across all doses of ICS, fluticasone furoate and vilanterol reduced exacerbations by $29 \%$ compared with vilanterol alone in patients with eosinophil counts $\geq 2 \%$, and by $10 \%$ in patients with eosinophil counts $<2 \%$. Analysis of data from the FLAME trial, showed no significant reduction in exacerbation among COPD patients exposed to salmeterol/fluticasone compared to indacaterol/gycopyrronium at blood eosinophil levels of $150-300 \mathrm{cells} / \mu \mathrm{L}$ versus 300 cells $/ \mu L^{8}{ }^{8}$ In this study, we use the word "eosinophilia" to mean elevated blood eosinophil counts based on our defined cut-offs.

However, studies with real-world evidence are currently limited and are needed to identify patients who will benefit from ICS use. Therefore, the aim of this study was to evaluate the risk of acute exacerbations, COPD-related hospitalisations/accident and emergency (AE) visits and all-cause mortality, with various levels of eosinophil counts among COPD patients using ICS.

\section{METHODS}

\section{Data source}

This study was conducted with data obtained from the Clinical Practice Research Datalink (CPRD). It provides detailed information on drug prescriptions, clinical events, demographics, specialist referrals, hospital admissions, and electronic lab link data of patients from 674 general practices, who are representative for $7 \%$ of the total British population. ${ }^{11,12}$ Data collection started on 1 January 2005, corresponding to the introduction of the Quality and Outcomes Framework (QOF) in April 2004, which 
improved routine recording of various diseases, including COPD. ${ }^{13}$ Routinely collected historical data was available, dating back to 1987. Previous studies with the CPRD have shown a high level of validity of recording of COPD, ${ }^{11}$ and COPD exacerbations. ${ }^{14}$ CPRD has previously been used to study COPD. ${ }^{15-17}$ The independent scientific advisory committee of Medicines and Healthcare products Regulatory Agency (MHRA) database research approved the study protocol (No: 17_065R).

\section{Study population}

We selected all patients aged $\geq 40$ years with a diagnosis of COPD, as recorded by a first read code during valid data collection from 1 January 2005 through 31 January 2014. We excluded all patients with a diagnosis of COPD as recorded by validated read codes before 1 January 2005. Patients were followed from the date of their COPD diagnosis (index date) until the end of data collection, date of death, end of study (31 January 2014) or when the outcome of interest occurred, whichever came first. The primary outcome of interest was an acute exacerbation of COPD, using validated read codes for acute exacerbations of COPD with $96 \%$ positive predictive value (PPV) in identifying acute exacerbations in the CPRD. ${ }^{18}$ Secondary outcomes were hospitalisation/AE visit for COPD and all-cause mortality. Only patients with blood eosinophil counts measured during study period were included. Blood eosinophil count closest to index date (i.e. start of follow-up) was used in our analyses. Relatively stable blood eosinophil counts have been reported among COPD patients over time within the UK population, irrespective of exposure to systemic glucocorticoids or other factors. ${ }^{19,20}$ We excluded patients with a history of asthma, those with COPD exacerbations, those with oral corticosteroids in the past month or those with ICS use in the past year.

\section{Exposure}

Exposure to ICS was determined time-dependently during follow-up. Each patient's follow-up time was divided into fixed periods of 90 days, starting at index date. Prior to the start of each interval, ICS exposure was determined based on the date of the prescription, and classified as current, recent, past or never use (patient without ICS exposure). Current users had received their most recent ICS prescription within the 30 days prior to the start of an interval, recent users were those with their most recent ICS prescription between 31 and 60 days prior, and past users were issued their most recent ICS prescription more than 60 days ago. Never users were those with no prior or current exposure to ICS at the start of an interval. At index date all patients were classified as never or current users, and could then move between exposure groups over time - meaning that e.g. past and recent users could become current users again when a new ICS prescription was issued. Current ICS users were stratified by serum counts of blood eosinophil at baseline and classified as low $(<2.0 \%)$, moderate 
( $\geq 2.0$ to $3.9 \%$ ), high $(4.0 \%$ to $5.9 \%$ ) or very high $(\geq 6.0 \%)$. We also stratified by absolute blood eosinophil count $\left(<0.34 \times 10^{9}\right.$ cells $/ \mathrm{L}$ versus $\geq 0.34 \times 10^{9}$ cells $\left./ \mathrm{L}\right)$. We

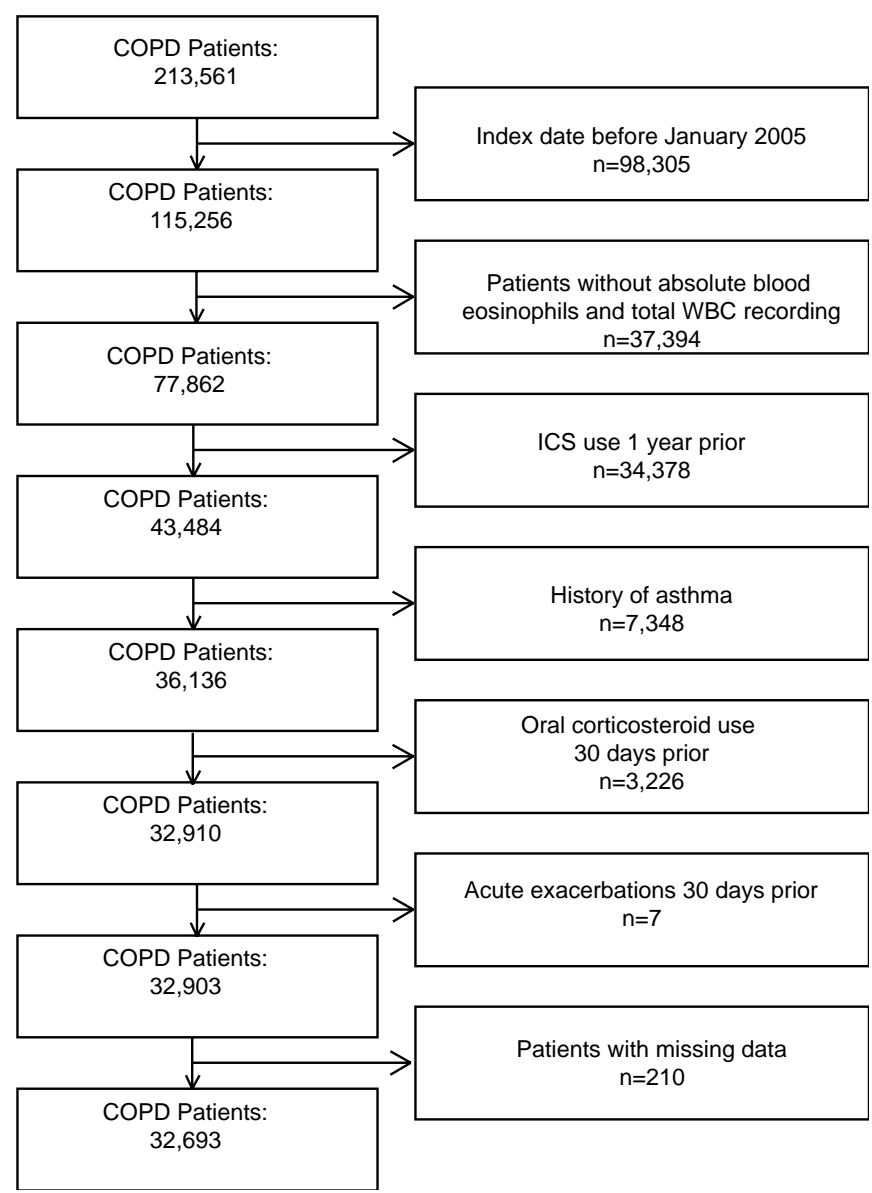

Figure 5.1: Flow chart showing the selection of eligible patients.

chose this analysis approach because of its reliability, in adequately assessing exposure status and covariates, which is essential to the validity of our results. ${ }^{21}$

\section{Covariates}

Potential confounders were assessed time-dependently; with the exception of gender, smoking status, alcohol use, and body mass index, which were determined at baseline. The following covariates were considered as potential confounders, and 
identified at the start of each 90-day interval: a history of congestive heart failure, anaemia, chronic liver disease, allergic rhinitis, all malignancies except nonmelanoma skin cancer, ischaemic heart disease, stroke, rheumatoid arthritis, diabetes mellitus, hypertension, pulmonary fibrosis, osteoporosis, and anxiety. Additionally, the use of antihistamines, oxygen, proton-pump inhibitors, antipsychotics, antidepressants, or statins were identified in the past 6 months. ${ }^{22-26}$ We adjusted for proxy indicators of the severity of obstructive airway disease, as previously defined as dispensed prescriptions of, short and long-acting beta-agonists, short and long-acting muscarinic antagonists, xanthine derivatives and oral corticosteroids. ${ }^{27,28}$

\section{Statistical analysis}

We evaluated the risk of study outcomes stratified by ICS use, gender, and age using Cox regression analysis SAS 9.4 PHREG procedure (SAS Institute, Cary, NC). Current ICS use was further, stratified by blood eosinophil counts. The difference between each eosinophil count strata was tested using Wald's test for relative and absolute blood eosinophil counts. To avoid immortal time bias, all patients were classified as never users until the first ICS prescription after the index date, and all exposure categories of ICS use were incorporated into the statistical model timedependently. We ran separate models for age, gender, absolute and relative counts avoiding collinearity between absolute and relative eosinophil counts. Kaplan-Meier curves were plotted using the life table procedure. Potential confounders were included in the final models if they independently changed the $\beta$-coefficient for current ICS exposure by at least $5 \%$, or when consensus existed within the team of researchers.

\section{RESULTS}

We identified 213,561 patients with COPD, of whom 32,693 met the inclusion criteria (Figure 5.1). Table 5.1 shows the baseline characteristics of COPD patients, who were predominantly elderly males. At baseline, the mean blood eosinophil count was $3.1 \%( \pm 2.7 \%)$ and $64.1 \%$ had a relative blood eosinophil count $\geq 2.0 \%$. More than half of all patients were either overweight (31.9\%) or obese $(25.8 \%)$, and a considerable proportion of COPD patients suffered from ischemic heart disease (15.4\%).

\section{Acute COPD exacerbations}

Current use of ICS was not associated with a significant reduction in risk of acute exacerbations (adjusted hazard ratio [adj.HR] 1.15; 95\% confidence interval [Cl] 1.091.21), Table 5.2 The risk of acute COPD exacerbations was not significantly lower among current ICS users with relative eosinophil counts $\geq 2 \%$, as compared to current users with relative counts $<2 \%$. This was similar when comparing absolute blood eosinophil counts $\geq 0.34 \times 10^{9}$ cells $/ L$ with counts $<0.34 \times 10^{9}$ cells $/ \mathrm{L}$. There was no difference in risk of acute exacerbations between all relative and absolute eosinophil 
categories. Figure 5.2a shows KM analysis. When stratified by age and gender, no significant association with the risk of acute exacerbations was observed, using males or those aged 40-59 as the reference (Table 5.2).

Table 5.1. Baseline characteristics of COPD patients.

\begin{tabular}{|c|c|c|}
\hline & $n=32,693$ & $\%$ \\
\hline Females & 14,551 & 44.5 \\
\hline Mean age (years, SD) & 68.4 & 10.8 \\
\hline Mean Follow-up time (years, SD) & $3 \cdot 1$ & $2 \cdot 2$ \\
\hline \multicolumn{3}{|l|}{ Age category (years) } \\
\hline 40-59 & 6,902 & 21.1 \\
\hline $60-79$ & 20,350 & 62.3 \\
\hline $80+$ & 5,441 & 16.76 \\
\hline \multicolumn{3}{|l|}{$\mathrm{BMI}\left(\mathrm{kg} / \mathrm{m}^{2}\right)$ in the past 6 months } \\
\hline Underweight $\left(\mathrm{BMI}<18.5 \mathrm{~kg} / \mathrm{m}^{2}\right)$ & 1,704 & 5.2 \\
\hline Normal weight (BMI $\left.18.5-24.9 \mathrm{~kg} / \mathrm{m}^{2}\right)$ & 11,286 & 34.5 \\
\hline Overweight (BMI $25.0-30.0 \mathrm{~kg} / \mathrm{m}^{2}$ ) & 10,412 & 31.9 \\
\hline Obese $\left(\mathrm{BMI}>30.0 \mathrm{~kg} / \mathrm{m}^{2}\right)$ & 8,437 & 25.8 \\
\hline Missing & 854 & 2.6 \\
\hline Mean relative eosinophil count $(\%, S D)$ & $3 \cdot 1$ & $2 \cdot 7$ \\
\hline \multicolumn{3}{|l|}{ Relative blood eosinophil count } \\
\hline Low $(<2.0 \%)$ & 11,756 & 36.0 \\
\hline Moderate $(\geq 2.0 \%-3.9 \%)$ & 13,059 & 39.9 \\
\hline High $(4.0 \%-5.9 \%)$ & 5,110 & 15.6 \\
\hline Very High $(\geq 6.0 \%)$ & 2,768 & 8.5 \\
\hline \multicolumn{3}{|l|}{ Absolute blood eosinophil count } \\
\hline$<0.34 \times 10^{y}$ cells $/ \mathrm{L}$ & 26,828 & 82.1 \\
\hline$\geq 0.34 \times 10^{y} \mathrm{cells} / \mathrm{L}$ & 5,865 & 17.9 \\
\hline \multicolumn{3}{|l|}{ Smoking status at index date } \\
\hline Never & 3,285 & 10.1 \\
\hline Current & 14,522 & 44.4 \\
\hline Former & 14,849 & 45.4 \\
\hline Missing & 37 & 0.1 \\
\hline \multicolumn{3}{|l|}{ Drug use (in the past 6 months) } \\
\hline SABAs & 15,307 & 46.8 \\
\hline LABAs & 2,724 & 8.3 \\
\hline SAMAS & 2,451 & 7.5 \\
\hline LAMAs & 4,432 & 13.6 \\
\hline Xanthine derivatives & 97 & 0.3 \\
\hline Antipsychotics & 352 & 1.1 \\
\hline \multicolumn{3}{|l|}{ History of co-morbidities } \\
\hline Diabetes Mellitus & 4,027 & 12.3 \\
\hline Anxiety & 4,865 & 14.8 \\
\hline Osteoporosis & 1,872 & 5.7 \\
\hline Malignancies excluding non-melanoma skin cancer & 4,867 & 14.9 \\
\hline Chronic liver disease & 110 & 0.3 \\
\hline Ischaemic heart disease & 5,027 & 15.4 \\
\hline
\end{tabular}

COPD-related hospitalisations/accident and emergency visits

Current use of ICS was associated with a 1.2-fold increased risk of COPD-related hospitalisations/AE visits (adj.HR 1.17; 95\% Cl: 1.04-1.32). Similar to acute COPD exacerbations, stratification by absolute or relative blood eosinophil count did not result in a significant difference in risk of COPD-related hospitalisations/AE visits). We also found no difference in risk when we tested the difference in risk between absolute and relative blood eosinophil counts. Figure 5.2b shows the KM life table analysis curves. We did not identify an increased risk of hospitalisations with current female ICS users compared to current male ICS users (adj.HR 0.98; 95\% Cl 0.77 1.11, Table 5.3), and there were no differences in the risk of hospitalisations with increasing age groups (Table 5.3). 
Table 5.2 Risk of acute COPD exacerbations with current use of ICS, stratified by blood eosinophil counts, gender and age.

\begin{tabular}{|c|c|c|c|c|}
\hline & $\begin{array}{l}\text { Exacerbations } \\
\qquad n=14,523^{d}\end{array}$ & $\begin{array}{c}\text { IR } \\
(/ 1000 \mathrm{PY})\end{array}$ & $\begin{array}{c}\text { Age and gender adjusted } \\
\text { HR } \\
(95 \% \mathrm{Cl})\end{array}$ & $\begin{array}{l}\text { Adjusted HR } \\
(95 \% \mathrm{Cl})^{\mathrm{a}}\end{array}$ \\
\hline \multicolumn{5}{|l|}{ ICS use } \\
\hline Never & 8,744 & 128.8 & Reference & Reference \\
\hline Past & 2,538 & 137.7 & $0.99(0.99-1.04)$ & $0.94(0.90-0.99)$ \\
\hline Recent & 882 & 188.7 & $1.38(1.28-1.47)$ & $1.11(1.03-1.19)$ \\
\hline Current & 2,359 & 208.6 & $1.49(1.41-1.55)$ & 1. $15(1.09-1.21)$ \\
\hline \multicolumn{5}{|c|}{ By relative blood eosinophil count } \\
\hline Low $(<2.0 \%)$ & 838 & 207.5 & Reference & Reference \\
\hline Moderate $(\geq 2.0 \%-3.9 \%)$ & 943 & 211.4 & $1.01(0.92-1.11)$ & $1.03(0.93-1.13)$ \\
\hline High $(4.0 \%-5.9 \%)$ & 373 & 214.6 & $1.03(0.91-1.16)$ & $1.04(0.92-1.17)$ \\
\hline Very High ( $\geq 6.0 \%)$ & 205 & 191.4 & $0.93(0.79-1.08)$ & $0.95(0.81-1.11)$ \\
\hline \multicolumn{5}{|c|}{ By absolute blood eosinophil count } \\
\hline$<0.34 \times 10^{y}$ cells $/ \mathrm{L}$ & 1,907 & 208.5 & Reference & Reference \\
\hline$\geq 0.34 \times 10^{y}$ cells $/ \mathrm{L}$ & 452 & 209 & $1.00(0.90-1.11)$ & $0.99(0.89-1.09)$ \\
\hline \multicolumn{5}{|l|}{ By gender } \\
\hline Males & 1,348 & 211.3 & Reference & Reference $^{\mathrm{b}}$ \\
\hline Female & 1,011 & 205.2 & $0.95(0.88-1.04)$ & $0.97(0.89-1.05)$ \\
\hline \multicolumn{5}{|l|}{ By age categories } \\
\hline $40-59$ years & 561 & 214.2 & Reference & Reference $^{c}$ \\
\hline $60-79$ years & 1,539 & 212.5 & $1.01(0.92-1.11)$ & $1.03(0.93-1.13)$ \\
\hline $80+$ year & 259 & 179.3 & $0.89(0.77-1.03)$ & $0.99(0.85-1.14)$ \\
\hline
\end{tabular}

Abbreviations: COPD, chronic obstructive pulmonary disease; ICS, Inhaled corticosteroids; IR, incidence rate; $\mathrm{HR}$, hazard ratio; $\mathrm{Cl}$, confidence interval; PY, person-years.

a adjusted for age, gender, smoking status, alcohol use, BMI, a history of heart failure, diabetes mellitus, chronic liver disease, pulmonary fibrosis, ischaemic heart disease, osteoporosis, anxiety, hypertension, anaemia, and the use of antipsychotics, statins, oxygen, proton-pump inhibitors, antidepressants, or antipsychotics, long-acting beta-2 agonist, short-acting beta-2 agonist, shortacting muscarinic agent, long-acting muscarinic antagonist, xanthine derivatives and oral corticosteroid use 6 months prior to the start of an interval.

${ }^{\mathrm{D}}$ adjusted for all confounders under (a) except gender.

cadjusted for all confounders under (a) except age.

${ }^{14,523}$ exacerbations were recorded among 32,693 patients with COPD.

Note: We evaluated the risk of study outcomes stratified by ICS use, gender, and age using Cox regression analysis.

\section{All-Cause Mortality}

Current use of ICS was associated with a statistically significantly increased risk of allcause mortality (adj.HR 1.20; 95\% Cl 1.12-1.29) compared to never ICS users, sTable 4. In contrast to the previous outcomes, when current ICS users were stratified by relative blood eosinophil counts, we observed a decreased risk of all-cause mortality among patients with increased eosinophil counts as compared to those with low $(<2 \%)$ eosinophil counts. We found a difference in risk of all-cause mortality between patients with low and moderate relative eosinophil counts $(p=0.001)$. No difference was found with absolute blood eosinophil counts. The KM curve shows differences in the proportion of patients with COPD who survived, stratified by relative blood eosinophil counts (Figure 5.2c). Stratification to by absolute blood eosinophil count did not show a significant association with all-cause mortality adj HR 0.92; 95\% $\mathrm{Cl}$ (0.79-1.06) for patients with absolute eosinophil counts $\geq 0.34 \times 10^{9}$ cells/L versus counts $<0.34 \times 10^{9}$ cells/L. Female users of ICS had a $21 \%$ decreased risk of allcause mortality (adj.HR $0.79 ; 95 \% \mathrm{Cl} 0.69-0.88$ ) compared to males, and we found an increased risk of all-cause mortality with age (Table 5.4). 
Table 5.3. Risk of COPD hospitalisations/AE visits with current use of ICS by blood eosinophil counts, gender and age

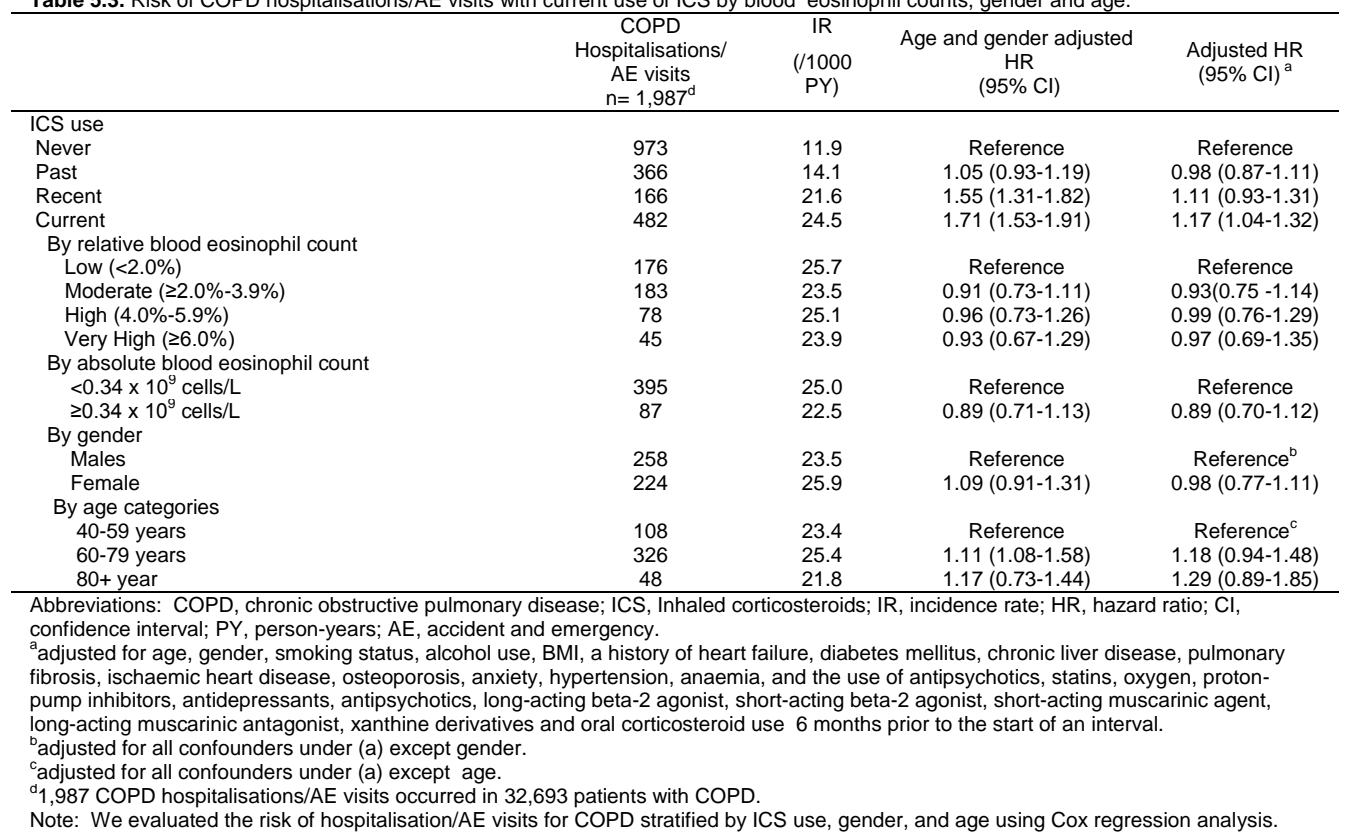

\section{DISCUSSION}

We found no reduced risk of COPD-related acute exacerbations or hospitalisations/AE visits among patients with blood eosinophilia in COPD patients using ICS. However, all-cause mortality was reduced among current ICS users with blood eosinophilia compared to current ICS users with low relative blood eosinophil count. However, this effect could not be detected with absolute eosinophil counts.

\section{ICS use and risk of exacerbations or COPD-related hospitalisations/AE visits}

As compared to never users, current users of ICS had a significantly increased risk of exacerbations or COPD-related hospitalisations/AE visits, although the risk between recent and current users was comparable. Similarly, Melo et al found an increased risk of first exacerbation among COPD patients currently exposed to ICS. ${ }^{27}$ Since ICS are prescribed in order to prevent these events, confounding by disease severity may explain this, in particular because the association is also present among ICS users who have recently stopped taking the drugs (recent users). Furthermore, recent and current users of ICS in our study might represent a different phenotype of COPD patients, maybe the so-called frequent exacerbators. ${ }^{29}$ Although a multicentre 4-year double blind study in COPD patients also reported an increased risk of first COPD exacerbation in patients exposed to any ICS compared to patients not exposed to ICS. ${ }^{30}$ 
Table 5.4. Risk of all-cause mortality with current use of ICS by baseline blood eosinophil counts, gender and age.

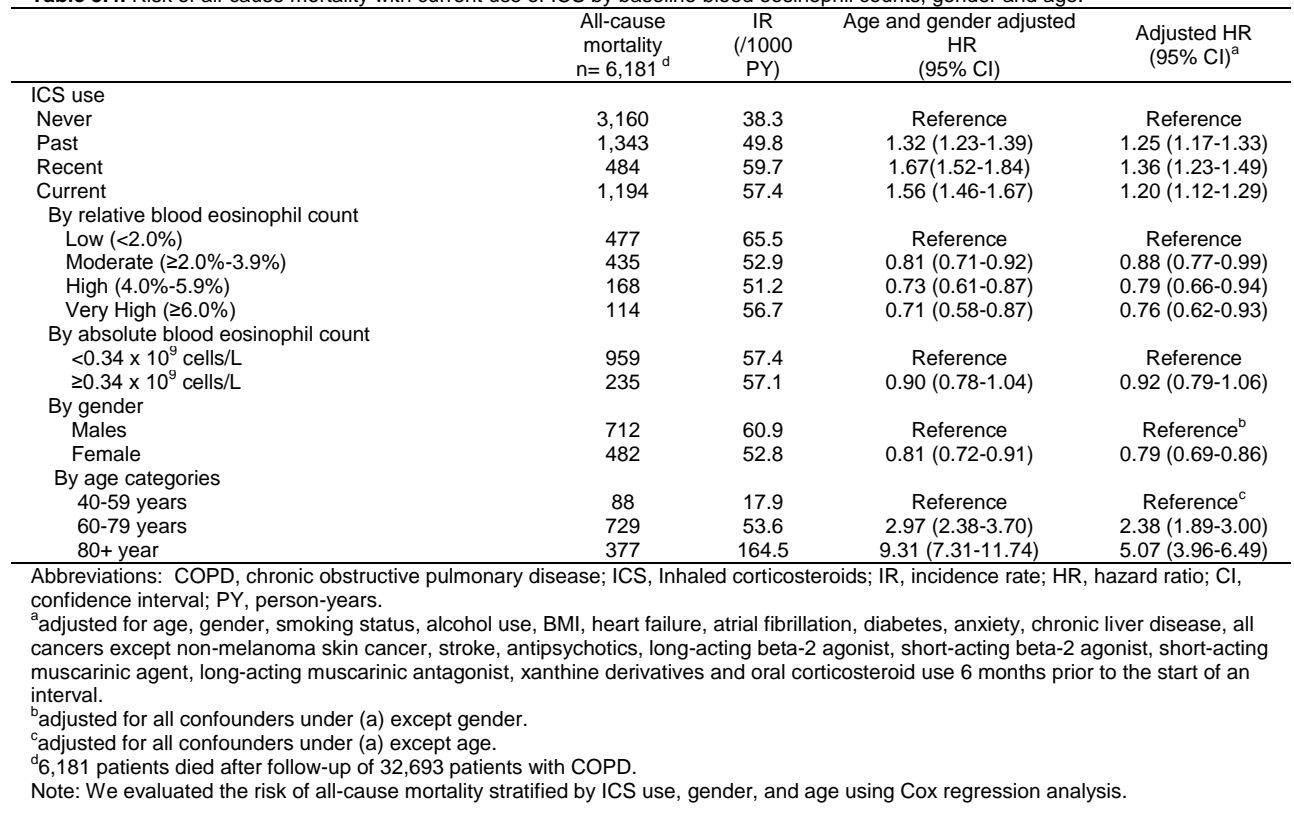

Impact of blood eosinophil counts on exacerbations and COPD-related hospitalisations/AE visits

Our findings are partially in line with previous research. While traditionally considered a characteristic of asthma, several studies have reported eosinophilic inflammation in patients with COPD. ${ }^{31,32}$ Pascoe and colleagues, ${ }^{6}$ concluded that COPD patients treated with ICS with higher blood eosinophil counts had reduced exacerbations compared to those with low blood eosinophil counts. While our observational study results are in contrast to this it is important to note we excluded patients with a history of asthma while Pascoe and co-workers only exclude active asthma patients and included patients with one or more exacerbations in previous year. ${ }^{33}$ The FLAME trial evaluated the time to the first exacerbation in COPD patients exposed to indacaterol/gycopyrronium compared to salmeterol/fluticasone and found no significant risk reduction in exacerbations among patients with blood eosinophil levels of 150 up to 300 cells $/ \mu \mathrm{L}$, versus 300 cells $/ \mu \mathrm{L}$ or more. ${ }^{8}$ When comparing our results to both previous studies, an important distinction was the comparator group, which may explain differences in results. Our findings were consistent with post-hoc analyses from the ISOLDE trial. $^{34}$ It showed no difference in the time-to-first exacerbation in patients with high or low eosinophil counts. It is important to note that our study also employed the time-to-first exacerbation approach. Similar to our study, three randomised clinical trials that studied blood eosinophils and ICS/long-acting bronchodilator reported no statistically significant effects for time to first moderate/severe exacerbation in patients with relative eosinophils counts $\geq 2 \%$ versus counts $<2 \%{ }^{35}$ 


\section{Impact of blood eosinophil counts on all-cause mortality}

Our findings are in agreement with a study which evaluated the 3-year survival using relative eosinophil count cut-off of $\geq 2 \%$, which showed that COPD patients with higher blood eosinophil counts had a significantly decreased 3-year mortality compared to COPD patients with blood eosinophil counts $<2 \%$ exposed to ICS. ${ }^{36}$ However a randomised, double-blind, placebo-controlled study by Barnes and co-workers, ${ }^{34}$ using subjects from the ISOLDE study, found no difference in the risk of deaths in COPD patients exposed to ICS with different eosinophil counts. Similarly, a clinical study involving 303 patients with COPD found that elevated blood eosinophil counts ( $\geq 200,300,400$ cells $/ \mu \mathrm{L}$ ) were not associated with mortality when compared with patients with decreased eosinophil counts. ${ }^{37}$

In recent years, various researchers have questioned the use of the $2 \%$ cutoff adopted by various studies to determine effective response to ICS in patients with COPD, others have argued in favour of the use of absolute blood eosinophil counts in making clinically beneficial decisions for patients with COPD. ${ }^{5,38,39}$ As absolute counts are less affected by total white blood cell count. ${ }^{8}$ Vedel-Krogh et al suggested that $0.34 \times 10^{9}$ cells/L cut-off was appropriate in detecting COPD exacerbations because this cut-off was associated with increased risk of moderate and severe exacerbations in patients with COPD in population-based settings. ${ }^{5}$ The exact mechanism underlying the presumed changes in COPD-related exacerbations in patients with varying baseline blood eosinophil counts remains unclear. ${ }^{6,7}$ However, it might be due to the non-T helper2 eosinophilic inflammation in COPD, induced by the epithelial innate lymphoid cell type 2 pathways. Innate lymphoid cell type 2 has been recognised in relation to the pathogenesis in severe non-allergic eosinophilic asthma. ${ }^{40}$

\section{Strengths and limitations}

A major strength of this study was the use of data from one of the world's largest primary care databases, thereby providing a very large population-based cohort of COPD patients with eosinophil measurements. Second, we used a validated definition for an acute exacerbation of COPD, using read codes which were reported to show a $96 \%$ PPV of identifying an acute exacerbation within the CPRD. ${ }^{18}$ Nevertheless, we may have missed a considerable amount of exacerbations that may be miscoded e.g. as respiratory tract infections or pneumonia. Third, Classification of exposure to ICS and covariates time-dependently during follow-up allowed us to conduct an "on-treatment analysis", which results in less non-differential misclassification of exposure than in an 'intention to treat analysis' which ignores ICS exposure during follow-up. Fourth, we eliminated patients with a history of asthma to avoid patients with reversible airflow limitation from our study. Lastly, we had information on important confounding factors such as smoking status, BMI and other comorbidities and drug use. Despite numerous strengths, this study also had limitations. In addition to those already mentioned, there is a potential for residual confounding as we lacked information on the disease severity and previous exacerbations. Although the positive predictive value of identifying patients with 
COPD in the CPRD is $90 \%,{ }^{11}$ lung function data were unavailable. While we excluded asthma patients, it was impossible to rule out the inclusion of patients with reversible airflow limitation. ${ }^{41}$ We lacked information on cause-specific mortality; as such we could not perform detailed analysis on the cause of death. Eosinophil counts are not been routinely collected as part of diagnosis of COPD patients, and thus, the patient population in this study may not be representative of all COPD patients. Moreover, this could have masked a true association between eosinophil counts and various outcomes. ICS inhalers are known to last for 25 to 100 days depending on the active ingredient and the dose prescribed by the GP, ${ }^{42}$ this might have led to non-differential misclassification of ICS exposure, masking the true effect (bias towards the null) leading to insignificant findings. Without this potential distortion, the risk of acute exacerbations or hospitalisation/AE visits might have been lower for patients with elevated blood eosinophil counts. However, we detected a significant risk of all-cause mortality irrespective of blood eosinophil counts, we do not believe that our results are influenced by the potential of a non-differential misclassification.

In conclusion, among COPD patients, we did not find a reduced risk of COPD-related acute exacerbations or hospitalisations/AE visits among patients with blood eosinophilia in COPD patients using ICS. However, all-cause mortality was reduced among current ICS users with blood eosinophilia compared to current ICS users with low relative blood eosinophil count. However, this effect could not be detected with the absolute eosinophil counts. There is an increasing body of evidence linking blood eosinophil counts to clinically relevant outcomes in patients with COPD. As such, these findings are potentially important and require further evaluation in prospective studies.

\section{Conflict of interest}

The authors declare no conflict of interest. 


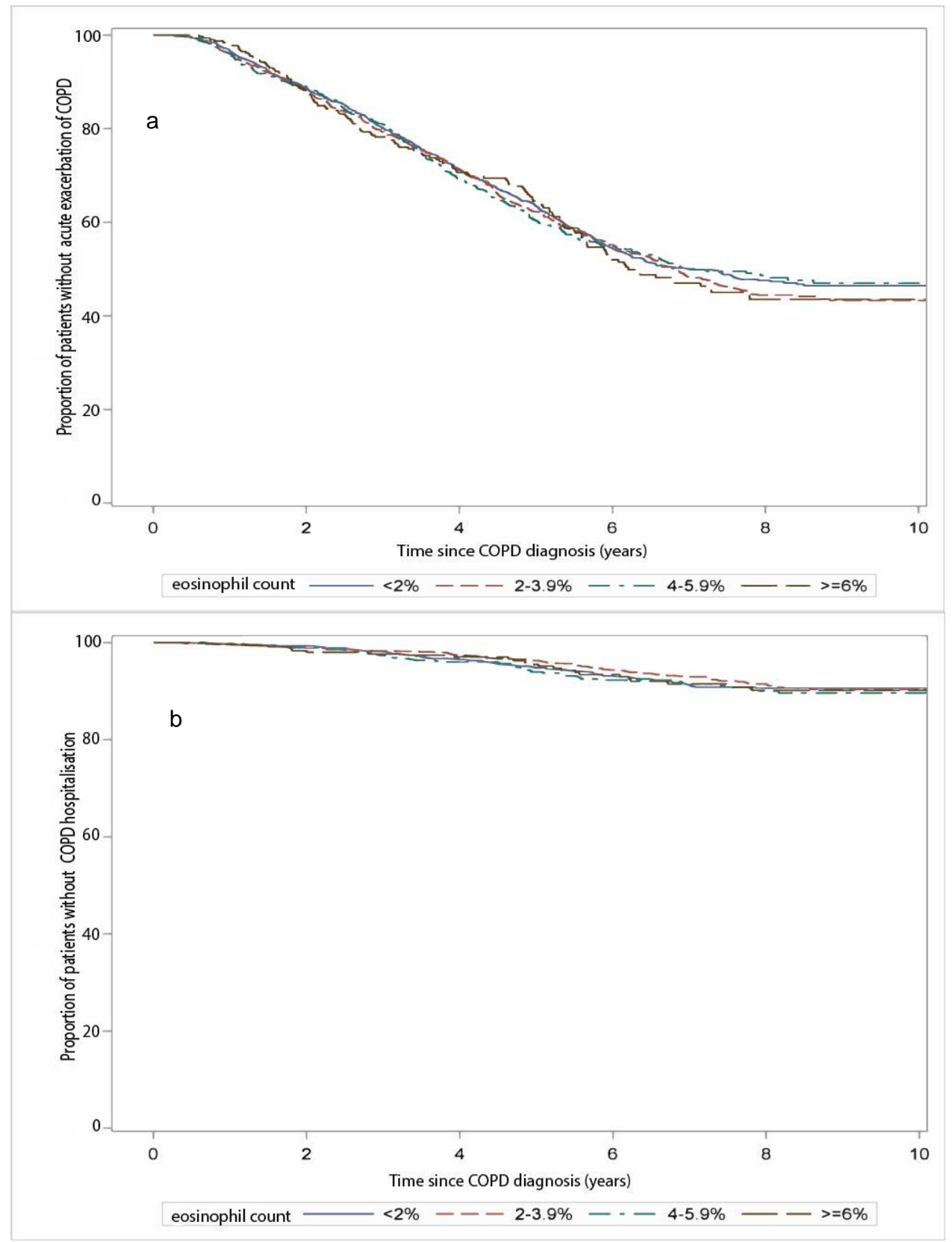




\section{Chapter 5}

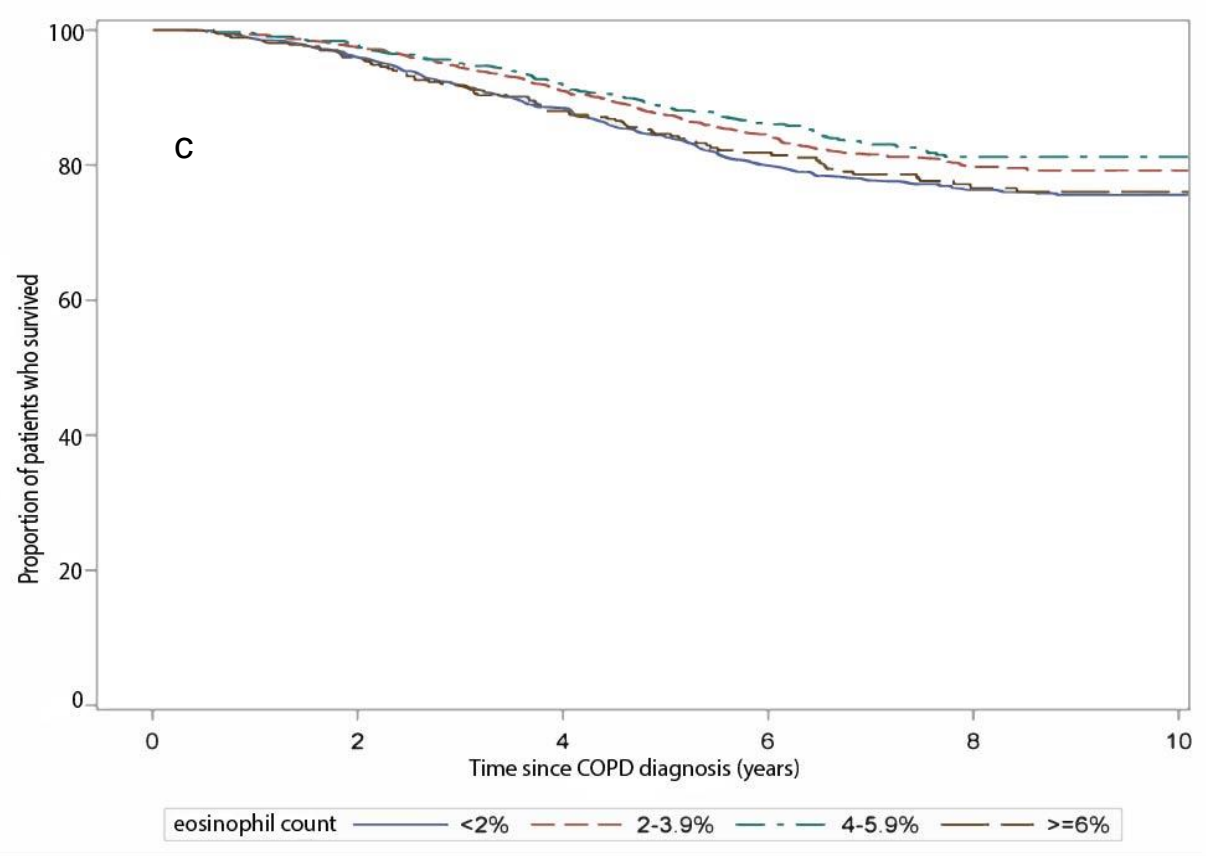

Figure 5.2. Kaplan Meier curve showing a) Proportion of patients without exacerbations with current ICS users stratified by blood eosinophil counts. b) Proportion of patients without COPD hospitalisations / accident and emergency visits among current ICS users stratified by blood eosinophil counts. c) Proportion of patients who survived among current ICS users stratified by relative blood eosinophil counts. 


\section{References}

1. Vogelmeier CF, Criner GJ, Martinez FJ, et al. Global Strategy for the Diagnosis, Management, and Prevention of Chronic Obstructive Lung Disease 2017 Report. GOLD Executive Summary. Am J Respir Crit Care Med. 2017;195(5):557-582.

2. Calverley PMA, Anderson JA, Celli B, et al. Salmeterol and fluticasone propionate and survival in chronic obstructive pulmonary disease. $N$ Engl J Med. 2007;356(8):775-789.

3. Wedzicha JA, Seemungal TA. COPD exacerbations: defining their cause and prevention.

Lancet. 2007;370(9589):786-796.

4. Kew KM, Seniukovich A. Inhaled steroids and risk of pneumonia for chronic obstructive pulmonary disease. Cochrane Database Syst Rev. 2014;3:CD010115.

5. Vedel-Krogh S, Nielsen SF, Lange P, et al. Blood Eosinophils and Exacerbations in COPD: the Copenhagen General Population Study. Am J Respir Crit Care Med. 2015:rccm.201509-18690C.

6. Pascoe S, Locantore N, Dransfield MT, et al. Blood eosinophil counts as markers of response to inhaled corticosteroids in COPD? -Authors' reply. Lancet Respir Med. 2015;3(8):e27.

7. Watz $\mathrm{H}$, Tetzlaff $\mathrm{K}$, Wouters EFM, et al. Blood eosinophil count and exacerbations in severe chronic obstructive pulmonary disease after withdrawal of inhaled corticosteroids: A post-hoc analysis of the WISDOM trial. Lancet Respir Med. 2016;4(5):390-398.

8. Roche N, Chapman KR, Vogelmeier $\mathrm{CF}$, et al. Blood Eosinophils and Response to Maintenance COPD Treatment: Data from the FLAME Trial. Am J Respir Crit Care Med. March 2017;195(9):1189-1197.

9. Calverley PMA, Tetzlaff K, Vogelmeier $\mathrm{C}$, et al. Eosinophilia, Frequent Exacerbations, and Steroid Response in Chronic Obstructive Pulmonary Disease. Am J Respir Crit Care Med. 2017; 196(9):1219-1221.

10. Price D, Wilson AM, Chisholm A, et al. Predicting frequent asthma exacerbations using blood eosinophil count and other patient data routinely available in clinical practice. J Asthma Allergy. 2016;9:1-12.

11. Quint JK, Müllerova H, DiSantostefano
$\mathrm{RL}$, et al. Validation of chronic obstructive pulmonary disease recording in the Clinical Practice Research Datalink (CPRD-GOLD). BMJ Open . 2014;4(7)

12. Herrett E, Gallagher AM, Bhaskaran K, et al. Data Resource Profile: Clinical Practice Research Datalink (CPRD). Int J Epidemiol. 2015;44(3):827-836.

13. Taggar JS, Coleman T, Lewis S, et al. The impact of the Quality and Outcomes Framework (QOF) on the recording of smoking targets in primary care medical records: cross-sectional analyses from The Health Improvement Network (THIN) database. BMC Public Health. 2012;12(1):1-11.

14. Rothnie KJ, Müllerová H, Hurst JR, et al. Validation of the recording of acute exacerbations of COPD in UK primary care electronic healthcare records. PLoS One. 2016;11(3).

15. Barakat MF, McDonald HI, Collier TJ, et al. Acute kidney injury in stable COPD and at exacerbation. Int J Chron Obstruct Pulmon Dis. 2015;10(1):20672077.

16. Mullerova $H$, Shukla A, Hawkins A, et al. Risk factors for acute exacerbations of COPD in a primary care population: a retrospective observational cohort study. BMJ Open. 2014;4(12):e006171.

17. Wurst KE, Shukla A, Muellerova $H$, Davis KJ. Respiratory pharmacotherapy use in patients newly diagnosed with chronic obstructive pulmonary disease in a primary care setting in the UK: a retrospective cohort study. COPD. 2014;11(5):521530.

18. Rothnie KJ, Müllerová H, Hurst JR, et al. Validation of the recording of acute exacerbations of COPD in UK primary care electronic healthcare records. PLoS One. 2016;11(3).

19. Oshagbemi OA, Burden AM, Braeken DCW, et al. Stability of blood eosinophils in patients with chronic obstructive pulmonary disease and in control subjects, and the impact of sex, age, smoking, and baseline counts. Am J Respir Crit Care Med. 2017;195(10).

20. Landis SH, Suruki R, Hilton E, et al. Stability of Blood Eosinophil Count in Patients with COPD in the UK Clinical Practice Research Datalink. COPD $J$ Chronic Obstr Pulm Dis. 
2017;14(4):382-388.

21. European Medicines Agency. The European Network of Centres for Pharmacoepidemiology and Pharmacovigilance ( ENCePP ) Guide on Methodological Standards in Pharmacoepidemiology ( Revision 4 ). 2015;44(June):1-77.

22. Cavaillès $A$, Brinchault-Rabin $G$ Dixmier A, et al. Comorbidities of COPD. Eur Respir Rev. 2013;22(130):454-475.

23. Chatila WM, Thomashow BM, Minai $\mathrm{OA}$, et al.Comorbidities in chronic obstructive pulmonary disease. Proc Am Thorac Soc. 2008;5(4):549-555.

24. Dal Negro RW, Bonadiman L, Turco P. Prevalence of different comorbidities in COPD patients by gender and GOLD stage. Multidiscip Respir Med. 2015;10(1):24.

25. Franssen FME, Rochester CL. Comorbidities in patients with COPD and pulmonary rehabilitation: Do they matter? Eur Respir Rev. 2014;23(131):131-141.

26. Divo M, Cote $\mathrm{C}$, De Torres JP, et al. Comorbidities and risk of mortality in patients with chronic obstructive pulmonary disease. Am J Respir Crit Care Med. 2012;186(2):155-161.

27. de Melo MN, Ernst P, Suissa S Inhaled corticosteroids and the risk of a first exacerbation in COPD patients. Eur Respir J. 2004;23(5):692-697.

28. Ernst P, Gonzalez A V, Brassard P, Suissa $S$. Inhaled corticosteroid use in chronic obstructive pulmonary disease and the risk of hospitalization for pneumonia. Am J Respir Crit Care Med 2007;176(2):162-166.

29. Hurst JR, Vestbo J, Anzueto A, et al. Susceptibility to exacerbation in chronic obstructive pulmonary disease. $N$ Engl J Med. 2010;363(12):11281138.

30. Morjaria JB, Rigby A, Morice $\mathrm{AH}$. Inhaled Corticosteroid use and the Risk of Pneumonia and COPD Exacerbations in the UPLIFT Study. Lung. 2017;195(3):281-288.

31. Bafadhel M, McKenna S, Terry S, et al. Acute exacerbations of chronic obstructive pulmonary disease: Identification of biologic clusters and their biomarkers. Am J Respir Crit Care Med. 2011;184(6):662-671.

32. Singh D, Kolsum U, Brightling CE, et al. Eosinophilic inflammation in COPD: prevalence and clinical characteristics. Eur Respir J. 2014; 44(6):1697-700.

33. Groenke L, Disse B. Blood eosinophil counts as markers of response to inhaled corticosteroids in COPD? Lancet Respir Med. 2015;3(8):e26.

34. Barnes NC, Sharma R, Lettis $S$, et al. Blood eosinophils as a marker of response to inhaled corticosteroids in COPD. Eur Respir J. 2016:1374-1382.

35. Pavord ID, Agusti A. Blood eosinophil count: a biomarker of an important treatable trait in patients with airway disease. Eur Respir J. 2016;47(5):1299 LP-1303.

36. Zysman M, Burgel PR, Paillasseur JL, et al. Relationship between blood eosinophil count (Eos), clinical characteristics and mortality of patients with COPD. Eur Respir J. 2016;48(suppl 60).

37. Marin Trigo JM, Martinez M, Cubero $P$, et al. Blood eosinophils and outcomes in COPD. Eur Respir J. 2016;48(suppl 60).

38. Pavord ID, Lettis S, Locantore N, et al. Blood eosinophils and inhaled corticosteroid/long-acting $\beta-2$ agonist efficacy in COPD. Thorax. 2016;71(2):118-125.

39. Iyer AS, Dransfield MT. Serum eosinophils as a COPD biomarker: ready for prime time? Lancet Respir Med. 2016;4(5):341-343.

40. Cheng S-L, Lin C-H. Effectiveness using higher inhaled corticosteroid dosage in patients with COPD by different blood eosinophilic counts. Int $J$ Chron Obstruct Pulmon Dis. 2016;11(1):2341-2348.

41. Gorska K, Krenke R, Korczynski P, et al. Eosinophilic airway inflammation in chronic obstructive pulmonary disease and asthma. $J$ Physiol Pharmacol. 2008;59 Suppl 6:261-270.

42. NHS. Inhaler Repeat Prescriptions. http://www.neneccg.nhs.uk/resources/u ploads/files/Inhaler-Repeat-

Prescriptions Patient information leaflet.pdf. Published 2002. Accessed January 4, 2017. 




\section{Blood eosinophil counts, withdrawal of inhaled corticosteroids and risk of COPD \\ exacerbations and mortality in the \\ Clinical Practice Research Datalink (CPRD)}

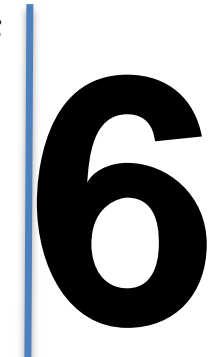

COPD J Chronic Obstr Pulm Dis 2019.23:1-8

Olorunfemi A. Oshagbemi

Frits M.E. Franssen

Suzanne van Kraaij Dionne C.W. Braeken

Henskens Yvonne

Emiel F.M. Wouters Anke-Hilse Maitland-van der Zee Johanna H.M. Driessen Frank de Vries

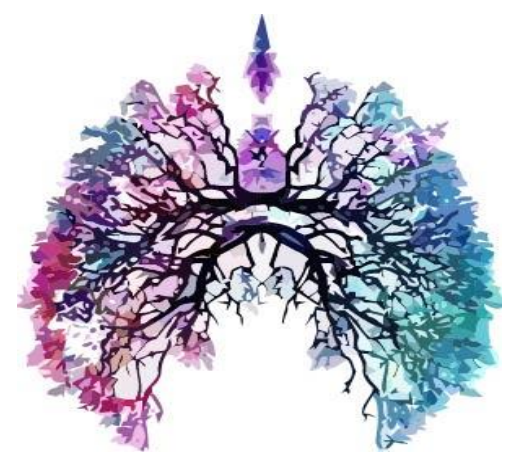




\section{ABSTRACT}

Background: Although recently introduced in the pharmacological treatment algorithm of chronic obstructive pulmonary disease (COPD), there is a need for more data supporting the use of blood eosinophil counts as a biomarker to guide inhaled corticosteroids (ICS) therapy. The aim of this study was to evaluate the risk of moderate and/or severe exacerbations and all-cause mortality in a large primary care population after withdrawal of ICS compared to continued users stratified by elevated blood eosinophil counts.

Methods: In this population-based cohort study, we used data from the Clinical Practice Research Datalink (CPRD) in the United Kingdom. We included subjects' age 40 or more who had a diagnosis of COPD. We excluded subjects with a history of asthma, pulmonary fibrosis, cardiac arrhythmia and bronchiectasis, COPD exacerbations occurring within 6 weeks prior to index date, or with myocardial infarction within 3 months prior to index date. Continuous users were subjects who received their most recent ICS prescription within 3 months before the start of an interval. ICS withdrawals were those who discontinued ICS for more than 3 months. We evaluated the risk of moderate and/or severe exacerbations and all-cause mortality among subjects with various blood eosinophil thresholds who withdrew from ICS compared to continuous ICS users with elevated blood eosinophil levels using Cox regression analysis adjusted for potential confounders.

Results: We identified 48,157 subjects diagnosed with COPD between 1 January 2005 to 31 January 2014. Withdrawal of ICS was not associated with an increased risk of moderate-to-severe exacerbations among subjects with absolute blood eosinophil counts $\geq 0.34 \times 10^{9}$ cells/L (adjusted hazard ratio [adj. HR] 0.72; 95\% confidence interval $[\mathrm{Cl}] 0.63-0.81$ ) or relative counts $\geq 4.0 \%$ (adj.HR $0.72 ; 95 \% \mathrm{Cl}$ : 0.66-0.78). Similarly, withdrawal of ICS was not associated with an increased risk of severe exacerbations among subjects with absolute blood eosinophil $\geq 0.34 \times 10^{9}$ cells/L (adj.HR 0.82; 95\% Cl: $0.61-1.10$ ) or relative blood eosinophil counts $\geq 4.0 \%$ (adj.HR $0.80 ; 95 \% \mathrm{Cl}$ : 0.61-1.04). No increased risk of all-cause mortality was observed among subjects who withdrew from ICS irrespective of elevated absolute or relative blood eosinophil counts.

Interpretation: In a real-world primary care population, we did not observe an increased risk of moderate and/or severe COPD exacerbations or all-cause mortality among subjects with eosinophilia who withdrew their use of ICS. 


\section{INTRODUCTION}

Chronic obstructive pulmonary disease (COPD) is a major cause of morbidity and mortality worldwide and is defined by the presence of chronic respiratory symptoms and persistent airflow limitation. Exacerbations play a central role in the pathophysiology of COPD as they are related to lung function decline, poor health status and increased mortality. ${ }^{2}$ While bronchodilators are the cornerstone of pharmacological management of COPD, patients with frequent exacerbations are often additionally treated with inhaled corticosteroids (ICS). ${ }^{3}$ While non-response to ICS therapy is common, ${ }^{4}$ potential side effects of ICS include fractures and pneumonia. ${ }^{3}$

Clinical data have suggested that elevated blood eosinophil counts, which is present in up to $40 \%$ of COPD patients, ${ }^{5}$ is a promising biomarker of response to ICS. ${ }^{6-9}$ Eosinophilic airway inflammation has been associated with an increased risk of exacerbations, and patients with eosinophilic inflammation responded better to ICS therapy than non-eosinophilic patients. ${ }^{6,10}$ The role of eosinophils in guiding ICS therapy is a growing area of research. Pascoe and colleagues, ${ }^{6}$ performed a post-hoc analysis of data and found that across all doses of ICS, fluticasone furoate and vilanterol reduced exacerbations by $29 \%$ compared with vilanterol alone in patients with eosinophil counts $\geq 2 \%$, and by $10 \%$ in patients with eosinophil counts $<2 \%$. Analysis of data from the Withdrawal of Inhaled Steroids during Optimized Bronchodilator Management (WISDOM) trial showed a reduction of the rate of moderate and severe exacerbations in patients with relative eosinophil counts of $4 \%$ or more, or absolute eosinophil counts of 300 cells $/ \mu \mathrm{L}$ or higher when ICS was continued compared to patients with the same eosinophil counts who tapered off ICS use. Therefore, it has been suggested that withdrawal of ICS in patients with eosinophil counts $\geq 4 \%$ and a history of exacerbations may increase the risk of COPD exacerbations. ${ }^{7}$ Although the Global Initiative for Obstructive Lung Disease (GOLD) recently introduced blood eosinophils in the pharmacological treatment algorithm of the disease, ${ }^{11}$ long-term effects of blood eosinophil-guided ICS withdrawal are currently unexplored and data in patients treated in real-life clinical setting are scarce. ${ }^{12}$ In this study, we use the word "eosinophilia" to refer to elevated blood eosinophil count based on our defined thresholds.

Therefore, the aim of this study was to evaluate the risk of moderate and/or severe exacerbations and all-cause mortality in a large primary care population in the United Kingdom (UK) after withdrawal of ICS compared to continued use of ICS among COPD subjects stratified by elevated relative or absolute eosinophil counts. A priori, we hypothesized that ICS withdrawal is associated with increased risk of exacerbations and mortality in subjects with blood eosinophilia. 


\section{METHODS}

\section{Data source}

This study was conducted with data obtained from the Clinical Practice Research Datalink (CPRD), providing detailed information on drug prescriptions, clinical events, demographics, specialist referrals, hospital admissions, and electronic lab link data of subjects from 674 general practices, who are representative for $7 \%$ of the total British population. $^{13,14}$ Data collection started on 1 January 2005, corresponding to the introduction of the Quality and Outcomes Framework (QOF) in April 2004, which improved routine recording of various diseases, including COPD. ${ }^{15}$ Routinely collected historical data was available, dating back to 1987. Previous studies with the CPRD have shown a high level of validity of recording of COPD, ${ }^{13}$ and COPD exacerbations. ${ }^{16}$ The independent scientific advisory committee (ISAC) for Medicines and Healthcare products Regulatory Authority (MHRA) database research approved the study protocol (No: 18_036R).

\section{Study population}

We selected subjects aged 40 years and older with a diagnosis of COPD recorded by a read code during valid data collection (1 January 2005 to 31 January 2014). Subjects were followed from the date of COPD diagnosis (index date) until their dates of transfer out of the database, the end of the study period (31 January 2014), death, or until the outcome of interest occurred, whichever occurred first. Only subjects with at least one blood eosinophil measurement were included. We excluded subjects with a history of asthma, pulmonary fibrosis, cardiac arrhythmia and bronchiectasis, COPD exacerbations occurring within 6 weeks prior to index date, or with a myocardial infarction within 3 months prior to index date.

\section{Outcomes and Exposure}

The primary outcome of interest was moderate-to-severe exacerbations of COPD. The secondary outcomes included severe exacerbations and all-cause mortality. Details about operational definitions of moderate-to-severe exacerbations and severe exacerbations of COPD using the clinical and referral files ${ }^{17}$ are listed in the supplementary Table S.6.1. Exposure to ICS was determined time-dependently during follow-up. Each patient's follow-up time was divided into fixed intervals of 90 days, starting at index date. Prior to the start of each interval, ICS exposure was determined based on the most recent date ICS prescription, and classified as current, past or never use (subjects without ICS prescriptions). For this study, current ICS users were defined as continuous users; these were subjects who received their most recent ICS prescription within 3 months before the start of an interval. Past users were those who withdrew from ICS for more than 3 months. While in the Study to Understand the Safety and Efficacy of ICS Withdrawal from Triple Therapy in COPD (SUNSET) trial ICS withdrawal effects were seen after 4 weeks, the early effects were 
comparable with the longer-term effects, suggesting that a different time interval, for example, 1 month versus the current 3 months period, would not result in different results regarding these outcomes. ${ }^{18}$ Moreover, as exacerbations and mortality were the primary outcomes in our study, we believe that discontinuation of ICS beyond 3 months is more appropriate. Also in the SUNSET trial, exacerbations were evaluated after 26 weeks. This threshold ( 3 months) has be found to be robust in evaluating the risk of exacerbations in patients withdrawn from ICS use. ${ }^{7,9}$ During follow-up subjects could move between different exposure categories. Continuous ICS users and those who had withdrawn ICS use were stratified by absolute eosinophil count (using $0.34 \mathrm{x}$ $10^{9}$ cells/L as a cut-off value) or relative eosinophil counts (using $4 \%$ as a cut-off value). ${ }^{7}$

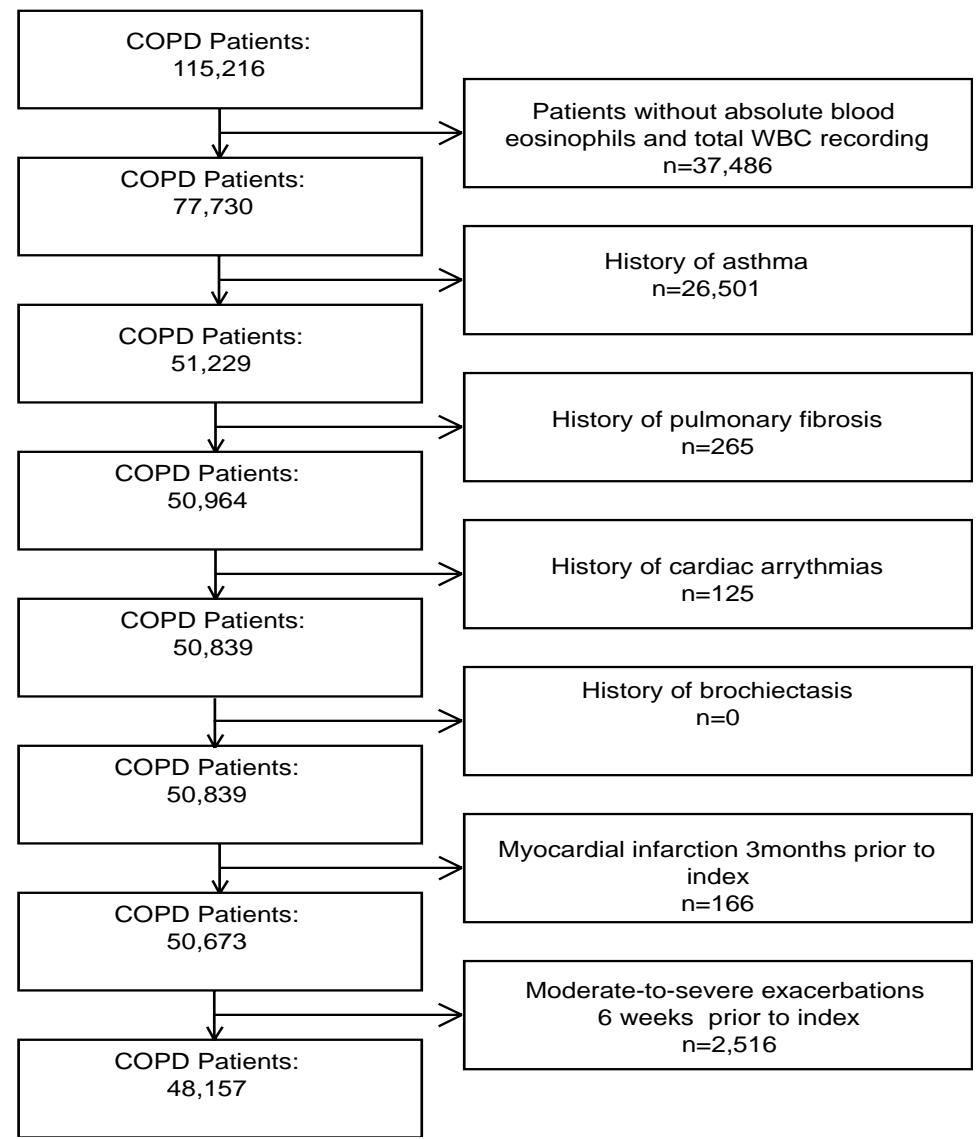

Figure 6.1. Flow chart showing the selection of eligible patients. 


\section{Covariates}

Potential confounders were assessed time-dependently with the exception of gender, smoking status, alcohol use, and body mass index, which were determined at baseline. The following covariates were considered as potential confounders, and identified at the start of each interval: a history of congestive heart failure, ischemic heart disease, anxiety, chronic liver disease, cancer excluding non-melanoma skin cancer, stroke, rheumatoid arthritis, diabetes mellitus, hypertension, inflammatory bowel disease, solid organ transplant, atopic dermatitis, renal dialysis, human immunodeficiency virus or osteoporosis. In addition, the use of the following drugs within 6 months prior to the start of an interval were considered as potential confounders: antihistamines, proton pump inhibitors, antipsychotics, or antidepressants. ${ }^{19-22}$ We statistically adjusted our analyses for proxy indicators of the severity of obstructive airway disease, as previously defined as the use of short- and long-acting beta-agonists, short- and long-acting anti-muscarinic agents, xanthine derivatives or oral corticosteroids. ${ }^{23,24}$

\section{Statistical analysis}

We evaluated the risk of moderate-to-severe exacerbations, severe exacerbations and all-cause mortality among subjects with elevated eosinophil counts who withdrew from ICS versus continuous ICS users with elevated blood eosinophil counts using Cox regression analysis SAS 9.4 (SAS Institute, Cary, NC). The difference between each blood eosinophil count stratum was tested using Wald's test. To avoid immortal time bias, never ICS users were incorporated into the statistical model. We assessed the presence of risk factors by reviewing subjects' records prior to each 90-day interval. Our initial analysis was adjusted for age and sex. All potential confounders were tested and adjusted for in the final model if they changed the beta-coefficient for continuous ICS exposure by at least $5 \%$ or when consensus about inclusion existed within the team of researchers, supported by clinical evidence from literature, or both.

\section{Sensitivity analyses}

Two sensitivity analyses were conducted. In the first analyses we stratified ICS users (continuous use and withdrawal groups) by absolute eosinophil count cuff-off $(0.15 \mathrm{x}$ $10^{9}$ cells $\left./ \mathrm{L}, 0.40 \times 10^{9} \mathrm{cells} / \mathrm{L}\right)$ and relative eosinophil cut-off $(2.0 \% \text { or } 6.0 \%)^{7}$ (See supplementary Table S.6.2-S.6.7). Secondly, for moderate-to-severe exacerbations as an outcome, we censored subjects on any hospitalisations/AE visit unrelated to COPD for absolute eosinophil count or relative eosinophil counts cut-off defined in our primary analysis (Table 6.5). 


\section{RESULTS}

213,561 subjects with COPD were identified, of whom 48,157 met the inclusion criteria (Figure 6.1). Table 6.1 shows the baseline characteristics of the COPD cohort, which consisted of $46 \%$ females, with a mean age of $68.4 \pm 10.9$ years. Most subjects were current $(43 \%)$ or former smokers $(47 \%)$. At baseline, elevated blood eosinophil counts (defined as absolute blood eosinophil counts $\geq 0.34 \times 10^{9}$ cells/L) were present in $18 \%(n=8,671)$ of all subjects. The overall population was either overweight $(32 \%)$ or obese (34\%) and $12 \%$ suffered from diabetes mellitus. About $28 \%$ had been prescribed any ICS (alone or in fixed combinations) at baseline.

Table 6.1. Baseline characteristics of COPD patients.

\begin{tabular}{|c|c|c|c|c|c|c|}
\hline & \multirow[b]{2}{*}{$\begin{array}{c}\text { Total } \\
\mathrm{n}=48,157\end{array}$} & \multirow[b]{2}{*}{$\%$} & \multicolumn{4}{|c|}{ Blood eosinophil counts } \\
\hline & & & $\begin{array}{c}<0.34 \times 10^{9} \text { cells } / L \\
n=39,486\end{array}$ & $\%$ & $\begin{array}{c}\geq 0.34 \times 10^{9} \text { cells } / L \\
n=8,671\end{array}$ & $\%$ \\
\hline Females & 22,081 & 45.9 & 19,042 & 48.2 & 3,039 & 35.0 \\
\hline Mean age (years, SD) & 68.4 & 10.9 & 68.3 & 10.9 & 68.6 & 10.8 \\
\hline \multicolumn{7}{|l|}{ Age category (years) } \\
\hline $40-59$ & 10,175 & 21.1 & 8,406 & 21.3 & 1,769 & 20.4 \\
\hline $60-79$ & 29,942 & 62.2 & 2,4481 & 62.0 & 5,461 & 63.0 \\
\hline $80+$ & 8,040 & 16.7 & 6,599 & 16.7 & 1,441 & 16.6 \\
\hline \multicolumn{7}{|l|}{$\mathrm{BMl}$ at index date $\left(\mathrm{kg} / \mathrm{m}^{2}\right)$} \\
\hline Underweight $\left(\mathrm{BMI}<18.5 \mathrm{~kg} / \mathrm{m}^{2}\right)$ & 2,418 & 5.0 & 2,068 & 5.2 & 350 & 4.0 \\
\hline Normal weight (BMI $18.5-24.9 \mathrm{~kg} / \mathrm{m}^{2}$ ) & 16,225 & 33.7 & 13,414 & 34.0 & 2,811 & 32.4 \\
\hline Overweight (BMI $\left.25.0-30.0 \mathrm{~kg} / \mathrm{m}^{2}\right)$ & 15,503 & 32.2 & 12,583 & 31.9 & 2,920 & 33.7 \\
\hline Obese $\left(\mathrm{BMI}>30.0 \mathrm{~kg} / \mathrm{m}^{<}\right)$ & 12,696 & 26.4 & 10,359 & 26.2 & 2,337 & 27.0 \\
\hline Missing BMI & 1,315 & 2.7 & 1,062 & 2.7 & 253 & 2.9 \\
\hline \multicolumn{7}{|l|}{ Smoking status } \\
\hline Never & 4,998 & 10.4 & 4,114 & 10.4 & 884 & 10.2 \\
\hline Current & 20,528 & 42.6 & 16,922 & 42.9 & 3,606 & 41.6 \\
\hline Former & 22,585 & 46.9 & 18,411 & 46.6 & 4,174 & 48.1 \\
\hline Missing & 46 & 0.1 & 39 & 0.1 & 7 & 0.1 \\
\hline \multicolumn{7}{|l|}{ Drug use (in the past 6 months) } \\
\hline SABAs & 27,091 & 56.3 & 22,022 & 55.8 & 5,069 & 58.5 \\
\hline LABAs & 4,297 & 8.9 & 3,459 & 8.8 & 838 & 9.7 \\
\hline SAMAs & 4,004 & 8.3 & 3,262 & 8.3 & 742 & 8.6 \\
\hline LAMAs & 8,563 & 17.8 & 7,041 & 17.8 & 1,522 & 17.6 \\
\hline ICS & 13,441 & 27.9 & 10,972 & 27.8 & 2,469 & 28.5 \\
\hline Xanthine derivatives & 359 & 0.7 & 281 & 0.7 & 78 & 0.9 \\
\hline Antipsychotics & 555 & 1.2 & 463 & 1.2 & 92 & 1.1 \\
\hline \multicolumn{7}{|l|}{ History of co-morbidities } \\
\hline Cardiovascular disease & 10,196 & 21.2 & 8,253 & 20.9 & 1,943 & 22.4 \\
\hline Diabetes Mellitus & 5,945 & 12.3 & 4,716 & 11.9 & 1,229 & 14.2 \\
\hline Anxiety & 7,142 & 14.8 & 5,974 & 15.1 & 1,150 & 13.3 \\
\hline Osteoporosis & 2,951 & 6.1 & 2,512 & 6.4 & 439 & 5.1 \\
\hline $\begin{array}{l}\text { Any cancer (except non-melanoma } \\
\text { skin cancer) }\end{array}$ & 7,196 & 14.9 & 5,935 & 15.0 & 1,261 & 14.5 \\
\hline Chronic liver disease & 147 & 0.3 & 118 & 0.3 & 29 & 0.3 \\
\hline
\end{tabular}

Abbreviations: Abbreviations: SD, standard deviation; COPD, chronic obstructive pulmonary disease; BMI, body mass index; SABAs, short-acting beta-2 agonists; LABAs, long-acting beta-2 agonists; SAMAs, short-acting muscarinic antagonists; LAMAs, long-acting muscarinic antagonists; ICS, Inhaled corticosteroids.

\section{Moderate-to-severe exacerbations}

Table 6.2 shows that among COPD subjects with an elevated blood eosinophil count, withdrawal of ICS was not associated with an increased risk of moderate-to-severe exacerbations as compared to continuous ICS users, yielding adjusted hazard ratios [adj. HR] of 0.72; 95\% confidence interval [Cl] 0.63-0.81 (eosinophilia defined by absolute values) and $0.73 ; 95 \% \mathrm{Cl}: 0.66-0.82$ (eosinophilia defined by relative values). We found a decreased risk of moderate-to-severe exacerbations with low 
relative or absolute blood eosinophil counts among patients withdrawn from ICS. Tables S.6.2 and S.6.5 show that these results were not considerably different when we used different absolute or relative threshold values to define eosinophilia among subjects who withdrew from ICS. Higher absolute cut-off of $\geq 0.40 \times 10^{9} \mathrm{cells} / \mathrm{L}$ yielded a fully adj. HR of $0.70 ; 95 \% \mathrm{Cl}: 0.62-0.80$ for the risk of moderate-to-severe exacerbations, while a lower cut-off value $\geq 0.15 \times 10^{9}$ cells/L showed (adj.HR 0.74 ; $95 \% \mathrm{Cl}: 0.69-0.79)$. Results were not substantially different for higher ( $\geq 6 \%$ ) or lower $(\geq 2 \%)$ thresholds to define relative eosinophilia.

Table 6.2. Risk of moderate-to-severe exacerbations with ICS use stratified by absolute and relative eosinophil counts among COPD patients.

\begin{tabular}{|c|c|c|c|c|}
\hline & $\begin{array}{l}\text { Moderate-to-severe } \\
\qquad \mathrm{n}=6,767^{\mathrm{c}}\end{array}$ & $\begin{array}{c}\text { IR } \\
(/ 1000 \mathrm{PY})\end{array}$ & $\begin{array}{c}\text { Age and gender adjusted } \\
\mathrm{HR} \\
(95 \% \mathrm{Cl})\end{array}$ & $\begin{array}{l}\text { Adjusted HR } \\
\qquad(95 \% \mathrm{Cl})^{\mathrm{a}}\end{array}$ \\
\hline \multicolumn{5}{|c|}{ Absolute eosinophil counts } \\
\hline \multicolumn{5}{|c|}{ Withdrawal from ICS } \\
\hline$<0.34 \times 10^{y} \mathrm{cells} / \mathrm{L}$ & 1,625 & 49.2 & $0.55(0.51-0.60)^{\mathrm{D}}$ & $0.72(0.66-0.78)^{\mathrm{D}}$ \\
\hline$\geq 0.34 \times 10^{y} \mathrm{cells} / \mathrm{L}$ & 366 & 49.5 & $0.57(0.50-0.64)$ & $0.72(0.63-0.81)$ \\
\hline \multicolumn{5}{|l|}{ Continuous ICS users } \\
\hline$<0.34 \times 10^{y} \mathrm{cells} / \mathrm{L}$ & 3,85 & 85.4 & $0.96(0.89-1.03)$ & $0.97(0.91-1.05)$ \\
\hline$\geq 0.34 \times 10^{9} \mathrm{cells} / \mathrm{L}$ & 926 & 87.7 & Reference & Reference \\
\hline \multicolumn{5}{|c|}{ Relative eosinophil counts } \\
\hline \multicolumn{5}{|c|}{ Withdrawal from ICS } \\
\hline$<4.0 \%$ & 1,511 & 49.8 & $0.60(0.55-0.65)^{b}$ & $0.74(0.68-0.80)^{b}$ \\
\hline$\geq 4.0 \%$ & 480 & 47.5 & $0.58(0.52-0.64)$ & $0.73(0.66-0.82)$ \\
\hline \multicolumn{5}{|l|}{ Continuous ICS users } \\
\hline$<4.0 \%$ & 3,652 & 86.9 & $1.04(0.97-1.11)$ & $1.01(0.94-1.08)$ \\
\hline$\geq 4.0 \%$ & 1,124 & 82.2 & Reference & Reference \\
\hline
\end{tabular}

Abbreviations: ICS, Inhaled corticosteroids; IR, incidence rate; HR, hazard ratio; Cl, confidence interval; PY, person-years.

${ }^{a}$ Adjusted for age, gender, smoking status, body mass index, alcohol use, history of heart failure, chronic liver disease, ischemic heart disease, use of antipsychotics, antidepressants, atopic dermatitis, use of oxygen, short-acting beta-2 agonists, long-acting beta-2 agonists, short-acting muscarinic antagonists, long-acting muscarinic antagonists, xanthine derivatives and oral corticosteroid 6 months prior to the start of an interval.

'Wald's statistics: Withdrawal of ICS with low eosinophil counts statistically significantly different $(P<0.05)$ from continuous ICS use with low eosinophil count.

${ }^{c}$ number of never ICS users with moderate-to-severe exacerbations not included.

\section{Severe exacerbations}

We found that withdrawal of ICS was not associated with an increased risk of severe exacerbations among subjects with absolute blood eosinophil $\geq 0.34 \times 10^{9}$ cells/L (adj.HR 0.82; $95 \% \mathrm{Cl}$ : 0.61-1.10) compared to continuous ICS users with elevated absolute blood eosinophil counts among patients withdrawn from ICS. For relative blood eosinophil counts $\geq 4.0 \%$ there was no significant difference in the risk of severe exacerbations (adj.HR 0.80; 95\% Cl: 0.61-1.04) compared to continuous ICS users with elevated relative blood eosinophil counts.

We found no increased risk of severe exacerbations when we used different absolute or relative threshold values to define eosinophilia. Absolute cut-off value of $\geq 0.40 \mathrm{x}$ $10^{9}$ cells/L resulted in (adj.HR 0.65; 95\% Cl: 0.48-0.89), while a lower cut-off value $\geq 0.15 \times 10^{9}$ cells/L showed (adj.HR 0.59; 95\% Cl: 0.50-0.69) Results were similar for higher $(\geq 6 \%)$ or lower $(\geq 2 \%)$ threshold values to define eosinophilia (supplementary Tables S.6.3 and S.6.6). 
Table 6.3. Risk of severe exacerbations with ICS use stratified by absolute and relative eosinophil counts among COPD patients.

\begin{tabular}{|c|c|c|c|c|}
\hline 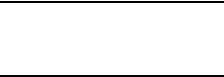 & $\begin{array}{l}\text { Severe exacerbations } \\
\qquad \mathrm{n}=1,177^{\mathrm{c}}\end{array}$ & $\begin{array}{l}\text { IR } \\
(/ 1000 \mathrm{PY})\end{array}$ & $\begin{array}{c}\text { Age and gender adjusted } \\
\mathrm{HR} \\
(95 \% \mathrm{Cl})\end{array}$ & $\begin{array}{c}\text { Adjusted } \\
\mathrm{HR} \\
(95 \% \mathrm{Cl})^{\mathrm{a}} \\
\end{array}$ \\
\hline \multicolumn{5}{|c|}{ Absolute eosinophil counts } \\
\hline \multicolumn{5}{|c|}{ Withdrawal of ICS } \\
\hline$<0.34 \times 10^{9}$ cells $/ \mathrm{L}$ & 263 & 6.9 & $0.57(0.47-0.70)^{\mathrm{b}}$ & $0.79(0.64-0.97)^{\mathrm{b}}$ \\
\hline$\geq 0.34 \times 10^{y}$ cells $/ \mathrm{L}$ & 63 & 7.4 & $0.61(0.46-0.82)$ & $0.82(0.61-1.10)$ \\
\hline \multicolumn{5}{|l|}{ Continuous ICS users } \\
\hline$<0.34 \times 10^{y}$ cells $/ \mathrm{L}$ & 690 & 12.4 & $1.02(0.86-1.21)$ & $1.03(0.87-1.23)$ \\
\hline$\geq 0.34 \times 10^{y} \mathrm{cells} / \mathrm{L}$ & 161 & 12.1 & Reference & Reference \\
\hline \multicolumn{5}{|l|}{ Relative eosinophil counts } \\
\hline \multicolumn{5}{|l|}{ Withdrawal of ICS } \\
\hline$<4.0 \%$ & 248 & 7.1 & $0.62(0.52-0.75)^{\mathrm{b}}$ & $0.82(0.67-0.99)^{\mathrm{b}}$ \\
\hline$\geq 4.0 \%$ & 78 & 6.7 & $0.59(0.45-0.77)$ & $0.80(0.61-1.04)$ \\
\hline \multicolumn{5}{|l|}{ Continuous ICS users } \\
\hline$<4.0 \%$ & 656 & 12.6 & $1.10(0.94-1.30)$ & $1.06(0.91-1.25)$ \\
\hline$\geq 4.0 \%$ & 195 & 11.4 & Reference & Reference \\
\hline \multicolumn{5}{|c|}{$\begin{array}{l}\text { Abbreviations: ICS, Inhaled corticosteroids; IR, incidence rate; HR, hazard ratio; } \mathrm{Cl} \text {, confidence interval; PY, person-years. } \\
\text { aAdjusted for age, gender, smoking status, body mass index, alcohol use, history of heart failure, chronic liver disease, diabetes } \\
\text { mellitus, ischemic heart disease, osteoporosis, use of proton-pump inhibitors, antidepressants, oxygen, antipsychotics, statins, short- } \\
\text { acting beta-2 agonists, long-acting beta-2 agonists, short-acting muscarinic antagonists, long-acting muscarinic antagonists, xanthine } \\
\text { derivatives and oral corticosteroid } 6 \text { months prior to the start of an interval. }\end{array}$} \\
\hline \multicolumn{5}{|c|}{$\begin{array}{l}\text { 'Wald's statistics: Withdrawal of ICS with low eosinophil counts statistically significantly different }(P<0.05) \text { from continuous ICS use } \\
\text { with low eosinophil count. }\end{array}$} \\
\hline
\end{tabular}

\section{All-cause mortality}

Table 6.4 shows that withdrawal of ICS was not associated with an increased risk of all-cause mortality among subjects with absolute blood eosinophil $\geq 0.34 \times 10^{9}$ cells/L (adj.HR 1.08; 95\% Cl: 0.96-1.22), compared to continuous ICS users with elevated absolute blood eosinophil counts. At relative blood eosinophil counts $\geq 4.0 \%$ there no increased risk of all-cause mortality (adj.HR $1.08 ; 95 \% \mathrm{Cl}$ : $0.97-1.21$ ) compared to continuous ICS users with elevated relative blood eosinophil counts.

Table 6.4. Risk of all-cause mortality with ICS use stratified by absolute and relative eosinophil counts among COPD patients.

\begin{tabular}{|c|c|c|c|c|}
\hline & $\begin{array}{l}\text { All-cause mortality } \\
\qquad n=6,008^{c}\end{array}$ & $\begin{array}{c}\text { IR } \\
(/ 1000 P Y)\end{array}$ & $\begin{array}{c}\text { Age and gender adjusted } \\
\mathrm{HR} \\
(95 \% \mathrm{Cl})\end{array}$ & $\begin{array}{l}\text { Adjusted } \\
\text { HR } \\
(95 \% \mathrm{Cl})^{\mathrm{a}} \\
\end{array}$ \\
\hline \multicolumn{5}{|c|}{ Absolute eosinophil counts } \\
\hline \multicolumn{5}{|c|}{ Withdrawal from ICS } \\
\hline$<0.34 \times 10^{y}$ cells $/ \mathrm{L}$ & 1,763 & 45.5 & $0.94(0.86-1.03)^{c}$ & $1.14(1.04-1.25)^{\mathrm{b}, \mathrm{c}}$ \\
\hline$\geq 0.34 \times 10^{y} \mathrm{cells} / \mathrm{L}$ & 415 & 47.4 & $0.93(0.82-1.05)$ & $1.08(0.96-1.22)$ \\
\hline \multicolumn{5}{|l|}{ Continuous ICS users } \\
\hline$<0.34 \times 10^{9} \mathrm{cells} / \mathrm{L}$ & 3,125 & 54.3 & $1.13(1.04-1.23)$ & $1.14(1.05-1.23)$ \\
\hline$\geq 0.34 \times 10^{9} \mathrm{cells} / \mathrm{L}$ & 705 & 51.3 & Reference & Reference \\
\hline \multicolumn{5}{|c|}{ Relative eosinophil counts } \\
\hline \multicolumn{5}{|c|}{ Withdrawal of ICS } \\
\hline$<4.0 \%$ & 1,676 & 47.0 & $1.08(0.99-1.17)^{\mathrm{b}, \mathrm{c}}$ & $1.25(1.15-1.36)^{\mathrm{b}}$ \\
\hline$\geq 4.0 \%$ & 502 & 42.4 & $0.91(0.81-1.01)$ & $1.08(0.97-1.21)$ \\
\hline \multicolumn{5}{|l|}{ Continuous ICS users } \\
\hline$<4.0 \%$ & 2,997 & 55.8 & $1.30(1.20-1.40)$ & $1.25(1.15-1.35)$ \\
\hline$\geq 4.0 \%$ & 833 & 47.3 & Reference & Reference \\
\hline
\end{tabular}

Abbreviations: ICS, Inhaled corticosteroids; IR, incidence rate; HR, hazard ratio; Cl, confidence interval; PY, person-years.

${ }^{a}$ Adjusted for age, gender, smoking status, body mass index, alcohol use, history of heart failure, chronic liver disease, ischemic heart disease, atopic dermatitis, diabetes mellitus, cancer, use of oxygen, statins, short-acting beta-2 agonists, long-acting beta-2 agonists, short-acting muscarinic antagonists, long-acting muscarinic antagonists, xanthine derivatives and oral corticosteroid use 6 months prior to the start of an interval.

b) Wald's statistics: Withdrawal of ICS with low eosinophil counts statistically significantly different $(P<0.05)$ from withdrawal of ICS with high eosinophil count.

'Wald's statistics: Withdrawal of ICS low eosinophil counts statistically significantly different $(P<0.05)$ from continuous ICS use with low eosinophil count.

${ }^{c}$ number of never ICS users who died not included. 
Results were not significantly different when we adopted different absolute or relative eosinophil counts (Table S.6.4 and S.6.7). Higher absolute cut-off value of $\geq 0.40 \times 10^{9}$ cells/L resulted in no increased risk of all-cause mortality (adj.HR 0.96; 95\% Cl: $0.85-$ 1.10) .

Sensitivity analysis

Table 6.5 shows the second sensitivity analyses for moderate-to-severe exacerbations, following censoring for any hospitalisations/AE visit unrelated to COPD for absolute or relative blood eosinophil counts the results was similar to Table 6.2.

\begin{tabular}{|c|c|c|c|c|}
\hline & $\begin{array}{c}\text { Moderate-to-severe } \\
\text { exacerbations } \\
n=6,027^{c}\end{array}$ & $\begin{array}{c}\mathrm{IR} \\
(/ 1000 \mathrm{PY})\end{array}$ & $\begin{array}{c}\text { Age and gender adjusted } \\
\mathrm{HR} \\
(95 \% \mathrm{Cl})\end{array}$ & $\begin{array}{c}\text { Adjusted } \\
\text { HR } \\
(95 \% \mathrm{Cl})^{\mathrm{a}} \\
\end{array}$ \\
\hline \multicolumn{5}{|c|}{ Absolute eosinophil counts } \\
\hline \multicolumn{5}{|c|}{ Withdrawal from ICS } \\
\hline$<0.34 \times 10^{9} \mathrm{cells} / \mathrm{L}$ & 1,429 & 47.8 & $0.55(0.51-0.60)^{\mathrm{b}}$ & $0.71(0.65-0.78)^{\mathrm{b}}$ \\
\hline$\geq 0.34 \times 10^{9} \mathrm{cells} / \mathrm{L}$ & 328 & 49.0 & $0.57(0.50-0.65)$ & $0.73(0.64-0.83)$ \\
\hline \multicolumn{5}{|l|}{ Continuous ICS users } \\
\hline$<0.34 \times 10^{9} \mathrm{cells} / \mathrm{L}$ & 3,44 & 83.4 & $1.09(0.30-0.96)$ & $0.98(0.91-1.06)$ \\
\hline$\geq 0.34 \times 10^{y} \mathrm{cells} / \mathrm{L}$ & 830 & 85.7 & Reference & Reference \\
\hline \multicolumn{5}{|l|}{ Relative eosinophil counts } \\
\hline \multicolumn{5}{|l|}{ Withdrawal of ICS } \\
\hline$<4.0 \%$ & 1,334 & 48.7 & $0.60(0.56-0.66)^{\mathrm{b}}$ & $0.75(0.69-0.81)^{\mathrm{b}}$ \\
\hline$\geq 4.0 \%$ & 423 & 46.1 & $0.58(0.52-0.65)$ & $0.73(0.65-0.82)$ \\
\hline \multicolumn{5}{|l|}{ Continuous ICS users } \\
\hline$<4.0 \%$ & 3,270 & 85.3 & $1.06(0.98-1.13)$ & $1.02(0.95-1.10)$ \\
\hline$\geq 4.0 \%$ & 1,000 & 79.6 & Reference & Reference \\
\hline \multicolumn{5}{|c|}{$\begin{array}{l}\text { Abbreviations: ICS, Inhaled corticosteroids; IR, incidence rate; HR, hazard ratio; CI, confidence interval; PY, person-years; A/E, } \\
\text { accident and emergency. } \\
\text { aAdjusted for age, gender, smoking status, body mass index, alcohol use, history of heart failure, chronic liver disease, ischemic heart } \\
\text { disease, use of antipsychotics, antidepressants, atopic dermatitis, oxygen, short-acting beta- } 2 \text { agonists, long-acting beta- } 2 \text { agonists, } \\
\text { short-acting muscarinic antagonists, long-acting muscarinic antagonists, xanthine derivatives and oral corticosteroid } 6 \text { months prior to } \\
\text { the start of an interval. }\end{array}$} \\
\hline \multicolumn{5}{|c|}{$\begin{array}{l}\text { 'Wald's statistics: Withdrawal of ICS with low eosinophil counts statistically significantly different }(P<0.05) \text { from continuous ICS use } \\
\text { with low eosinophil count. }\end{array}$} \\
\hline
\end{tabular}

\section{DISCUSSION}

In this study conducted in a real-world primary care population, we did not observe an increased risk of moderate and/or severe COPD exacerbations or all-cause mortality among patients with relative or absolute peripheral blood eosinophilia after withdrawal from ICS, in comparison to continuous users with blood eosinophilia. Opposite to our hypothesis, risk of exacerbations was significantly lower in patients withdrawn from ICS compared to those with continued use with blood eosinophilia. In addition, no increased mortality risk was observed in patients with blood eosinophilia withdrawn from ICS compared to continuous ICS users with blood eosinophilia.

Our results are consistent with the WISDOM trial which found no difference in the risk of exacerbations among COPD patients withdrawn from ICS therapy. ${ }^{25}$ However, a decreased risk of severe exacerbations was seen in some sub-groups in our study. More recently, in a Study to Understand Mortality and Morbidity (SUMMIT) trial, which enrolled more than 16,000 COPD patients with heightened cardiovascular risk, over three-years also found that withdrawal from ICS had no effect on the risk of 
exacerbations in all groups compared. ${ }^{26}$ Similarly, a meta-analysis of various clinical trials exploring the effects of ICS withdrawal among COPD patients without a history of asthma, found that overall the withdrawal of ICS did not significantly affect the risk of moderate-to-severe exacerbations, although they found that the withdrawal of ICS significantly impaired both Forced Expiratory Volume in $1 \mathrm{sec}\left(\mathrm{FEV}_{1}\right)$ and St George Respiratory Questionnaire (SGRQ) score. ${ }^{27}$

Only a few studies have evaluated the withdrawal of ICS and the risk of exacerbations stratified by absolute or relative blood eosinophil counts. ${ }^{78}$ In the posthoc analysis of data from the WISDOM trial, Watz et $\mathrm{al}^{7}$ reported that blood eosinophil count $\geq 4 \%$ or $\geq 300$ cells $/ \mu \mathrm{L}$ might help identify patients with greater risk of exacerbations following ICS withdrawal. Nevertheless, they found no increased risk of exacerbations following withdrawal of ICS at eosinophil counts $>6.0 \%$ consistent with our findings. ${ }^{7}$ Furthermore, it is important to note that they only enrolled patients with severe to very severe COPD, a history of exacerbations and over $70 \%$ of patients used ICS before study entry. ${ }^{7}$ COPD patients in CPRD are derived from primary practice, a population not enriched for exacerbation risk in which use of bronchodilators and ICS use are lower compared to the clinical trials. A recent UK population-based cohort study reported that ICS-LABA therapy was more effective than LAMA in patients with blood eosinophil counts $>4 \%$ or $>300$ cells $/ \mu \mathrm{L} .{ }^{28}$ In our previous work using COPD patients from the same data source, we found similar results for moderate-to-severe and severe exacerbations. However, an important difference is the fact that in our previous study only patients with prior history of ICS use were included. ${ }^{29}$ Analyses of data from the FLAME trial reported that LABA/LAMA combination was superior to LABA/ICS combination in exacerbation reduction for relative or absolute blood eosinophil threshold $(2 \%, \geq 2 \%, 3 \%,<5 \%$, and $<150$ cells $/ \mu \mathrm{L}$ subgroups), and at no threshold was LABA/ICS superior to LABA/LAMA. ${ }^{8}$ However, the SUNSET trial found that ICS withdrawal led to an increased risk of exacerbations among COPD patients with $\geq 300$ cells $/ \mu \mathrm{L} .{ }^{18}$ It is important to note, that unlike our study all patients included in the SUNSET trial were on long-term ICS regimens and were non-frequent exacerbators (i.e. patients with 0 to 1 exacerbation in the previous year). With approximately $29 \%$ of COPD patients reported to have 2 or more exacerbations 1 year prior in the UK general practice, ${ }^{30}$ it raises questions on the generalisability of their findings in a general practice setting. Furthermore, the researchers were not convinced that their study could be referred to as a "pure ICS" withdrawal study given that patients withdrew to a LABA/LAMA combination, which may not be applicable with other therapies. ${ }^{18}$

All-cause mortality is an important end-point, which is seldom assessed among COPD patients partly due to the short duration of patient follow-up in most studies. We did not find an increased risk of all-cause mortality among patients who withdrew from ICS treatment with elevated absolute or relative blood eosinophil counts in our study. There is conflicting evidence on ICS treatments and reduced mortality in COPD. Two large trials among patients exposed to a combination of a 
long-acting beta-agonist (LABA) and an inhaled corticosteroid (ICS) the reduction in mortality was not statistically significant. ${ }^{3,31}$ However, the INSPIRE trial which included severe and very severe COPD patients receiving LABA/ICS experienced fewer deaths than those receiving LAMA $^{32}$ Furthermore, Vestbo et $\mathrm{al}^{33}$ performed a stratified pooled analysis of all fatal adverse events comparing ICS-containing versus ICS-free treatments in 3 recent 52-week studies among patients with severe to very severe COPD at increased risk for exacerbations. They found no statistically significant reduction in the risk of developing a fatal event. Furthermore, they found a reduced risk of non-respiratory fatal events suggesting that therapy containing an ICS may have a direct or indirect effect on chronic diseases that is almost consistently associated with mostly severe symptomatic COPD This might be due to cardiovascular events, being less likely if the underlying COPD is more stable. ${ }^{33}$

A major strength of this study was the inclusion of patients from one of the world's largest primary care databases, thereby providing a large population-based cohort of COPD patients with eosinophil measurements followed over time. Second, in our study we used validated definitions for moderate and/or severe exacerbations of COPD, using read codes reported to have a $96 \%$ positive predictive value of identifying an acute exacerbation within the CPRD. ${ }^{16}$ Nevertheless, we may have missed considerable numbers of exacerbations, which may be miscoded e.g. as respiratory tract infections such as pneumonia. Third, time-varying classification of exposure to ICS and covariates allowed us to conduct an "on-treatment analysis", which results in less non-differential misclassification of exposure than in an intention to treat analysis' which ignores ICS exposure during follow-up as in other studies. Lastly, data on confounding factors such as smoking status, BMI, comorbidities, and drugs prescribed were available and as such these covariates were adjusted for in our models.

Despite numerous strengths, this study also had limitations. In addition to those already mentioned, there is a potential for residual confounding as we lacked information on the disease severity and exacerbation history. While we excluded asthma patients, it was impossible to rule out the inclusion of patients with reversible airflow limitations. Eosinophil counts are not routinely collected as part of diagnosis of COPD patients, they are most likely requested by the GP for a purpose and might have introduced an information bias in our study. We expect this bias to be nondifferential among COPD patients who withdrew from ICS and those who continued ICS therapy leading to bias estimates towards the null. While this might have masked the true risk of severe exacerbations among patients with blood eosinophil counts, we found significant associations irrespective of the absolute or relative blood eosinophil counts for moderate and/or severe exacerbations and mortality, suggesting that our results could not have been affected by this bias. Also, there have been concerns on the stability of blood eosinophil counts overtime, however blood eosinophil counts among COPD patients have been shown to be relatively stable over time..$^{34,35}$ Confounding by indication is a major concern in observational studies, ${ }^{23}$ because the 
reason for withdrawal or continuation of ICS is often associated with the outcome of interest. While the hospital episode statistics (HES) is known to capture most hospitalisations in the UK, a low positive predictive value of identifying COPD-related hospitalisation using read codes for hospitalisation within the CPRD linked to hospital episode statistics (HES) was observed. ${ }^{36}$ Linkage to HES will further limit our overall sample size and subsequently our ability to detect any risk this is because only $58 \%$ of practices have consented to participating in the CPRD linkage scheme. ${ }^{14}$

In conclusion, this study did not show an increased risk of moderate and/or severe COPD exacerbations or all-cause mortality among patients with blood eosinophilia who withdrew from ICS therapy.

\section{Conflict of interest}

No potential conflict of interest was reported. 


\section{References}

1. Vogelmeier CF, Criner GJ, Martinez FJ, et al. Global Strategy for the Diagnosis, Management, and Prevention of Chronic Obstructive Lung Disease 2017 Report. GOLD Executive Summary. Am J Respir Crit Care Med. 2017;195(5):557-582.

2. Wedzicha JA, Seemungal TA. COPD exacerbations: defining their cause and prevention.

Lancet. 2007;370(9589):786-796.

3. Calverley PMA, Anderson JA, Celli B, et al. Salmeterol and fluticasone propionate and survival in chronic obstructive pulmonary disease. $N$ Engl J Med. 2007;356(8):775-789.

4. Kew KM, Seniukovich A. Inhaled steroids and risk of pneumonia for chronic obstructive pulmonary disease. Cochrane Database Syst Rev. 2014;3:CD010115.

5. Vedel-Krogh S, Nielsen SF, Lange P, V et al. Blood Eosinophils and Exacerbations in COPD: the Copenhagen General Population Study. Am J Respir Crit Care Med. 2015:rccm.201509-18690C.

6. Pascoe S, Locantore N, Dransfield MT, et al. Blood eosinophil counts as markers of response to inhaled corticosteroids in COPD? -Authors' reply. Lancet Respir Med. 2015;3(8):e27.

7. Watz H, Tetzlaff K, Wouters EFM, et al. Blood eosinophil count and exacerbations in severe chronic obstructive pulmonary disease after withdrawal of inhaled corticosteroids: A post-hoc analysis of the WISDOM trial. Lancet Respir Med. 2016;4(5):390-398.

8. Roche N, Chapman KR, Vogelmeier $\mathrm{CF}$, et al. Blood Eosinophils and Response to Maintenance COPD Treatment: Data from the FLAME Trial. Am J Respir Crit Care Med. March 2017;195(9):1189-1197.

9. Calverley PMA, Tetzlaff K, Vogelmeier $\mathrm{C}$, et al. Eosinophilia, Frequent Exacerbations, and Steroid Response in Chronic Obstructive Pulmonary Disease. Am J Respir Crit Care Med. 2017; 196(9):1219-1221.

10. Price D, Rigazio A, Postma D, et al. Blood eosinophilia and the number of exacerbations in COPD patients. Eur Respir J. 2014;44(Suppl 58).

11. GOLD. Global strategy for the prevention, diagnosis and treatment of chronic obstructive pulmonary disease
(2019 Report). 2018.

https://goldcopd.org/wp-

content/uploads/2018/11/GOLD-2019v1.7-FINAL-14Nov2018-WMS.pdf.

Accessed November 15, 2018.

12. Vogelmeier C, Worth $\mathrm{H}$, Buhl R, et al. "Real-life" inhaled corticosteroid withdrawal in COPD: a subgroup analysis of DACCORD. Int $J$ Chron Obstruct Pulmon Dis. 2017;12:487494.

13. Quint JK, Müllerova H, DiSantostefano $R L$, et al. Validation of chronic obstructive pulmonary disease recording in the Clinical Practice Research Datalink (CPRD-GOLD). BMJ Open . 2014;4(7)

14. Herrett E, Gallagher AM, Bhaskaran K, et al. Data Resource Profile: Clinical Practice Research Datalink (CPRD). Int J Epidemiol. 2015;44(3):827-836.

15. Taggar JS, Coleman T, Lewis S, et al. The impact of the Quality and Outcomes Framework (QOF) on the recording of smoking targets in primary care medical records: cross-sectional analyses from The Health Improvement Network (THIN) database. BMC Public Health. 2012;12(1):1-11.

16. Rothnie KJ, Müllerová $H$, Hurst JR, et al. Validation of the recording of acute exacerbations of COPD in UK primary care electronic healthcare records. PLoS One. 2016;11(3).

17. Padmanabhan S. CPRD GOLD Data Specification.

https://www.ed.ac.uk/files/atoms/files/c prd_gold_full_data_specification.pdf.

Published 2015. Accessed May 15, 2018.

18. Chapman KR, Hurst JR, Frent S-M, et al. Long-Term Triple Therapy Deescalation

Indacaterol/Glycopyrronium in Patients with Chronic Obstructive Pulmonary Disease (SUNSET): A Randomized, Double-Blind, Triple-Dummy Clinical Trial. Am J Respir Crit Care Med. 2018;198(3):329-339.

19. Chatila WM, Thomashow BM, Minai $\mathrm{OA}$, et al. Comorbidities in chronic obstructive pulmonary disease. Proc Am Thorac Soc. 2008;5(4):549-555.

20. Dal Negro RW, Bonadiman L, Turco P. Prevalence of different comorbidities in COPD patients by gender and GOLD stage. Multidiscip Respir Med. 2015;10(1):24. 
21. Franssen FME, Rochester CL. Comorbidities in patients with COPD and pulmonary rehabilitation: Do they matter? Eur Respir Rev. 2014;23(131):131-141.

22. Divo M, Cote $\mathrm{C}$, De Torres JP, et al. Comorbidities and risk of mortality in patients with chronic obstructive pulmonary disease. Am $J$ Respir Crit Care Med. 2012;186(2):155-161.

23. de Melo MN, Ernst $P$, Suissa $S$. Inhaled corticosteroids and the risk of a first exacerbation in COPD patients. Eur Respir J. 2004;23(5):692-697.

24. Ernst P, Gonzalez A V, Brassard P, Suissa S. Inhaled corticosteroid use in chronic obstructive pulmonary disease and the risk of hospitalization for pneumonia. Am J Respir Crit Care Med. 2007;176(2):162-166.

25. Magnussen $H$, Disse B, RodriguezRoisin R, et al. Withdrawal of Inhaled Glucocorticoids and Exacerbations of COPD. $N$ Engl $J$ Med. 2014;371(14):1285-1294.

26. Vestbo J, Anderson JA, Brook RD, et al. Effect of Treatment Withdrawal on Outcomes in the SUMMIT Study. In: C41. LONG ACTING BRONCHODILATOR THERAPY IN COPD II. American Thoracic Society International Conference American Thoracic Society; 2017:A5483-A5483.

27. Calzetta L, Matera MG, Braido F, et al. Withdrawal of inhaled corticosteroids in COPD: A meta-analysis. Pulm Pharmacol Ther. 2017;45:148-158.

28. Suissa S, Dell'Aniello S, Ernst P. Comparative effectiveness of LABAICS versus LAMA as initial treatment in COPD targeted by blood eosinophils: a population-based cohort study. Lancet Respir Med. October 2018; 6(11):855862

29. Oshagbemi OA, Franssen FME Braeken DCW, et al. Blood eosinophilia, use of inhaled corticosteroids, and risk of COPD exacerbations and mortality. Pharmacoepidemiol Drug Saf. 2018;0(0).

30. Merinopoulou E, Raluy-Callado M, Ramagopalan S, et al. COPD exacerbations by disease severity in England. Int J COPD. 2016;11(1):697709.

31. Vestbo J, Anderson JA, Brook RD, et al. Fluticasone furoate and vilanterol and survival in chronic obstructive pulmonary disease with heightened cardiovascular risk (SUMMIT): A double-blind randomised controlled

32. Wedzicha JA, Calverley PMA, Seemungal TA, et al. The prevention of chronic obstructive pulmonary disease exacerbations salmeterol/fluticasone propionate or tiotropium bromide. Am J Respir Crit Care Med. 2008 ;177(1):19-26.

33. Vestbo J, Fabbri L, Papi A, et al. Inhaled corticosteroid containing combinations and mortality in COPD. Eur Respir J. January 2018:1801230.

34. Oshagbemi OA, Burden AM, Braeken DCW, et al. Stability of blood eosinophils in patients with chronic obstructive pulmonary disease and in control subjects, and the impact of sex, age, smoking, and baseline counts. Am J Respir Crit Care Med. 2017;195(10).

35. Landis SH, Suruki R, Hilton E, et al. Stability of Blood Eosinophil Count in Patients with COPD in the UK Clinical Practice Research Datalink. COPD J Chronic Obstr Pulm Dis. 2017;14(4):382-388.

36. Rothnie KJ, Müllerová H, Thomas SL, et al. Recording of hospitalizations for acute exacerbations of COPD in UK electronic health care records. Clin Epidemiol. 2016;8:771-782. 


\section{Supplementary Materials}

Table S.6.1. Read codes and descriptions.

\begin{tabular}{llll}
\hline Read code & Medical code & Clinical event & Read term \\
\hline H312200 & 1446 & 172705 & Acute exacerbation of chronic obstructive airways disease \\
H3y1.00 & 7884 & 58765 & Chron Obstruct Pulmonary dis with exacerbation, unspec \\
8H2R.00 & 11019 & 13645 & Admit COPD emergency \\
66Yi.00 & 46036 & 956 & Multiple COPD emergency hospital admissions \\
\hline
\end{tabular}

Table S.6.2. Risk of moderate-to-severe exacerbations with ICS use stratified by absolute and relative eosinophil counts among COPD patients.

\begin{tabular}{|c|c|c|c|c|}
\hline & $\begin{array}{c}\text { Moderate-to-severe } \\
\text { exacerbations } \\
(n=6,767)^{c}\end{array}$ & $\begin{array}{c}\text { IR } \\
(/ 1000 P Y)\end{array}$ & $\begin{array}{c}\text { Age and gender adjusted } \\
\text { HR } \\
(95 \% \mathrm{Cl})\end{array}$ & $\begin{array}{l}\text { Adjusted } \\
\text { HR } \\
(95 \% \mathrm{Cl})^{\mathrm{a}}\end{array}$ \\
\hline \multicolumn{5}{|c|}{ Absolute eosinophil's counts } \\
\hline \multicolumn{5}{|c|}{ Withdrawal of ICS } \\
\hline$<0.40 \times 10^{9}$ cells $/ \mathrm{L}$ & 1,677 & 49.4 & $0.55(0.51-0.60)^{\mathrm{b}}$ & $0.72(0.66-0.79)^{\mathrm{b}}$ \\
\hline$\geq 0.40 \times 10^{9} \mathrm{cells} / \mathrm{L}$ & 314 & 48.8 & $0.56(0.49-0.63)$ & $0.70(0.62-0.80)$ \\
\hline \multicolumn{5}{|l|}{ Continuous ICS user } \\
\hline$<0.40 \times 10^{y} \mathrm{cells} / \mathrm{L}$ & 3,97 & 85.4 & $0.96(0.89-1.03)$ & $0.98(0.91-1.05)$ \\
\hline$\geq 0.40 \times 10^{9} \mathrm{cells} / \mathrm{L}$ & 806 & 87.9 & Reference & Reference \\
\hline \multicolumn{5}{|l|}{ Relative eosinophil } \\
\hline \multicolumn{5}{|l|}{ counts } \\
\hline \multicolumn{5}{|l|}{ Withdrawal of ICS } \\
\hline$<6.0 \%$ & 1,817 & 49.3 & $0.54(0.49-0.60)^{\mathrm{c}}$ & $0.67(0.60-0.74)^{b}$ \\
\hline$\geq 6.0 \%$ & 174 & 48.6 & $0.54(0.46-0.65)$ & $0.68(0.57-0.81)$ \\
\hline \multicolumn{5}{|l|}{ Continuous ICS user } \\
\hline$<6.0 \%$ & 4,333 & 85.4 & $0.94(0.85-1.03)$ & $0.91(0.82-1.00)$ \\
\hline$\geq 6.0 \%$ & 443 & 89.6 & Reference & Reference \\
\hline
\end{tabular}

Abbreviations: ICS, Inhaled corticosteroids; IR, incidence rate; HR, hazard ratio; $\mathrm{Cl}$, confidence interval; PY, person-years.

${ }^{a}$ Adjusted for age, gender, smoking status, body mass index, alcohol use, history of heart failure, chronic liver disease, ischemic heart disease, antipsychotics, antidepressants, atopic dermatitis, use of oxygen, short-acting beta-2 agonists, long-acting beta-2 agonists, short-acting muscarinic antagonists, long-acting muscarinic antagonists, xanthine derivatives and oral corticosteroid 6 months prior to the start of an interval.

'Wald's statistics: Withdrawal of ICS with low eosinophil counts statistically significantly different $(P<0.05)$ from continuous ICS use with low eosinophil count.

${ }^{c}$ numbers of never ICS user with moderate-to-severe exacerbations not included. 
Table S.6.3. Risk of severe exacerbations with ICS use stratified by absolute and relative eosinophil counts among COPD patients.

\begin{tabular}{|c|c|c|c|c|}
\hline & $\begin{array}{l}\text { Severe exacerbations } \\
\qquad \mathrm{n}=1,177^{\mathrm{c}}\end{array}$ & $\begin{array}{c}\text { IR } \\
(/ 1000 \mathrm{PY})\end{array}$ & $\begin{array}{c}\text { Age and gender adjusted } \\
\mathrm{HR} \\
(95 \% \mathrm{Cl}) \\
\end{array}$ & $\begin{array}{l}\text { Adjusted } \\
\text { HR } \\
(95 \% \mathrm{Cl})^{\mathrm{a}}\end{array}$ \\
\hline \multicolumn{5}{|c|}{ Absolute eosinophil's counts } \\
\hline \multicolumn{5}{|c|}{ Withdrawal of ICS } \\
\hline$<0.40 \times 10^{9} \mathrm{cell} \mathrm{s} / \mathrm{L}$ & 268 & 6.9 & $0.57(0.47-0.71)^{\mathrm{b}}$ & $0.79(0.64-0.98)^{\mathrm{b}}$ \\
\hline$\geq 0.40 \times 10^{9}$ cells $/ \mathrm{L}$ & 58 & 7.8 & $0.65(0.48-0.89)$ & $0.87(0.64-1.19)$ \\
\hline \multicolumn{5}{|l|}{ Continuous ICS user } \\
\hline$<0.40 \times 10^{9}$ cells $/ \mathrm{L}$ & 713 & 12.4 & $1.03(0.86-1.24)$ & $1.05(0.88-1.26)$ \\
\hline$\geq 0.40 \times 10^{9} \mathrm{cells} / \mathrm{L}$ & 138 & 11.9 & Reference & Reference \\
\hline \multicolumn{5}{|l|}{ Relative eosinophil counts } \\
\hline \multicolumn{5}{|c|}{ Withdrawal of ICS } \\
\hline$<6.0 \%$ & 298 & 7.0 & $0.59(0.46-0.76)^{\mathrm{b}}$ & $0.78(0.60-1.01)^{\mathrm{b}}$ \\
\hline$\geq 6.0 \%$ & 28 & 6.8 & $0.58(0.37-0.89)$ & $0.77(0.50-1.20)$ \\
\hline \multicolumn{5}{|l|}{ Continuous ICS user } \\
\hline$<6.0 \%$ & 776 & 12.3 & $1.04(0.82-1.32)$ & $1.01(0.79-1.28)$ \\
\hline$\geq 6.0 \%$ & 75 & 11.9 & Reference & Reference \\
\hline \multicolumn{5}{|c|}{$\begin{array}{l}\text { Abbreviations: ICS, Inhaled corticosteroids; IR, incidence rate; HR, hazard ratio; Cl, confidence interval; PY, person-years; AE, } \\
\text { accident and emergency. } \\
\text { adjusted for age, gender, smoking status, body mass index, alcohol use, history of heart failure, chronic liver disease, diabetes } \\
\text { mellitus, ischemic heart disease, osteoporosis, use of proton-pump inhibitors, antidepressants, oxygen, antipsychotics, statins, short- } \\
\text { acting beta-2 agonists, long-acting beta-2 agonists, short-acting muscarinic antagonists, long-acting muscarinic antagonists, xanthine } \\
\text { derivatives and oral corticosteroid } 6 \text { months prior to the start of an interval. } \\
\text { 'Wald's statistics: Withdrawal of ICS with low eosinophil counts statistically significantly different ( }(P<0.05) \text { from continuous ICS use } \\
\text { with low eosinophil count. } \\
\text { cnumbers of never ICS user with severe exacerbations not included. }\end{array}$} \\
\hline
\end{tabular}

Table S.6.4. Risk of all-cause mortality with ICS use stratified by absolute and relative eosinophil counts among COPD patients.

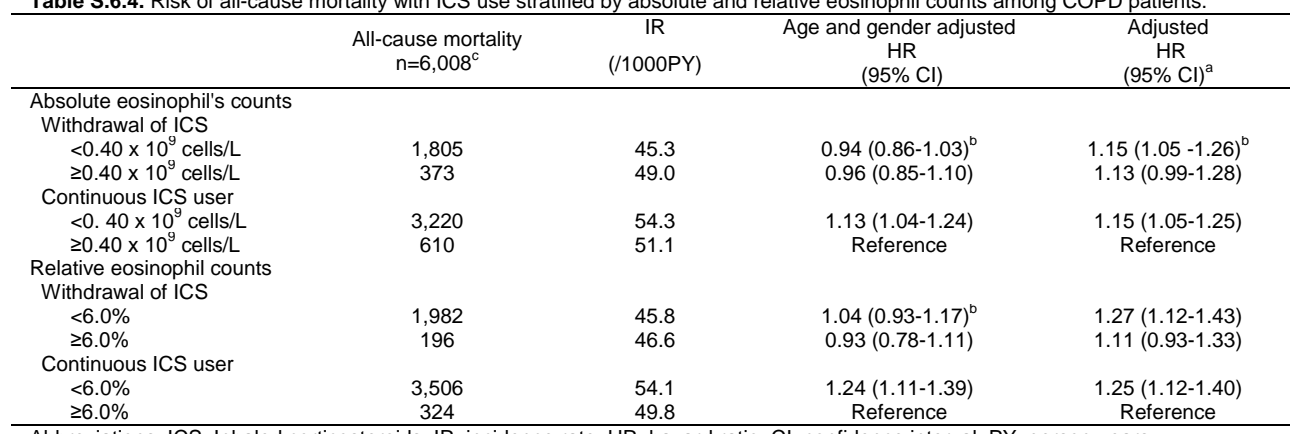

Abbreviations: ICS, Inhaled corticosteroids; IR, incidence rate; $\mathrm{HR}$, hazard ratio; $\mathrm{Cl}$, confidence interval; PY, person-years.

${ }^{a}$ Adjusted for age, gender, smoking status, body mass index, alcohol use, history of heart failure, chronic liver disease, ischemic heart disease, atopic dermatitis, diabetes mellitus, cancer, use of oxygen, statins, short-acting beta-2 agonists, long-acting beta-2 agonists, short-acting muscarinic antagonists, long-acting muscarinic antagonists, xanthine derivatives and oral corticosteroid use 6 months prior to the start of an interval.

Wald's statistics: Withdrawal of ICS with low eosinophil counts statistically significantly different $(P<0.05)$ from continuous ICS use with low eosinophil count.

${ }^{c}$ numbers of never ICS user who died not included. 
Table S.6.5. Risk of moderate-to-severe exacerbations with ICS use stratified by absolute and relative eosinophil counts among COPD patients.

\begin{tabular}{|c|c|c|c|c|}
\hline & $\begin{array}{c}\text { Mosderate-to-severe } \\
\text { exacerbations } \\
n=6,767^{c} \\
\end{array}$ & $\begin{array}{c}\text { IR } \\
(/ 1000 \mathrm{PY})\end{array}$ & $\begin{array}{c}\text { Age and gender adjusted } \\
\text { HR } \\
(95 \% \mathrm{Cl}) \\
\end{array}$ & $\begin{array}{l}\text { Adjusted } \\
\text { HR } \\
(95 \% \mathrm{Cl})^{\text {a }} \\
\end{array}$ \\
\hline \multicolumn{5}{|c|}{ Absolute eosinophil counts } \\
\hline \multicolumn{5}{|c|}{ Withdrawal of ICS } \\
\hline$<0.15 \times 10^{9}$ cells $/ \mathrm{L}$ & 640 & 47.9 & $0.56(0.51-0.61)^{\mathrm{b}}$ & $0.71(0.65-0.78)^{\mathrm{b}}$ \\
\hline$\geq 0.15 \times 10^{y}$ cells $/ \mathrm{L}$ & 1,351 & 50.0 & $0.59(0.55-0.63)$ & $0.74(0.69-0.79)$ \\
\hline \multicolumn{5}{|l|}{ Continuous ICS user } \\
\hline$<0.15 \times 10^{9}$ cells $/ \mathrm{L}$ & 1,617 & 87.0 & $1.02(0.96-1.08)$ & $1.00(0.94-1.06)$ \\
\hline$\geq 0.15 \times 10^{9} \mathrm{cells} / \mathrm{L}$ & 3,159 & 85.2 & Reference & Reference \\
\hline \multicolumn{5}{|l|}{ Relative eosinophil counts } \\
\hline \multicolumn{5}{|l|}{ Withdrawal of ICS } \\
\hline$<2.0 \%$ & 701 & 49.8 & $0.59(0.54-0.64)^{\mathrm{b}}$ & $0.72(0.67-0.79)^{\mathrm{b}}$ \\
\hline$\geq 2.0 \%$ & 1,290 & 49.0 & $0.59(0.55-0.63)$ & $0.74(0.69-0.79)$ \\
\hline \multicolumn{5}{|l|}{ Continuous ICS user } \\
\hline$<2.0 \%$ & 1,799 & 89.8 & $1.07(1.01-1.13)$ & $1.02(0.96-1.08)$ \\
\hline$\geq 2.0 \%$ & 2,977 & 83.6 & Reference & Reference \\
\hline
\end{tabular}

Abbreviations: ICS, Inhaled corticosteroids; IR, incidence rate; HR, hazard ratio; Cl, confidence interval; PY, person-years.

${ }^{a}$ Adjusted for age, gender, smoking status, body mass index, alcohol use, history of heart failure, chronic liver disease, ischemic heart disease, antipsychotics, antidepressants, atopic dermatitis, use of oxygen, short-acting beta-2 agonists, long-acting beta-2 agonists, short-acting muscarinic antagonists, long-acting muscarinic antagonists, xanthine derivatives and oral corticosteroid 6 months prior to the start of an interval.

Wald's statistics: Withdrawal of ICS with low eosinophil counts statistically significantly different $(P<0.05)$ from continuous ICS use with low eosinophil count.

${ }^{c}$ number of never ICS users with moderate-to-severe exacerbations not included.

Table S.6.6. Risk of severe exacerbations with ICS use stratified by absolute and relative eosinophil counts among COPD patients.

\begin{tabular}{|c|c|c|c|c|}
\hline & $\begin{array}{l}\text { Severe exacerbations } \\
\qquad n=1,177^{\mathrm{c}}\end{array}$ & $\begin{array}{c}\text { IR } \\
(/ 1000 \mathrm{PY})\end{array}$ & $\begin{array}{c}\text { Age and gender adjusted } \\
\mathrm{HR} \\
(95 \% \mathrm{Cl}) \\
\end{array}$ & $\begin{array}{c}\text { Adjusted } \\
\mathrm{HR} \\
(95 \% \mathrm{Cl})^{\mathrm{a}} \\
\end{array}$ \\
\hline \multicolumn{5}{|c|}{ Absolute eosinophil counts } \\
\hline \multicolumn{5}{|c|}{ Withdrawal of ICS } \\
\hline$<0.15 \times 10^{9} \mathrm{cells} / \mathrm{L}$ & 115 & 7.5 & $0.65(0.53-0.80)^{\mathrm{b}}$ & $0.88(0.71-1.08)^{\mathrm{b}}$ \\
\hline$\geq 0.15 \times 10^{9} \mathrm{cells} / \mathrm{L}$ & 211 & 6.8 & $0.59(0.50-0.69)$ & $0.79(0.67-0.93)$ \\
\hline \multicolumn{5}{|l|}{ Continuous ICS user } \\
\hline$<0.15 \times 10^{9} \mathrm{cells} / \mathrm{L}$ & 317 & 13.8 & $1.19(1.04-1.37)$ & $1.17(1.02-1.35)$ \\
\hline$\geq 0.15 \times 10^{9} \mathrm{cells} / \mathrm{L}$ & 534 & 11.6 & Reference & Reference \\
\hline \multicolumn{5}{|c|}{ Relative eosinophil counts } \\
\hline \multicolumn{5}{|l|}{ Withdrawal of ICS } \\
\hline$<2.0 \%$ & 125 & 7.7 & $0.69(0.57-0.85)^{\mathrm{b}}$ & $0.89(0.73-1.09)^{\mathrm{b}}$ \\
\hline$\geq 2.0 \%$ & 201 & 6.6 & $0.59(0.50-0.70)$ & $0.80(0.67-0.95)$ \\
\hline \multicolumn{5}{|l|}{ Continuous ICS user } \\
\hline$<2.0 \%$ & 355 & 14.3 & $1.28(1.11-1.46)$ & $1.20(1.05-1.38)$ \\
\hline$\geq 2.0 \%$ & 496 & 11.2 & Reference & Reference \\
\hline
\end{tabular}

Abbreviations: ICS, Inhaled corticosteroids; IR, incidence rate; HR, hazard ratio; Cl, confidence interval; PY, person-years; AE, accident and emergency.

${ }^{a}$ Adjusted for age, gender, smoking status, body mass index, alcohol use, history of heart failure, chronic liver disease, diabetes mellitus, ischemic heart disease, osteoporosis, use of proton-pump inhibitors, antidepressants, oxygen, antipsychotics, statins, shortacting beta-2 agonists, long-acting beta-2 agonists, short-acting muscarinic antagonists, long-acting muscarinic antagonists, xanthine derivatives and oral corticosteroid 6 months prior to the start of an interval.

'Wald's statistics: Withdrawal of ICS with low eosinophil counts statistically significantly different $(P<0.05)$ from continuous ICS use with low eosinophil count.

${ }^{c}$ number of never ICS users with severe exacerbations not included. 
Blood eosinophil counts, withdrawal of ICS and risk of COPD exacerbations and mortality in the CPRD

Table S.6.7. Risk of all-cause mortality with ICS use stratified by absolute and relative eosinophil counts among COPD patients.

\begin{tabular}{|c|c|c|c|c|}
\hline & $\begin{array}{l}\text { All-cause mortality } \\
\qquad n=6,008^{d}\end{array}$ & $\begin{array}{c}\text { IR } \\
(/ 1000 \mathrm{PY})\end{array}$ & $\begin{array}{l}\text { Age and gender adjusted HR } \\
\qquad(95 \% \mathrm{Cl})\end{array}$ & $\begin{array}{c}\text { Adjusted } \\
\text { HR } \\
(95 \% \mathrm{Cl})^{\mathrm{a}}\end{array}$ \\
\hline \multicolumn{5}{|c|}{ Absolute eosinophil counts } \\
\hline \multicolumn{5}{|c|}{ Withdrawal of ICS } \\
\hline$<0.15 \times 10^{9}$ cells $/ \mathrm{L}$ & 825 & 52.8 & $1.06(0.97-1.14)^{\mathrm{b}, \mathrm{c}}$ & $1.23(1.13-1.33)$ \\
\hline$\geq 0.15 \times 10^{9} \mathrm{cells} / \mathrm{L}$ & 1,353 & 42.5 & $0.88(0.82-0.94)$ & $1.05(0.98-1.13)$ \\
\hline \multicolumn{5}{|l|}{ Continuous ICS user } \\
\hline$<0.15 \times 10^{9} \mathrm{cells} / \mathrm{L}$ & 1,526 & 64.4 & $1.31(1.23-1.40)$ & $1.27(1.19-1.35)$ \\
\hline$\geq 0.15 \times 10^{9} \mathrm{cells} / \mathrm{L}$ & 2,304 & 48.4 & Reference & Reference \\
\hline \multicolumn{5}{|l|}{ Relative eosinophil counts } \\
\hline \multicolumn{5}{|l|}{ Withdrawal of ICS } \\
\hline$<2.0 \%$ & 892 & 54.0 & $1.16(1.07-1.25)^{\mathrm{b}, \mathrm{c}}$ & $1.30(1.20-1.41)^{\mathrm{b}}$ \\
\hline$\geq 2.0 \%$ & 1,286 & 41.6 & $0.89(0.83-0.95)$ & $1.06(0.99-1.14)$ \\
\hline \multicolumn{5}{|l|}{ Continuous ICS user } \\
\hline$<2.0 \%$ & 1,692 & 65.8 & $1.44(1.35-1.53)$ & $1.34(1.26-1.43)$ \\
\hline$\geq 2.0 \%$ & 2,138 & 46.9 & Reference & Reference \\
\hline \multicolumn{5}{|c|}{$\begin{array}{l}\text { Abbreviations: ICS, Inhaled corticosteroids; IR, incidence rate; HR, hazard ratio; } \mathrm{Cl} \text {, confidence interval; PY, person-years. } \\
\text { a) Adjusted for age, gender, smoking status, body mass index, alcohol use, history of heart failure, chronic liver disease, ischemic heart } \\
\text { disease, atopic dermatitis, diabetes mellitus, cancer, use of oxygen, statins, short-acting beta- } 2 \text { agonists, long-acting beta- } 2 \text { agonists, } \\
\text { short-acting muscarinic antagonists, long-acting muscarinic antagonists, xanthine derivatives and oral corticosteroid use } 6 \text { months } \\
\text { prior to the start of an interval. } \\
\text { b) Wald's statistics: Withdrawal of ICS with low eosinophil counts statistically significantly different }(P<0.05) \text { from withdrawal of ICS } \\
\text { with high eosinophil count. } \\
\text { 'Wald's statistics: Withdrawal of ICS with low eosinophil counts statistically significantly different }(P<0.05) \text { from continuous ICS use } \\
\text { with low eosinophil count. } \\
\text { dnumber of never ICS users who died not included. }\end{array}$} \\
\hline
\end{tabular}





\section{Use of high-dose intermittent systemic glucocorticoids and the risk of fracture in patients with chronic obstructive pulmonary disease}

Bone. 2018;110:238-243

Olorunfemi A. Oshagbemi

Andrea M. Burden Kimberley N. Shudofsky Johanna H.M. Driessen

Peter Vestergaard Andreas Krings Frits M.E. Franssen Joop van den Bergh

Frank de Vries

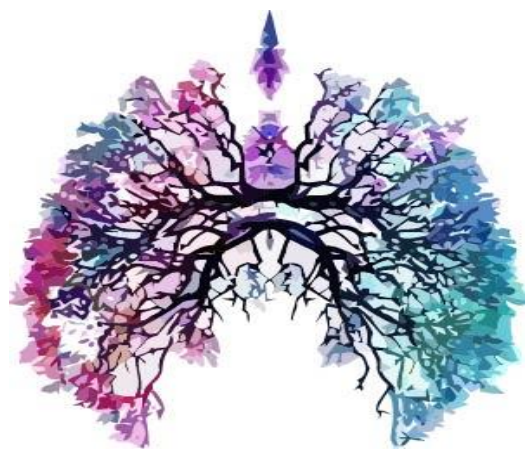




\section{ABSTRACT}

Introduction: Chronic obstructive pulmonary disease (COPD) is characterised by persistent airflow obstruction and respiratory symptoms. While short-course systemic glucocorticoids (GCs) are prescribed in patients with acute COPD exacerbations, little is known of the risk of fractures with intermittent exposure to high-dose GC and the effect of proxies of disease severity.

Method: A case-control study was conducted using the Danish National Hospital Discharge Registry (NHDR) between January 1996 to December 2011. Conditional logistics regression models were used to derive adjusted odds ratios (OR) risk of fractures in subjects with COPD stratified by intermittent high-dose, and proxies of disease severity.

Results: A total of 635,536 cases and the same number of controls were identified (mean age $67.5 \pm 13.8,65 \%$ female). COPD patients with intermittent use of high average daily dose oral glucocorticoids did not have an increased risk of any, osteoporotic, hip or clinically symptomatic vertebral fracture compared to non-COPD patients (adj. OR 0.65; 95\% Cl: 0.50-0.86, 0.70; 95\% Cl: 0.70-0.99, 1.17; 95\% Cl: $0.59-2.32,1.98 ; 95 \% \mathrm{Cl}: 0.59-6.65$ respectively). We identified an elevated risk of osteoporotic fracture among patients who visited the emergency unit (adj.OR 1.47; 95\% Cl 1.20-1.79) or were hospitalised in the past year for COPD (adj.OR 1.76; 95\% Cl 1.66-1.85). Current GC use among COPD patients was associated with an increased risk of osteoporotic, hip and clinically symptomatic vertebral fractures compared to patients without COPD.

Conclusions: Intermittent high-dose GCs was not associated with an increased risk of any, osteoporotic, hip or clinically symptomatic vertebral fractures in patients with COPD. Current GC use was however associated with an increased risk of hip and clinically symptomatic vertebral fractures. Therefore, emphasis on prophylactic treatment of fractures may not be essential in patients with COPD receiving intermittent dose of GCs, whereas this should be considered for high-dose long-term users with advanced COPD disease stage, postmenopausal women and men over 40 years. 


\section{INTRODUCTION}

Chronic obstructive pulmonary disease (COPD) is characterised by persistent airflow obstruction and respiratory symptoms. It is projected to be the third leading cause of morbidity and mortality by 2030.1,2 Pharmacologic management of stable COPD consists of short- and long-acting bronchodilators, as well as inhaled and oral glucocorticoids (GCs). ${ }^{3}$ In patients with acute COPD exacerbations, short courses of systemic GCs are prescribed in order to reduce exacerbations, shorten recovery time and reduce the length of hospital stay. ${ }^{3}$ Although not recommended by current international guidelines, a proportion of COPD patients are chronically treated with low-dose oral GCs. ${ }^{4}$

The detrimental effects of GCs on bone mineral density (BMD), resulting in an increased (hip or vertebral) fracture risk, are well established. ${ }^{5-9}$ While elevated fracture risk may be caused by several factors related to disease severity which negatively influences bone structure, fracture risk remains elevated in patients using oral GCs even after adjustment for proxy indicators of disease severity. ${ }^{10-12}$ Consequently, GC use is included in risk prediction tools such as FRAX, ${ }^{8}$ and international clinical guidelines on the prevention of GC-induced osteoporosis. ${ }^{13}$

Fracture risk associated with oral GC use increases rapidly, particularly during the first 3 months of treatment, and is partially independent of a decreased BMD. ${ }^{14}$ The increase in fracture risk is directly, and linearly, related to the daily, and possibly also to cumulative, dose of oral GCs; yet the relative relationship between the two is not consistent. ${ }^{5-7,15}$ Thus clinicians suggest the use of intermittent dosing of GCs to mitigate and manage GC-induced adverse effects, such as fractures. ${ }^{16}$ De Vries et al. evaluated the risk of fracture with intermittent use of high-dose oral GC and found a small increased risk of osteoporotic fractures among patients with various disease conditions requiring GC use. ${ }^{7}$ They defined intermittent high dose exposure as daily dose $\geq 15 \mathrm{mg}$ and cumulative dose exposure $\leq 1 \mathrm{~g}$ (for instance $30 \mathrm{mg}$ prednisolone equivalents per day for 2-4 weeks).

While the risk of fracture in patients with obstructive airways disease exposed to intermittent high-dose oral GC was examined by de Vries et al in a large British population, little is known of this risk in COPD patients in other settings. Therefore the objective of the present study was to investigate the effects of intermittent high-dose glucocorticoid use on fracture risk in patients with COPD, the impact of proxy indicators of disease severity and the effect of dose, compared to patients without COPD. 


\section{METHODS}

\section{Design and source population}

A population-based case-control study was conducted using healthcare records from the Danish National databases. In Denmark, separate registers of computerized medical records on all contacts to hospitals and drug prescriptions can be linked for the entire population (approximately 5.5 million inhabitants). The register was founded in 1977 and covers all inpatients contacts from 1977 to 1994, and from 1995 onwards also includes all outpatient visits to hospitals, outpatient clinics, and emergency rooms. After discharge, the physician enters the reason for the contact according to the International Classification of Diseased (ICD) system. The register has a nationwide coverage of public health facilities with an almost $100 \%$ completeness of recordings and a high precision of diagnoses ${ }^{17,18}$, particularly for fracture diagnoses. ${ }^{6}$

The Danish Medicines Agency keeps a nationwide prescription database, the Register of Medicinal Product Statistics, with information on prescriptions for refundable drugs. The database includes information on the patient's civil registry number, the type and amount of drug prescribed in accordance to the Anatomical Therapeutic Chemical (ATC) classification system ${ }^{2}$ and the date when the prescription was filled by the patient. This permits an evaluation of the average daily dose and cumulative exposure. All registers can be interconnected through the use of the civil registry number that is assigned to all Danes. ${ }^{19}$

\section{Study population / outcome}

Cases were identified as patients aged 45 years and older who had sustained a fracture between January 1996 and December 2011. Fractures considered included a fracture of the hip (ICD10 code S72.0-S72.2), clinical symptomatic vertebrae (S12, S22.0-S22.1, S32.0-S32.2, S32.7, S32.8, T08), osteoporotic (defined as a fracture of the hip, clinical symptomatic vertebrae, radius/ulna [S52] or humerus [S42.2-S42.4] according to the World Health Organisation's (WHO) definition. ${ }^{20}$ Any fracture was determined by the following International Classification of Diseases and Related Health Problems (ICD)-10 codes: S02, S12, S22, S32, S42, S52, S62, S72, S82, S92, T02, T08, T10 and T12. For each case, one control patient (who had not sustained a fracture) was matched by gender and year of birth using incidence-density sampling. ${ }^{21}$ The date of the first fracture defined the index date for cases, and controls were assigned the index date of their matched cases.

\section{Exposure}

Presence of COPD before the index date was defined based on ICD-10 code J43 or J44. Individuals without an ICD-10 code for COPD were categorized as non-COPD patients and used as the reference category in all analyses. Furthermore, among COPD patients we evaluated oral glucocorticoid (GC) use before the index date. Based on the time since the most recent GC dispensing from the index date patients 
were classified as current (1-91 days), recent (92-182), past (183-364 days) or distant (over 364 days) users. For each current user, the cumulative and average daily GC exposure was estimated. The average daily dose was calculated by dividing the cumulative GC exposure by the treatment time (i.e. the time between the first GC dispensing and the index date). Intermittent high-dose of GC was defined as daily dose $\geq 15 \mathrm{mg}$ and cumulative exposure $<1 \mathrm{~g}$. ${ }^{7}$ This roughly corresponds to $30 \mathrm{mg}$ prednisolone per day for 2-4 weeks. It is recommended that patients with COPD receive 30-40 mg of prednisolone for 7-14 days and no longer that in the event of an exacerbation. ${ }^{3}$ The cumulative dose was calculated by adding up all previous GC dispensing using the defined daily dosages (DDDs). The average daily dose was calculated by dividing the cumulative GC exposure by the treatment time (i.e. the time between the first GC dispensing and the index date). GC exposure was expressed as oral prednisolone equivalents.

\section{Confounders}

We considered the following potential confounders before the index date: history of fracture, rheumatoid arthritis, inflammatory bowel disease (IBD), secondary osteoporosis (type 1 diabetes, hyperthyroidism, hypogonadism and renal failure), dementia, type 2 diabetes mellitus, cerebrovascular disease, pneumonia, malignancies (excluding non-melanoma skin cancer) and gout. These potential confounders have been related to fractures and COPD in previous studies. ${ }^{11,22}$ Other potential confounders included a dispensing in the six months before the index date of the following drugs: inhaled cromoglycates, xanthine derivatives, bisphosphonates, vitamin D, calcium, raloxifene, strontium, denosumab, calcitonin, parathyroid hormone, hormone replacement therapy, antipsychotics, antidepressants, hypnotics/anxiolytics, anticonvulsants, anti-parkinson drugs, antihypertensive drugs and proton pump inhibitors. Proxy indicators of respiratory disease severity variables included a dispensing of inhaled corticosteroids, long-acting beta-2 agonists, shortacting beta-2 agonists, long-acting anticholinergics, short-acting anticholinergics, roflumilast, oxygen and the number of accident and emergency registrations or hospitalisations for COPD in the previous year. ${ }^{11}$

\section{Statistical analysis}

Conditional logistic regression was used to estimate odds ratios (ORs) for fracture risk (SAS 9.3 (SAS Institute, Cary, NC)). Final regression models were determined by stepwise backward elimination using a significance level of 0.05 . Patients without COPD were the reference category. Analyses were stratified by intermittent GC exposure, proxies of disease severity and average daily and cumulative dose exposure for specific fracture sites. Proxies of disease severity considered include hospitalisation and emergency visits for COPD in previous year. All results were presented as OR with corresponding 95\% confidence intervals (Cls). 


\section{RESULTS}

The study population consisted of 635,536 cases and the same number of controls. Baseline characteristics of the study participants are shown in Table 7.1. The mean age at index date was $67.5 \pm 13.8$ and $65 \%$ were female. Approximately $18 \%$ of the cases $(n=113,553)$ and $15 \%$ of the controls $(n=97,460)$ used GCs in the six months before the index date. There was a history of fracture among $24.4 \%$ of the cases and $8 \%$ of the controls. A higher proportion of cases had used anticonvulsants, hypnotics, anxiolytics, and antidepressants in the six months prior to index date. There were $38,013(6 \%)$ patients with COPD among the cases and 28,490 (4.5\%) among controls.

\begin{tabular}{|c|c|c|c|c|}
\hline & \multicolumn{2}{|c|}{ Cases } & \multicolumn{2}{|c|}{ Controls } \\
\hline & $\mathrm{n}=635,536$ & $\%$ & $\mathrm{n}=635,536$ & $\%$ \\
\hline Male sex & 224,182 & 35.3 & 224,182 & 35.3 \\
\hline Mean age at index date (years, SD) & 67.5 & 13.8 & 67.5 & 13.8 \\
\hline $45-60$ & 220,166 & 34.6 & 220,158 & 34.6 \\
\hline $60-74$ & 194,647 & 30.6 & 194,664 & 30.6 \\
\hline $75+$ & 220,723 & 34.7 & 220,714 & 34.7 \\
\hline \multicolumn{5}{|l|}{ History of co-morbidities } \\
\hline Fracture & 154,923 & 24.4 & 49,742 & 7.8 \\
\hline COPD & 38,013 & 5.9 & 28,490 & 4.5 \\
\hline Pneumonia & 21,106 & 3.3 & 15,771 & 2.5 \\
\hline Rheumatoid arthritis & 12,245 & 1.9 & 9,133 & 1.4 \\
\hline Inflammatory bowel disease & 12,962 & 2.0 & 10,005 & 1.6 \\
\hline Secondary osteoporosis & 32,275 & 5.1 & 25,041 & 3.9 \\
\hline Type 1 diabetes mellitus & 13,897 & 2.2 & 8,439 & 1.3 \\
\hline Type II diabetes mellitus & 31,252 & 4.9 & 25,535 & 4.0 \\
\hline Hyperthyroidism & 13,934 & 2.2 & 13,614 & 2.1 \\
\hline Hypogonadism & 612 & 0.1 & 408 & 0.1 \\
\hline Renal failure & 5,570 & 0.9 & 3,496 & 0.6 \\
\hline Dementia & 16,572 & 2.6 & 9,251 & 1.5 \\
\hline Cerebrovascular disease & 54,999 & 8.7 & 41,511 & 6.5 \\
\hline Malignancies (excl. non-melanoma skin cancer) & 71,393 & 11.2 & 62,780 & 9.9 \\
\hline \multicolumn{5}{|l|}{ Drug use within six months before index date } \\
\hline Oral glucocorticoids & 113,553 & 17.9 & 97,460 & 15.3 \\
\hline Inhaled corticosteroids & 215,50 & 3.4 & 19,236 & 3.0 \\
\hline Inhaled bronchodilators & 44,096 & 6.9 & 37,105 & 5.8 \\
\hline Xanthine derivatives & 5,427 & 0.9 & 4,653 & 0.7 \\
\hline Bisphosphonates & 16,941 & 2.7 & 10,211 & 1.6 \\
\hline Vitamin D & 740 & 0.1 & 627 & 0.1 \\
\hline Calcium & 8,535 & 1.3 & 5,777 & 0.9 \\
\hline Raloxifene & 747 & 0.1 & 493 & 0.1 \\
\hline Hormone replacement therapy & 45,381 & 7.1 & 55,626 & 8.8 \\
\hline Antipsychotics & 31,258 & 4.9 & 20,080 & 3.2 \\
\hline Antidepressants & 89,941 & 14.2 & 53,689 & 8.5 \\
\hline Hypnotics/anxiolytics & 72,682 & 11.4 & 54,384 & 8.6 \\
\hline Anticonvulsants & 21,443 & 3.4 & 10,456 & 1.7 \\
\hline Anti-Parkinson drugs & 7,030 & 1.11 & 3,987 & 0.6 \\
\hline Antihypertensive drugs & 228,310 & 35.9 & 227,776 & 35.8 \\
\hline Proton pump inhibitors & 56,646 & 8.9 & 41,382 & 6.5 \\
\hline COPD related Emergency visit in past year & 588 & 0.1 & 302 & 0.1 \\
\hline COPD related Hospitalisation in past year & 9,658 & 1.5 & 4,252 & 0.7 \\
\hline
\end{tabular}

Abbreviations: SD: standard deviation; COPD: chronic obstructive pulmonary disease.

Table 7.2 presents the adjusted fracture risk among COPD patients currently exposed to oral glucocorticoid, compared with patients without COPD. COPD patients with intermittent use of high average daily dose oral glucocorticoids did not have an increased risk of any, osteoporotic, hip or clinically symptomatic vertebral fracture 
compared to patients without COPD (adj. OR 0.65; 95\% Cl: 0.50-0.86, 0.70; 95\% Cl: 0.70-0.99, 1.17; 95\% Cl: 0.59-2.32, 1.98; 95\% Cl: 0.59-6.65 respectively).

However, the risk of osteoporotic fractures was significantly increased among long-term heavy users receiving a cumulative dose between 1 and 4.9 grams (adj.OR: $1.46 ; 95 \% \mathrm{Cl}: 1.07-1.20)$, and the risk of hip fracture increased among COPD patients with cumulative dose of 5.0-9.9 g (adj.OR: $2.88 ; 95 \% \mathrm{Cl}: 1.27-6.57$ ). As a proxy for disease severity, we further stratified COPD patients by patients with an emergency visit or hospitalisation for COPD in the year prior to fracture (Table 7.3). We identified an elevated risk of osteoporotic fracture among patients who visited the emergency unit (adj.OR 1.47; 95\% Cl 1.20-1.79) or were hospitalised in the past year for COPD (adj.OR 1.76; 95\% Cl 1.66-1.85), as compared to patients without COPD (Table 7.3). Similarly the risk of hip fracture was elevated in hospitalised patients (adj.OR: 2.47; 95\% Cl: 2.26-2.70) and those who visited the emergency unit (adj.OR: $2.13 ; 95 \% \mathrm{Cl}$ : 1.49-3.04) in the past year, compared to non-COPD patients. The risk of clinically symptomatic vertebral fractures showed a 3-fold increase among COPD patients

Table 7.2. Adjusted risk fractures among COPD patients compared to patients without COPD stratified by current GC use.

\begin{tabular}{|c|c|c|c|c|}
\hline & $\begin{array}{l}\text { Any Fracture } \\
\text { Adj. OR } \text { OR }^{\mathrm{a}, \mathrm{b}} \\
(95 \% \mathrm{Cl}) \\
\end{array}$ & $\begin{array}{l}\text { Osteoporotic fracture } \\
\text { Adj. OR } \text { OR }^{\mathrm{a}, \mathrm{b}} \\
(95 \% \mathrm{Cl}) \\
\end{array}$ & $\begin{array}{l}\text { Hip Fracture } \\
\text { Adj. OR }{ }^{a, b} \\
(95 \% \mathrm{Cl})\end{array}$ & $\begin{array}{l}\text { Clinical Symptomatic Vertebral } \\
\text { Adj. OR }{ }^{a, b} \\
(95 \% \mathrm{Cl})\end{array}$ \\
\hline No COPD & Reference) & Reference & Reference & Reference \\
\hline COPD & $1.06(1.04-1.08)$ & $1.03(1.00-1.06)$ & $1.08(1.03-1.13)$ & $1.31(1.20-1.44)$ \\
\hline \multicolumn{5}{|c|}{ By GC exposure } \\
\hline Current use & $1.01(0.96-1.06)$ & $1.12(1.05-1.20)$ & $1.23(1.10-1.37)$ & $1.87(1.52-2.31)$ \\
\hline \multicolumn{5}{|c|}{ By average daily dose $\geq 15 \mathrm{mg} /$ day (oral prednisolone equivalents) } \\
\hline$<1$ gram & $0.65(0.50-0.86)$ & $0.70(0.49-0.99)$ & $1.17(0.59-2.32)$ & $1.98(0.59-6.65)$ \\
\hline $1.0-4.9 \mathrm{~g}$ & $1.14(0.90-1.43)$ & $1.46(1.07-2.00)$ & $1.61(0.95-2.73)$ & $2.43(0.95-6.22)$ \\
\hline $5.0-9.9 \mathrm{~g}$ & $1.36(0.97-1.89)$ & $1.40(0.91-2.16)$ & $2.88(1.27-6.57)$ & $0.93(0.35-2.44)$ \\
\hline$\geq 10 \mathrm{~g}$ & $1.07(0.84-1.36)$ & $1.19(0.85-1.65)$ & $1.59(0.89-2.87)$ & $1.25(0.52-3.00)$ \\
\hline
\end{tabular}

Abbreviations: OR: odds ratio; GC: glucocorticoid; COPD: chronic obstructive pulmonary disease; Cl: confidence interval.

Current GC use: most recent GC dispensing with 1-91 days before index date.

${ }^{a}$ Values are the adjusted odds ratios (95\% confidence interval)

badjusted for: prior fracture, history of pneumonia, inhaled corticosteroids, inhaled bronchodilators, antidepressants,

hypnotics/anxiolytics, proton pump inhibitors, emergency visit for COPD, hospitalisation for COPD, never, distant, past, and recent use of oral GCs.

following hospitalisation and emergency visit in the past year when compared to patients without COPD. We also noticed an increased risk of any fracture in patients with emergency visits or hospitalisation for COPD.

The individual breakdown of average daily dose and cumulative dose by fracture type among COPD patients, compared to non-COPD patients, is provided in Table 7.4. Current GC use among COPD patients was associated with an increased risk of osteoporotic (adj.OR: 1.12; 95\% Cl: 1.05-1.20), hip (adj.OR: 1.23; 95\% Cl: 1.10-1.37) and clinically symptomatic vertebral fractures (adj.OR: 1.87; 95\% Cl: $1.52-$ 2.31) as compared to patients without COPD except risk for any fracture. The risk of hip and clinically symptomatic vertebral fractures increased with increasing average daily doses, with patients exposed to 7.5-15 mg/day having the greatest risk. Cumulative dose of $5.0-9.9 \mathrm{~g}$ was associated with an increased risk of clinically symptomatic vertebral fractures (adj.OR: 2.26 ; $95 \% \mathrm{Cl}: 1.52-3.35$ ). 
Table 7.3. Adjusted risk of fracture among COPD patients stratified by proxies of disease severity compared to patients without COPD.

\begin{tabular}{|c|c|c|c|c|}
\hline & $\begin{array}{l}\text { Any Fracture } \\
\text { Adj. OR } \text { OR }^{\mathrm{a}, \mathrm{b}} \\
(95 \% \mathrm{Cl})\end{array}$ & $\begin{array}{l}\text { Osteoporotic fracture } \\
\text { Adj. OR } \text { a,b }^{\mathrm{a}, \mathrm{b}} \\
(95 \% \mathrm{Cl})\end{array}$ & $\begin{array}{l}\text { Hip Fracture } \\
\text { Adj. OR }{ }^{a, b} \\
(95 \% \mathrm{Cl})\end{array}$ & $\begin{array}{c}\text { Clinical Symptomatic } \\
\text { Vertebral } \\
\text { Adj. OR } \text { OR }^{\mathrm{a}, \mathrm{b}} \\
(95 \% \mathrm{Cl})\end{array}$ \\
\hline No COPD & Reference) & Reference & Reference & Reference \\
\hline COPD & $1.05(1.03-1.07)$ & $1.03(1.00-1.06)$ & $1.08(1.03-1.13)$ & $1.31(1.20-1.44)$ \\
\hline Emergency visit in past year for COPD & \multicolumn{4}{|c|}{ Proxy indicators of disease } \\
\hline No & $1.05(1.03-1.07)$ & $1.03(1.00-1.06)$ & $1.08(1.03-1.13)$ & $1.31(1.20-1.44)$ \\
\hline Yes & $1.47(1.27-1.71)$ & $1.47(1.20-1.79)$ & $2.13(1.49-3.04)$ & $3.15(1.64-6.07)$ \\
\hline \multicolumn{5}{|c|}{ Hospitalisation in past year for COPD } \\
\hline No & $1.07(1.05-1.10)$ & $1.06(1.03-1.08)$ & $1.11(1.06-1.17)$ & $1.35(1.23-1.48)$ \\
\hline Yes & $1.66(1.60-1.73)$ & $1.76(1.66-1.85)$ & $2.47(2.26-2.70)$ & $3.08(2.57-3.69)$ \\
\hline
\end{tabular}

Abbreviations: OR: odds ratio; GC: glucocorticoid; COPD: chronic obstructive pulmonary disease; Cl: confidence interval.

Current GC use: most recent GC dispensing with 1-91 days before index date.

avalues are the adjusted odds ratios (95\% confidence interval)

${ }^{b}$ Adjusted for previous fracture, history of pneumonia, inflammatory bowel disease, cerebrovascular disease, inhaled corticosteroids, inhaled bronchodilators, antidepressants, hypnotics/anxiolytics, proton pump inhibitors, hospitalisations for COPD, emergency visits for COPD, and previous use of oral GCs.

Table 7.4. Adjusted risk of fracture among COPD patients compared to patients without COPD stratified by average daily and cumulative exposure.

\begin{tabular}{|c|c|c|c|c|}
\hline & $\begin{array}{c}\text { Any Fracture } \\
\text { Adj. OR } \text { OR }^{\mathrm{a} b} \\
(95 \% \mathrm{Cl})\end{array}$ & $\begin{array}{l}\text { Osteoporotic fracture } \\
\text { Adj. OR } \text { a,b }^{\mathrm{a} b} \\
(95 \% \mathrm{Cl})\end{array}$ & $\begin{array}{l}\text { Hip Fracture } \\
\text { Adj. OR }{ }^{a, b} \\
(95 \% \mathrm{Cl})\end{array}$ & $\begin{array}{c}\text { Clinical Symptomatic } \\
\text { Vertebral } \\
\text { Adj. OR }{ }^{\mathrm{a}, \mathrm{b}} \\
(95 \% \mathrm{Cl})\end{array}$ \\
\hline No COPD & Reference) & Reference & Reference & Reference \\
\hline $\begin{array}{l}\text { COPD } \\
\text { By GC exposure }\end{array}$ & $1.06(1.04-1.08)$ & $1.03(1.00-1.06)$ & $1.08(1.03-1.13)$ & $1.31(1.20-1.44)$ \\
\hline Current use & $1.01(0.96-1.06)$ & $1.12(1.05-1.20)$ & $1.23(1.10-1.37)$ & $1.87(1.52-2.31)$ \\
\hline \multicolumn{5}{|c|}{ By average daily dose (oral prednisolone equivalents) } \\
\hline$<7.5 \mathrm{mg} / \mathrm{day}$ & $0.98(0.92-1.04)$ & $1.08(0.99-1.17)$ & $1.16(1.01-1.34)$ & $1.53(1.18-1.99)$ \\
\hline $7.5-15 \mathrm{mg} /$ day & $1.08(0.99-1.17)$ & $1.20(1.07-1.34)$ & $1.23(1.02-1.47)$ & $2.98(2.05-4.33)$ \\
\hline$\geq 15 \mathrm{mg} / \mathrm{day}$ & $1.01(0.89-1.15)$ & $1.15(0.96-1.37)$ & $1.66(1.21-2.28)$ & $1.55(0.94-2.54)$ \\
\hline \multicolumn{5}{|c|}{ By cumulative dose (oral prednisolone equivalents) } \\
\hline$<1.0 \mathrm{~g}$ & $0.87(0.77-0.99)$ & $1.01(0.86-1.18)$ & $1.19(0.89-1.59)$ & $1.96(1.10-3.46)$ \\
\hline $1.0-4.9 \mathrm{~g}$ & $0.96(0.89-1.04)$ & $1.09(0.98-1.22)$ & $1.21(1.01-1.45)$ & $1.60(1.15-2.24)$ \\
\hline $5.0-9.9 \mathrm{~g}$ & $1.11(1.00-1.22)$ & $1.15(1.02-1.31)$ & $1.23(0.99-1.53)$ & $2.26(1.52-3.35)$ \\
\hline$\geq 10 \mathrm{~g}$ & $1.06(0.98-1.15)$ & $1.18(1.06-1.31)$ & $1.26(1.06-1.51)$ & $1.87(1.33-2.64)$ \\
\hline
\end{tabular}

Abbreviations: OR: odds ratio; GC: glucocorticoid; COPD: chronic obstructive pulmonary disease; Cl: confidence interval.

Current GC use: most recent GC dispensing with 1-91 days before index date.

${ }^{2}$ values are the adjusted odds ratios (95\% confidence interval)

${ }^{\mathrm{D}}$ Adjusted for previous fracture, history of pneumonia, inhaled corticosteroids, inhaled bronchodilators, antidepressants,

hypnotics/anxiolytics, proton pump inhibitors, hospitalisations for COPD, emergency visits for COPD, and previous use of oral GCs.

\section{DISCUSSION}

In the current study, we found that exposure to intermittent high-dose glucocorticoid was not associated with an increased risk of any, osteoporotic, hip and clinically symptomatic vertebral fracture in COPD patients compared to patients without COPD. Furthermore, we showed that proxies of disease severity (hospitalisation and emergency visit for COPD in the past year) were associated with an increased risk of any, osteoporotic, hip and clinically symptomatic vertebral fractures among patients with COPD compared to patients without COPD.

This study extends previous knowledge from large population-based studies. ${ }^{5,6} \mathrm{~A}$ cohort study by de Vries et $\mathrm{al}^{7}{ }^{7}$ showed that intermittent high-dose of glucocorticoid among patients with various diseases requiring GC use was associated with a small increased risk of osteoporotic and vertebral fractures, but no increased risk of hip fractures. In their study, intermittent use of GC was defined as daily dose $\geq$ $15 \mathrm{mg}$ and cumulative exposure $\leq 1 \mathrm{~g}$ similar to our study. However, they employed a 
cohort study design adjusting for covariates time-dependently. This might explain the absence of the small increased risk of osteoporotic and vertebral fractures with intermittent exposure in our study. Another study among patients with COPD found no increased risk of vertebral fracture with intermittent use of systemic GC. ${ }^{23}$ The investigators defined intermittent use of GC as exposure to prednisolone for an average of 4 months during the patient's lifetime and the study population was comprised of men over 50 years. Additionally, intermittent use of GCs (daily dose $\geq$ $10 \mathrm{mg}$ and cumulative dose $\leq 1 \mathrm{~g}$ ) did not change the BMD in patients with COPD, ${ }^{24}$ this might explain our result. However, COPD patients exposed to continuous GC use were 2.4 times more likely to have one or more vertebral fractures. ${ }^{23}$

In our study, we defined emergency visits and hospitalisations for COPD in the past year as proxies for disease severity. Patients with COPD who were hospitalised or who visited the emergency unit in the past year had an increased risk of hip, osteoporotic and clinically symptomatic vertebral fractures. The severity of the disease may influence the dose and duration of GC administered. ${ }^{9}$ However, severity of pulmonary disease was shown to be inversely proportional to BMD. ${ }^{11}$ Our findings are in line with a population-based case-control study of Danish patients with fractures exposed to corticosteroids $(n=124,655)$, reporting that overall fracture risk increased with the number of days in which COPD patients were hospitalised. ${ }^{14}$ While hospitalisation was identified as an important proxy for disease severity, the duration of disease has been found not to correlate with fracture risk, as it does not reflect severity of disease ${ }^{14}$. Adjustment for disease severity is limited in fracture studies $5,25,26$. In our study, we adjusted the primary analysis for proxies of disease severity. Furthermore, studies have identified the importance of disease severity on fracture risk in patients exposed to GC. Consequently, adequate adjustments should be made when studying the risk of fractures in COPD patients. ${ }^{11}$

The present results are in line with a previous observational study, which evaluated cumulative/daily dose and the risk of fractures using the CPRD. The researchers found an increased risk of hip and vertebral fractures with higher daily doses of oral corticosteroids compared to patients using lower doses. ${ }^{10}$ Our findings are also supported by a large case-control study that reported an increased risk of hip fractures with increasing average daily dose. ${ }^{10}$ Vestergaard et $a{ }^{14}{ }^{14}$ also reported a dose-dependent increased risk of fractures, with the greatest risk of hip fractures observed at a dose of $\geq 7.5 \mathrm{mg} /$ day. Their study was carried out in a subset of our population. In our study, an increased risk of osteoporotic, clinically symptomatic vertebral and hip fractures was observed at a dose of 7.5 to $15 \mathrm{mg} /$ day compared to patients without COPD. The perceived increased risk of hip and osteoporotic fracture with increasing cumulative dose seems to disappear after adjustment for various confounders. However, the risk of GC related fractures was reported to be strongly associated with daily dose than with cumulative dose. ${ }^{6,27}$ This may be due to misclassification of exposures to GC as participant's exposures were ascertained by interviews and prone to recall bias. Researchers have emphasised the importance of 
daily dose monitoring in patients exposed to $\mathrm{GC}$, as the risk of fracture have been seen to return towards baseline following termination of GC therapy irrespective of cumulative dose. $^{6}$

Several mechanisms have been suggested for the possible relationship between COPD and fracture. GC use has been associated to the reduction in bone mineral density and increased fracture risk, which include inhibition of steroid synthesis and inhibition over reduced calcium absorption from the gut and increased loss of osteoclast, osteoblast, insulin-like growth factor and collagen. ${ }^{28,29}$ It has been suggested that factors associated with COPD itself may contribute to loss of bone mineral density. ${ }^{30,31}$ Similarly, low dietary calcium is correlated with low BMD and increases fracture risk. ${ }^{25}$ However, the risk of fracture among patients receiving oral GCs is somewhat independent of decreased bone mineral density. ${ }^{7}$ Damage to the micro-architecture of the trabecular bone has been attributed to deformities of the vertebrae. $^{32}$ Furthermore, it is been reported that cumulative exposure to GCs correlates with the degree of the trabecular network of bones. ${ }^{33}$ Furthermore, smoking remains a major risk for COPD and may induce osteoporosis via various mechanism which includes the alteration of metabolism of calciotropic hormone; dysregulation in the production, metabolism, and binding of estradiol, altered metabolism of adrenal cortical hormone and bone angiogenesis. ${ }^{34}$

The main strength of our study was the large sample size among cases and controls. This was possible because our study was conducted using the Danish National database with roughly 5 million anonymised patient records from across Denmark. ${ }^{17}$ We considered hospitalisation and emergency visit in the past year as proxies for disease severity. ${ }^{14}$ Although we adjusted our analyses for these proxies this might not have completely corrected for the severity of the disease. Our limitations included the lack of information on smoking, alcohol use, inflammatory markers, muscle mass or strength and BMD as such we could not adjust for these potential confounders in our analysis. There is also the problem of diagnosis of vertebral fracture, which is mostly done by clinical and radiological assessment, as such asymptomatic vertebral fractures are most likely to go undetected. ${ }^{6}$ We could not independently confirm the predictive values of cases diagnosed with fractures by the general practitioner. Although a high positive predictive value $(93 \%)$ of diagnosis of fractures has been reported in the Danish database. ${ }^{26}$ This limits the possibility of non-differential misclassification. As with most observational studies, we could not rule out the possibility of misclassification of exposure to GCs. Information on potential treatment received prior to entry into the Danish national database was also not available. We also lacked information on the severity of COPD as such there may be confounding by indication. ${ }^{9}$

In conclusion, intermittent high-dose GC was not associated with an increased risk of any, osteoporotic, hip or clinically significant vertebral fractures in patients with COPD. Current GC use, however, was associated with an increased risk of hip and clinically symptomatic vertebral fracture. It is important to also note that 
COPD alone increases the risk of fracture compared to those without COPD, especially among patients with history of hospitalisation or emergency room visit for COPD. Therefore, emphasis on prophylactic treatment of fractures may not be essential in patients with COPD receiving intermittent dose of GCs, whereas this should be considered for high-dose long-term users with advanced COPD disease stage, postmenopausal women and men over 40 years.

\section{Conflict of interest}

Andrea M. Burden's salary is supported by the Canadian Institute of Health Research (CIHR) fellowship (2014-2017). All other authors declare no conflict of interest. 


\section{References}

1. Raherison C, Girodet P-O. Epidemiology of COPD. Eur Respir Rev 2009;18:213 LP-221.

2. Vestergaard P, Mosekilde L. Fracture risk in patients with celiac disease, Crohn's disease, and ulcerative colitis: A nationwide follow-up study of 16,416 patients in Denmark. Am J Epidemiol 2002;156:1-10.

3. GOLD: Global strategy for the Diagnosis, Management and Prevention of COPD, Global Initiative for Chronic Obstructive Lung Disease (GOLD). 2014. $<$ http://www.goldcopd.org >

4. Franssen FME, Spruit MA, Wouters EFM. Determinants of polypharmacy and compliance with GOLD guidelines in patients with chronic obstructive pulmonary disease. Int $J$ Chron Obstruct Pulmon Dis 2011;6:493-501.

5. Van Staa TP, Leufkens HG, Abenhaim $\mathrm{L}$, et al. Use of oral corticosteroids and risk of fractures. J Bone Min Res 2000;15:993-1000.

6. van Staa TP, Leufkens HG, Abenhaim $L$, et al. Oral corticosteroids and fracture risk: relationship to daily and cumulative doses. Rheumatology 2000;39:1383-1389.

7. De Vries F, Bracke M, Leufkens HGM et al. Fracture risk with intermittent high-dose oral glucocorticoid therapy. Arthritis Rheum 2007;56:208-214.

8. Majumdar SR, Morin SN, Lix LM, et al. Influence of recency and duration of glucocorticoid use on bone mineral density and risk of fractures: Population-based cohort study. Osteoporos Int 2013;24:2493-2498.

9. Vestergaard P, Rejnmark L, Mosekilde L. Fracture risk associated with systemic and topical corticosteroids. $J$ Intern Med 2005;257:374-384.

10. De Vries F, Pouwels S, Lammers JWJ et al. Use of inhaled and oral glucocorticoids, severity of inflammatory disease and risk of hip/femur fracture: A population-based case-control study. J Intern Med 2007;261:170-177.

11. de Vries $F$, van Staa TP, Bracke MSGM, et al. Severity of obstructive airway disease and risk of osteoporotic fracture. Eur Respir J 2005;25:879884.

12. Van Staa TP, Leufkens HGM, Cooper $\mathrm{C}$, et al. Inhaled corticosteroids and hip fracture: disease or drugs? $A m \mathrm{~J}$
Respir Crit Care Med 2003;168:128129.

13. Grossman JM, Gordon R, Ranganath VK, et al. American College of Rheumatology 2010 recommendations for the prevention and treatment of glucocorticoid-induced osteoporosis. Arthritis Care Res (Hoboken) 2010;62:1515-1526.

14. Vestergaard P, Rejnmark L, Mosekilde $\mathrm{L}$. Fracture risk in patients with chronic lung diseases treated with bronchodilator drugs and inhaled and oral corticosteroids. Chest 2007;132:1599-1607.

15. Van Staa TP, Laan RF, Barton IP, et al. Bone Density Threshold and Other Predictors of Vertebral Fracture in Patients Receiving Oral Glucocorticoid Therapy. Arthritis Rheum 2003;48:3224-3229.

16. Liu D, Ahmet A, Ward L, et al. A practical guide to the monitoring and management of the complications of systemic corticosteroid therapy. Allergy, Asthma, Clin Immunol 2013;9:30.

17. Andersen TF, Madsen M, Jørgensen J, et al.The Danish National Hospital Register. A valuable source of data for modern health sciences. Dan Med Bull 1999;46:263-8.

18. Mosbech J, Jorgensen J, Madsen M, et al. The national patient registry. Evaluation of data quality. Ugeskr Laeger 1995;157:3741-3745.

19. Nielsen GL, Sørensen HT, Zhou W, et al. The Pharmacoepidemiologic Prescription Database of North Jutland - a valid tool in pharmacoepidemiological research. Int J Risk Saf Med 1997;10:203-5.

20. Kanis $\mathrm{J}$ a. Assessment of osteoporosis at the primary health care level. World Health 2007;339.at <http://www.shef.ac.uk/FRAX/pdfs/WH O_Technical_Report.pdf>.

21. Vestergaard $P$, Prieto-Alhambra $D$, Javaid MK, et al. Fractures in users of antidepressants and anxiolytics and sedatives: Effects of age and dose. Osteoporos Int 2013;24:671-680.

22. Oshagbemi OA, Driessen JHM, Pieffers $A$, et al. Use of systemic glucocorticoids and the risk of major osteoporotic fractures in patients with sarcoidosis. Osteoporos Int 2017; Oct:28(10):2859-2866

23. McEvoy CE, Ensrud KE, Bender E, et 
al. Association between corticosteroid use and vertebral fractures in older men with chronic obstructive pulmonary disease. AmJRespirCrit Care Med 1998;157:704-709.

24. Dubois EF, Röder E, Dekhuijzen PNR, et al. Dual energy x-ray absorptiometry outcomes in male COPD patients after treatment with different glucocorticoid regimens. Chest 2002;121:1456-1463.

25. Hubbard RB, Smith CJP, Smeeth L, et al. Inhaled corticosteroids and hip fracture: a population-based casecontrol study. Am J Respir Crit Care Med 2002;166:1563-1566.

26. Vestergaard $\mathrm{P}$, Olsen ML, Johnsen, S $P$, et al. Corticosteroid use and risk of hip fracture: a population-based casecontrol study in Denmark. J Intern Med 2003;254:486-493.

27. Dykman TR, Gluck OS, Murphy WA, et al. Evaluation of factors associated with glucocorticoid-induced osteopenia in patients with rheumatic diseases. Arthritis Rheum 1985;28:361-368.

28. Canalis E. Mechanisms of glucocorticoid-induced osteoporosis. Curr Opin Rheumatol 2003;15:454457.

29. Patschan D, Loddenkemper K, Buttgereit F. Molecular mechanisms of glucocorticoid-induced osteoporosis. Bone 2001;29:498-505.

30. Praet JP, Peretz A, Rozenberg S, et al. Risk of osteoporosis in men with chronic bronchitis. Osteoporos Int 1992;2:257-261.

31. Hall GM, Spector TD, Delmas PD. Markers of bone metabolism in postmenopausal women with rheumatoid arthritis. Arthritis Rheum 1995;38:902-906.

32. Legrand E, Chappard D, Pascaretti C et al. Trabecular bone microarchitecture, bone mineral density, and vertebral fractures in male osteoporosis. J Bone Miner Res 2000;15:13-19.

33. Carbonare LD, Arlot ME, Chavassieux et al. Comparison of trabecular bone microarchitecture and remodeling in glucocorticoid induced and postmenopausal osteoporosis. J Bone Miner Res 2001;16:97-103.

34. Sarkar M, Bhardwaj R, Madabhavi I, et al. Osteoporosis in chronic obstructive pulmonary disease. Clin Med Insights Circ Respir Pulm Med 2015;9:5-21. 


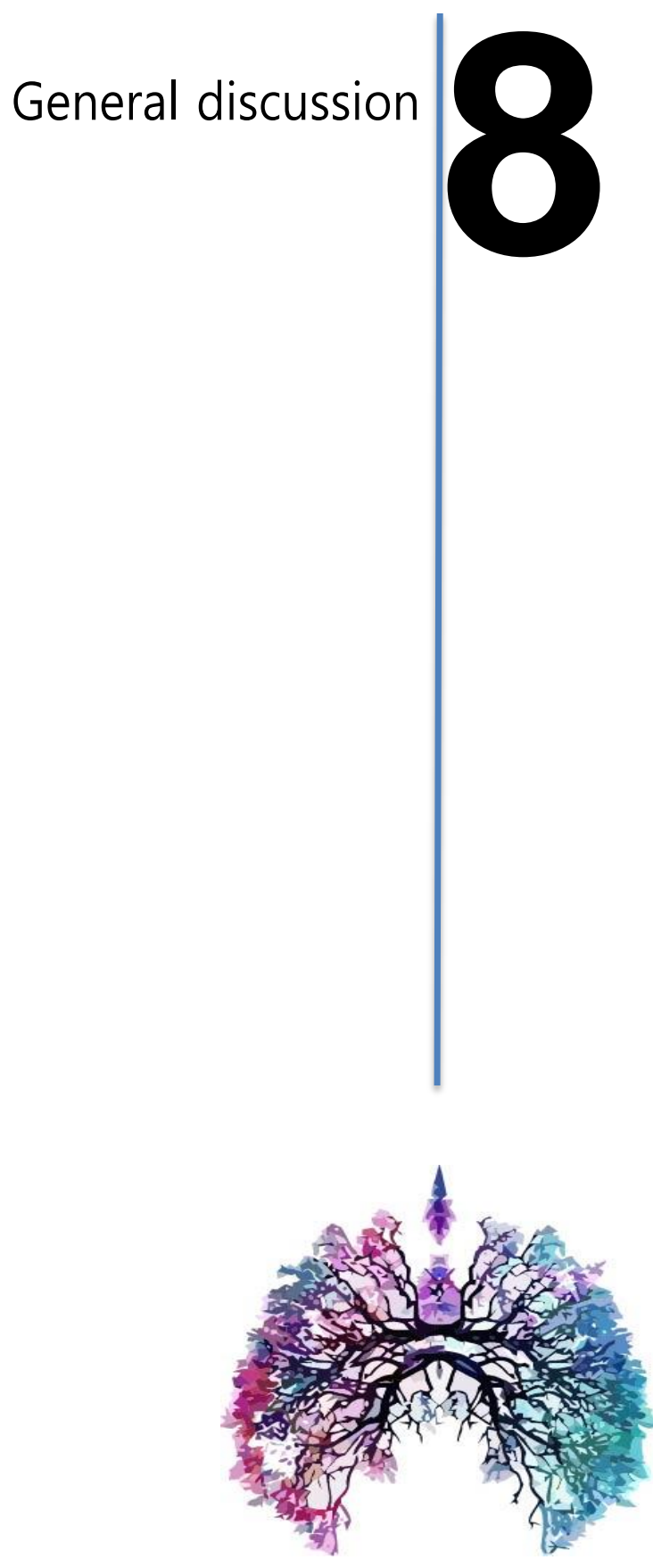


\section{INTRODUCTION}

Chronic obstructive pulmonary disease (COPD) is a major cause of morbidity and mortality worldwide and is defined by the presence of chronic respiratory symptoms and persistent airflow limitation. ${ }^{1}$ Although bronchodilators are central to the pharmacological management of COPD, patients with recurrent exacerbations are often additionally treated with inhaled corticosteroids (ICS). ${ }^{2}$ Exacerbations play a central role in the pathophysiology of COPD as they are linked to lung function decline, poor health status, and increased mortality. ${ }^{3}$ Corticosteroid use has been associated with increased risk of pneumonia and fractures. ${ }^{4,5}$ There is growing interest in precision medicine using biomarkers in COPD. ${ }^{6}$

Biomarkers such as blood eosinophils and C-reactive proteins (CRP) have been identified as important markers of inflammation in COPD. Clinical data suggest that elevated blood eosinophil counts, which is present in up to $40 \%$ of COPD patients, ${ }^{7}$ is a promising biomarker of response to ICS. ${ }^{8-11}$ Elevated blood eosinophil counts have been associated with an increased risk of exacerbations, and patients with eosinophilic inflammation responded better to ICS therapy than non-eosinophilic patients. 8,12 The exact mechanism by which ICS reduces exacerbation among eosinophilic patients remains unclear. ${ }^{9}$ Evaluation of COPD Longitudinally to Identify Surrogate End-points (ECLIPSE) investigators identified several biomarkers including CRP, believed to be an important biomarker among COPD patients. ICS has been reported to attenuate CRP levels. This dissertation investigates the role of blood eosinophil and CRP in COPD management and examines the trends in exacerbations and the risk of fractures with systemic corticosteroid use.

\section{BIOMARKERS AND INHALED CORTICOSTEROID USE IN COPD}

Recently, there has been a focus on the use of biomarkers to help guide management of COPD patients with the aim of improving COPD-related outcomes such as exacerbations. Accumulating evidence indicates that COPD patients with elevated blood eosinophil counts respond better to ICS therapy. 8,9 However, if blood eosinophils are to be useful in the clinical management of COPD, it is important to address certain concerns which includes; the correlation of eosinophils in various tissues, the stability of blood eosinophil counts over-time, clinically relevant cut-offs of blood eosinophils, role blood eosinophils and ICS in the reduction of COPD-related exacerbations. It has been established that up to $40 \%$ of patients with stable COPD have elevated blood eosinophil counts ${ }^{13}$ with reported positive correlation between blood and sputum counts. ${ }^{14-16}$ Although the strength of the correlation between blood and sputum eosinophilia is still been debated. ${ }^{17}$ Various studies have sought to establish the repeatability and reproducibility of blood eosinophil measurements in COPD patients with varying results. ${ }^{18,19}$ Previous studies have focused primarily on measurements of blood eosinophil counts among small numbers of patients, with short durations of follow-up durations typically spanning few weeks, deemed to be 
inadequate in understanding the long-term stability of blood eosinophils. There is a consensus among researchers and clinicians that for blood eosinophil counts to be central in ICS management, the long-term stability of blood eosinophil counts needed to be determined among COPD patients in clinical populations. Therefore the aim of Chapter 3 was to determine the stability of blood eosinophil counts among patients with COPD and the impact of sex, age, smoking and baseline counts. Following our investigations, we found that the stability of blood eosinophils among COPD patients was approximately $90 \%$ at 6 months, $82 \%$ at 2 years of follow-up and declined progressively irrespective of comorbidities or drug exposures. Furthermore, patients with baseline blood eosinophil counts $\geq 6 \%$ showed higher stability, age and sex also had a significant impact on blood eosinophil counts. ${ }^{20}$ While several studies reported cross-sectional data on eosinophilia in COPD, none have investigated the stability of blood eosinophil counts among COPD patients using longitudinal data. Pascoe et al, ${ }^{8}$ reported $66 \%$ prevalence of blood eosinophilia $\geq 2 \%$ in former or current smokers with moderate-to-severe COPD and a history of exacerbation. Using identical cut-offs to later, Watz et al, ${ }^{9}$ reported a prevalence of $54 \%$ in former or current smokers with severe airflow limitation and at least one exacerbation in the previous 12 months These findings extends our understanding of blood eosinophil as a potential biomarker in COPD management.

Post-hoc analyses of RCTs suggest that patients with elevated blood eosinophil counts ( $\geq 2 \%$ ) were more likely to benefit from ICS treatments. ${ }^{8}$ Thereafter, a significant number of post-hoc analyses of RCTs have been conducted to evaluate the effect of ICS on exacerbation risk reduction among COPD patients with elevated blood eosinophil counts adopting various relative blood eosinophil thresholds, with conflicting findings. ${ }^{21-23}$ These findings not only raised questions on the exact relative blood eosinophil thresholds which could best predict the beneficial effects of ICS therapy on exacerbation risk reduction but also whether relative blood eosinophil counts were useful as a guide to targeted treatments in clinical settings. A metaanalysis assessing whether relative blood eosinophil counts of $\geq 2 \%$ was effective in guiding ICS therapy found that the use of relative blood eosinophil thresholds $\geq 2 \%$ was insufficient in identifying patients who might potentially benefit from ICS treatment. ${ }^{24}$ Researchers have since reported that the use of absolute blood eosinophil counts was more robust in predicting the risk of exacerbations compared to relative counts, ${ }^{25,26}$ thus shifting the focus of investigators towards the potential of absolute blood eosinophil counts as a guide for ICS therapy in COPD. Thus, in Chapter $\mathbf{5}$ we evaluated the role of absolute or relative blood eosinophil counts in ICS-guided therapy in a large population-based COPD cohort. We found no reduced risk of COPD-related acute exacerbations or hospitalisations/accident and emergency $(A E)$ visits among patients with high relative or absolute blood eosinophil counts currently exposed to ICS. However, all-cause mortality was reduced among current ICS users with elevated relative blood eosinophil counts, although, this effect was no detected with absolute blood eosinophil counts. ${ }^{27}$ Other studies have reported the 
potential of blood eosinophils to guide ICS therapy among patients with COPD, ${ }^{8-10}$ with others reporting conflicting results. ${ }^{27}$

The exact reasons for our findings are unknown, but it is important to note that studies exploring blood eosinophil counts as a guide to ICS treatment among COPD patients have primarily included only former or current smokers. ${ }^{8-10,28}$ Smoking plays a central role in the cascade of events leading to the systemic inflammation in COPD. As such this group of patients represent a unique COPD sub-group. ${ }^{29}$ Researchers also observed that elevated blood eosinophil counts best predicts exacerbations in only a sub-group of COPD patients who were ex-smokers. ${ }^{30}$ In our study, we excluded patients with a history of asthma to avoid enrolling patients with reversible airflow limitation. However, various studies have included patients with a history of asthma who are inherently different from COPD patients. Also, patients included in prior studies had two or more exacerbations in the previous year and a significant proportion of patients were exposed to ICS at baseline. Owing to the heterogeneity of COPD, these patients are inherently different from the subjects in our study population. One study, which postulated that COPD patients with higher baseline blood eosinophil counts would have reduced exacerbation rate in response to additional ICS therapy. ${ }^{8}$ Reported differences between treatments within each eosinophil count stratum, rather than the differences in response rates between strata, hence did not directly test this hypothesis. ${ }^{31}$ Additionally, most studies, which reported conflicting findings to our study, have come from post-hoc analyses of randomised controlled trials (RCTs). The relatively short duration of follow-up and severity of COPD in these post-hoc analyses is a considerable limitation on the reported findings. ${ }^{32}$ Investigators have acknowledged that among COPD patients without a history of exacerbation as in our study, no data currently suggests that blood eosinophil counts will predict ICS response in the future..$^{8,33}$ Thus, our study provides valuable information among these patient groups and will need to be replicated in prospective studies, including pre-specified RCTs and observational studies. Essential to the idea of precision medicine is the understanding of the heterogeneous nature of COPD and the need for better management of specific groups. ${ }^{34}$ This thesis provides valuable information among newly diagnosed COPD patients in clinical settings exposed to ICS, compared to studies focused on patients with advanced disease stage, having prior history of exacerbations. ${ }^{35}$

Furthermore, discontinuation of corticosteroids is of great importance to clinicians, this is partly due to the potential adverse reactions resulting from abrupt corticosteroid discontinuation and also the documented side effects of continuous ICS exposure such as pneumonia and fractures. ${ }^{36,37}$ Post-hoc analyses of data from the Withdrawal of Inhaled Steroids during Optimized Bronchodilator Management (WISDOM) trial, suggested an increased risk of exacerbations following ICS withdrawal among COPD patients with elevated blood eosinophil counts. ${ }^{9}$ Thus, we evaluated the risk of moderate-to-severe exacerbations, severe exacerbations and all-cause mortality following the withdrawal of ICS compared to continuous ICS users among COPD patients stratified by relative and absolute eosinophil counts 
(Chapter 6). We found no increased risk of moderate and/or severe exacerbations among patients who discontinued ICS irrespective of absolute or relative blood eosinophil counts. The risk of all-cause mortality among patients who discontinued ICS was significantly higher among those with low absolute or relative blood eosinophil counts. Furthermore, we did not find patient groups at increased risk of moderate and/or severe exacerbations following various sensitivity analyses. Our results are comparable with a randomised controlled trial (RCT) which found no difference in the risk of severe exacerbations among COPD patients who discontinued ICS therapy and those who continued. ${ }^{38}$ However, post-hoc analysis of the WISDOM trial suggested that blood eosinophil counts of $\geq 4 \%$ or $\geq 300$ cells $/ \mu \mathrm{L}$ might help identify patients with greater risk of exacerbations following ICS withdrawal. ${ }^{9}$ In line with a previous study, we detected an opposite effect among patients with elevated relative blood eosinophil counts. ${ }^{10}$ The exact reasons for the disparities in our findings and the post-hoc analyses of the WISDOM trials remain uncertain. However, it is important to note that unlike in our study the WISDOM trial only enrolled patients with severe to very severe COPD, additionally all patients had a history of exacerbation and over $70 \%$ of patients in their study were exposed to ICS prior to study entry. ${ }^{9}$ A recent trial analysis evaluating the comparative effectiveness of ICS treatments showed that inclusion of patients with a history of asthma, prior ICS use, and prior exacerbations at randomisation were significant effect-modifiers resulting in depletion of susceptible, subsequently influencing exacerbation rates. ${ }^{39}$ Future studies aimed at improving precision management in COPD would benefit from excluding patients with previous or current asthma diagnosis (an important factor for fixed airway obstruction), address the withdrawal of ICS at randomisation and should stratify patients by their degree of eosinophilia. ${ }^{35,39}$

The use of a single biomarker to help guide the management of COPD is deemed a "one-eyed" approach, thus the use of several biomarkers is believed to improve robustness and precision in COPD management. ${ }^{40}$ C-reactive protein (CRP) was identified as another biomarker of significant interest in COPD. ${ }^{41}$ Elevated CRP levels have been linked with increased risk of exacerbations requiring hospitalisation and increased risk of mortality among COPD patients. Reports suggest that ICS therapy attenuates CRP levels in COPD. ${ }^{42-44}$ In Chapter 4, we explored the risk of moderate-to-severe exacerbations, severe exacerbations and all-cause mortality among COPD patients with elevated levels of CRP exposed to ICS compared to patients never exposed to ICS without elevated CRP levels. We found no reduced risk of moderate and/or severe exacerbations among COPD patients currently exposed to ICS with elevated CRP levels. However, we found an increased risk of all-cause mortality among patients with elevated CRP levels regardless of ICS exposure. Very few researchers have evaluated the role of CRP in guiding ICS therapy aimed at improvement of moderate-to-severe or severe exacerbations of COPD. Thomsen et $\mathrm{al}^{45}$ reported that patients with elevated CRP levels, fibrinogen, and leucocyte counts had increased risk of exacerbations. However, when the investigators evaluated each elevated biomarker separately, they found no significantly increased risk of frequent 
exacerbations with elevated CRP levels alone, (not in combination with other biomarkers) which is in line with the results from our study. We noted an increased risk of moderate and/or severe exacerbations when we controlled only for age and sex. After adjustments for all confounders, the observed risk disappeared. This is the first study to specifically evaluate the risk of moderate-to-severe, severe exacerbations and all-cause mortality among COPD patients currently exposed to ICS stratified by CRP levels. In a double-blind randomized placebo-controlled trial of COPD patients across 11 centers, no reduction in CRP levels was observed among COPD patients exposed to ICS with or without LABA, although serum protein D levels decreased, suggesting that ICS treatment affects lung-specific biomarkers rather than systemic inflammatory markers. ${ }^{43}$ Furthermore, the ECLIPSE investigators reported that elevated levels of CRP, fibrinogen and leukocyte counts were associated with the occurrence of exacerbations in the first year in a univariate analysis. ${ }^{46}$ However, the effect disappeared in the elevated CRP group following multivariate adjustments. A meta-analysis of 15 randomised and non-randomised studies, found that elevated CRP levels were associated with higher mortality rates among COPD patients with varying degree of ICS exposure at baseline. ${ }^{47}$ A lack of consensus on the threshold of CRP to be employed in interventions studies have led to the adoption of arbitrary cutoffs. $^{40}$ In our study, we stratified patients by several CRP cut-offs based on the distribution of CRP in our cohort.

Although ICS has been shown to attenuate the levels of CRP among patients with COPD, this reduction might not necessarily mean a reduced risk of exacerbations, considering the fact that significant numbers of COPD patients have normal CRP levels during exacerbations. ${ }^{44}$ The heterogeneity of systemic inflammation has been recognised in patients with COPD. These include a high heterogeneity in serum CRP levels and other biomarkers that have been largely attributed to individual or disease-related factors. ${ }^{48}$ In general populations, a doserelated effect has been reported between cigarette smoking and increased levels of CRP and fibrinogen. ${ }^{49,50}$ CRP levels remained elevated for close to two decades after smoking cessation. ${ }^{51}$ Although improved understanding of the effects of confounders on CRP levels exist, stability and variability of CRP remain critical to its relevance as a guide for therapeutic interventions in COPD. ${ }^{52}$ The ECLIPSE study reported CRP as the least stable biomarker assessed, with only $21 \%$ of patients having a 3 -months measurement within $25 \%$ of baseline values. ${ }^{53}$ Furthermore, CRP is known to have a half-life in plasma of 19 hours and the National Health and Nutrition Examination Survey (NHANES) observed significant short-term variability (approximately 2.5 weeks) in CRP levels, particularly at high levels. ${ }^{54}$ This, in addition to our findings makes CRP a poor biomarker for personalised management of COPD exacerbations.

\section{EXACERBATIONS OF COPD AND THE USE SYSTEMIC CORTICOSTEROIDS}

Exacerbation of chronic obstructive pulmonary disease (COPD) is defined as an acute episode of increased respiratory symptoms necessitating additional therapy. ${ }^{3}$ 
Symptoms include; dyspnoea, cough and sputum production and/or purulence. Exacerbations significantly affect the quality of life and morbidity of COPD patients ${ }^{55}$ and is a key driver for hospitalisations and re-admissions, resulting in a high burden of disease on the health system. ${ }^{56}$ Consequently, prevention of exacerbations of COPD is central to the pharmacologic treatment of the disease and multiple options for drug therapy are available. ${ }^{57}$ In the United Kingdom (UK), £253 million is spent yearly on COPD management, with more than half of the costs attributed to exacerbations. ${ }^{58}$ Furthermore, COPD-related mortality has increased from 2004 to 2012 while the incidence of COPD decreased and then remained stable over the same period. COPD results in over a million bed days and 140,000 hospital admissions each year in the UK. ${ }^{59}$ In Chapter 2, we examined the incidence rates of moderate and severe exacerbations by age and gender within the UK primary care setting. While several studies have evaluated the incidence and prevalence of COPD as a disease, only a few studies have considered the trend in exacerbations among COPD patients. Our study showed a significant increase in the incidence rates from 2005 to 2013 for the primary endpoint, any exacerbations of COPD. For severe exacerbations, incidence rates increased from 2008 to 2013. Women had higher incidence rates of any exacerbations compared to men throughout the study period but they had similar incidence rates of severe exacerbations for COPD from 2005 to 2013. The incidence rate of any exacerbations for COPD was higher in patients 80 years and older from 2005 to 2008, after which this trend was not observed. Fuhrman et al,$^{60}$ examined the temporal trends of acute exacerbations and related hospitalisations from 1998 to 2007 in France, found that admission rates increased significantly, especially among females. Although our study reported an increase in severe exacerbations there were only slight differences by gender for all years. Another study conducted in Brazil found no changes in hospitalisation rates from 1998 to $2009 .{ }^{61}$ The exact reason for the observed trends in our study remains unknown. However, it could be linked to various factors; while emphasis has been on adherence to treatment guidelines by general practitioners (GPs) as a means of mitigating COPD-related exacerbations, a significant dissociation has been reported between recommendations of guidelines and actual management of COPD patients. ${ }^{62}$ It has been reported that COPD patients in the UK were not managed in accordance with recommendations of the Global Initiative of Chronic obstructive Lung Disease (GOLD) and the National Institute for Health and Care Excellence (NICE), with a substantial amount of patients receiving inappropriate treatments. ${ }^{55}$ Despite treatment advances in COPD management, we found no objective reduction in exacerbations in our study. In addition to factors mentioned earlier, low adherence to therapy ${ }^{63}$ and improper inhaler technique among COPD patients ${ }^{57}$ may have contributed to our findings. Similarly, variations in the incidence rates of exacerbations seem to follow the incidence of influenza $A$ in the UK, suggesting that this might have had an impact on our results. ${ }^{64}$

Among patients with acute COPD exacerbations, short courses of systemic GCs are prescribed in order to help reduce exacerbations, shorten recovery time and shorten the length of hospital stay. ${ }^{65}$ Although not recommended by current 
international guidelines, a proportion of COPD patients are chronically treated with low-dose oral GCs. ${ }^{66}$ The detrimental effects of long-term exposure to systemic corticosteroids and the risk of fractures have been well documented. ${ }^{67-69}$ However, there is limited information, on intermittent exposure to high-dose systemic corticosteroids and fracture risk in population-based settings. ${ }^{70}$ Hence, In Chapter 7, we investigated the effects of intermittent high-dose glucocorticoids (GCs) use on fracture risk among patients with COPD, the impact of proxies of disease severity and the effect of dose. Using a large population-based COPD cohort, we found that exposure to intermittent high-dose glucocorticoids was not associated with an increased risk of any, osteoporotic, hip and clinically symptomatic vertebral fractures among COPD patients compared to patients without COPD. Furthermore, we showed that proxies of disease severity (hospitalisations and emergency visits for COPD in the past year) were associated with an increased risk of any, osteoporotic, hip and clinically symptomatic vertebral fractures among patients with COPD compared to patients without COPD. ${ }^{71}$ Our findings are in-line with a large cohort study exploring the risk of intermittent-high dose GCs and fracture risk ${ }^{70}$ and expands on other population-based studies. ${ }^{67,68}$ Based on our findings, we conclude that emphasis on prophylactic treatment of fractures may not be essential in patients with COPD receiving intermittent dose of GCs, however, this should be considered among highdose long-term users with advanced COPD disease stage, postmenopausal women and men over 40 years.

\section{CLINICAL IMPLICATIONS AND FUTURE RESEARCH DIRECTIONS}

This thesis investigates the role of blood eosinophil counts and CRP in COPD management and examines the trends in COPD-related exacerbations and the risk of fractures with systemic corticosteroid use. In the drive towards precision medicine in COPD management, this dissertation provided the first population-based evidence on the stability of blood eosinophil counts as a biomarker for targeted corticosteroid treatment among patients with COPD. We reported relatively stable (variable) blood eosinophil counts among COPD patients over time. Our work on the stability of blood eosinophil counts broadens the current knowledge of this biomarker among COPD patients in general practice and was included in the GOLD 2019 recommendations for the management of patients with COPD. However, in a large real-life cohort of COPD patients, we did not find evidence supporting the role of blood eosinophil counts as a guide to ICS use among patients with COPD. We also found that while CRP might be useful in detecting acute infections in COPD, it does not seem to have the potential to guide ICS treatment among COPD patients. Currently available evidence on the potential for blood eosinophil to guide ICS therapy in COPD has come from post-hoc analyses of previous studies. Our findings should be interpreted and adapted by clinicians in the light of the patients included in our studies. Additional evidence on the role of biomarkers in COPD management is needed from well-designed observational studies and clinical trials to confirm our findings. Owing to the 
heterogeneity of COPD, It is important that researchers pay particular attention to the selection of study participants, patient follow-up, exposure to ICS at study entry, prior asthma and exacerbation history.

Furthermore, this dissertation provides an understanding of the trends of moderate and/or severe exacerbations by age and sex among patients with COPD. Based on our findings policies and interventions aimed toward reducing exacerbations should be especially targeted at women and older patients with COPD. Additionally, it is important that clinicians adhere to current treatment guidelines, so as to optimize treatment and reduce episodes of exacerbations, as discordance has been found between recommendations of guidelines for COPD management and actual clinical practice. Considering the negative impacts of COPD-related exacerbations on patients and the health system, the trends of exacerbations should be explored in other general practice settings. The efficacy and safety of intermittent high-dose systemic corticosteroids in COPD management are essential. In this thesis, we found no increased risk of fractures among COPD patients, exposed to high-dose intermittent GCs in our study. Therefore, clinicians should opt for prophylactic treatment of patients receiving long-term high-dose GC or among post-menopausal women. Prophylactic treatment of COPD patients receiving high-dose intermittent GCs may not be necessary.

In recent times, there has been extensive research work, geared towards understanding the role of biomarkers in the management of COPD among patients with severe to very severe disease and prior history of exacerbations. Considering the heterogeneous nature of COPD, and the increasing trends of exacerbations among newly diagnosed patients. It is therefore imperative that future research is geared towards understanding the role of biomarkers in guiding therapy among newly diagnosed COPD patients. 


\section{References}

1. GOLD. Global strategy for the prevention, diagnosis and treatment of chronic obstructive pulmonary disease (2019 Report). 2018. https://goldcopd.org/wpcontent/uploads/2018/11/GOLD-2019v1.7-FINAL-14Nov2018-WMS.pdf. Accessed November 15, 2018.

2. Calverley PMA, Anderson JA, Celli B, et al. Salmeterol and fluticasone propionate and survival in chronic obstructive pulmonary disease. $N$ Engl J Med. 2007;356(8):775-789.

3. Wedzicha JA, Seemungal TA. COPD exacerbations: defining their cause and prevention.

Lancet. 2007;370(9589):786-796.

4. Suissa S, Patenaude V, Lapi F, et al. Inhaled corticosteroids in COPD and the risk of serious pneumonia. Thorax. 2013;68(11):1029-1036.

5. Crim C, Calverley PMA, Anderson JA et al. Pneumonia risk in COPD patients receiving inhaled corticosteroids alone or in combination: TORCH study results. Eur Respir J. 2009;34(3):641-7

6. Wedzicha JA. Eosinophils as Biomarkers of Chronic Obstructive Pulmonary Disease Exacerbation Risk. Maybe Just for Some? 2016; 193(9):937-8.

7. Vedel-Krogh S, Nielsen SF, Lange P, et al. Blood Eosinophils and Exacerbations in COPD: the Copenhagen General Population Study. Am J Respir Crit Care Med. 2015:rccm.201509-18690C.

8. Pascoe S, Locantore N, Dransfield MT, et al. Blood eosinophil counts as markers of response to inhaled corticosteroids in COPD? -Authors' reply. Lancet Respir Med. 2015;3(8):e27.

9. Watz H, Tetzlaff K, Wouters EFM, et al. Blood eosinophil count and exacerbations in severe chronic obstructive pulmonary disease after withdrawal of inhaled corticosteroids: A post-hoc analysis of the WISDOM trial. Lancet Respir Med. 2016;4(5):390-398.

10. Roche N, Chapman KR, Vogelmeier $\mathrm{CF}$, et al. Blood Eosinophils and Response to Maintenance COPD Treatment: Data from the FLAME Trial. Am J Respir Crit Care Med. 2017;195(9):1189-1197.

11. Calverley PMA, Tetzlaff K, Vogelmeier $\mathrm{C}$, et al. Eosinophilia, Frequent Exacerbations, and Steroid Response in Chronic Obstructive Pulmonary Disease. Am J Respir Crit Care Med. 2017; 196(9):1219-1221.

12. Price D, Rigazio A, Postma D, et al. Blood eosinophilia and the number of exacerbations in COPD patients. Eur Respir J. 2014;44(Suppl 58).

13. Saha S, Brightling CE. Eosinophilic airway inflammation in COPD. Int $J$ Chron Obstruct Pulmon Dis. 2006;1(1):39-47.

14. Shrimanker R, Thulborn SJ, Mistry V, et al. The Peripheral Blood Eosinophil Count as a Biomarker of Eosinophilic Airway Inflammation in Patients with Asthma and COPD. Experience from a Single Centre. In: A33. CLINICAL STUDIES IN OBSTRUCTIVE LUNG DISEASE. American Thoracic Society International Conference. American Thoracic Society; 2017:A1343-A1343.

15. Negewo N, McDonald V, Baines K, et al. Can blood eosinophils predict sputum eosinophils in stable COPD? Eur Respir J. 2015;46(suppl 59).

16. Hastie AT, Martinez FJ, Curtis JL, et al. Association of sputum and blood eosinophil concentrations with clinical measures of COPD severity: an analysis of the SPIROMICS cohort. Lancet Respir Med. 2017;5(12):956967.

17. Kostikas K, Brindicci C, Patalano F. Blood Eosinophils as Biomarkers to Drive Treatment Choices in Asthma and COPD. Curr Drug Targets. 2018;19(16):1882-1896.

18. Balkissoon R. COPD association and repeatability of blood biomarkers in the ECLIPSE cohort. COPD J Chronic Obstr Pulm Dis. 2012;9(1):84.

19. Bafadhel M, McKenna S, Terry S, et al. Blood eosinophils to direct corticosteroid treatment of exacerbations of chronic obstructive pulmonary disease: A randomized placebo-controlled trial. Am J Respir Crit Care Med. 2012;186(1):48-55.

20. Oshagbemi OA, Burden AM, Braeken DCW, et al. Stability of blood eosinophils in patients with chronic obstructive pulmonary disease and in control subjects, and the impact of sex, age, smoking, and baseline counts. Am J Respir Crit Care Med. 2017;195(10).

21. Barnes NC, Sharma R, Lettis S, et al. Blood eosinophils as a marker of response to inhaled corticosteroids in COPD. Eur Respir J. 2016:1374-1382. 
22. Pavord ID, Lettis S, Locantore N, et al. Blood eosinophils and inhaled corticosteroid/long-acting $\beta$-2 agonist efficacy in COPD. Thorax. 2016;71(2):118-125.

23. Zysman M, Burgel PR, Paillasseur JL, et al. Relationship between blood eosinophil count (Eos), clinical characteristics and mortality of patients with COPD. Eur Respir J. 2016;48(suppl 60).

24. Vos T, Flaxman AD, Naghavi M, et al. Years lived with disability (YLDs) for 1160 sequelae of 289 diseases and injuries 1990-2010: A systematic analysis for the Global Burden of Disease Study 2010. Lancet. 2012;380(9859):2163-2196.

25. Zeiger RS, Tran TN, Butler RK, et al. Relationship of Blood Eosinophil Count to Exacerbations in Chronic Obstructive Pulmonary Disease. $J$ allergy Clin Immunol Pract. 2018;6(3):944-954.e5.

26. Yun JH, Lamb A, Chase R, et al. Blood eosinophil count thresholds and exacerbations in patients with chronic obstructive pulmonary disease. $J$ Allergy Clin Immunol. 2018;141(6):2037-2047.e10.

27. Oshagbemi OA, Franssen FME, Braeken DCW, et al. Blood eosinophilia, use of inhaled corticosteroids, and risk of COPD exacerbations and mortality. Pharmacoepidemiol Drug Saf. 2018;0(0).

28. Chapman KR, Hurst JR, Frent S-M, et al. Long-Term Triple Therapy Deescalation

Indacaterol/Glycopyrronium in Patients with Chronic Obstructive Pulmonary Disease (SUNSET): A Randomized, Double-Blind, Triple-Dummy Clinical Trial. Am J Respir Crit Care Med. 2018;198(3):329-339.

29. Kerkhof $M$, Freeman $D$, Jones $R$, Chisholm A, Price DB. Predicting frequent COPD exacerbations using primary care data. Int $J$ COPD. 2015;10:2439-50

30. Kerkhof M, Sonnappa S, Postma DS, et al. Blood eosinophil count and exacerbation risk in patients with COPD. Eur Respir J. 2017;50(1).

31. Groenke L, Disse B. Blood eosinophil counts as markers of response to inhaled corticosteroids in COPD? Lancet Respir Med. 2015;3(8):e26.

32. Eriksson G, Calverley PM, Jenkins CR, et al. The effect of COPD severity and study duration on exacerbation outcome in randomized controlled trials. Int J Chron Obstruct Pulmon Dis. 2017;12:1457-1468.

33. Pavord ID. COUNTERPOINT: Should an Attempt Be Made to Withdraw Inhaled Corticosteroids in All Patients With Stable GOLD $3(30 \%</=$ FEV $1<$ $50 \%$ Predicted) COPD? No. Chest. 2018;153(4):782-784.

34. Hurst JR. Precision Medicine in Chronic Obstructive Pulmonary Disease. Am J Respir Crit Care Med. 2016;193(6):593-594.

35. Soriano JB, Polverino F, Cosio BG. What is Early COPD and Why is it Important? Eur Respir J. January 2018:1801448

36. Vogelmeier C, Worth H, Buhl R, et al. "Real-life" inhaled corticosteroid withdrawal in COPD: a subgroup analysis of DACCORD. Int $J$ Chron Obstruct Pulmon Dis. 2017;12:487494.

37. Suissa S, Patenaude V, Lapi F, Ernst $P$. Inhaled corticosteroids in COPD and the risk of serious pneumonia. Thorax. 2013;68(11):1029 LP-1036.

38. Magnussen H, Disse B, RodriguezRoisin R, et al. Withdrawal of Inhaled Glucocorticoids and Exacerbations of COPD. $N$ Engl J Med. 2014;371(14):1285-1294.

39. Suissa S, Ariel A. Triple therapy trials in COPD: a precision medicine opportunity. Eur Respir J. 2018;52(6):1801848.

40. Müller B, Tamm M. Biomarkers in acute exacerbation of chronic obstructive pulmonary disease: Among the blind, the one-eyed is king. Am J Respir Crit Care Med. 2006;174(8):848-849.

41. Comes A, lanosi ES, Gabriela Jimborean. Inflammatory Biomarkers in Chronic Obstructive Pulmonary Disease. J Interdiscip Med. 2016;1:12.

42. Sin DD, Lacy P, York E, Man SFP. Effects of Fluticasone on Systemic Markers of Inflammation in Chronic Obstructive Pulmonary Disease. Am J Respir Crit Care Med. 2004;170(7):760-765.

43. Sin DD, Man SFP, Marciniuk DD, et al. The effects of fluticasone with or without salmeterol on systemic biomarkers of inflammation in chronic obstructive pulmonary disease. $\mathrm{Am} \mathrm{J}$ Respir Crit Care Med. 2008;177(11):1207-1214.

44. Lin $\mathrm{Y}-\mathrm{H}$, Liao $\mathrm{X}-\mathrm{N}$, Fan $\mathrm{L}-\mathrm{L}$, et al.. Long-term treatment with budesonide/formoterol attenuates circulating CRP levels in chronic obstructive pulmonary disease patients 
of group D. PLoS One. 2017;12(8):e0183300.

45. Thomsen $M$, Ingebrigtsen TS, Marott $\mathrm{JL}$, et al. Inflammatory biomarkers and exacerbations in chronic obstructive pulmonary disease. JAMA - J Am Med Assoc. 2013;309(22):2353-2361.

46. Hurst JR, Vestbo J, Anzueto A, et al. Susceptibility to exacerbation in chronic obstructive pulmonary disease. $N$ Engl J Med. 2010;363(12):11281138.

47. Leuzzi G, Galeone C, Taverna F, et al. C-reactive protein level predicts mortality in COPD: a systematic review and meta-analysis. Eur Respir Rev. 2017;26(143).

48. Breyer M, P A Rutten E, Spruit M, et al. Systemic Inflammation in Patients with Chronic Obstructive Pulmonary Disease: Results from the Cosmic Study. Open J Respir Dis. February 2012;2:3

49. Kannel WB, D'Agostino RB, Belanger AJ. Fibrinogen, cigarette smoking, and risk of cardiovascular disease: insights from the Framingham Study. Am Heart J. 1987;113(4):1006-1010.

50. Bazzano LA, He J, Muntner P, et al. Relationship between cigarette smoking and novel risk factors for cardiovascular disease in the United States. Ann Intern Med. 2003;138(11):891-897.

51. Wannamethee SG, Lowe GDO, Shaper AG, et al. Associations between cigarette smoking, pipe/cigar smoking, and smoking cessation, and haemostatic and inflammatory markers for cardiovascular disease. Eur Heart J. 2005;26(17):1765-1773.

52. Agusti A, Sin DD. Biomarkers in COPD. Clin Chest Med. 2014;35(1):131-141.

53. Dickens JA, Miller BE, Edwards LD, et al. COPD association and repeatability of blood biomarkers in the ECLIPSE cohort. Respir Res. 2011;12(1):146.

54. Bower JK, Lazo M, Juraschek SP, et al. Within-person variability in highsensitivity C-reactive protein. Arch Intern Med. 2012;172(19):1519-1521.

55. Price D, West D, Brusselle $G$, et al. Management of COPD in the UK primary-care setting: An analysis of real life prescribing patterns. Int $J$ COPD. 2014;9:889-905.

56. Oshagbemi OA, Keene SJ, Driessen $\mathrm{JHM}$, et al. Trends in moderate and severe exacerbations among COPD patients in the UK from 2005 to 2013. Respir Med. 2018;144:1-6

57. Vogelmeier CF, Criner GJ, Martinez
FJ, et al. Global Strategy for the Diagnosis, Management, and Prevention of Chronic Obstructive Lung Disease 2017 Report. GOLD Executive Summary. Am J Respir Crit Care Med. 2017;195(5):557-582.

58. Qureshi H, Sharafkhaneh A, Hanania NA. Chronic obstructive pulmonary disease exacerbations: latest evidence and clinical implications. Ther $A d v$ Chronic Dis. 2014;5(5):212-227.

59. Snell N, Strachan D, Hubbard R, et al. S32 Epidemiology of chronic obstructive pulmonary disease (COPD) in the uk: findings from the british lung foundation's 'respiratory health of the nation' project. Thorax. 2016;71(Suppl 3):A20.1-A20.

60. Fuhrman $\mathrm{C}$, Roche $\mathrm{N}$, Vergnenègre $\mathrm{A}$, Zureik $M$, et al. Hospital admissions related to acute exacerbations of chronic obstructive pulmonary disease in France, 1998-2007. Respir Med. 2011;105(4):595-601.

61. Antunes FP, Costa M da CN, Paim JS, et al. Trends in hospitalizations for respiratory diseases in Salvador, Bahia State, Brazil, 1998-2009. Cad Saude Publica. 2012;28(5):869-877.

62. Chalmers JD, Tebboth A, Gayle A, Ternouth $A$, et al. Determinants of initial inhaled corticosteroid use in patients with GOLD A/B COPD: a retrospective study of UK general practice. NPJ Prim Care Respir Med. 2017;27:43.

63. Wisniewski D, Porzezinska M, Gruchala-Niedoszytko M, et al. Factors influencing adherence to treatment in COPD patients and its relationship with disease exacerbations. Pneumonol Alergol Pol. 2014;82(2):96104.

64. Hardelid P, Rait G, Gilbert R, Petersen I. Recording of influenza-like illness in UK primary care 1995-2013: Cohort study. PLoS One. 2015;10(9).

65. GOLD: Global Strategy for the Diagnosis, Management and Prevention of COPD, Global Initiative for Chronic Obstructive Lung Disease (GOLD).; 2014 http://www.goldcopd.org.

66. Franssen FME, Spruit MA, Wouters EFM. Determinants of polypharmacy and compliance with GOLD guidelines in patients with chronic obstructive pulmonary disease. Int $J$ Chron Obstruct Pulmon Dis. 2011;6:493-501.

67. Van Staa TP, Leufkens HG, Abenhaim $L$, et al. Use of oral corticosteroids and risk of fractures. $J$ Bone Min Res. 2000;15(6):993-1000. 
68. van Staa TP, Leufkens HG, Abenhaim L, Zhang B, Cooper C. Oral corticosteroids and fracture risk: relationship to daily and cumulative doses.

Rheumatology. 2000;39(12):1383-1389.

69. Majumdar SR, Morin SN, Lix LM, et al. Influence of recency and duration of glucocorticoid use on bone mineral density and risk of fractures: Population-based cohort study. Osteoporos Int. 2013;24(9):2493-2498.
70. De Vries F, Bracke M, Leufkens HGM, et al. Fracture risk with intermittent high-dose oral glucocorticoid therapy. Arthritis Rheum. 2007;56(1):208-214.

71. de Vries F, van Staa TP, Bracke MSGM, et al. Severity of obstructive airway disease and risk of osteoporotic fracture. Eur Respir J. 2005;25(5):879884. 



\title{
Appendices
}

\author{
Summary \\ Samenvatting \\ Valorisation Addendum \\ Acknowledgements \\ List of Publications \\ About the Author
}

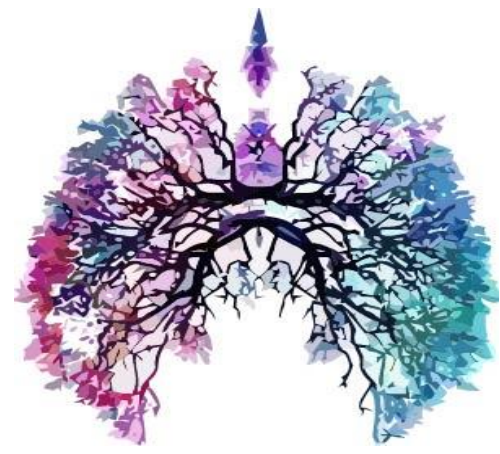




\section{Summary}

\section{Introduction}

Chronic obstructive pulmonary disease (COPD) is a common, preventable and treatable disease characterised by relentless respiratory symptoms and airflow limitation that is due to airway and/or alveolar aberrations usually triggered by significant exposure to noxious gases. Diagnosis of COPD should be considered in subjects with respiratory symptoms such as dyspnoea, chronic cough, excessive sputum production and history of tobacco use, although occupational and indoor air pollution also contributes to the disease onset. Spirometry is employed in COPD diagnosis. COPD remains a leading cause of morbidity and mortality worldwide and it is projected to be the third leading cause of death worldwide by 2030 . Additionally, the disease is associated with huge social and economic impacts.

The natural course of COPD is characterised by acute exacerbations, which are defined as the worsening of a patient's condition beyond normal day-to-day variation in symptoms that requires additional pharmacotherapy. Exacerbations of COPD have a considerable impact on health status, lung function and exercise capacity. The goal of management of patients with COPD is to reduce symptoms, improve exercise tolerance, health status and decrease the frequency and severity of exacerbations. In the United Kingdom (UK), £253 million is spent yearly on COPD management, with over half of the costs attributed to exacerbations. Consequently, prevention of exacerbations of COPD is central to the pharmacologic treatment of the disease and multiple options for drug therapy are needed.

Biomarkers such as blood eosinophils and C-reactive proteins (CRP) have been identified as important markers of inflammation in COPD. Clinical data suggest that elevated blood eosinophil counts, present in up to $40 \%$ of COPD patients, is a promising biomarker of response to inhaled corticosteroids (ICS). Elevated eosinophil counts have been associated with an increased risk of exacerbations, and patients with eosinophilic inflammation responded better to ICS therapy than non-eosinophilic patients. The Evaluation of COPD Longitudinally to Identify Surrogate End-points (ECLIPSE) investigators identified several biomarkers including CRP believed to be an important marker in COPD. ICS have been reported to attenuate CRP levels. Therefore the current dissertation investigates the role of blood eosinophil and CRP in COPD management. We also examined the trends in exacerbations and the risk of fractures with systemic corticosteroid use.

\section{Findings}

In Chapter 3 we determine the stability of blood eosinophil counts among patients with COPD and the impact of sex, age, smoking and baseline counts. Following our investigations, we found that the stability of blood eosinophils among COPD patients was approximately $90 \%$ at 6 months, $82 \%$ at 2 years of follow-up and declined 
progressively irrespective of comorbidities or drug exposures. Furthermore, patients with baseline blood eosinophil counts $\geq 6 \%$ showed higher stability, age and sex also had significant impact on blood eosinophil counts. This is the first study to have investigated the stability trajectory of blood eosinophil counts among COPD patients using longitudinal data. This finding extends our understanding of blood eosinophil as a potential biomarker in COPD management.

Post-hoc analyses of RCTs suggest that patients with elevated blood eosinophil counts $(\geq 2 \%)$ are more likely to benefit from ICS treatments. Thus, in Chapter $\mathbf{5}$ we evaluated the role of absolute or relative blood eosinophil counts in ICS guided therapy among patients with COPD in general practice settings. We found no reduced risk of COPD-related acute exacerbations or hospitalisations/ accident and emergency (AE) visits among patients with high blood eosinophil counts currently exposed to ICS. However, all-cause mortality was reduced among current ICS users with elevated relative blood eosinophil counts, although this effect was not detected with absolute eosinophil counts. While post-hoc analyses of data have reported the potential of blood eosinophil counts as a guide for ICS therapy among COPD patients, conflicting results abound.

Furthermore, discontinuation of corticosteroids is of great importance to clinicians, this is partly due to the potential adverse reactions resulting from abrupt corticosteroid discontinuation and the documented adverse effects of continuous ICS exposure such as pneumonia and fractures. Thus, in Chapter 6 we evaluated the risk of moderate-to-severe exacerbations, severe exacerbations and all-cause mortality following the withdrawal of ICS compared to continuous ICS users among COPD patients stratified by elevated relative and absolute eosinophil counts. We found no increased risk of moderate and/or severe exacerbations among patients who discontinued ICS irrespective of absolute or relative blood eosinophil counts. The risk of all-cause mortality among patients who discontinued ICS was significantly higher among those with low absolute or relative blood eosinophil counts. We did not find patient groups at increased risk of moderate and/or severe exacerbations following various sensitivity analyses.

The use of a single biomarker to help guide the management of COPD is deemed a "one-eyed" approach; as such we also evaluated the role of CRP in COPD management. Elevated CRP levels have been associated with increased risk of exacerbation requiring hospitalisation and increased risk of mortality among COPD patients. Reports suggest that ICS therapy attenuates CRP levels in COPD. In Chapter 4, we explored the risk of moderate-to-severe exacerbations, severe exacerbations and all-cause mortality among COPD patients with elevated levels of CRP exposed to ICS compared to patients never exposed to ICS without elevated CRP levels. We found no reduced risk of moderate and/or severe exacerbations among COPD patients currently exposed to ICS with elevated CRP levels. However, we found an increased risk of all-cause mortality among patients with elevated CRP levels regardless of ICS exposure. Very few researchers have evaluated the role of CRP in guiding ICS use in the improvement of moderate-to-severe or severe 
exacerbations. Although ICS has been shown to attenuate the CRP levels among patients with COPD, this reduction in CRP levels might not necessarily mean a reduced risk of exacerbations, considering the fact that significant numbers of COPD patients have normal CRP levels during exacerbations. The heterogeneity of systemic inflammation has been recognised in patients with COPD. These include a high heterogeneity in serum CRP levels and other biomarkers that have been largely attributed to host or disease-related factors.

Considering the burden, and high cost associated with COPD exacerbations, it was essential to understand the trends of exacerbations among COPD patients over time. Consequently, in Chapter 2 we examined the incidence rates of moderate and severe exacerbations of COPD by age and gender within the UK primary care setting. While several studies have evaluated the incidence and prevalence of COPD as a disease, only a few studies have considered the trend in exacerbations among COPD patients. We found a significant increase in the incidence rates from 2005 to 2013 for the primary endpoint, any exacerbations of COPD. For severe exacerbations, incidence rates increased from 2008 to 2013. Women had higher incidence rates of any exacerbations compared to men throughout the study period but they had similar incidence rates of severe exacerbations for COPD from 2005 to 2013. Incidence rates of any exacerbations of COPD were higher in patients 80 years and older from 2005 to 2008 , after which this trend was not observed. We found no objective reduction in exacerbations in our study. In addition to factors mentioned earlier, low adherence to therapy, and improper inhaler technique among COPD patients may have contributed to our findings. Similarly, variations in the incidence of exacerbations seem to follow the incidence of influenza A in the UK, suggesting that this might have had an impact on our results.

The long-term exposure to systemic corticosteroids and the risk of fractures have been well documented. However, In Chapter 7, we investigated the effects of intermittent high-dose glucocorticoids (GCs) use and fracture risk among patients with COPD, the impact of proxies of disease severity and the effect of dose. Using a large population-based COPD cohort, we found that exposure to intermittent high-dose glucocorticoids was not associated with an increased risk of any, osteoporotic, hip and clinically symptomatic vertebral fractures in COPD patients compared to patients without COPD. Furthermore, we showed that proxies of disease severity (hospitalisations and emergency visits for COPD in the past year) were associated with an increased risk of any, osteoporotic, hip and clinically symptomatic vertebral fractures among patients with COPD compared to patients without COPD.

\section{Conclusion}

In chapter 8, we discussed the clinical implications and future perspectives of this thesis for researchers and clinicians. COPD is a heterogeneous disease and biomarkers play an important role in the disease process. The exact mechanism by which ICS reduces exacerbations among patients with elevated blood eosinophil counts remains unclear. However, in view of the findings of this thesis, we conclude 
that considering the rising trends of COPD exacerbations, among newly diagnosed COPD patients. It is important that future research is geared towards understanding the role of biomarkers in the management of newly diagnosed COPD patients, taking into consideration prior exacerbations, history of asthma, and ICS exposure prior to follow-up. 


\section{Samenvatting}

\section{Introductie}

Chronisch obstructieve longziekten (COPD) is een alledaagse aandoening die zowel voorkomen, als behandeld kan worden. COPD wordt gekenmerkt door aanhoudende symptomen in de luchtwegen en een gelimiteerde luchtstroom. Dit wordt veroorzaakt door afwijkingen aan de luchtwegen en/of de longblaasjes, als gevolg van een significante blootstelling aan schadelijke gassen. De diagnose van COPD moet overwogen worden bij personen met respiratoire symptomen, zoals kortademigheid, chronisch hoesten, buitensporige slijmproductie en een historie van roken, hoewel luchtvervuiling ook bij kan dragen aan het ontstaan van de aandoening. Bij de diagnose van COPD wordt gebruik gemaakt van spirometrie. COPD is de belangrijkste oorzaak van morbiditeit en mortaliteit wereldwijd en er wordt geschat dat dit in 2030 wereldwijd de derde plek zal innemen als belangrijkste oorzaak. Daarnaast is de aandoening geassocieerd met een grote sociale en economische impact.

Het natuurlijk verloop van COPD wordt gekenmerkt door acute exacerbaties, die gedefinieerd zijn als een periode waarin de conditie van de patiënt ernstiger verslechtert dan toe te wijzen is aan de gemiddelde dagelijkse variatie. Voor de behandeling van deze acute exacerbaties is aanvullende farmacotherapie noodzakelijk. COPD-exacerbaties hebben een aanzienlijke impact op de gezondheidstoestand, de longfunctie en het vermogen om oefeningen uit te voeren. Het doel van de behandeling van patiënten met COPD is om de symptoomlast te verlagen, de gezondheidstoestand en het vermogen om oefeningen uit te voeren te verbeteren, en de frequentie en de ernst van exacerbaties te verlagen. In het Verenigd Koninkrijk (UK) wordt jaarlijks 253 miljoen pond uitgegeven aan de COPDbehandeling, waarbij meer dan de helft uitgegeven wordt aan de behandeling van acute exacerbaties. Om die reden is de preventie van de acute exacerbaties een centraal doel binnen de farmacologische behandeling van COPD-patiënten en hiervoor zijn verschillende therapieën beschikbaar.

Biomarkers, zoals bloed eosinofielen en C-reactief proteïne (CRP), zijn reeds geïdentificeerd als belangrijke ontstekingsmarkers in COPD. Klinische resultaten laten zien dat een verhoogd aantal bloed eosinofielen, aanwezig bij $40 \%$ van de COPDpatiënten, een veelbelovende biomarker is voor de mogelijke respons op inhalatiecorticosteroïden. Een verhoogd aantal bloed eosinofielen is geassocieerd met een toegenomen risico op exacerbaties, en patiënten met een eosinofiele ontsteking reageren beter op een behandeling met inhalatiecorticosteroïden dan patiënten zonder verhoogd aantal eosinofielen. De onderzoekers van de ECLIPSE-studie (Evaluation of COPD Longitudinally to Identify Surrogate End-points) hebben verschillende biomarkers geïdentificeerd, zoals CRP, waarvan men verondersteld dat het een belangrijke marker is in COPDpatiënten. Daarnaast is gerapporteerd dat inhalatiecorticosteroïden in staat zijn om 
het CRP-niveau te verlagen. Om die reden wordt in dit proefschrift gekeken naar de rol van het aantal bloed eosinofielen en CRP binnen de behandeling van COPDpatiënten. Daarnaast is ook gekeken naar trends binnen het optreden van COPDexacerbaties en het fractuurrisico bij systemisch corticosteroïde-gebruik.

\section{Uitkomsten}

In hoofdstuk 3 hebben we gekeken naar de stabiliteit van het aantal bloed eosinofielen bij COPD-patiënten en de impact van leeftijd, geslacht, roken en de nulmeting. In het onderzoek vonden wij dat de stabiliteit van bloed eosinofielen bij COPD-patiënten na zes maanden ongeveer $90 \%$ was, en na twee jaar $82 \%$. De stabiliteit van bloed eosinofielen nam geleidelijk af in de tijd wat onafhankelijk was van de comorbiditeiten of de blootstelling aan geneesmiddelen. Daarnaast hebben patiënten met een nulmeting (van het aantal bloed eosinofielen) groter dan $6 \%$ een grotere stabiliteit. De leeftijd en het geslacht van de patiënt had daarnaast ook een significant effect op het aantal bloed eosinofielen. Dit is de eerste studie waarbij het stabiliteitstraject van het aantal bloed eosinofielen is onderzocht bij COPD-patiënten waarbij gebruik gemaakt werd van longitudinale data. De uitkomst van deze studie vergroot ons begrip over de rol die bloed eosinofielen kan innemen als een potentiële biomarker binnen de behandeling van COPD.

Post-hoc analysen van RCTs suggereren dat patiënten met een verhoogd aantal bloed eosinofielen ( $\geq 2 \%$ ) waarschijnlijker zijn om een voordeel te ervaren van de behandeling met inhalatiecorticosteroïden. Om die reden hebben is in hoofdstuk 5 gekeken naar de impact van zowel het absolute als het relatieve aantal bloed eosinofielen op de behandeling met inhalatiecorticosteroïden. Dit onderzoek werd uitgevoerd in de eerste lijn. Er werd geen verlaagd risico gevonden voor acute COPD-exacerbaties, ziekenhuisopnames of het aantal bezoeken aan de spoedeisende hulp bij patiënten met een verhoogd aantal bloed eosinofielen die behandeld werden met inhalatiecorticosteroïden. Daarentegen was de mortaliteit wel lager in de groep met een relatief verhoogd aantal bloed eosinofielen die gebruik maakte van inhalatiecorticosteroïde. Dit effect werd niet gezien voor het absoluut aantal bloed eosinofielen. Ondanks dat post-hoc analysen laten zien dat er een mogelijke rol weggelegd is voor het aantal bloed eosinofielen als richtsnoer voor de behandeling met inhalatiecorticosteroïden bij COPD-patiënten, blijven de resultaten tegenstrijdig.

Een ander interessant punt voor artsen is het stoppen van de behandeling met corticosteroïden. Dit wordt enerzijds veroorzaakt door de potentiële bijwerkingen die op kunnen treden wanneer de behandeling met de corticosteroïden abrupt gestopt wordt, maar anderzijds ook de reeds bekende bijwerkingen die op kunnen treden bij een continue blootstelling aan corticosteroïden, zoals pneumonie en fracturen. Om die reden wordt in hoofdstuk 6 gekeken naar het risico op gematigde - ernstige exacerbaties, ernstige exacerbaties en mortaliteit na het stoppen van de behandeling met corticosteroïden. De groep patiënten bij wie de behandeling gestopt is wordt 
vergeleken met een groep patiënten bij wie de behandeling met corticosteroïden is voortgezet, waarbij er in de analyse gestratificeerd is voor het relatief en absoluut verhoogd aantal bloed eosinofielen. In onze analyse werd geen verhoogd risico gevonden op gematigde en/of ernstige exacerbaties bij patiënten bij wie de behandeling met corticosteroïden gestopt was. Dit resultaat was onafhankelijk van het absolutie of relatieve aantal bloed eosinofielen. Het mortaliteitsrisico was echter significant hoger bij patiënten die stopten met de behandeling met corticosteroïden bij wie tegelijkertijd sprake was van een laag absoluut of relatief aantal bloed eosinofielen. Daarnaast werden er in de verschillende gevoeligheidsanalysen geen groepen patiënten gevonden voor wie er sprake was van een verhoogd risico op een gematigde en/of ernstige exacerbatie.

Indien er voor het sturen van de behandeling van COPD patiënten slechts gebruik gemaakt wordt van één biomarker, wordt er gesproken over een eenzijdige aanpak. Om die reden hebben we de rol van CRP binnen de behandeling van COPDpatiënten geëvalueerd. Een verhoogd niveau CRP is geassocieerd met een verhoogd risico op een exacerbatie die leidt tot een ziekenhuisopname, en mortaliteit bij COPDpatiënten. Daarnaast suggereert bepaalde literatuur dat het CRP-niveau afneemt door de behandeling met corticosteroïden. In hoofdstuk 4 hebben we daarom gekeken naar het risico op gematigde - ernstige exacerbaties, ernstige exacerbaties en overlijden bij COPD-patiënten met een verhoogd CRP niveau die behandeld werden met corticosteroïden. Deze groep patiënten werd vergeleken met COPD-patiënten zonder verhoogd CRP-niveau, die daarnaast nooit behandeld zijn met corticosteroïden. In dit onderzoek werd geen verlaagd risico gevonden voor gematigde en/of ernstige exacerbaties bij COPD-patiënten met een verhoogd CRPniveau die behandeld werden met corticosteroïden. Daarentegen vonden we wel een verhoogd risico op overlijden bij patiënten met een verhoogd CRP-niveau onafhankelijk van de blootstelling aan corticosteroïden. Binnen de literatuur is nog maar weinig aandacht besteed aan de mogelijke rol die CRP kan vervullen binnen de behandeling van gematigde - ernstige en ernstige exacerbaties. Een verlaging van het CRP-niveau als gevolg van een behandeling met corticosteroïden bij COPDpatiënten hoeft niet direct te leiden tot verlaagd risico op het hebben van een exacerbatie. Dit wordt ondersteund door het feit dat er bij een significant aantal COPD patiënten sprake is van een normaal CRP-niveau gedurende een exacerbatie. De heterogeniteit wat betreft de mate van systemische ontsteking is reeds erkend bij patiënten met COPD. Dit omvat ook de hoge mate van heterogeniteit in CRP-niveau in het serum en andere biomarkers. Deze heterogeniteit wordt grotendeels toegedicht aan gastheer- of aandoening-specifieke factoren.

Gezien de ziektelast en de hoge kosten die gepaard gaan met COPD exacerbaties, was het van essentieel belang om de trends in exacerbaties bij COPD patiënten over de tijd te begrijpen. In hoofdstuk 2 hebben we daarom de incidentie van gematigde en ernstige COPD exacerbaties onderzocht gespecificeerd voor leeftijd en geslacht binnen de eerste lijns zorg in het Verenigd Koninkrijk (UK). Hoewel reeds verschillende studies hebben gekeken naar de incidentie en prevalentie van 
COPD als aandoening, hebben weinig studies zich gericht op de trend van exacerbaties bij COPD-patiënten. We vonden een significante toename in de incidentie van 2005 tot 2013 voor het primaire eindpunt; elk type exacerbatie. Voor ernstige exacerbaties nam de incidentie van 2008 tot 2013 toe. Vrouwen hadden een hogere incidentie voor elk type exacerbatie in vergelijking met mannen gedurende de gehele studieperiode maar de incidentie van ernstige exacerbaties was vergelijkbaar tussen mannen en vrouwen van 2005 tot 2013. De incidentie van elk type exacerbatie was ook hoger in patiënten ouder dan 80 jaar van 2005 tot 2008, na 2008 was deze trend niet langer zichtbaar. In deze studie werd ook geen objectieve reductie gezien van het aantal exacerbaties. Als aanvulling op de factoren die eerder al genoemd zijn, kunnen een lage therapietrouw, en een onjuiste inhalatietechniek bij COPD-patiënten mogelijk hebben bijgedragen aan onze bevindingen. Evenzo, variaties in de incidentie van COPD-exacerbaties lijken de incidentie van influenza $A$ in de UK te volgen, wat suggereert dat dit ook mogelijk een impact heeft op onze resultaten.

De relatie tussen een langdurige blootstelling aan een systemische behandeling met corticosteroïden en het risico op een fractuur zijn reeds uitgebreid beschreven. In hoofdstuk 7 hebben wij gekeken naar het effect van een periodieke behandeling met een hoge dosering glucocorticosteroïde op het fractuurrisico bij COPD-patiënten. Daarnaast is ook gekeken naar de impact van de ziektelast (op basis van afgeleide parameters) en het effect van de dosis. Gebruik makend van een groot COPD-cohort vonden wij dat blootstelling aan een periodieke behandeling met een hoge dosering glucocorticosteroïde niet geassocieerd is met een verhoogd risico op elk type fractuur, een fractuur vanwege osteoporose, een heupfractuur, of een klinisch symptomatisch wervelfractuur bij COPD patiënten, wanneer deze vergeleken worden met patiënten zonder COPD. Daarnaast vonden we dat afgeleide parameters voor de ziektelast (ziekenhuisopnames en bezoeken aan de spoedeisende hulp vanwege COPD in het laatste jaar) geassocieerd waren met een verhoogd risico op elk type fractuur, een fractuur vanwege osteoporose, een heupfractuur, of een klinisch symptomatisch wervelfractuur in COPD patiënten wanneer deze vergeleken werden met patiënten zonder COPD.

\section{Conclusie}

In hoofdstuk 8 worden de klinische implicaties en het toekomstperspectief op basis van dit proefschrift voor onderzoekers en artsen besproken. COPD is een heterogene aandoening en biomarkers spelen een belangrijke rol binnen het ziekteproces. Het exacte mechanisme waardoor inhalatiecorticosteroïden de kans op een exacerbatie verlagen bij patiënten met een verhoogd aantal bloed eosinofielen blijft onduidelijk. Echter, op basis van de resultaten gepresenteerd in dit proefschrift concluderen wij dat het noodzakelijk is om in de toekomst verder onderzoek te doen naar de rol van biomarkers binnen COPD om zo beter te kunnen begrijpen hoe deze ingezet kunnen worden binnen de behandeling van nieuwe COPD-patiënten, gelet op het feit dat het aantal exacerbaties toeneemt bij nieuwe COPD patiënte. 


\section{Valorisation Addendum}

Valorisation is defined as the process of ensuring the knowledge gained from scientific learning and research available or useful for economic or societal utilisation, or translating it to competing products, services, processes, and new business. ${ }^{1}$ In this section, the societal relevance of this work will be discussed, alongside how this dissertation is currently impacting society.

\section{Health Problem}

Chronic obstructive pulmonary disease (COPD) is a common, preventable and treatable disease characterised by relentless respiratory symptoms and airflow limitation that is due to airway and/or alveolar aberrations usually triggered by significant exposure to noxious gases. ${ }^{2}$ COPD is a leading cause of morbidity and mortality worldwide. Within non-communicable diseases, it was the third leading cause of disability-adjusted life years according to the Global Burden of Disease Study $2017,{ }^{3}$ and it is projected to hold an equal position among the leading causes of death worldwide in 2030.,5 Additionally, the disease is associated with tremendous social and economic impact. ${ }^{6}$ In the European Union, COPD accounts for 38.9 billion euros and 52.4 billion dollars in direct and indirect cost in the United States (U.S), ${ }^{7,8}$ and places a very high burden on health systems. ${ }^{2}$

The natural course of COPD is characterised by acute events, referred to as exacerbations, defined as the acute worsening of a patient's condition beyond normal day-to-day variation in symptoms that requires additional pharmacotherapy. ${ }^{2}$ Exacerbations of COPD have considerable impact on health status ${ }^{9}$, lung function. ${ }^{10}$ and exercise capacity. ${ }^{11}$ Furthermore, exacerbations are associated with substantial mortality and economic impact. Nearly $60 \%$ of all cost of COPD is associated with severe acute exacerbations requiring hospital admission. ${ }^{12}$

A biomarker is defined as a measure of any molecule or material, which could be either cells or tissues that reflect a disease process. ${ }^{13}$ The essential roles of biomarkers in health includes; enhancing disease diagnosis, monitoring of disease prognosis, and guiding therapy, with the aim of improving patient outcomes and reducing potential side effects of treatments. ${ }^{13}$ Over the past decade, there has been an increased interest in biomarkers such as C-reactive protein (CRP) and blood eosinophil counts in COPD. ${ }^{14-16}$

\section{Research Investigations}

In this dissertation, we investigated the long-term stability of blood eosinophils as a biomarker among patients with COPD using real-life data from general practice. In a detailed analysis, we assessed the stability of this biomarker by age, sex, smoking status, and baseline blood eosinophil counts among patients with COPD. In addition, we explored the role of blood eosinophil counts as a biomarker for guiding inhaled corticosteroids (ICS) therapy in COPD management. Furthermore, we studied the 
trends of moderate-to-severe and severe exacerbations by age and sex. We also determined the potential of creatine reactive protein (CRP) as a biomarker to help guide ICS use in COPD management. We employed data from the UK general practice setting for most of the research presented in this thesis. We also evaluated the management of exacerbations with high-dose intermittent glucocorticoids (GCs) and the risk of fractures among COPD patients using data from the Danish population.

\section{Main findings}

In contrast to short-term studies, which tried to evaluate the stability of blood eosinophil counts among patients with COPD by assessing counts over short hospital visits spanning few weeks. In this thesis, we evaluated the long-term stability of blood eosinophil counts and the impact of age, sex, smoking status, and baseline eosinophil counts. Our study was the first and largest observational study to explore the longterm stability of blood eosinophil counts among COPD patients. We found that blood eosinophil counts stability though lower in COPD patients compared to controls was relatively stable in COPD patients. We also showed that age and sex had a significant impact on the stability of blood eosinophil counts. Furthermore, we found that blood eosinophil counts did not serve as a clinically relevant guide for the initiation or withdrawal of ICS among newly diagnosed COPD patients. We also showed that CRP was not a reliable biomarker for targeting ICS therapy among COPD patients. However, we found an increased risk of all-cause mortality among patients with elevated CRP levels regardless of ICS exposure. Furthermore, in this thesis, we showed an increased incidence of moderate-to-severe exacerbations among COPD patients, especially among women, and this trend is increasing. Lastly, intermittent use of high-dose glucocorticoids was not associated with increased risk of fractures among COPD patients.

\section{Target population and perspective for future research}

This dissertation is of importance to general practitioners, especially those managing newly diagnosed COPD patients, pulmonologists, rheumatologists, respiratory researchers, policymakers, and other stakeholders. Short-term studies have tried to assess the stability of blood eosinophils as a biomarker in COPD management. However, for blood eosinophil counts to play a vital role in COPD management the long-term stability of this biomarker among large populations of COPD patients was needed to establish its potential. Our findings on the stability of blood eosinophil counts provided useful insight into the potential of this biomarker to help guide COPD treatment. The study was published in the American Journal of Respiratory and Critical care Medicine, and was incorporated into the 2019 Global Initiative for Chronic Obstructive Lung Disease (GOLD) recommendations from the management of COPD, and played a pivotal role in the recommendations of blood eosinophils as a biomarkers in COPD management. ${ }^{2}$ This work has been of relevance to various 
researchers investigating the role of blood eosinophil counts in COPD management in real-world settings and has been cited by numerous sources.

Post-hoc analyses of data from randomised controlled trials (RCTs) reported reduced risk of exacerbations among COPD patients, with elevated blood eosinophil counts treated with ICS. While this might be true among patients with advanced disease and history of prior exacerbations as reported by post-hoc analyses of RCTs, we found no reduced risk of moderate-to-severe or severe exacerbations among newly diagnosed COPD patients exposed to ICS. Additionally, we did not observe an increased risk of moderate-to-severe exacerbations or severe exacerbations following the withdrawal of ICS among newly diagnosed COPD patients with elevated blood eosinophil counts. This finding is beneficial to clinicians managing newly diagnosed COPD patients in general practice. Future research should, therefore, focus on the potential of blood eosinophil as a guide to ICS therapy among newly diagnosed COPD patients.

Only a few studies have assessed the long-term trends of moderate or severe exacerbations in general populations, but none has explored this trend among COPD patients in the United Kingdom (UK) general practice. Our findings on the trends of exacerbations are of importance as it could help target essential interventions and policies aimed at reducing the incidence of moderate or severe exacerbations especially, among female patients. Furthermore, oral glucocorticoids are additionally used in the management of exacerbations among COPD patients. We found no increased risk of fractures with exposure to high-dose intermittent GCs. Our findings are supported by a previous study, which employed similar definitions for intermittent GCs exposure in evaluating fractures risk among COPD patients in the general practice. ${ }^{17}$ Therefore, emphasis on prophylactic treatment of fractures by clinicians may not be essential in patients with COPD exposed to intermittent dose of GCs, whereas this should be considered for high-dose long-term users with advanced COPD disease, postmenopausal women, and men over 40 years.

Furthermore, observational research focused on the potential of biomarkers in the personalised management of various diseases can benefit from the pharmacoepidemiological approaches employed in this dissertation. Particularly the novel approach used in the evaluation of the stability of blood eosinophil counts, adopting composite definitions for outcomes, the use of validated definitions for exposures and outcomes, time-dependent assessment of biomarkers and medication exposures.

In conclusion, this thesis provides essential real-life evidence on the stability of blood eosinophil counts in large populations of COPD patients, and this finding has been incorporated into the 2019 GOLD recommendations. Additionally, it provides insights into blood eosinophil counts as a guide to ICS management of COPD exacerbations among newly diagnosed patients without prior history of exacerbations, ICS use or asthma, which serves as useful information for practitioners charged with the management of this group of COPD patients. We hope that the results from this 
dissertation will help stimulate interventions and policies aimed at addressing the rising trend of exacerbations among COPD patients in the UK, especially among women. Lastly, clinicians can be confident in the use of high-dose intermittent GCs in the management of COPD patients with fewer concerns of any potential risk of fractures. 


\section{References}

1. Buzink R, Cauffman C, Cruijssen M, Massar K. Valorization of Knowledge: The Desirability and Financing of SpinOffs at Maastricht University.; 2015. https://www.maastrichtuniversity.nl/site s/default/files/downloadables/steep_fac e alp-valorisation_of knowledge.pdf.

2. GOLD. Global strategy for the prevention, diagnosis and treatment of chronic obstructive pulmonary disease (2019 Report). 2018. https://goldcopd.org/wpcontent/uploads/2018/11/GOLD-2019v1.7-FINAL-14Nov2018-WMS.pdf. Accessed November 15, 2018.

3. Roth GA, Abate D, Abate $\mathrm{KH}$, et al. Global, regional, and national age-sexspecific mortality for 282 causes of death in 195 countries and territories, 1980-2017: a systematic analysis for the Global Burden of Disease Study 2017. Lancet. 2018;392(10159):17361788.

4. GBD 2010 Mortality and Causes of Death Collaborators. Global and regional mortality from 235 causes of death for 20 age groups in 1990 and 2010: A systematic analysis for the Global Burden of Disease Study 2010. Lancet. 2012;380(9859):2095-2128.

5. Vos T, Flaxman AD, Naghavi M, et al. Years lived with disability (YLDs) for 1160 sequelae of 289 diseases and injuries 1990-2010: A systematic analysis for the Global Burden of Disease Study 2010. Lancet. 2012;380(9859):2163-2196.

6. Jinjuvadia $C$, Jinjuvadia $R$, Mandapakala C, Durairajan N, Liangpunsakul S, Soubani AO. Trends in Outcomes, Financial Burden, and Mortality for Acute Exacerbation of Chronic Obstructive Pulmonary Disease (COPD) in the United States from 2002 to 2010. COPD. 2016; 14(1):72-79.

7. Lõpez-Campos JL, Tan W, Soriano JB. Global burden of COPD. Respirology. 2016;21(1):14-23.

8. Guarascio AJ, Ray S, Finch CK, Self T. The clinical and economic burden of Chronic Obstructive Pulmonary
Disease in the USA. Clin Outcomes Res. 2013;5:235-245.

9. Spencer S, Jones PW. Time course of recovery of health status following an infective exacerbation of chronic bronchitis. Thorax. 2003;58(7):589593.

10. Celli BR, Thomas NE, Anderson J a, et al. Effect of pharmacotherapy on rate of decline of lung function in chronic obstructive pulmonary disease: results from the TORCH study. Am J Respir Crit Care Med. 2008;178(4):332-338.

11. Cote CG, Dordelly LJ, Celli BR. Impact of COPD exacerbations on patientcentered outcomes. Chest. 2007;131(3):696-704.

12. Hilleman DE, Dewan N, Malesker M, Friedman M. Pharmacoeconomic evaluation of COPD. Chest. 2000.

13. Cazzola M, MacNee W, Martinez FJ, et al. Outcomes for COPD pharmacological trials: from lung function to biomarkers. Eur Respir J. 2008;31(2):416 LP - 469.

14. Sin DD, Man SFP, Marciniuk DD, et al. The effects of fluticasone with or without salmeterol on systemic biomarkers of inflammation in chronic obstructive pulmonary disease. $A m J$ Respir Crit Care Med. 2008;177(11):1207-1214.

15. Pascoe S, Locantore N, Dransfield MT, Barnes NC, Pavord I. Blood eosinophil counts as markers of response to inhaled corticosteroids in COPD? Authors' reply. Lancet Respir Med. 2015;3(8):e27.

16. Watz $\mathrm{H}$, Tetzlaff $\mathrm{K}$, Wouters EFM, et al. Blood eosinophil count and exacerbations in severe chronic obstructive pulmonary disease after withdrawal of inhaled corticosteroids: A post-hoc analysis of the WISDOM trial. Lancet Respir Med. 2016;4(5):390-398.

17. De Vries F, Bracke M, Leufkens HGM, Lammers JWJ, Cooper C, Van Staa TP. Fracture risk with intermittent highdose oral glucocorticoid therapy. Arthritis Rheum. 2007;56(1):208-214. 


\section{Acknowledgements}

It has been an exceptionally exciting road towards the completion of this work. A number of individuals played vital and amiable roles along the way. I would at this junction like to acknowledge those that helped in realising this goal.

First and foremost, I would like to thank my parents, Chief and Mrs H.O Oshagbemi for granting me an opportunity to pursue my dreams from an early age and for always emphasizing the importance of dedication to duty and hard work especially as it relates to my academic pursuits. My heartfelt gratitude goes out to my mum who departed this world on the $24^{\text {th }}$ May of 2017 . I will never forget the roles you played in my life and the virtuous lessons you instilled in me. You talked about seeing me complete this doctoral thesis. Guess what STAR MUM, your son did it! I hope you are beaming down your every lovely and captivating smile. This thesis is dedicated to you, ma. To my Dad, your patience, guidance, encouragement, prayers and financial support enabled me to complete this course of study. For this, I will always be grateful.

I would also like to thank my promoters Prof. dr. E.F Wouters, Prof. dr. F.de Vries and dr. F.M.E. Franssen for all the support and guidance accorded me throughout the course of my research. You all created an apt environment for scientific interactions, making yourselves readily assessable for questions and queries at short notice. A huge thanks, goes out to members of my family tree; Capt. Adedotun, Omoniyi, Dr. Mojisola, Yemisi, and Ireti for your prayers, love, and words of encouragement. My love goes out to the Michel's, a warm-hearted kind and loving family, with special appreciation to Steffi, you are the best! To the Ogungbe's I will always be indebted to you for your support and the vital role you all played in the course of this journey. To Simi, Dokun, and Lanumi, your electrifying smiles, beautiful chuckles, and inquisitive minds kept me going through the tough times. To Liam, I will always have fond of the good times and of course "wawa".

I also extend my deepest gratitude to my colleagues and those whom I had a pleasure of knowing, interacting and working with during the course of my doctoral program. You all impacted me in too many ways to mention. My appreciation goes out to Diana, Manon, Jacqueline, and Marlien - who all ensured that this process was smooth and hitch-free. Special thanks goes out to Andrea, Annemariek, Yannick, Judith, Amalia, and Spencer for the lively social and academic interactions, and to my paranymphs - Ard and Shahab for their constant support. Nikki, I appreciate the crash course in Dutch, with particular reference to "mera.." without the ants. Finally, my gratitude goes to all members of staff of the Department of Clinical Pharmacy and Toxicology, Maastricht University Medical Centre (MUMC+) for your hospitality and warmth throughout my stay in the Netherlands. 


\section{List of publications}

1. Oshagbemi OA, Burden AM, Braeken DCW, et al. Stability of blood eosinophils in patients with chronic obstructive pulmonary disease and in control subjects, and the impact of sex, age, smoking, and baseline counts. Am J Respir Crit Care Med. 2017;195(10).

2. Nielen JTH, Oshagbemi O, De Vries F, Burden AM. Effects of colchicine on risk of cardiovascular events and mortality among patients with gout: The effect of index date selection? Ann Rheum Dis. 2016;75(5).

3. Oshagbemi OA, Keene SJ, Driessen JHM, et al. Trends in moderate and severe exacerbations among COPD patients in the UK from 2005 to 2013. Respir Med. 2018;144:1-6.

4. Oshagbemi OA, Burden AM, Shudofsky KN, et al. Use of high-dose intermittent systemic glucocorticoids and the risk of fracture in patients with chronic obstructive pulmonary disease. Bone. 2018;(110):238-243.

5. Oshagbemi OA, Driessen JHM, Pieffers A, et al. Use of systemic glucocorticoids and the risk of major osteoporotic fractures in patients with sarcoidosis. Osteoporos Int. 2017;28(10):2859-2866.

6. Abtahi S, Oshagbemi A, Van Veelen A. Impact of average daily and cumulative dose of statins on mortality risk among healthy elderly. Am J Med. 2019;02.029

7. Abtahi S, Oshagbemi OA, Van Veelen A, Van Geel R. The role of misclassification of exposure in the association between aspirin and nonsteroidal anti-inflammatory drug use and keratinocyte cancers. $\mathrm{Br} J$ Dermatolo. 2019;0.

8. Oshagbemi OA, Franssen FME, van Kraaij S, et al. Blood Eosinophil Counts, Withdrawal of Inhaled Corticosteroids and Risk of COPD Exacerbations and Mortality in the Clinical Practice Research Datalink (CPRD). COPD J Chronic Obstr Pulm Dis. 2019;(23):1-8.

9. Oshagbemi OA, Franssen FME, Wouters EFM, et al. C-reactive protein as a biomarker of response to inhaled corticosteroids among patients with COPD. (under peer-review).

10. Oshagbemi OA, Odiba JO, Daniel A, et al. Absolute blood eosinophil counts to guide inhaled corticosteroid therapy among COPD patients: Systematic reiew and meta-analysis. Current Drug Targets. 2019;20(14)

11. Oshagbemi OA, Franssen FME, Braeken DCW, et al. Blood eosinophilia, use of inhaled corticosteroids, and risk of COPD exacerbations and mortality. Pharmacoepidemiol Drug Saf. 2018;27(11):1191-1199. 



\section{About the author}

Olorunfemi Ayodele Oshagbemi was born on the $6^{\text {th }}$ of November 1987 and completed his six years of secondary school education at the Federal Government College in Nigeria. After which he preceded to the Faculty of Pharmaceutical Sciences, Ahmadu Bello University, Zaria where he obtained a Bachelor of Pharmacy degree (B.Pharm) after 5 years of training. On completion of his degree, he worked as a hospital pharmacist at the National Hospital Abuja. In September 2013 Olorunfemi completed his Masters of Public Health degree (M.P.H) at the Nuffield Centre for International Health and Development, University of Leeds.

In September 2015, he began his Ph.D. under the supervision of prof. dr. E.F. Wouters, dr. F. de Vries, and dr. F.M.E. Franssen. During his Ph.D. he worked at, and was affiliated to the Department of Clinical Pharmacy and Toxicology, Maastricht University, Department of Epidemiology, School of Public Health and Primary Care (CAPHRI), Division of Pharmacoepidemiology and Clinical Pharmacology, Utrecht Institute of Pharmaceutical Sciences, Centre for Expertise in Chronic Organ Failure (CIRO), Horn, Cardiovascular Research Institute Maastricht (CARIM). He is a member of the Pharmaceutical Society of Nigeria, International Society of Pharmacoepidemiology, the Netherlands and European Respiratory Societies. His work on the stability of blood eosinophil counts was published in the American Journal of Respiratory and Critical Care Medicine and was included in the Global Initiative for Obstructive Lung Disease (GOLD) 2019 recommendations. He has reviewed manuscripts for the Pharmacoepidemiology and Drug Safety Journal, European Respiratory Journal Open and the British Journal of General Practice.

Olorunfemi was twice awarded the International Society for Pharmacoepidemiology scholarship to attend conferences in Dublin and Prague where he gave podium and poster presentations. He is currently appointed as a postdoctoral fellow at the National Institute of Health, Maryland, United States. 
